\title{
Re-writing "the little coloured ball of earth entirely": Language and Ecology in Gertrude Stein, H.D., and Virginia Woolf
}

\author{
by \\ Kimberley Ann Sigouin
}

A thesis submitted to the Faculty of Graduate and Postdoctoral Affairs in partial fulfillment of the requirements for the degree of

Doctor of Philosophy

in

English Language and Literature

Carleton University

Ottawa, Ontario

(C) 2017, Kimberley Ann Sigouin 


\begin{abstract}
My dissertation investigates the relationship between experimental writing, bodies, and ecology in the work of modernist women writers. Specifically, I propose that the stylistic experiments of Gertrude Stein, H.D., and Virginia Woolf are inseparable from these authors' theorizations on the body and material environments. They examine how questions of language and the body are ecologically inflected. By "ecology," I do not simply refer to traditional representations of "green ecologies" that explore the human agent's place within balanced ecosystems consisting of plants and animals. Ecocritical readings of these modernist writers' works typically promote Stein's, H.D.'s, and Woolf's interest in restoring harmonious environments by emphasizing a return to serene and stable environments. As a result, the nonhuman world is cast as a pastoral, romantic, or distinctly feminine space of tranquility and restoration. In contrast, I examine precarious environments of which the body is not simply an integral component but indiscernible from the material composition of the nonhuman world. My dissertation builds upon but fundamentally reconceptualises a standard account of feminist modernisms' return to the body in light of the recent turn in both modernist scholarship and feminist studies towards ecocritical models of reading. My critique aligns with emerging conversations on the trans-corporeal body and agential materialism. Both Stacy Alaimo and Karen Barad reconsider how the body, materiality, and discursive processes are bound up in a material recreation of the world. These ideas are part of a larger conversation on the "narratives of matter" investigated by new material ecocriticism. I argue that as Stein, H.D., and Woolf examine the tension between the nonhuman world and socially constructed ideas of what is "natural," they suggest that nature is not a
\end{abstract}


restorative space separate from cultural locales, but an unpredictable, volatile force central to their artistic projects. This rethinking of reductive readings of nature reveals how women writers and literary modernism move beyond discussions that focus on linguistic, historical, and cultural reconstructions of the self and the world, and instead considers how these discussions are imbricated in the ongoing performance of human and nonhuman matter. 


\section{Acknowledgements}

I would like to express sincere gratitude to Dr. Adam Barrows for his supervision of this dissertation. Thank you for introducing me to modernism and ecology in my first year of the $\mathrm{PhD}$ program, and thank you for your invaluable insight, constant support, and encouragement. Dr. Jodie Medd and Dr. Brian Johnson— thank you both for your excellent and astute feedback on my writing. Your careful attention to my project has been beneficial in helping me to shape and refine my ideas. I would also like to thank Dr. Miranda Hickman and Dr. Chris Russill for taking the time to participate in the defence.

Thank you to my fellow colleagues. Alex Grammatikos, you are a kind and generous friend. Thank you for always pushing me to take risks and face my fears. Chris Doody, your exceptional knowledge of formatting has been an incredible resource. Alicha Keddy - I was ecstatic to share my ideas with another modernist. Thank you for invigorating conversation and, most importantly, thank you for your immense support. Your excitement for my project and your faith in my abilities motivated me when I had none. John Coleman — your presence has been a comfort during this long and arduous ride. Thank you for celebrating my successes with me. Lana Keon-words cannot begin to describe the wonderful impact you've had on my mental and physical well-being. Thank you for your warmth and your wisdom.

My family and friends have always supported me and I am grateful. Thank you to my parents and to my sister for cheering me on. Also, many thanks to Steve for checking in and sharing his stories about his own rigorous, frustrating, and humorous grad experiences. Many thanks go to my theatre friends, especially Noémi, for reviving the passion for life and learning. 
Finally, I would like to thank my grandparents. Their stories of dedication and perseverance along with their genuine joie de vivre have inspired my love for literature. My dissertation was supported financially through an Ontario Graduate Scholarship and the Gordon J. Wood Graduate Scholarship in English. 


\section{Table of Contents}

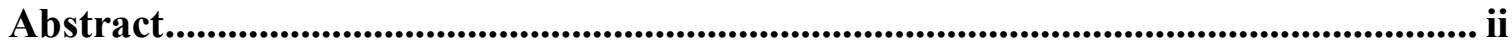

Acknowledgements ..................................................................................................................... iv

Table of Contents ....................................................................................................... vi

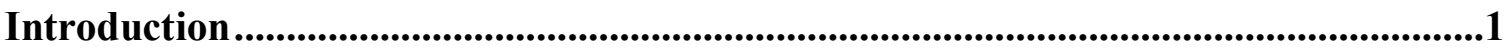

Chapter One: "The resistance outside of you and inside of you, a shadow upon you, and the thing which you must express": Cognition, Language, and Nature in Gertrude Stein ....................................................................................................................32

"What is English Literature?”: From the Laboratory to an American Tour .............. 41

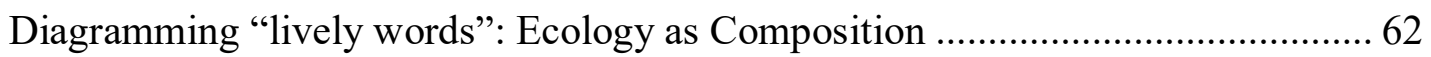

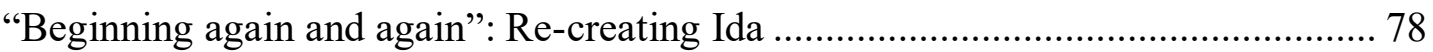

Chapter Two: "Things were in people, people were in things": Material-Discursive Ecologies in H.D ...............................................................................................93

Redefining "the murky, dead, old, thousand-times explored old world": Notes on Thought and Vision and "The Wise Sappho" ........................................................... 103

The Image and the Cyclops: H.D.'s Film Reviews ………................................... 124

HERmione: "put the thing in writing" ....................................................................137

Chapter Three: "Dispersed Are We": Re-imagining Environmental Holism in Woolf's Between the Acts and other essays........................................................................159

From the "co-operative imagination" to a "common" experience ………………... 165

"This little hard granular knob": Aimless Wandering and the "Proper Stuff of

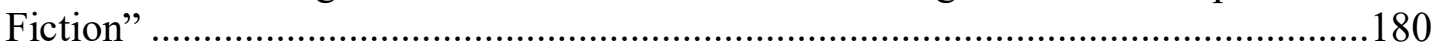

"The vanishing play": Unpredictable Environments in Woolf's Diaries and Between the Acts.

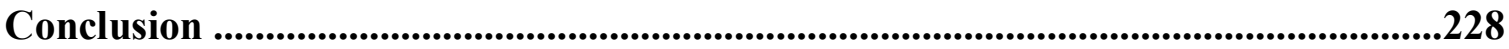

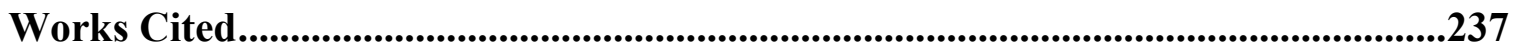




\section{Introduction}

Virginia Woolf's tombstone, erected by Leonard in their garden at Monk's House, blends in with the quietude of the natural surroundings, arguably symbolizing a peaceful end to a life plagued with mental disturbance. Bunny Guinness, writing about the garden at Monk's House in a recent article in The Telegraph, captures this typical characterization of Woolf as finding tranquil solace in nature away from the excitement and industrial disturbances of modernity. ${ }^{1}$ Leonard Woolf and Virginia Woolf purchased the house in 1919, following one of Virginia's severe bouts of mental health issues. The severity of her condition drastically altered her behaviour. She was diagnosed as "incoherent, excited and violent" and placed "under constant surveillance" (Bell 39). Moreover, the house is the location in which Woolf resided before committing suicide in the River Ouse and it is most famous for being her final resting place. The garden consequently becomes a traditional place of repose for the author. The natural landscape acts as a remedy for her struggle as her body is immersed in the natural setting. The garden is typically characterized as "an undisturbed sanctuary" (Guinness) ${ }^{2}$ and its purpose is twofold: the environ of Monk's house is both a sedative for Woolf's mental health conditions as it instills a sense of calm, and a creative space influencing the author's prose work. Guinness's description supports these traditional representations of the garden. She

\footnotetext{
${ }^{1}$ Caroline Zoob writes, "it was clear to Leonard that periods of quiet country life, following a peaceful routine, were to be an essential part of avoiding further breakdowns. It was for this reason he had moved their London base to Richmond in 1915, believing that the perennial stimulation of life in Bloomsbury militated against Virginia's recovery. Now they had to look for a new country home" (18). Nuala Hancock also discusses "the doctor's recuperative regime" (252). That is, "'as a lover of nature' [Woolf] should be 'health-employed out of doors"” (252) and away from the excitement of the modern city.

${ }^{2}$ Many critics have explored how the garden at Monk's House significantly influenced the works of Virginia Woolf, suggesting that the garden is both a sanctuary and a creative space. For example, see Caroline Zoob and Nuala Hancock.
} 
suggests that Woolf "was surrounded by views conducive to creative thought" and further states, "there was no doubt that the peace and tranquility of the garden helped soothe her mind during her well documented periods of illness and depression" (Guinness). As such, the garden was not only "a source of inspiration," but also "a vital part of her creative routine" (Guinness).

This common narrative of Monk's House casts nature as an idyllic setting that restores and sustains the human agent. It calls attention to a tenuous binarism between a natural environment and the industrial landscapes of modernity; the natural locale remedies the alienated and contaminated "modern" body, alleviating it from the decrepit conditions of modernity. This rhetoric fosters a Wordsworthian notion of the individual's immersion into the natural world that "reveals how affective engagement with the natural world can unlock the bodily, material processes of interconnectedness and transcendence" (Reno 31). This natural trope establishes an intimate connection between the human and the nonhuman world that instigates a creative surge. Nature connotes a resource that benefits the human agent, expanding their creative capacities as they become more attuned to natural processes. The human agent's exposure to the grandeur of nature expands the individual's consciousness and thereby replenishes the human agent's relation to the nonhuman world and inspires a sense of responsibility. One must seek to initiate and preserve this intimate interconnection and oppose the contamination erupting from the rapidly increasing industrial age. Johnathon Bate refers to this Wordsworthian interaction with the natural world as an individual's immersion with a "loving Nature" which is synonymous with a "political act" (Bate 28). This romanticized concept of nature fosters an opposition between the natural world that harbours plants 
and animals, and the artificial industrial world that further separates natural forms of being from cultural constructs. ${ }^{3}$ The human agent negotiates between these disjointed realms, occasionally tapping into the dynamism of the natural world to ensure the betterment of the human species.

This Worsdworthian concept of nature advances the notion of a natural world that is dynamic, interconnected, and material. However, it also perpetuates many predominant Western binarisms, including spirit and body, and nature and culture which animate literary environmental studies. ${ }^{4}$ The Wordsworthian concept champions a natural world that instructs the individual, disclosing an ethical design delineated in the elaborate structure of the natural world. The individual must then strive to secure an intimate connection with nature and obtain guidance from its ethical pattern, which ultimately inspires the individual to strive to conserve nature. This "ethical turn" characterizes the environmental movement in literature, which is predetermined by culturally inflected notions of "natural bodies" and "natural designs." These naturalized constructions orient the individual and divulge systems through which an entire populace can organize themselves as a means to ensure the survival of the human species while simultaneously provide moral instruction. This harmonious relation between human and nonhuman

\footnotetext{
${ }^{3}$ Scott Hess suggests that Wordsworth supported "the division between an embodied world and the seemingly disembodied consciousness through which the poet observes it" (8). The poet views nature as "a space of refuge or transcendence" wherein "spontaneous inspiration" is associated with "the scene of nature" (16). In nature, Wordsworth "[celebrates] mainly the transcendental autonomy of his own poetic self" (8) and "consistently defines 'nature' in opposition to the modern social and economic world, especially the city" (9). Only once he leaves the city can he "discover both his 'true self' and his poetic vocation" (15).

${ }^{4}$ Wordsworth is typically designated the "poet of Nature" (Hess 4) and as a result, ecocritical readings rely on definitions of nature implicit to Romantic humanism. Hess cautions against such tendencies by situating a Wordsworthian concept of nature in relation to "social position and historically specific models of culture and identity, rather than universalizing (these models of reading nature) under the sign of ecology or "nature"" (11).
} 
spaces is at play in the article in The Telegraph. By characterizing the garden as a location that instills a sense of calm and restores traumatic mental phenomena, Guinness sheds light on a body that has deviated from the "natural" state. This deviation is typically aligned with the division between natural and industrial spaces. In this way, the rapidly changing cosmopolitan landscapes of modernity and technological advances seem cataclysmic and adverse to the preservation of the natural world since the move to predominant urban environments contaminates the body and renders it "unnatural." To restore the body, one must "return" to the natural world, to immerse oneself within nature. This restoration, however, is inflected by particular ideological structures that inform specific moral customs. For example, biblical narratives that promote a primordial edenic sanctuary as a substitute for humankind's inevitable descent into the modern world endorse the commonplace notion of nature as a "restorative" setting. ${ }^{5}$

Woolf was not the only modernist author whose life and work has been biographically framed in relation to a restorative or remedial natural world. Gertrude Stein and H.D., because of their traumatic experiences and non-heteronormative relationships, have also been represented as women who sought relocation to nature in order to restore their health or to preserve in isolation their non-normative bodies and experiences. ${ }^{6}$ In these readings, the environments these authors inhabit are integral to the construction of their identities and are "vital" (Guinness) to the composition of their work. To illustrate, Stein is known for taking walks on the countryside in France and her

\footnotetext{
${ }^{5}$ For more on an edenic nature, see Susan Stanford Friedman, Joshua Schuster, Jeffrey Jerome Cohen and Levi R. Bryant.

${ }^{6}$ For more on Woolf's, H.D.'s, and Stein's traumatic experiences, see Thomas C. Caramagno's The Flight of the Mind: Virginia Woolf's Art and Manic-Depressive Illness, Susan Stanford Friedman's Psyche Reborn: The Emergence of H.D., and Barbara Will's Gertrude Stein, Modernism, and the Problem of "Genius."
} 
salon on 27 rue de Fleurus is famous for generating artistic debates. Its close proximity to the garden of Luxembourg permitted her to surround herself in the greenery of the immense historical garden. Although fabricated to imitate the parks in Florence, the Luxembourg garden nurtures a sense of calm that is clearly delineated from the cityscape. The natural world in relation to Stein tends to be described as a source of inspiration, but also as a refuge from the medical expertise that discredited her literary writing experiments. For example, Dr. Morris Fishbein characterized her writing as nonsensical stammering typically practiced by someone diagnosed with a "sleeping sickness" known as palilalia (Fishbein qtd. in Meyer 50). Moreover, her status as a Jew during the World Wars further designated her an "unnatural” body in relation to the German army's attempt to establish a harmonious world under the guise of preserving a particular notion of "natural" bodies. Nature in relation to Stein becomes a place of refuge remote from the dangers of civilization. ${ }^{7}$

Similarly, H.D. travelled to Greece to foster a closer connection with the natural world, one that would imbue her with a sense of calm and ultimately rehabilitate her body from the effects of trauma. After the death of her brother in the First World War, a miscarriage, and a divorce, H.D. suffered from a series of traumatic illnesses. She travelled to Greece with Bryher to receive psychoanalytic treatments and, like Stein, this physical displacement suggests a restorative natural space separated from modernity. This relocation is one that is typically framed as a "return" to a pristine, primordial world, a movement from industrial landscapes to a therapeutic natural environment. It reflects her attempt to seek "Edenic bliss" which, as Annette Debo suggests, is recreated in a

\footnotetext{
${ }^{7}$ For more on Stein and nature, see Bonnie Kime Scott's In the Hollow of the Wave, p. 27-29.
} 
scrapbook collection (Debo 140). ${ }^{8}$ The scrapbook exhibits a series of collages that blend American and Greek landscapes, serving as a backdrop for H.D.'s and Bryher's naked bodies. Nature figures predominantly in H.D. criticism as "a spiritualized space" (Hogue 846) exposing "themes of hope and resurrection in the natural order" (Freer 109). Cynthia Hogue's most recent article is the first to focus on the "ecopoetic concerns" (840) prevalent in H.D.'s works, particularly in The Sword went out to Sea. Here, Hogue exposes H.D.'s "environmental awareness" (853) and casts "the earth-as-feminine body" (852). Hogue therefore frames nature as a prelapsarian setting, which is in concert with traditional readings of H.D. in which nature connotes mythical and pastoral landscapes.

The biographies of these modernist women writers cast nature as an "escape" and "refuge" separate from a threatening social realm. The Wordsworthian trope of nature is at play as these marginalized women writers find "imaginative refuge" (Hess 16) on the outskirts of society. Nature is not only an "imaginative refuge" from which these authors find inspiration to write, but it "becomes a refuge for the autonomous self, defining its identity apart from human society through the illusion of freedom" (17). That is, these authors "can go to nature to escape the social," but this notion of nature "creates a dangerous illusion" since it assumes that human agents "can find [their] 'true self' in nature, apart from other social constructions such as class, gender, race, ethnicity, sexuality, and so on" (18). As seen above, these women writers turn to nature as a means to restore an authentic sense of self. This illusion, however, adheres to a gendered reading of literary modernism that advances essentialist notions of gender. Within the Wordsworthian trope, the "individualized self" turns to the natural world and, in doing

\footnotetext{
${ }^{8}$ For more on the scrapbook created by H.D. and Bryher, see Annette Debo's The American H.D., pp. 137-143.
} 
so, the poet nurtures his "authentic, 'natural,' and real" self (17). However, the individual poetic self in this romantic tradition is typically male and nature is associated "with silence, solitude, high-aesthetic activity, and contemplation" (5). In other words, nature is female. The poet comes into contact with a feminized nature in order to achieve imaginary transcendence from the everyday. Wordsworth uses "women to connect him to the sensual and the particular, while he continues to associate himself with the 'superior' subject of position of male intellect, autonomy, and abstraction" (15).

This escape from physical contamination through imaginary and contemplative transcendence fosters an aversion to the physical body and matter. This aversion, according to Scott Hess, stems from gender binarisms implicit in this ethical turn which are "rooted in the Western tradition" (188). ${ }^{9}$ Men are associated with "agency" (190) and "disembodied consciousness" (189); women, by contrast, "become associated with and limited by nature in a mediating role that serves primarily male needs and desires, rather than their own" (190). This opposition is at play in narratives of the garden at Monk's House. Nuala Hancock attributes agency to Leonard Woolf by focusing on his “'heroic' commitment to the garden — pruning, spraying, climbing trees, installing pools, planning terraces" (257). Through her "idea of a Woolfian 'garden aesthetic"” (245), she juxtaposes Leonard's cultivation efforts with Woolf's bodily connection to nature. Nature is simply an extension of Woolf's emotional and psychological state. Hancock casts natural spaces as "emotionally freighted arenas" (251) since they "are emotionally

\footnotetext{
${ }^{9}$ This association between women and nature suggests that women are "often connected to home and to place, in contrast to the detached subjectivity of the male traveler" (Hess 190). This embodied attachment to nature imposes strict limitations on women's bodies and subjectivities as "they become instrumentalized as resources or auxiliars, much like nature itself, to support the male master subject" (189).
} 
textured; psychically toned. They are saturated with pleasure; fretted over with memory; pierced with loss" (259).

This trend of separating male agency from a woman's bodily and emotional state is not only characteristic of individual authors and their relation to nature. It is also prevalent in literary modernism, specifically in relation to male modernist authors' works wherein male characters seek authority, contemplation, and imaginary transcendence. Nature typically functions as a medium from which they reassure their authenticity and male intellect. To illustrate, F. T. Marinetti's "The Founding and Manifesto of Futurism" celebrates the energy and speed of twentieth-century machinery in relation to the strength and male bravado of the futurists. He describes both male bodies and machines as bestial, adopting characteristics of "snorting beasts" (Marinetti 20). This image of animalism, however, represents male strength. The energy and violence of the masculine futurist body opposes the "maternal ditch" which simply "nourishes" (21) these men and their aesthetic vision. ${ }^{10}$ Marinetti celebrates novelty through an aggressive "revolt" (21) against tradition exemplified through the earth's renewal. ${ }^{11}$ He praises the "very first dawn," the "Centaur's birth," and "the splendour of the sun's red sword" (20). This renewal signals his aversion for the material world as he strives to eradicate the past and past conceptions of the world, and replace it with a future that glorifies male strength and

\footnotetext{
${ }^{10}$ The Wordsworthian trope is at play in the manifesto. This trope "[uses] women and nature to enable the construction of the autonomous male self" (Hess 188). Typically, Wordsworth stresses how "the celebrated imaginative autonomy of the poet depends on stationing a female figure in the landscape who connects the male wanderer to nature, home, and place without constraining his sense of independence" (188). As such, "the stationed female becomes the mediator between male transcendence and an emplaced, embodied nature - the unacknowledged umbilical cord that connects the male autonomous self to its environment, to the body, and to direct human relationship" (188).

${ }^{11}$ According to Marinetti, the earth consists of "the enthusiastic fervor of the primordial elements" (21). It is an energized, violent place of grandeur.
} 
intellect. This celebration of masculinity permits the futurists to "erect on the summit of the world" from which they "hurl defiance at the stars" (24). This image of mastery and defiance celebrates the individual, placing him above the nonhuman world.

The splendour and fervor of the nonhuman world are present in other male modernists' texts. Both Joseph Conrad's Heart of Darkness and D.H. Lawrence's Women in Love celebrate the energy and strength of masculine bodies, and women "become associated with denied but necessary aspects of this masculine self, including the body, emotions, the natural, and the irrational" (Hess 189). Conrad demonstrates Marlow's ability to obtain mastery over an exotic "wilderness" (104) which often stands in for the unconscious and the uncivilized. In his narrative of male heroism and adventure, women are cast as abject bodily figures who blend in with the nonhuman world. ${ }^{12}$ This image of male dominance is further reinforced in D.H. Lawrence's Women in Love. The strength and energy of Gerald's body is reduced to a "frozen carcase of a dead male" (Lawrence 495). Birkin looks at his "inert body" (495) which "was dead, like clay" (498) in "disgust" (495). The absence of a vigorous and active masculine body elicits disgust, contrasting the "splendour" and energy that Marinetti celebrates.

These male authors, like Wordsworth, celebrate the individual and, as a result, neglect depictions of complex environments in favour of grandiose depictions of the nonhuman world. They depict "the expression of a vast egotism [rather] than an actual ecosystem" (Hess 8). Stein, H.D., and Woolf, by contrast, destabilize representations of authentic and absolute individuals by demonstrating how the body is intricately bound up with nonhuman environments. Whereas Marinetti glorifies war as "the world's only

\footnotetext{
${ }^{12}$ Marianne DeKoven argues that " "the dark continent' is notoriously a figural conflation of racial and female-maternal otherness for white Western masculinity" ("Modernism and Gender" 181).
} 
hygiene" which will ultimately cleanse the world of institutions, movements, and even bodies that contradict the futurist movement, ${ }^{13}$ Stein describes war as a "natural phenomena" ("Composition" 519). War, according to Stein, is not a movement engineered by humans to implement new ideas, but an unpredictable movement consisting of both human and nonhuman agents. Rather than focus on the future and the absolute abolition of the past, H.D. explores "an infinitesimal fraction of a moment" (HERmione 212) which exposes the complex intermingling of material, temporal, and spatial units. Rather than "erect" the individual "on the summit of the world," Woolf situates the modernist author "down in the plain" where "little is visible" ("Modern Fiction" 103).

Unlike the Wordsworthian trope that aggrandizes the individual and praises male intellect, Stein, H.D., and Woolf deflate the notion of individuality by showcasing the porous interaction between bodies and the nonhuman world. This porous interaction recasts the aversion to the body by showing how the intimate connection between intellect and emotion is necessary for their experimental writing. During her early scientific studies at Radcliffe, Stein examines the relationship between the brain, motor automatisms, and language. She examines how the "nerve centers" (Stein, "Cultivated Motor" 305) are attuned to the vibrancy of the nonhuman world, altering the way the human agent speaks and writes. H.D. proposes that there are "two centers of consciousness" in the body: one in the head and the other in the womb or "love-region" of the body. Her revision of the body as articulated in her manifesto Notes on Thought and Vision refuses the separation between intellect and emotion. H.D. suggests that the

\footnotetext{
${ }^{13}$ Marinetti advocates the eradication of museums and libraries, and further voices his disregard for "gouty naturalists" (21) and feminism.
} 
composition of a human agent consists of an intricate network of body, mind, and overmind which reaches out to the material surroundings. Specifically, she describes the chemical transmutation of the ecstatic body as a source of creativity. Although Woolf does not focus on the chemical make-up of the body, she does turn to the ill body. In her essay, "On Being Ill," Woolf considers the absence of the body in traditional literary texts. Rather than create a space for the body, she exposes how the interaction between the material body and the nonhuman world animates her understanding of modern fiction. Their reconceptualizations of the body advance the notion of an irrational, weak, and incapacitated body, but this type of body often neglected in literature and overlooked in their respective biographical narratives is essential to their modernist aesthetic.

Their modernist aesthetic consists of a form of experimental writing that derives from the body's relation to "nature." In fact, nature figures predominantly in these authors' works, but it does not elevate the human agent to a state of imaginary transcendence. In "Composition as Explanation," Stein examines the relation between "natural phenomena" and the "modern composition." In Notes on Thought and Vision, H.D. positions the body in relation to "Nature." In essays such as "Craftsmanship," Woolf examines the "nature" of words. By exposing the intimate connection between "nature" and their stylistic experiments, these authors champion a dynamic language that opposes established linguistic models. To illustrate, Stein contests strict grammatical and syntactical rules that regulate the way a human agent speaks and writes. She employs the term "natural" to discuss a more fluid re-arrangement of words that do not rely on grammar and punctuation. This "natural" writing excites and transforms "stale" literary conventions (Stein qtd. in Meyerowitz 7). Similarly, H.D. opposes forms of writing that 
imitate scientific theorems that classify the material world. She examines the ongoing material performance of the world to reveal how words "disprove" (H.D., HERmione 76) this type of analytical writing. Moreover, Woolf champions the "nature" of words to combat systematic language models that associate singular meanings to each word. Dictionaries, encyclopedias, and even BBC broadcasts during the Second World War endorse this type of systematic language that preserves an unchanging narrative framework. She refers to this regulatory narrative method as a "campaign" (Woolf, "On Being Ill" 199) that overlooks the dynamic processes of the body and the nonhuman world. To contest this strict linguistic "campaign," she examines a motile form of language.

Although their reflections on nature or the nonhuman world seem subtle in these earlier works, their theories are enacted in well-known texts. In their respective fictional biographies, Ida: A Novel and HERmione, Stein and H.D. display how the fluid identities of female protagonists blend with nonhuman environments. Similarly, in her final novel Between the Acts, Woolf depicts Miss La Trobe's historical drama as she watches from the outer edges of the audience, "down among the bushes" (90) and "behind the tree" (49). In these works, the nonhuman world functions not only as a backdrop for the protagonists, but is a creative force through which these protagonists find expression. The natural settings in these texts, however, along with the "nature" of words are often read in relation to a Worsdworthian trope. That is, critics typically read these works as "an experimentation with form and syntax that creates space for female meanings" (Harrison and Peterson xi). They often view these authors' experimental writing in opposition to patriarchal linguistic models to uncover a creative space for women's voices. Whereas 
male writers like Marinetti celebrate the individual who is able to "compose the entire landscape pictorially around a single, central point of view" (Hess 12), Stein, H.D., and Woolf deflate conceptions of the autonomous author and further indicate how the nonhuman world cannot be systematically organized or effectively replicated through language. They do not champion "the visual detachment and general disembodiment of the observer" (DeKoven, "Modernism" 188), but support a pluralistic mode of seeing and experiencing the nonhuman world. This opposition pits masculine forms of writing against experimental female forms.

As Elizabeth Jane Harrison and Shirley Peterson note, “increasingly, mainstream modernism is characterized as an elitist movement involving a closed circle of male writers who valorized art as a defense against the rise of a feminized mass culture" (ix). The absence of women writers and women's voices ${ }^{14}$ in a literary movement that "was unconsciously gendered as masculine" (Scott qtd. in Kaufmann 59) invites readings of women authors that emphasize their stylistic differences from male authors. This opposition of female space and patriarchal language fosters the notion of abject material bodies that typify "a subversive feminine consciousness" (DeKoven, "Modernism” 188). Their stylistic experiments "emphasize their own displacement from public authority" and also "demonstrate the destabilization of language itself" (xi). Stein, H.D., and Woolf in some way compare to Miss La Trobe whose experimental drama opposes chronological historical developments that celebrate social achievements resulting from the heroism and innovation of the individual. Her commentaries on the play are often

\footnotetext{
${ }^{14}$ Although Unmanning Modernism was published in 1997, Anne Fernald's 2013 article indicates that this is an ongoing issue in the field. She notes how "Modernism/modernity, the flagship journal of the new modernism and the MSA, has not, in nineteen years, devoted a special issue to a women writer or to feminist theory. Only eight essays in that journal have 'feminist' or 'feminism' as a key term, while an additional twenty-six have 'women' as a key term” (229-230).
} 
allocated to the intervals of the drama as Woolf positions her on the threshold between the audience and the nonhuman world. This hidden artist blends in with the nonhuman world, occupying a marginalized space between plants, animals and human bodies. This marginalized female artist sheds light on the gender discrepancies in literary modernism as her historical drama contests patriarchal models that silence women's voices. ${ }^{15}$

My dissertation builds upon but fundamentally reconceptualizes a standard account of feminist modernisms' return to the body in light of the recent turn in both modernist scholarship and feminist studies towards ecocritical models of reading. Stein, H.D., and Woolf are usually understood as providing an avant-garde challenge to commonplace understandings of language as a medium of representation by distinguishing between ecstatic motile forms of language, on the one hand, and a systematic linguistic order that coerces the body to conform to normative notions of identity, on the other. In their strategic deformation of linguistic codes that would promote homogeneity and communicative ease, Stein, H.D., and Woolf are typically seen as championing the subversive plasticity of a feminist protolanguage rooted in the body. ${ }^{16}$ Stacy Alaimo's notion of a trans-corporeal materiality, however, revises this standard feminist approach by widening the significance of the modernist women writers' turn towards the material body. She maintains that questions of language and the body are ecologically inflected and so introduces "a conception of the body that is neither essentialist, nor genetically determined, nor firmly bounded, but rather a body in which

\footnotetext{
${ }^{15}$ These three canonical women modernist writers are often read in relation to male authors. As a result, their artistic projects are framed as a retaliation against a predominantly masculine modernist movement. For example, these three women authors make an appearance in the chapter, "Modernism and Gender," in the Cambridge Companion to Modernism, but only in relation to male authors and theorists. The chapter indulges in a conversation on Joseph Conrad, Freud, Henry James, and other male writers before discussing Stein, H.D., and Woolf. ${ }^{16}$ See Marianne DeKoven, Rachel Blau DuPlessis, and Harriett Scott Chessman.
} 
social power and material/geographic agencies intra-act" (Alaimo, Bodily Natures 63). ${ }^{17}$

Her study reveals how aesthetic framing devices or "aesthetic captures" impose dominant frameworks that "exemplify the Enlightenment subject/object divide, where objective truth is available to all, free of perspectives, systems of power, or other entanglements (Alaimo, "Feminist Science" 198). Rather than focus on experimental methods by which to subvert "narratives of discovery and conquest" (201) that frame "discrete [objects] for the human gaze" (198), I read these modernist texts in dialogue with the notion of transcorporeal materiality to demonstrate how these authors actively pursue more complex and porous interactions between the body and nonhuman matter.

I propose that as Stein, H.D., and Woolf examine the tension between nonhuman environments and socially constructed ideas of what is "natural," they suggest that nature is not a restorative space separate from cultural locales, but an unpredictable, volatile force central to their artistic projects. Moving away from romantic humanism's emphasis on noble pursuits of imaginary transcendence, I turn to Alaimo's notion of transcorporeality to show how they position the nonhuman world as central to their epistemological inquiries without reverting to reductive readings of material "natures." Alaimo imagines "human corporeality as trans-corporeality, in which the human is always intermeshed with the more-than-human world" and therefore "underlines the extent to which the substance of the human is ultimately inseparable from 'the

\footnotetext{
${ }^{17}$ Alaimo borrows the term "intra-act" from quantum theorist Karen Barad. Barad employs the term intra-action to emphasize how "human bodies and human subjects do not preexist as such," but they are "part of the world in its open-ended becoming" ("Posthumanist" 150). Intra-action differs from "the usual 'interaction,' which presumes the prior existence of independent entities or relata" (Barad, Meeting 139). Matter is "a dynamic intra-active becoming that never sits stillan ongoing reconfiguring that exceeds any linear conception of dynamics in which effect follows cause end-on-end" (170).
} 
environment"' (Bodily Natures 2). Like Alaimo, these modernist authors are concerned with questions of framing or "aesthetic captures." They explore how to aesthetically reproduce identities and environments through art without limiting or "capturing" the essence of the human agent. They critique dominant understandings of scientific and historical narratives that celebrate accuracy and authority.

Although my project focuses on three modernist women writers, I am not suggesting that their theorizations on "nature" should act as a model by which to read other female modernist writers. Instead, I treat Stein, H.D., and Woolf as case studies that challenge traditional alliances between women authors and nature. In order to do this, I examine how their theories on nature, which extend to theories on language and the body, explicitly challenge typical representations of nature. I propose that they place the transcorporeal body at the centre of their discussion of a modernist aesthetic to expose "the often unpredictable and unwanted actions of human bodies, nonhuman creatures, ecological systems, chemical agents, and other actors" (Alaimo, "Feminist Science" 190). Stein, H.D., and Woolf question dominant understandings of "normal" or "natural" bodies; however, they do so in different ways. Stein challenges the autonomy and individuality of the author figure. Her study of psychology and language contests common understandings of the body as a composite of "essential elements" and instead exposes "movement across different sites" (190). H.D. expands on this notion of the body by focusing on a "concern" for the body (H.D., Notes 50). She proposes that in order to create art, the body must achieve a state of "equilibrium" (17). She uses an image of gardening to carefully attend to the intellectual and emotional growth of the human agent. This concern for the body extends to a concern for the nonhuman world, demonstrating 
Alaimo's contention that "human health [is] a matter of environmental health" (Bodily

Natures 125). Although H.D. champions a body in "equilibrium," she also suggests that there is no "safe" (137) environment, only erratic spaces that are indifferent to the wellbeing of the human agent. Woolf, by contrast, marks a shift in focus from a "concern" for the body to a concern for the future that begins with an awareness of the crisis of the present moment. She champions the ill body, suggesting that it demystifies the "illusion" (Woolf, "On Being Ill" 196) of a mechanistic world and exposes chaotic nonhuman processes. Read in relation to each other, these authors revise the traditional conceptions of normal bodies imbricated in a volatile and precarious environment, thereby contesting tranquil natural settings.

It is important to note that texts that lend themselves to an ecocritical model of reading do not simply romanticize the natural world and cast humanity as its despoiler; rather they investigate what constitutes "nature." Yet, the affinity of these modernist women authors and nature enforces an intimate tie between a pristine natural world and a woman's "natural" disposition. ${ }^{18}$ The idea of nature as an uncontaminated and "nonartificial" site containing "minimum or only benign cultural interference" (Clark, "Nature" 78) motivated early models of ecocritical readings of texts that contributed to the "green" movement of literary studies. This movement associates "green"19 with the

\footnotetext{
${ }^{18}$ The association between women and nature in the romantic tradition is still prevalent in literary modernism as well as in the historical and social dimensions of modernity. Anne Raine explains how twentieth-century "nature work, amateur and professional, was a form of public service for which women seemed naturally fitted" ("Science, Nature" 802). That is, "cleaning up polluted environments, conserving natural resources, protecting wildlife and scenic beauty, and teaching children to care for living things were natural extensions of women's domestic roles as homemakers and mothers" (802).

${ }^{19}$ Prismatic Ecology: Ecotheory Beyond Green is a response to the literary "green" movement. In this work, critics "explore the role colors have in building not only green rhetorics of ecological discourse but also human imagination about life, places, elements, processes, and changes"
} 
plenitude of plants and vegetation and a vast array of diverse organisms. Although this "green" movement is immensely influential in reinforcing the relation between environmental studies and literature, material ecocritics address a need to redefine environments in order to surpass the limitations of "green" spaces. For Stein, H.D., and Woolf, the meaning of the term "nature" varies throughout the authors' texts as they demonstrate how the complexity of the terms "nature" and "natural" signifies the human agent's limited perception of the nonhuman world. The aim of this dissertation then is not to locate "nature" in their respective texts, but to investigate the established narratives that support particular representations of nonhuman environments and to examine how these narratives are imbricated in the material processes of the nonhuman world.

Moving away from a focus on "green" natures, I examine questions of ecology. I show how the ecological implications of these authors' works stem from the epistemological inquiries animating their artistic projects. Their theorizations on language inform new and complex conceptualizations of ecology that challenge Ernst Haeckel's definition of ecology that typically informs ecocritical models of reading. According to Haeckel, "by ecology we mean the body of knowledge concerning the economy of

(Iovino and Oppermann, "After Green” 330). Jeffrey Jerome Cohen discloses how "green" attributes a "revelatory power [to] the wilderness" which "must be imagined as a purified place to which one travels rather than dwells always within: separate from the human, empty, foundationally pure" (xxi). His argument builds off of Timothy Morton's critique of "green" ecology. That is, Morton "points out, a preponderance of ecocritical writing is conducted in the shade of 'bright green,' a hue that tends to be 'affirmative, extraverted and masculine' as well as "sunny, straightforward, ableist, holistic, and "healthy" (xxi). He argues that "green" is associated with solitude, individuality, romanticism, "personal revelations and solipsistic calm" (xxi). In a later chapter, Iovino and Oppermann examine how the "new postgreen movement" suggests that "the green elements that have been read as emanatory of the predominant epistemological trends are now being disrupted, but also enhanced by the new discourse that is premised on being committed to the entire planetary palette" (331). They propose that "color is intellectually and socially significant in cultural poetics, in the production of cultural narratives, social practices, meanings, and regimes of power knowledge" (Iovino and Oppermann, "After Green" 331). They investigate how "the color spectrum of biological entities and ecosystems is inextricably enmeshed with the aesthetic palettes of human environmental imagination" (332). 
nature - the investigation of the total relations of the animal both to its inorganic and to its organic environment" (Haeckel qtd. Bate 36). This definition suggests that ecology does not refer directly to the material composition of environments, but to the "body of knowledge" that influences the epistemological frameworks by which we understand environments. Moreover, this definition advances binarisms that tend to characterize predominant discussions of environments: "inorganic" and "organic" refer to the duality between natural and artificial locales that extends to the division between nature and culture; "friendly inimical relations" animate ethical models of ecocriticism. Stein, H.D., and Woolf, however, are not concerned primarily with exposing the structure of "nature." Instead, they are interested in exploring "the body of knowledge" that solidifies the frameworks which promote dominant understandings of the environment. Rather than provide alternative forms that contest prevalent narratives of environments in which organic and inorganic components "[come] directly or indirectly into contact" (Haeckel qtd. in Bate 36), they champion a material language that affects and is affected by the intra-action of bodily and physical material.

My thesis pairs the history of ecocriticism with questions of language and the body to show how these authors consistently challenge how we come to know and frame the nonhuman world. Current material ecocritical scholarship rejects hegemonic linguistic patterns that foster the notion of a "pure" world that can be measured, contained, and categorized. ${ }^{20}$ Stein, H.D., and Woolf contest established forms of

\footnotetext{
${ }^{20}$ See Lawrence Buell's The Future of Environmental Criticism: Environmental Crisis and Literary Imagination (2005) and The Environmental Imagination: Thoreau, Nature Writing and the Formation of American Culture (1996).
} 
representation that classify and thereby immobilize nature. ${ }^{21}$ The contestation begins with their conception of the body that is inextricably bound up with a nonhuman world that is problematic, complex, and vast. The nonhuman world cannot be reduced to "old hegemonic patterns" (Kostkowska 1) that encourage notions of stability and endurance. Instead, they advance a more dynamic form of experimental writing that anticipates Lawrence Buell's study of language "as a means of refiguring the world" (Buell qtd. in Kostkowska 6). However, as I argue, language is not an abstract entity used to delimit the contours of the world, but is imbricated in the material performance of the world. Stein proposes that changing historical and geographical movements recreate language; H.D. suggests that language surpasses the analytical quality of words that "cut" or "catalogue" matter; Woolf depicts words in motion that sink "down into the mud" (Between the Acts 125). This intimate connection between environments and language reveals what material ecocritics term the “"narrativity” of matter” (Iovino and Oppermann, Material Ecocriticism 8). Serenella Iovino and Serpil Oppermann assert that "the landscape of discourses, words, and conceptual descriptors melts with the landscape of elements, of geology, of telluric and atmospheric agencies, of biotic ecosystemic balances” (106). That is, language and narrative "are co-extensive with material processes in the many ways the world 'articulates' itself" (Iovino and Oppermann, "Theorizing Material" 454). Stein's, H.D.'s, and Woolf's experimental writing does not examine how narratives

\footnotetext{
${ }^{21}$ Stein, H.D., and Woolf respond to predominant systems of classification. As a student of psychology, Stein shifts from the inert materialistic brain models that she encountered in the university to more dynamic theories on matter and psychology. Similarly, both H.D. and Woolf revise the psychological and medical theories that they were exposed to as patients and also through their connections with experts in the field. H.D. received psychoanalytic treatment from Freud. Also, her grandfather was a botanist and her father taught astronomy. Woolf was institutionalized for her mental health issues, and she published Freud's work.
} 
"frame" the nonhuman world, but show how those narratives change with the material processes of the nonhuman world to produce "storied matter" (468).

These authors introduced and grappled with these issues before bringing them to fruition in canonical and well-known texts. Rather than focus exclusively on language and text, they turn to the visual arts to demonstrate how the process of creating art is ultimately entangled in complex material networks. For instance, Stein's early scientific reports and early writings on theatre are foundational texts that explore the body's interaction with unstable environments. In her reports, she examines the "nerve centers" (Stein, "Cultivated Motor" 305) of the body, which expand to a sense of nervousness stimulated by theatrical performances. This nervousness creates a sense of unfamiliarity or lack of connection between the body and nonhuman agents, a disconnection that Stein suggests is necessary to combat established language systems. H.D.'s rarely consulted film reviews provide insight into her understanding of psychology, language, and the environment. She examines the mechanization of film to expand the representational function of language. She contrasts strict censorship regimes in America with experimental cinema in Russia to explode the tenuous opposition between real and artificial environments. Woolf also turns to the cinema, but to advance a notion of history that does not rely on linearity or causality. In "The Cinema" and "Flying Over London," she examines how the cinema and the aeroplane deflate chronological accounts of evolution. She suggests that these inventions do not exemplify human progress and improvement, but magnify the material performance of the world which is not immediately accessible to the human eye. Woolf's exploration of perspective detailed in her essays investigates how genre, form, and conventional literary techniques distort the 
environment by constructing and perpetuating the notion of nature as a contained entity and as a site for human conquest.

This intricate entanglement of bodies, nonhuman matter, and language does not promote the notion of a "biospherical egalitarianism" (Marland 850) promoted by deep ecologists and ecofeminists. Instead, Stein, H.D., and Woolf expose the ongoing material performance of human and nonhuman agents. This ongoing performance exposes what quantum theorist Karen Barad suggests is the "discursive" quality of materiality. In her theories on agential realism, ${ }^{22}$ Barad argues that "discourse is not a synonym for language" (Meeting 146) and "meaning is not a property of individual words or groups of words but an ongoing performance of the world in its differential dance of intelligibility and unintelligibility" (149). Moving away from theories of representationalism, she argues that "statements are not the mere utterances of the originating consciousness of a unified subject" (147). Rather "discursive practices are specific material (re)configurings

\footnotetext{
${ }^{22}$ Karen Barad's philosophy of "agential realism" reworks the "familiar notions of discursive practices, materialization, and agency, and causality, among others" ("Posthumanist" 129). Agential realism is influenced by Niels Bohr's "quantum model of the atom" which "poses a radical challenge not only to Newtonian physics but also to Cartesian epistemology and its representationalist triadic structure of words, knowers, and things" (131). Barad argues that "since individually determinate entities do not exist, measurements do not entail an interaction between separate entities; rather, determinate entities emerge from their intra-action" (Barad, Meeting 128). She introduces "the term 'intra-action' in recognition of their ontological inseparability, in contrast to the usual 'interaction,' which relies on a metaphysics of individualism (in particular, the prior existence of separately determinate entities). A phenomenon is a specific intra-action of an 'object' and the 'measuring agencies'; the object and the measuring agencies emerge from, rather than precede, the intra-action that produces them. Crucially, then, we should understand phenomena not as objects-in-themselves, or as perceived objects (in the Kantian or phenomenological sense), but as specific intra-actions" (128). From this, she develops an "onto-epistem-ology - the study of practices of knowing in being" and suggests that this "is probably a better way to think about the kind of understandings that are needed to come to terms with how specific intra-actions matter" (Barad, "Posthumanist" 147). She thus argues that "discursive practices and material phenomena do not stand in a relationship of externality to one another; rather, the material and the discursive are mutually implicated in the dynamics of intra-activity" (140). For more on intra-action, see Barad's "Posthumanist Performativity: Toward an Understanding of How Matter Comes to Matter" and Meeting the Universe Halfway: Quantum Physics and the Entanglement of Matter.
} 
of the world through which the determination of boundaries, properties, and meanings is differentially enacted" (148). Discursive practices then permit us to see how these authors' experimental writing does not simply create a distinctly feminine space resistant to a patriarchal linguistic model, but illuminates more complex understandings of materiality and psychology that upset essentialist models of femininity and masculinity. ${ }^{23}$

Whereas trans-corporeality concerns the erosion of traditional distinctions between bodies and nonhuman matter, Barad's notion of intra-action concerns the erosion of traditional distinctions between discourse and matter. Together, Alaimo and Barad disclose the limitations of nature as a "discursive category" (Hess 5) within the context of romantic humanism. They expand on discursively produced notions of nature that characterize feminist scholarship. Alaimo argues "that because woman has long been defined in Western thought as a creature mired in 'nature'," she has remained "outside the domain of human transcendence, rationality, subjectivity, and agency" (Bodily Natures 4-5). As a result, "most feminist theory has worked to disentangle women from nature" (5). Moving away from the notion of matter and corporeality as debased and essentialist, Alaimo reconceptualizes predominant Western traditions that preserve this "cultivated" (5) dualism. She proposes:

rather than fleeing from this debased nature, which is associated with corporeality, mindlessness, and passivity, it would be more productive for feminist theory to undertake the transformation of gendered dualismsnature/culture, body/mind, object/subject, resource/ agency, and others - that have

\footnotetext{
${ }^{23}$ The notion of trans-corporeal materiality expands contemporary and early twentieth-century studies of biology and ecology that reconceptualized the body as an unstable, permeable entity. Critics like Mark S. Morrisson and Stephen Meyer reveal how modernist authors were attentive to changes in the environment and investigated how these changes altered biological processes and, by extension, perception and language.
} 
been cultivated to denigrate and silence certain groups of human as well as nonhuman. (5)

Alaimo then shifts the discussion of nature to a focus on trans-corporeal materiality to disclose "a material world that is never merely an external place but always the very substance of our selves and others" (158). The trans-corporeal body exemplifies Barad's notion of discursive processes, which alters the way we think about narrative frameworks.

Recently, however, modernist studies have developed an environmental stance that investigates new methods of conceptualizing nature, environments, and ecosystems that are driven by questions of representation rather than discursive processes. Susan Stanford Freidman, for example, proposes the notion of "planetarity" to oppose the limitations of Western constructs of nature and environments. ${ }^{24}$ She suggests that the "planetary turn" (Planetary 5) calls for a "paradigm shift" (4) which radically enlarges commonplace spatial and temporal dimensions. However, this peripheral expansion that demands an ever-widening scale secures a vantage point from which the human agent can observe the planet. ${ }^{25}$ Joshua Schuster argues that this tendency to expand the scale is

\footnotetext{
${ }^{24}$ Friedman argues, "the idea of modernity [is] an invention of the West" (Planetary 3). In order to move beyond the limitations of Western ideologies, she proposes "the planetary turn" through which "we must rethink modernity and modernism outside the long twentieth century, outside the post-1500 temporal frame commonly understood as the period of the modern in its stages from early to late" (7). Specifically, "the planetary turn" examines how a "scalar thinking effect" expands our conceptions of time and space and consequently breaks away from "prevailing stories about modernity" (10).

${ }^{25}$ Friedman's understanding of "planetarity," however, is somewhat reductive. She uses the term interchangeably with other all-encompassing terms such as "global," Earth," and "worldness." However, Timothy Clark, turning to Henri Lefèbvre's critique of "the conflation of the terms 'planet', 'earth', 'worldwide', and 'universe'" (Ecocriticism 8), proposes how the human agent is incapable of fully conceptualizing the planet. Clark argues, "the earth is not 'one' in the sense of an entity we can see, understand or read as a whole" (15), and so, "the image of the whole earth, impossible fully to conceptualize and fragile, remains still an event and impetus to thought" (21). Rather than envision the planet, which promotes conceptions of a "singular world" (9), the human
} 
prefaced on literary modernism's interest in novelty which is summed up in the modernist mantra: make it new. Schuster proposes that "'make it new' implies a plenitude of seemingly inexhaustible resources" (155). The expansion of the scale assumes that the environment is an autonomous, self-sustaining entity, and neglects the perils of the human species' immersion in the fabric of ecosystems and the environmental crisis that stems from the human agent's excessive consumption of nonhuman resources. Moving away from questions of nature to questions of ecology, he "[considers] how ecology became a formal and aesthetic question as much as a scientific and ethical one" (Schuster xii). ${ }^{26} \mathrm{He}$ demonstrates how "modernist American artists sought to try out new ways of representing environs, experimenting with new kinds of framing, which made environments legible in new ways" (x), and further suggests that "at the outset of the twentieth century, ecology is as much about organisms interacting with environs as it is about finding new ways to conceptualize, imagine, record, and document ecological change" (ix).

My dissertation is situated at the intersection of these relatively new studies of modernism that are inflected by questions of the nonhuman world. Stein, H.D., and Woolf reconceptualize the body's relation to the nonhuman world and move away from anthropocentric accounts of the nonhuman world. ${ }^{27}$ In several of their essays, lectures,

agent should strive to recognize the "limits" of thought which leads to "a matter of inventing modes of discourse less closed to events and processes happening at scales that may be imperceptible to the present, such as the steady, slow-motion degradation of the biosphere" (11). ${ }^{26}$ Schuster examines the "quadrat," a unit of measurement that sought to "remove the human factor in order to study the human factor, among other ecological actors" (x). The quadrat draws attention to "how recording affects what one records" (ix). This differs from nineteenth-century American thought, which suggested that "nature had to meet standards of beauty, sublimity, and other hierarchies of value in order to be worthy of attention" (viii).

${ }^{27}$ Timothy Clark argues that "our embodied existence" (Ecocriticism 30) then becomes a means through which we imbue surrounding environments with meaning, and typically "we experience 
and diary entries, I propose that they advance the notion of the trans-corporeal body and therefore resist the notion of the body as the primary instrument through which the human agent deciphers meaning. As such, they challenge dominant epistemic models as seen in the university and throughout history. The trans-corporeal body alters the way we think about knowledge. For Stein, H.D., and Woolf, knowledge is not a question of discovery, conquest, or the accumulation of facts. It relies on the body's intra-action with the precariousness of the nonhuman world. Barad argues that "knowing is not about seeing from above or outside or even seeing from a prosthetically enhanced human body. Knowing is a matter of intra-acting” (Barad, Meeting 149). Similarly, Alaimo advances "more entangled modes of being, doing, and knowing" that contest the idea of a benign "nature" ("Feminist Science" 189). Although Alaimo demonstrates how the transcorporeal body is visible in several texts, she does not reveal how trans-corporeal materiality modifies language. Stein, H.D., and Woolf not only disclose the transcorporeal body, but they also examine how this intimate connection between human and nonhuman matter affects the way we speak, imagine, and frame the nonhuman world.

Their respective understandings of a material language expose the mutability of words, demonstrating how language is a process that evolves with the human agent's intra-action with the material composition of the nonhuman world. Influenced by William James, Stein examines how language is not a matter of reproduction, but a "recreation" ("Poetry" 40) and so opposes traditional scientific modes of diagramming. H.D.'s

phenomena at a mostly fairly stable and consistent speed" (29). This notion of meaning-making that relies on embodied existence, however, presupposes a conscious effort to measure and categorize the world around us using precise material dimensions. It further suggests that our embodied sense of time in relation to predictable environmental conditions produces consistent knowledge structures that are shared by collective bodies. 
exploration of psychology and vision radically reconceptualizes the composition of the body and mind. This reveals how she distinguishes her work from scientific classification regimes practiced by her father and grandfather. ${ }^{28}$ I propose that her manifesto Notes on Thought and Vision advances notions of a trans-corporeal body that intra-acts with environments, resisting certain tendencies in H.D. criticism that frame consciousness and environments as an archeological expedition to uncover a classical past. Moreover, Woolf's essays "Modern Fiction" and "On Being Ill” reimagine commonplace scientific understandings of materiality as she sheds light on unpredictable environmental processes that contrast repetitive social routines, and demands new artistic forms that originate from these changes. She expands on these theories in "Craftsmanship" as she opposes traditional taxonomic methodologies by proposing how we cannot "pin" words "down to one meaning" (132). Words are motile and their definitions are constantly changing.

The following chapters explore how Stein, H.D., and Woolf recognize "matter and meaning as correlated 'entangled agencies"” (Iovino and Oppermann, "Theorizing Material" 453). I argue that their stylistic experiments are inseparable from their articulation of a range of biocentric worldviews that contest and complicate more reductive representations of the environment. My aim is not to attribute activist intentions to these authors that would anticipate more contemporary environmental movements by demonstrating how they compose alternative environmental narratives that contest older models of the environment. Rather, I am interested in their theorizations on material languages that derive from and are extensively modified by the body's intra-action with nonhuman matter. Agency is not attributed to one creator but implies that all matter

\footnotetext{
${ }^{28}$ Her grandfather, Francis Wolle, was a botanist, and her father, Charles Doolittle was an astronomer. Their scientific methodologies rely on mathematical "exactitude" (Morris, How to Live 158).
} 
reorganizes itself, revealing "that aesthetic encounters may themselves be forms of entanglement" (Alaimo, "Feminist Science" 193). Language then is imbricated in ecosystemic networks that resist notions of causality and linearity. Instead, their unpredictability opens up a creative space by which to imagine environments without reducing them to definitive dimensions.

My dissertation consists of three chapters. Each chapter begins with Stein's, H.D.'s, and Woolf's theorizations on their notion of a modernist aesthetic that considers questions of the body, the nonhuman world, and language. This extends into a discussion on how these theories are enacted in a canonical or well-known text. In the first chapter, "Cognition, Language, and Nature in Gertrude Stein," I show how Stein establishes the interdependent relation between the individual's embodied cognitive functions and volatile forces in the environment, revealing how immediate bodily experiences reconfigure an individual's conceptualization of the self and of the external world. I read Stein's Ida: A Novel in light of an ecolinguistic reconsideration of her essays on literary composition, drama, and performativity. By exploring Stein's writing in relation to cognitive linguistics, I demonstrate how trans-corporeal materiality transforms traditional readings of her works that reduce the playful and repetitive quality to nonsensical verbiage. Instead, she discloses the intra-action between the performance of the text and "an ongoing performance of the world" (Barad, "Posthumanist" 139) as she continually questions the autonomy of the artistic "I" composing the text.

The second chapter, “'Things were in people, people were in things': MaterialDiscursive Ecologies in H.D.," examines how H.D. pushes language beyond its merely representational function to explore its material dimension. Whereas Stein reimagines the 
limitations of descriptive scientific rhetoric to destabilize the autonomous artist figure, H.D. focuses on the material construction of the image in order to examine the material emergence of art. In Notes on Thought and Vision and "The Wise Sappho," she outlines her theories of artistic practices and contemplates the complex figure of the artist which is subject to infinite cultural and discursive reproductions. She expands on these theories in her later film reviews published in the film journal, Close-up. In particular, she compares the limitations of the American censor, or what she refers to as the singular vision of the Cyclops, to linguistic models that severely restrict the definition of words. By placing her scientific manifesto in dialogue with her film reviews, I demonstrate how H.D.'s considerations of material processes reimagine individual, national, and cultural ontological narratives. I then take her novel HERmione as a case study to show how H.D. performs the rich intermingling of nonhuman elements and the sensorial apparatus of the body in order to underline the mutable texture of language.

In the third chapter, “'Dispersed Are We': Re-imagining Environmental Holism in Woolf's Between the Acts and other essays," I explore the tension between the construction and reconstruction of historical narratives in works by Virginia Woolf. Here, I look specifically at how irregular nonhuman forces subvert strict regimes of conventionality preserved in social routines and literary conventions. To do so, I examine the development of Woolf's theorizations on materiality as articulated in "On Being Ill," "Modern Fiction," and "Craftsmanship," and further explore how she applies these theories to bodies, environments, and art. Representations of unpredictable environments are prevalent throughout her literary oeuvre and culminate in her final novel, Between the Acts. Yet she does not frame this unpredictability as an incentive to defend the remnants 
of a "green" world from the growing industrial spaces of modernity. Moreover, unstable environments do not convey an existential crisis that marks humanity's descent into oblivion. Whereas Stein and H.D. explore the material-discursive production and reproduction of art, Woolf examines the human agent's capacity to imagine possible futures. She demonstrates a creative process through which the artist does not reach a solution, but through which the art form itself takes on the characteristics of transcorporeal materiality and "opens up a mobile space" (Alaimo, "Feminist Science" 190) of unpredictable outcomes.

Stein's, H.D.'s, and Woolf's study of material language anticipates the ecological implications of language as articulated in contemporary theorizations of ecology. By turning to the visual arts (film and theatre), and by utilizing and critiquing innovations in technology, these authors reveal that the human agent is an integral component of the nonhuman world. Stein's critique of an authorial "I" in relation to H.D.'s critique of the single eye of the Cyclops sheds light on Woolf's representation of history where any concept of singularity is contested. Together, these canonical authors question commonplace understandings of a "green" nature to upset traditional literary affiliations of women and nature. They interrogate the transparency of established language systems, maintaining that these established models perpetuate reductive representations of the environment and neglect the complex material make-up of the human being. As both Anne Raine and Christina Alt note, "nature" remains a complex and highly contested term in modernist studies. ${ }^{29}$ Elaborating on these critics' works, my research pays particular attention to language not as a distinctly human trait, but as a material process

\footnotetext{
${ }^{29}$ See Anne Raine's "Ecocriticism and Modernism" and Christina Alt's Virginia Woolf and the Study of Nature.
} 
that affects and is affected by the environment. Schuster argues, "modern ecology $[\ldots]$ begins when one is no longer sure what nature means, when one does not begin with preset assumptions of what nature should be, when nature does not have ontological, aesthetic, or moral certainty and is an open, urgent question" (Schuster 21). I propose that Stein, H.D., and Woolf expose "preset assumptions" of nature not to devise a clear movement away from such established narratives, but to disclose the material processes of which these narratives are an integral part. 


\section{Chapter One}

\section{"The resistance outside of you and inside of you, a shadow upon you, and the thing which you must express": Cognition, Language, and Nature in Gertrude Stein}

"When they ask me why I don't write as I talk, I answer quite simply that of course I write as I talk because I talk exactly as I write which is perfectly easy if you listen to what I say." - Stein, "Gertrude Stein"

\section{Introduction}

In a 1934 issue of Newsweek, Dr. Morris Fishbein dismisses Gertrude Stein's experimental writing style, claiming that the enigmatic quality of her literary aesthetic results from palilalia, “a frequent encephalitic, better but less correctly known as 'sleeping sickness"” (Newsweek qtd. in Meyer 50). After attending one of her lectures while on her American tour, he supposes that the author's physical condition modifies her use of language. Fishbein’s “diagnosis” misconstrues Stein’s explanation of her experimental literary aesthetic and reduces her work to nonsensical, incoherent phrases that originate from her individual pathology. Similarly, during her arrival in New York in the same year, reporters asked her, "Why don't you write the way you talk?" (Meyerowitz 9), assuming a direct correlation between the author's body and her use of language. This correlation is one that Stein takes up in the discussion of her literary work. The quotation that prefaces this chapter demonstrates her playful response to these criticisms: "Of course I write as I talk because I talk exactly as I write” (Stein, "Gertrude Stein"). The attribution of the author's nonsensical writing style to her body's physical and psychological state is a common thread throughout Stein's lectures as she attempts to explain her experimental literary projects. For example, in "What is English Literature," she attempts to explain literature by carefully conveying what "[she knows] about it" (31). She reinforces this claim in the conclusion of the essay, stating, "and so this is the 
history of English literature of all the writing as I understand it" (57). Moreover, in both “Composition as Explanation," and "Poetry and Grammar," she explains her literary projects by reiterating "by this I mean" (21) and "I have said" (123) respectively. In doing so, she consistently reminds the reader or listener of the "I" that composes the text.

Whereas Fishbein traces a causal relationship between Stein's unique experimental language and the deteriorating state of her ill body, Patricia Meyerowitz proposes that the lectures do not showcase the author's unique psychological state, but advance her attempts to revive "stale literary words" (Stein qtd. in Meyerowitz 7). She details Stein's response to a student's inquiry while conducting a seminar at the University of Chicago during the same tour in which she is accused of showing signs of "palilalia." A student asked Stein for "the meaning" of one of her well-known, but convoluted lines of poetry: "rose is a rose is a rose"" (Meyerowitz 7). The author admits that part of the work of her literary projects is to reanimate "wornout literary words" from which "the excitement of pure being had withdrawn" (Stein qtd. in Meyerowitz 7). Stein suggests that there is a tendency to imitate the language of the past centuries and this reproduction has drained the language of its vitality. The task of the modern author, according to Stein, is to "work in the excitingness of pure being" and "get back that intensity into the language" (7). To do so, Stein examines how the dynamic interrelation of the body and the material world is integral to the vitality of words. She does not produce artistic projects through the mimetic reproduction of language, but demonstrates how the trans-corporeal body reanimates and revives language.

I argue that Stein insists on the intra-action between the body and material environments, advocating the notion of a material language that resists established 
linguistic models and registers the "unpredictable" and "unwanted" (Alaimo, "Feminist Science" 190) actions of bodies and matter. Stein challenges established languages, which she argues are descriptive and "solid" (Stein, "What is English" 41). These "solid" and "descriptive" languages manifest in the form of grammatical and syntactical rules and in the form of established literary genres. These established language models produce a type of "prepared" (Stein, "Composition" 514) knowledge that is only ever replicated rather than contested. Stein, however, champions a language that "moves" (Stein, "What is English" 39). This movement "is what makes [language] exciting" (39) since it rearranges words into sequences that defy conventional discursive practices (like genres and styles). This movement infuses the language with "the excitingness of pure being" that she claims has "withdrawn" over centuries. She exposes this movement by drawing attention to the intimate connection between bodies, environments, and languages, which are all bound up in what Karen Barad terms discursive processes.

Stein does this in many different ways. In this chapter, I trace her exploration of an exciting and moving language. First, I look at her early scientific reports published in The Psychological Review. In these reports, she begins to explore a tension between scientific methodologies that systematically record data, and more dynamic theorizations on bodies and psychology. ${ }^{30}$ Specifically, she examines the different forms of writing characteristic of "normal" and "hysterical" bodies. Normal bodies imitate writing patterns to produce "real writing" (Stein, "Cultivate Motor" 299). Hysterical bodies, by contrast, produce a more experimental writing to produce "things resembling words" (303). Stein,

\footnotetext{
${ }^{30}$ Her critique of formulaic scientific modes of recording extends to her critique of literary conventions. Steven Meyer suggests that the columnist of the Newsweek article who cited Fishbein does not consider how Stein's seemingly nonsensical lecture "parodies equally the programmatic analysis of the literary critic and the time-honored formula of medical prescription" (52).
} 
however, dissolves the barrier between "normal" and "hysterical" bodies and reveals how language, specifically the process of writing language, is not primarily an act of imitation, but a perpetually recreated process as the body incorporates new movements. Second, I show how the results achieved in these experiments animate her attempts to revive "stale" and "wornout" literary words. To contest "solid" normative writing patterns, she turns to "natural" processes. In essays like "Composition as Explanation" and "Poetry and Grammar," she suggests that language, bodies, and environments "naturally" change. Moreover, she turns to the "lively words" of plays, revealing words in motion that cannot be reduced to traditional literary forms and grammatical and syntactical structures. Third, I show how this "natural" language is enacted in Ida: A Novel. In this fictional biography, Stein discloses how Ida experiences the world. She explores how Ida translates those experiments into language and further demonstrates how language, as a material discursive process, is part of her experience.

According to Stein, language derives from the human agent's psychological and physical state. For instance, in "Poetry and Grammar," she indicates that "language as a real thing is not imitation" but an "intellectual recreation" (140). However, she does not imply that language exists only in the mind. Whereas her scientific reports expose the connection between bodily and psychological movements, her essays highlight the human agent's intra-action with historical movements. In "Composition as Explanation," she uses the term composition to expose the relation between questions of epistemology, history, and language. I interpret "composition" as a complex, expansive notion that goes well beyond standard ideas of literary or artistic composition. The term refers to the social and historical environments that the body inhabits. Her reflections on the theatre 
emphasize the ongoing performance of a "composition." In "Plays," her theoretical insights on performance destabilize common conceptions of the body as contained and singular. The performance space stimulates a sense of nervousness that establishes and maintains a sense of unfamiliarity. The body's nervous interaction with an unfamiliar environment stimulates the type of movement that Stein wants to infuse in "stale" and "wornout" languages. Stein indicates that the sentient body's interaction with the material world leads to the constant revision of established linguistic systems. Her notion of composition and performance reveals how the speaking subject or the narrative "I" discloses "movement across different sites" (Alaimo, "Feminist Science" 190).

I propose that Stein's emphasis on the unbounded authorial "I" opens up her works to questions of ecology. By “ecology,” I refer to Serenella Iovino's and Serpil Oppermann's definition of the term which means “thinking the copresence through porous boundaries" (Iovino and Oppermann, “After Green” 329). Stein achieves this by consistently employing the term "natural." For example, she repeatedly uses the term in essays like "Composition as Explanation," and "How Writing is Written" to connote difference or to signal a transition. Stein's dynamic experimental writing combats "stale literary words" by showcasing how words take on different connotations, thereby changing the meaning of the text. These textual variances address one of the main concerns in current ecocritical debates. Iovino and Oppermann stress the need to break away from "nature" as an umbrella term that usually connotes "green" spaces. Instead, they point to the variable meaning of the terms "nature" or "natural" to advance "a pluralist vision" of the nonhuman world that "[interprets] the world as the result of endless meditations and combinations" (334). Other material ecocritics like Jeffrey 
Jerome Cohen also suggest that the complexity of the term nature exposes how the nonhuman world is not "a creature of seclusion and solace, but a concept for repeated interrogation" and further displays how it "is a term without transparent explanatory force" (xxii). In this light, I read Stein's works in relation to material ecocritics who examine how material performances "[redraw] the maps of knowledge and practice, and [...rethink] object and subject, nature and culture not as juxtaposed terms but as a circulating system" (Oppermann and Iovino, “After Green" 454). In doing so, I move away from traditional readings of Stein's works.

Typically, critics read Stein's experimental writing as adhering to or complicating the "linguistic turn" in modernist studies. This linguistic turn neglects the body by promoting language as a disembodied construct that frames reality. For example, Marianne DeKoven and Anne Timoche provide a psychoanalytic reading of Stein's works, suggesting that the author's stylistic use of language evinces a return to a preOedipal or prelinguistic stage. ${ }^{31}$ These critics emphasize Stein's concern with prelinguistic states, negotiating between linguistic constructs that organize fixed referential models of normative identity and bodily drives that deviate from these models. Moving away from an emphasis on bodily drives, Harriett Scott Chessman argues that "biology is almost comically elusive in Stein" since "she catapults us instead into a world of words" (6). This emphasis on language exposes "Stein's modernist and feminist project" (2) wherein "language is the primary cultural agency" (Chessman 5). Moreover, Rachel Blau DuPlessis and Mary E. Galvin differentiate between "masculine and feminine stylistic modes" of writing (DuPlessis 39). Galvin proposes that Stein's experimental writing

${ }^{31}$ See Marianne DeKoven's A Different Language: Gertrude Stein's Experimental Writing and Anne Timoche's "The Body: Figure/Text: A Reading of Marguerite Duras and Gertrude Stein." 
combats "the traditional role of linear sequence in the creation of "meaning", (42) as she uncovers an alternative to "patriarchal language" and "heterocentric thinking," both of which "depend on a categorical approach toward identity" (43).

Whereas these critics examine the opposition between linguistic and prelinguistic states, Joshua Schuster suggests that "it might be more correct to say that Stein writes in a way that is prior to making these binary distinctions" (Schuster 69). That is, he argues that "normative grammar relies on subject and object distinctions" (69) and further proposes that "it is not that Stein is intending outright nonsense; rather, she writes in a state prior to a determinate distinction between sense and nonsense" (68). I propose that Stein's experimental writing is not "prior to a determinate distinction between sense and nonsense" but is bound up with a material-discursive becoming. My project expands on Stein's "feminist project" (Chessman 2) by complicating gender binarisms typically preserved in language. Stein is not a "language outlaw" (DuPlessis 37). On the contrary, her notion of language as an "intellectual recreation" exposes the "natural" movement of language. "Nature," according to Stein, remains an open and unbounded entity that always exceeds linguistic and epistemic structures.

My project differs from those critics who focus on "[recovering] nature, [and] women" from patriarchal discourses or from "the chasms of degradation and injustice" (Fitzpatrick 2). ${ }^{32}$ Instead, the "'human' is always already part of an active, often unpredictable, material world"' (Alaimo, Bodily Natures 17). The human cannot be recovered, only "recreated." The human agent's immersion in the nonhuman world does

\footnotetext{
${ }^{32}$ My project therefore moves away from ecofeminism to ecocritical materialism. Noël Sturgeon proposes that ecofeminism "articulates the theory that the ideologies that authorize injustices based on gender, race, and class are related to the ideologies that sanction the exploitation and degradation of the environment" (Sturgeon qtd. in Campbell vii). Material ecocriticsm builds off of this by examining the ongoing material processes from which ideologies emerge.
} 
not imply a cordial relationship, but one that is disjointed. Stein suggests that human agents are never in sync with historical or geographical movements, or with each other. They are always aware of some degree of separation. Stein exposes this sense of separation in her scientific experiments as she proposes that "inside" psychological processes and "outside" processes cannot be fully assimilated. She further displays this separation through her notion of "disconnection" in "What is English Literature" and through the body's reaction to unfamiliar performance spaces in "Plays." This separation is not to be overcome; instead, it is a "natural" process. Through her description of composition, Stein proposes that everything is "naturally" different (Stein, "Composition" 514). The vitality of language results from this difference and therefore language cannot be reduced to acts of imitation. Language is a material "emergence" (Iovino and Oppermann, "Theorizing Material" 451) and this emergence discloses the “discursive dynamics" of Stein's literary experiments.

The material emergence of language also exposes an immersive or entangled method of knowing that moves away "from a subject/object epistemology to a humannonhuman performative onto-epistemology" (455-56). The intimate connection between language and epistemology reveals what Iovino and Oppermann refer to as an "edgeeffect" (457). Ultimately, the edge-effect complicates the notion of a human agent who objectively observes an external reality by re-thinking the human agent as intra-acting with that reality. Whereas traditional readings of Stein rely on binarisms such as male/ female, and cultural/natural, the edge-effect "[questions] the ontological boundaries set up by our cognitive practices" (454). Contemporary cognitive studies elaborate on the theories of psychology that Stein encountered in the university by illuminating the mind's 
immersion in the nonhuman world. Cognitive theorists like Boguslowska-Tafelska, John Taylor, and Sune Vork Steffenson demonstrate how cognitive processes and language production are affected by external environments. They advance the notion of an "ecology" of language and language "niches." In this chapter, I put these cognitive theorists in dialogue with material ecocritics' understanding of ecology to show how Stein's experimental writing moves beyond incomprehensible musings to expose her theorization on language as a dynamic material process.

By reading Stein's work in relation to the trans-corporeal body, I move away from an emphasis on "the linguistic turn that placed a concerted emphasis on linguistic construction of the world" and explore how "the new materialist paradigm is premised on the integral ways of thinking language and reality, discourse and matter together" (Iovino and Oppermann, Material Ecocriticism 262). By putting her scientific studies in dialogue with her fictional works, I will show how Stein's Ida: A Novel is a performance of her theorizations on language. Specifically, by focusing on this fictional biography, I demonstrate how the body's place within a complex network of material processes generates the continuous reorganization of established language systems. The trajectory of the novel does not chronicle a linear developmental process, but displays how natural forces dismantle established linguistic systems that promote homogeneity by perpetuating social norms that regiment the body. According to Stein, the human agent is an integral part of the environment, and transformative nonhuman processes radically reconfigure "stale" human systems of classification. Thus, by integrating cognitive functions into an ecocritical framework, I examine the interplay between nonhuman processes that influence language, and discursively produced notions of the environment. Stein 
dismisses rigid cultural regimes by reconceptualizing the human and the environment as a dynamic intra-acting system.

\section{"What is English Literature": From the Laboratory to an American Tour}

My contention is not to promote Stein as a steadfast activist for environmental ethics, diligently striving to expose deteriorating ecosystems and advancing a rallying cry to sustain and preserve "green" landscapes. Instead, I show how her attention to literary experimental form is inflected by questions of ecology. Before diving into a discussion of Stein's essays and literary works, it is important to first contextualize her literary oeuvre in relation to competing scientific discourses with which Stein actively engaged as a student. During her undergraduate work at Radcliffe College, her scientific training covered a wide range of courses, including zoology, botany, and psychology. ${ }^{33}$ She later continued her research in experimental psychology at Johns Hopkins Medical School, specializing in the neuroanatomical structure of the brain. As a woman training within a predominantly masculine discipline, she was restricted by the types of tasks she could perform in the university. ${ }^{34}$ She eventually transitioned from inanimate brain models to the investigation of dynamic psychological phenomena.

As a student, Stein published two scientific reports in the Psychological Review based on experiments that tested a subject's ability to reproduce standardized writing. ${ }^{35}$

\footnotetext{
${ }^{33}$ See Daniel, p. 28.

${ }^{34}$ As a woman, Stein was allowed to "[participate] in a research project on brain anatomy, cutting tissue sections and making models and drawings of the structure of the brain" (808). She was also not allowed to take part in specific tasks because of her gender. See Steven Meyer.

${ }^{35}$ These reports show Stein's move away from inert matter to physical and psychological processes. Mark Micale explores this growing tension between competing sciences. Early twentieth-century sciences contested and revised dominant nineteenth-century scientific modes. He writes, "throughout the period orthodoxies of medical positivism remained firmly intact: in
} 
She co-authored the first report, "Normal Motor Automatism" (1896), with her colleague, Leon M. Solomons. She published the second report, "Cultivated Motor Automatism; a Study of Character in its Relation to Attention" (1898), on her own. Under investigation are "types" of bodies and the instrumentality of writing. The reports reveal that bodies surpass categorical "types," such as "normal" and "hysterical" bodies. Hysterical bodies showcase a dynamism that is typically assumed to be absent in "normal" bodies. Solomons and Stein employ the term "double personality" to refer to the "remarkable development in the subconscious life" demonstrated in "many hysterical subjects" (Solomons and Stein 492). This is also referred to as "subliminal consciousness" which is presumably different from the "conscious consciousness" (493) of "normal" subjects. The visible bodily manifestations of the subconscious are commonly conceived as “essentially different from the merely automatic movements of ordinary people" (493). To deflate this theory, Solomons and Stein attempt to stimulate characteristics typically observed in persons diagnosed with hysteria in "normal" bodies in order "to determine the limit of normal automatism" (493). The experiments expose how external stimuli directly impact bodily impulses and render movements voluntary or involuntary, discrediting the conventional notion that "subliminal consciousness" and "conscious consciousness" are categorically distinct mental states.

sickness and health, the human body and mind were to be studied, understood, and eventually mastered through precise and detailed observation by a community of experts. Pathology was seen to have rational causes, subject to immutable and ascertainable patterns or laws. Conversely, nonempirical methods of investigation and sources of insight were to be rejected as corrupting, contaminating forces in the quest for objective value-neutral knowledge" (Micale qtd. in Morrisson 128-129). Specifically, "positivist medical science was the ultimate 'discourse of the real' seeking to produce an authoritative account of an unproblematically real world of the human body and mind" (129). 
In the first report, Solomons and Stein propose that these interrelated mental states are directly tied to the physical body. They attempt to disprove the opposition between "normal" and hysterical bodies by examining the body's sensitivity to changes in external environments. By recognizing the body's conscious and unconscious actions, they attempt to trigger "the essential elements of the "second personality", (493) or “double personality" (492). By triggering these "essential elements," they show how psychical processes, much like the physical make-up of the body, are malleable. In both reports, Stein tracks this sensitivity by observing a subject's ability to write. By examining the subject's writing processes, she attempts to decipher the seemingly invisible motions of psychic currents and how they affect and are affected by bodily movements. She investigates the correlation between internalized mental processes and the outer translation of these processes into linguistic forms, tracking "the relation of writing to the work of the brain" (Daniel 33). In each experiment, a subject is asked to produce words through controlled, repetitive actions with their arm. This repetition represents the "stale" production of language achieved through imitation. Any visible bodily movements that interrupt these repetitive motions expose the "vitality" of the unconscious.

The first experiment is prefaced on the assumption that "ordinary" bodies or bodies exhibiting habitual movements are entirely different from hysterical bodies, or bodies exhibiting uncontrollable emotional states. Solomons and Stein are the only two participants, acting as "representatives of the perfectly normal—or perfectly ordinarybeing, so far as hysteria is concerned" (Solomons and Stein 494). Each subject placed their hands on a planchette composed of "a glass plate mounted on metal balls, with a 
metal arm holding a pencil" (494). Once the subject grips the metal arm, the other introduced "very slight stimuli" to begin moving the arm. The subject then reproduced the motion while attempting to get "as deeply interested in a novel as possible" (494). The subject strives to become totally engrossed in the novel so that the movement of the arm on the planchette becomes unconscious. The "normal" subject's unconscious movements are automatic, only disrupted by changes to the external environment. If "the story gets too exciting" then "emotional reflexes are likely to interfere either by causing violent movement or by stopping all movement" (495). As the subject becomes more engaged in the literature, the researcher examines the "spontaneous" movements of the subject, noting instances in which the subject begins reproducing words from the text. This action is non-voluntary as the subject remains unaware of having written words. The "knowledge" of having written a word "was obtained from sensations from the arm" (496). The involuntary movements disclose a type of writing that digresses from established linguistic models. Stein, however, questions the results of the first experiment, suggesting the data is inaccurate since her and Solomons' participation in the experiment might have predetermined the results. To remedy these potential errors, Stein composed a second report in which she reinforces the separation between the researcher and the experimental subject by enlisting the help of several students.

Much like the first experiment, she focuses on habituated bodily movements, but draws attention to "the nerve centers" (Stein, "Cultivated Motor" 305) of the body. In particular, she examines how these nerve centers respond to external stimuli by having the participants rest their arm on a planchette "suspended from a high ceiling board just large enough to support the forearm, the hand hanging over and holding a pencil" (295). 
By adjusting the direction of the planchette, Stein had the participants engage in a repetitive motion that resulted in the writing of words or letters. She prefaces the experiment by noting distinct characteristics about the subjects under observation. She reveals how the group of students can be divided into two "types": the first are "nervous, high-strung, very imaginative" and they have "the capacity to be easily roused and intensely interested" (297). The second type are "phlegmatic" and "their power of concentrated attention is very small" (297). All participants varied in their degrees of nervousness or agitation, but nevertheless, Stein suggests that the nerve centers of the body were receptive to the distorted movements of the planchette. The other notable characteristic of the subjects is that they were mostly "New Englanders" (299). Stein considers how a specific geographical environment produces a particular "type" of character. ${ }^{36}$ For instance, the subjects display "the intense self-consciousness, the morbid fear of 'letting go,' that is so prominent an element in the New England character" (299). They were persistent in their efforts to resist new movements. When Stein introduced new stimuli to interrupt automatic motor movements, "there was a continued return to the old movement" (296). Eventually, however, "the new movement conquered and was freely continued" (296).

These experiments expose two main components that are integral to Stein's notion of English literature: the trans-corporeal body and material-discursive processes. She displays the former through the body's resistance to categorical types and "essential elements." She reveals the latter through her attention to the apparatus measuring and recording the data both in the form of the scientist and the method through which the

\footnotetext{
${ }^{36}$ Stein makes fun of this correlation between geographical areas and character "types" in her novel Ida.
} 
scientist records the data. Although the subjects under examination exhibit habitual character traits, they eventually overcome these habits by adopting a "new movement." The subjects eventually cease to "return to the old movement." Stein thereby dismisses the notion of a "return" to expose the "unwanted" actions of the body. The new movement prevents the subject from imitating a word or letter. The experiments, I argue, thus shed light on Stein's explanation of her literary experiments. They reveal how bodies resist "stale" words and instead "work in the excitingness of pure being" (Stein qtd. in Meyerowitz 7). The "new movement" demonstrates "the intensity" that Stein attempts to infuse "into the language" (7) as she reminds the reader of the body composing the text. Unlike the passive and inert matter of brain models that she encountered in the university, these experiments disclose the vibrancy of the material composition of the body. Stein suggests that "the writing of a word at dictation" (Solomons and Stein 498) is complex and thus it cannot be reduced to the mere imitation of writing patterns. "The writing of the word at dictation" consists of four elements: "the heard sound;" "the formation of a motor impulse;" "a feeling of effort;" and a" sensation from the arm telling of the written word" (498). She examines the material dimensions of language, tracing the relation between sound, bodily impulses, and sensations. The interplay between bodily and psychical processes made possible through the "nerve centers" of the body "ordinarily innervates our writing" (498).

Stein further notes that "the writing of a word at dictation" also "consists of a melange of visual and kinaesthetic material" (498). Anne Raine suggests that Stein's interest in vibrant bodies stems from the "new kinaesthetic" (Raine, "Science, Nature" 805), which demonstrates how “"the insides of people' were not a passive object of 
laboratory study but a vital locus of creative energy, linked through the kineasthetic body to what Stein, not coincidentally, called 'the rhythms of the visible world"” $(805) .{ }^{37}$ The gradual shift in bodily movements evidenced by each participant indicates that changes in the environment stimulated the nerve centers in various ways and ultimately modified the written word. The experiments thus disclose the opposition between the prescriptive scientific rhetoric of the report that organizes the data and the spontaneous, involuntary writing under investigation. In each case study, Stein monitors the response of the reflexes and "nervous jerks" (Stein, "Cultivated Motor" 303), noting the subject's agitation or excitement. Moreover, she provides a number of results that showcase her attention to the effects of this agitation on the writing process, tracking instances in which the nerve centers of the body were minutely affected, permitting the subject to produce "real writing" (299), and instances in which the subject's movements were increasingly affected by the change in conditions, producing "things resembling words" (303). The opposition between "real writing" and "things resembling words" frustrates the use of language as a measuring unit that records and preserves data obtained in scientific experiments. Language is not simply a measuring apparatus. That is, language is not an established structure exempt from the study that organizes the data "intact and uncompromised" (Alaimo, "Feminist Science" 195), but materially produced and changeable.

Stein's reconceptualization of the body that exposes "movement across different sites" (190) questions the authority and accuracy of writing as a tool to record data. By dissolving the separation between "real writing" and "things resembling words," she

${ }^{37}$ Raine further suggests that the new kineasthetic "unsettled conventional notions of human character and creativity, enabling [Stein] to imagine writing as behavior rather than as the expression of character understood in moral or sentimental terms" ("Science, Nature" 810). 
reveals how language as a measuring apparatus within the university is itself mutable. Similarly, Karen Barad argues that apparatuses "do not possess inherent outside boundaries limiting them to laboratory spaces or experimental practices" (169). By recognizing this aspect of the apparatus, it becomes clear how any device used to capture data is always part of "unruly materiality" (Alaimo, Bodily Natures 116). As Stein transitions from modern sciences to the arts, she does not reject her scientific studies, but rather she continues to investigate how language as an "apparatus" is never static or deterministic. Instead, language necessitates change and this change "excites" literary conventions. That is, whereas traditional and canonical texts advance a specific understanding of "real writing," Stein examines how experimental modernist writing exposes a material-discursive process. For instance, in an essay composed in 1934 and presented during her 1935 American tour, Stein attempts to explain what constitutes literature, differentiating between traditional literary models that define a particular genre and form, and the emergence of new literary practices. Like her scientific experiments, she investigates variations in language by focusing on how language is produced in literary form while also considering how people use language in their everyday experiences. The laboratory shifts to "the daily island life" (Stein, "What is English" 33) of England and the subjects under investigation make up the population of this "daily island life." She tracks the evolution of English literature, both historically and geographically.

Stein begins the essay, "What is English Literature," not with a clear explanation of English literature but with "the question what is knowledge" and its subsequent answer, "knowledge is what one knows" (31). She extends her exploration of her 
knowledge of English literature by examining how one knows; however, she ends the essay by stating, "And so this is the history of English literature of all the writing written in English as I understand it" (57). The essay does not provide a conclusive statement that authoritatively defines English literature, but is a performance of "what one knows." It is an exercise in explanation, revealing how individuals who explain, "said what they thought and they were thinking about what they thought" (48). ${ }^{38}$ This definition of explanation exposes the relation between thought and language, specifically the translation of thought in the form of writing. The repetitive and playful tone of the essay might invite some readers to share Dr. Fishbein's response to Stein's American lectures, suggesting that this is simply the incomprehensible musings of a woman suffering from exhaustion. The essay, I argue, cannot be so easily dismissed since it sheds light on some of the main concerns animating Stein's experimental writing projects. The relation between the body, knowledge production, and the translation of "what one knows" in language, informs her notion of literature which stems from her early scientific reports. ${ }^{39}$

The essay, like the experiments, positions the artist as the person who investigates the evolution of English literature while the artist is simultaneously under investigation. Stein both examines traditional models of English literature and sheds light on traditional methods by which the human agent obtains knowledge of literature. She explains how

\footnotetext{
${ }^{38}$ Woolf also structures her famous essay "Modern Fiction" as a performance or exercise in explanation and denies the reader any conclusive statement on modern fiction.

39 These reports shed light on important transformations in early twentieth-century sciences that can ultimately help us better understand questions of knowledge and language at play in the essay. Stein is a transitional figure. By this I mean she studied science and psychology at the end of the nineteenth century and wrote most of her modernist work in the twentieth century. She witnessed the transition from nineteenth-century science that promoted "observable, empirical, objective certainty" (Linett 8) to more experimental twentieth-century sciences. The aim of scientific practices in the nineteenth-century was "to formulate a knowledge ideally independent of the subject" (Banfield 6). Moreover, "language, in the nineteenth century, had been thoroughly instrumentalized as an object and vehicle of knowledge" (Eysteinsson 49).
} 
external material changes in geography and society, and internal material changes in psychical and biological phenomena perpetually alter language and writing processes. By focusing on "a feeling of the way English literature feels inside [her]" (24), she investigates how the "daily island life" (33) of England both modifies and alters the way we speak and write. The essay experiments with learning models as Stein proposes "two ways of thinking about literature as the history of English literature" (32). She distinguishes between "the literature as it is a history of it and the literature as it is a history of you" (32). Through "the habit of reading," Stein suggests that we "have our own history of English literature inside us" (32). This history does not become external until we "tell it to somebody else as [she is] now telling [hers]" (32). This does not suggest that internal processes of the mind determine authoritative claims on reality. The separation between a universal history and a concept of history bound up with the individual indicates that knowledge rests on a form of communication. This communication between universal and individual agents alters what we know and how we translate what we know into language. This notion of communication demonstrates the intra-acting processes integral to Stein's understanding of language and literature.

The essay chronicles a brief history of English literature, indicating that the routinized actions of the "daily island life" of England solidified traditional models of English literature. "The daily island life" produced a "habit of reading" that perpetuated "the descriptions of the daily, the hourly descriptions of this island life" (33). Stein suggests that "the thing that has made the glory of English literature is description simple concentrated description" (33). Description implies reproducing or imitating language models as one "[writes] the way it has already been written" (56). Her critique of "simple 
concentrated description" echoes her critique of systematic methods of recording in the university, which focus on inert matter like she experienced with brain models rather than the "intensity" or "excitingness of pure being." Stein, however, notes that the nineteenth century initiated a shift from an emphasis on description to an emphasis on "explanation." ${ }^{40}$ Explaining differs from description since it necessitates a direct interaction with material realities. ${ }^{41}$ Since the essay is an exercise in explanation, Stein seeks to establish "a direct interaction" with the listener or reader. This interaction will continue to modify the definition of English literature. It cannot be adequately described. She notes how English literature has always eluded some descriptive definition since literary conventions change throughout history and will continue to change.

Although Stein seems to support the notion of a chronological historical narrative, she dismisses a linear evolution that culminates in the act of explaining. By tracing the history of English literature from the fourteenth to the nineteenth century, Stein does not imply that the members of a collective social body thought the same way. Throughout the essay, she appeals to the listener or the reader: "do you see what I say" (Stein, "What is English" 55) and "do you quite see what I mean. I know quite completely what I mean"

\footnotetext{
${ }^{40}$ The distinction between "description" and "explanation" echoes the tension between nineteenth-century science and experimental twentieth-century science. The move away from language as a form of description to language as a process relates to the reconceptualization of the body as a process. Meyer notes that during Stein's time at Johns Hopkins, she "found herself in the midst of a paradigm shift," grappling with two competing theories of neural organization. These include "the reticular theory" that recognizes "the existence of continuous network of branches connecting nerve cells" juxtaposed with the notion that "nerve cells, like all other types of cells, are discontinuous from one another," suggesting that nerve patterns "depend entirely upon contact or contiguity, not upon organic connection" (Meyer 79). The former implies a formulaic pattern that reduces the human and the environment to contained entities that can be adequately defined. The latter recognizes unpredictable relations between nerve cells, indicating that the complex nature of the human and the environment resists reductive scientific discourses. ${ }^{41}$ Like Stein's experiments, the direct interaction between the subject and the external stimuli introduced a "new movement." This direct interaction altered the writing process by interrupting the act of imitating a writing pattern.
} 
(53). This exchange sheds light on the complexities of "knowing" and the multimodal senses involved in one's ability to translate thought into language through the process of explaining. This is not simply meant to confuse the listener or the reader, but to produce "a lack of connection" (56). This "disconnection" is what Stein attempts to achieve through her literary experimental writing. She explains how she "kept breaking the paragraph down, and everything down to commence again" (56). ${ }^{42}$ This "disconnection" is characteristic of American literature and distinguishable from traditional writing practices that simply "describe" or "state" facts.

She further explores the distinction between description and explanation through the separation between "mammon" and "god." She states, "if you write the way it has already been written the way writing has already been written then you are serving mammon, because you are living by something some one has already been earning or has earned" (56). ${ }^{43}$ The act of explaining, by contrast, suggests that one "[writes] as [they] are to be writing" which means that they "are serving as a writer god because [they] are not earning anything" (56). ${ }^{44}$ Stein notices a difference between the terms "mammon" and "god," proposing that the former "may be anything that is done indirectly" (38) and the latter indicates that "the thing done and the doer must be direct" (38-39). Although she

\footnotetext{
${ }^{42}$ This notion of "commencing again" reflects her famous notion of "beginning again" in an earlier essay, "Composition as Explanation."

${ }^{43}$ Stein's early scientific work in which she diagrammed anatomical models of the brain relates to "serving mammon" as she participated in descriptive efforts to reproduce what has already been "written before." This emphasis on modelling and diagramming did not only apply to the body and psychology but to natural sciences as well.

${ }^{44}$ This opposition between mammon and god is at play in her scientific reports. The degrees to which external stimulants affected the nervous system, and the degrees to which various levels of irritability in the subjects impeded the writing process manifest in Stein's distinction between mammon and god. The mimetic recreation of words showcases the subject's indirect experience and thereby relates to the subject "serving mammon." By contrast, any inconsistencies reveal the subject's direct experience and consequently exhibits a subject "serving god."
} 
champions nineteenth-century American literature as the genre of literature that introduces the writer-god and subsequently initiates the process of explanation, Stein ends the essay by revealing, "there is no choice. Nobody chooses" (57). The writing process is not simply a conscious effort to promote a specific stylistic formula and a particular methodology. In other words, writing is not the direct translation of internal thoughts to external symbols. She demonstrates how language changes over time: "one century has words, another century chooses words, another century uses words and then another century using the words no longer has them" (40). Language, according to Stein, is a process that has no clear direction since it does not culminate in an idealized evolved state.

This theory of language as a process shares similarities with William James. While attending both institutions, Stein studied under James, whose pragmatic inquiries into the study of consciousness influenced Stein's psychological research. As one of James' students, she studied the correlation between linguistic and neuroanatomical processes and the creation and recreation of knowledge paradigms. James contends that external stimuli trigger neurological patterns of the brain, dismissing the notion of disembodied consciousness, and examining instead the interrelation between internal subjective space and the external environment. In his work The Principles of Psychology, he declares that "a mind is an object in a world of other objects" (James), resisting the notion that the mind is an abstract and absolute entity that can be dissected and fully comprehended. Instead, he proposes "psychology, as a natural science, confines itself to the present life, in which every mind appears yoked to a body through which its manifestations appear" (James). He examines how the "entire brain is nothing but our 
name for the way in which a million of molecules arranged in certain positions may affect our sense" (James). Claiming that knowledge systems are constantly rearranging since "our sensibility is altering all the time," he compares psychical processes to "the aurora borealis" in which the brain's "whole internal equilibrium shifts with every pulse of change" (James).

Part of James' study of the brain opens up to a discussion of language as he explores how neuroanatomical processes translate ideas and emotions into language. $\mathrm{He}$ states, "there is no centre of speech in the brain any more than there is a faculty of speech in the mind," further noting that "the entire brain, more or less, is at work in a man who uses language" (James). ${ }^{45}$ Language then does not suggest an outward unidirectional flow of thoughts and emotions from the interiority of the brain to external linguistic models. Language is not transparent, but produced and modified by the intra-action of internal and external material processes. Current cognitive studies expand on James' notion of language, examining the connection between the perceiving subject and the environment. Language production is not allocated to specific regions in brain architecture: "Language is not processed by some general learning capacity, but by quite heterogeneous cognitive subsystems, none of which is a language processor by design" (Deacon 298). Moreover, "according to cognitive linguistics, conceptual and linguistic activity is ultimately

\footnotetext{
${ }^{45}$ The study of neuroanatomical processes and language production are not unique to James's study of psychology. Pierre Paul Broca and Carl Wernicke were nineteenth-century psychologists who investigated the interrelation between the physical anatomy of the brain and its effects on language. Specifically, they examined the interplay between neuroanatomical and auditory speech impediments, their research resulting in Broca's aphasia and the Wernicke area of the brain respectively. Advancements in nineteenth-century psychology thus considered the material dimensions of language, exposing how brain regions, external sensations, and the written and spoken word were interconnected.
} 
grounded in embodied human experience," resulting in the constant revision of linguistic systems "arising from 'our bodily sense of spatiality" (Richardson 4).

This material and bodily recreation of language aligns with Stein's overview of English literature. Language affects and is affected by external conditions such as wars and geography. Language is never solely produced "inside" the brain, but relies on the interchange between "inside" and "outside" (Stein, "What is English" 41). Stein claims that, "after all the way you write has everything to do with where you are insofar as you are anywhere, and of course and inevitably you are somewhere" (41) ${ }^{46}$ In "the nineteenth century," she proposes that "the inside had become so solidly inside that all the outside could be outside" (41). This "solid" separation between inside and outside inevitably changes. As Stein moves through each century ranging from the fourteenth century to the nineteenth, she exposes how wars such as the Norman conquest and the Napoleonic wars "[upset] things" (37). This is not to suggest that wars are the sole producers of change, but that they increase exponentially what is already in the process of changing and make it more accessible to the perceiver. Wars or catastrophes "make a change which is a change which is about to be a change go faster as much faster as a war can go, and even a slow war a slow catastrophe goes quite fast" (46). Wars then alter the environments that the human agent inhabits and thereby alters the writing process. What was solid becomes fluid.

\footnotetext{
${ }^{46}$ James's psychology exposes how the human agent is immersed in the nonhuman environment, revealing how elaborate neural and cellular patterns shape developmental processes. The neural networks of the body and the topography of the brain form a cohesive unit, resisting a linear evolutionary process that culminates in a teleological goal. Instead, the neural circuitry of the brain inhibits repetitive, mechanical functions, and produces flexible cognitive processes as the body interacts with the environment.
} 
Current cognitive studies demonstrate how languages change in relation to material changes in the world, and these changes "[remain] open, unpredictable, and free" (Boyd 122). The variations in cognitive processes produce flexible language structures since "the way we build discourses and develop linguistic categories can immediately be derived from the way we experience our environment and use that experience in species-specific communication" (Heine 3). Since "a brain literally adapts to its body" (Deacon 194), the intermedial processes of neural networks and natural processes "[make] it possible for the nervous system as a whole to participate actively in its own construction" (195). These processes also "[offer] an important source of variations and adaptations that play a role in brain evolution" (195). Similarly, Stein suggests that with every new century "there was bound to be a change because after all nothing goes on longer that it can" (Stein, "What is English" 51). Change is inevitable and this, according to Stein, is a "natural" process. Nature therefore connotes erratic and ongoing change.

Although the essay does not focus specifically on "nature," Stein employs the term "natural" to explain historical occurrences as she transitions from one century to the next. Not only are external material changes "natural," but so are changes in writing processes and discursive practices. For instance, she maintains that "it must be understood that explaining was invented, naturally invented” (48). Similarly, material ecocritic Levi Bryant argues that nature "is not static, eternal, and unchanging, but rather creative, constructive, and inventive" (Bryant 297). Nature as a "creative," and “inventive" force directly alters the human agent's creative capacities. In this way, Stein's essay anticipates "the new materialist's paradigm" which "is premised on the 
integral ways of thinking language and reality, discourse and matter together" (Iovino and Oppermann, "Theorizing Material" 462). She begins the essay by stressing the relation between the perceiving subject and knowledge structures. She is not simply transferring knowledge from one body to the next, but demonstrating how "disconnection," and the relation between the speaker and the listener (or reader) are mutually involved in the production and reconstruction of meaning-making models. This porous interaction between bodies and environments exposes "knowing [as] a materialdiscursive becoming" (455).

Stein refuses to associate language with artificial reproductions of the world, but recognizes the artist's immersion within a dynamic intra-acting system. Stein's "writing explores language and consciousness as processes that are thoroughly material, but autopoietic rather than deterministic" (Raine, "Modernism" 110). Literary experiments seemingly necessitate artificial reconstructions that immobilize material processes. Raine, however, substantially revises typical conceptions of Stein's literary projects that tend to associate artistic creations with a move away from organic materiality toward a world of artifice. ${ }^{47}$ This implies that an artist can reduce the external world to a knowable entity that can be accurately replicated. Raine, instead, turns to Steven Meyer's study of Stein's earlier scientific work on physiological psychology and asserts that "what appears to be a movement away from nature is instead a reimagining of nature as a dynamic, rhythmic totality that includes the 'insides' of artistic consciousness as well as nonhuman phenomena" (Raine, "Science, Nature" 819). Nature is never simply a given concrete locale that can be mimetically reproduced. Nature in relation to Stein is complicated by

${ }^{47}$ This artificial world derives from the "linguistic turn" typically associated with high modernism. Language is ahistorical and autonomous, and literature constructs a world of artifice distinct from the "natural" world. 
various social, linguistic, and scientific constructions of the nonhuman world. This is why, as Joshua Schuster notes, Stein "scoffed at being labeled a naturalist, which would indicate being derivative or mimetic" (Schuster 53). To expand on Schuster's claim, she "scoffed" at any descriptive categorical label. Stein, however, was not alone in proposing a fluctuating natural world that affects the human agent. Her theories of "disconnection" are heavily influenced by one of the leading philosophers at the time, Alfred North Whitehead.

When she left the scientific world of the university to pursue a literary career, Stein met Whitehead whose holistic view of the natural world informed her notion of the human and language systems as a process. Steven Meyer proposes that "Whitehead's analysis of what he initially called 'rhythm,' and subsequently referred to as 'vibrating pattern' or 'vibratory organism,' provides a scientific framework for understanding Stein's claims to recreate, and not merely represent, individuals" (Meyer 4). ${ }^{48}$ Pertinent to Whitehead's critique is the investigation of individual cognitive capacities, which he claims are inextricably bound up with physiological processes that respond to unpredictable forces in the environment. In his work Science and the Modern World (1925), Whitehead criticizes the extreme subjectivism of scientific investigation that reduces the natural world to systems of classification. This form of extreme subjectivism suggests that external reality is simply a projection of the mind, and that the individual is incapable of interacting with external environments. He also undermines objective analyses of the natural world in which the environment is reduced to geographical

\footnotetext{
${ }^{48}$ Many critics have noted the relationship between Stein and Whitehead. Meyer and Raine examine his influence on Stein's writing. Specifically, they suggest that "Stein's work resonates with her friend Alfred North Whitehead's efforts to replace subject/object dualism with a new ontology of process and event" (Raine, "Ecocriticism and Modernism"110).
} 
coordinates and fixed quantifiable attributes obtained from observation. ${ }^{49}$ This objective mode of scientific investigation relies heavily on empirical facts and advances "the famous mechanistic theory of nature" (Whitehead 74). Whitehead criticizes the dualistic notion of the mind and body perpetuated by these forms of scientific experimentation which situate the individual body as the primary source of knowledge, and by extension, promote a concept of nature that is quantifiable and ordered. He is a leading figure at the center of a drastic shift in conceptualization that informed literary modernism. ${ }^{50}$

Although he dismisses the notion of the mind and cognitive functions as the main source through which to obtain apprehension of the natural world, he maintains that "we have to admit that the body is the organism whose states regulate our cognizance of the world," further noting that "the unity of the perceptual field therefore must be a unity of bodily experience" (133). He thus claims that "in being aware of the bodily experience, we must thereby be aware of aspects of the whole spatio-temporal world as mirrored within the bodily life" (133). Cognitive semantics expands this theory by proposing the material composition of meaning-making. For instance, cognitive theorist Peter Gärdenfors reveals that image schemas and neural patterns in the brain "are connected to our perceptual mechanisms, directly or indirectly" and so "meanings are, at least partly, embodied" (Gärdenfors 58). As such, "these patterns emerge as meaningful structures for us chiefly at the level of our bodily movements through space, our manipulations of objects, and our perceptual interactions" (Johnson qtd. in Gärdenfors 63). Whitehead thus

\footnotetext{
${ }^{49}$ Robert Chodat suggests that the distinction between subjectivism and objectivism introduces two competing epistemological concerns in Stein's scientific and literary endeavours. He attempts to bridge the separation between objective and subjective models of knowledge. Specifically, he explores the "sense-making activities" (Chodat 603) in Stein's works, suggesting that they are not grounded in an "extreme subjectivism" (581) nor are they grounded in a purely objective understanding of the world.

${ }^{50}$ See Ann Banfield's The Phantom Table: Woolf, Fry, and the Epistemology of Modernism.
} 
maintains that scientific discourses constructed and preserved an anthropocentric worldview. He proposes instead a conception of an entangled world in motion that reimagines the nonhuman world not as a separate entity but as a process of disparate networks of which the human species is intricately bound up. This notion of an interconnected world compares to Arthur Tansley's understanding of ecosystems as mutually interrelated networks. Whitehead stresses that "the materialistic starting point is from independently existing substances, matter and mind," opposed to "the organic starting point [which] is from the analysis of process as the realisation of events disposed in an interlocked community" (Whitehead 219). Stein builds upon this opposition between "materialistic" and "organic" points of view through her notion of language.

Whereas Whitehead introduces "the theory of organic mechanism" to combat the rigid structures of scientific materialism, advocating that "molecules differ in their intrinsic characters according to the general organic plans of the situations in which they find themselves" (116), Stein illuminates how the body's sensitivity to nonhuman agents is integral to producing and modifying material and discursive "captures" of the environment. Stein's opposition of descriptive and mimetic forms of writing and speaking, and her move towards more dynamic or "discursive" forms reveal what Alaimo suggests is critical to environmental studies: we must move away from "Enlightenment models of knowledge" and focus on material agents that "remake rather than discover" environments ("Violet" 238). The human agent never simply organizes their understating of the world under their interpretation of it; their interpretative skills are always entangled in the nonhuman world. This is better understood through current ecological theories that inflect language and cognition. For instance, Marta Boguslawska-Tafelska advances her 
notion that "the human mind [is] a part of nature and natural ecosystems, not outside of them" (40), and so, suggests "that humans perceiving and experiencing the environment around and in themselves, activate their multimodal, cognitive, neurobiological, linguistic and non-linguistic resources in the very process" (33). ${ }^{51}$ The nervous architecture of the body both extracts data from the external world, and is modified by materialistic changes in the external world, revealing the reciprocal relation between embodied cognitive functions and the environment.

By establishing the complex interplay between mental states and bodily functions, Stein contemplates the human agent's place within an intra-acting network of discursive agents that influence individual and collective language models. A human agent's entry into an established language system either through writing or speaking does not provide them with a universal formula. The physical body never fully adopts an established language system through imitation, but actively engages in the reconstruction of these systems. Although her scientific reports do not focus on nature, they do question what it means to be "normal." Normal often implies an unchanging categorical type that is perpetuated through normative actions and normative speech. Stein is heavily criticized for digressing from a "normal" body practicing a "normal" language since her experimental writing style, which she claims is bound up with the way she talks, is often reduced to nonsensical stammering. Stein later addresses this idea of normality through her use of the term "natural." The term "natural" implies change, rather than stability and "essential" types. In literary works outlining her notion of a dynamic writing style, she explicitly makes the connection between "natural phenomena" and textual composition.

\footnotetext{
${ }^{51}$ Cultural codes are not exclusively separated from natural processes, but this reconsideration of materialism reveals how "societies are themselves ecologies of the natural world" and "social relations are a type of ecological relation" (Bryant 294).
} 
To illustrate, in "Composition as Explanation," she examines how "natural phenomena" (Stein, "Composition" 28) exceed the scientific descriptions of nature obtained through observation and examines how individuals collect and organize information of the external world.

\section{Diagramming "lively words": Ecology as Composition}

In Stein's essay "Composition as Explanation," she echoes the distinction between description and explanation from "What is English Literature." In this section, I turn to Stein's notion of composition, her critique of grammar and punctuation, and the "lively words" of plays to show how the trans-corporeal body combats "the complete and direct and simple and real description" (Stein, "What is English" 41) that she opposes. Whereas description makes a "real solid body of writing" (41), Stein reveals how bodily processes such as breathing re-arrange sentence structures. She further investigates complex emotional capacities, including nervousness, stimulated by theatrical performances. Specifically, she investigates how the body processes information, negotiating between established linguistic codes and new configurations of words that reinforce and unsettle the human agent's relation to material environments. Stein explores culturally produced notions of identity and individual corporeal experiences that prevent individual bodies from settling within static representations of selfhood. ${ }^{52}$ These cultural modes of production range from the military to universities. Stein, however, does not

\footnotetext{
${ }^{52}$ Alaimo explores how bodies in relation to political, economic, and cultural theories "are infused with value, meaning, and agency" (Bodily Natures 39). These social markers often define and frame identities and neglect the material make-up of the body.
} 
simply demonstrate how culture is in fact natural, but bypasses typical cultural/natural binarisms to show discursive processes. ${ }^{53}$

In arguably her best-known essay, "Composition as Explanation" (1925), Stein employs the term "composition" to undermine teleological evolutionary processes and linear historical accounts from which one can pinpoint precise shifts in artistic movements. Stein's notion of "composition" refers to both material environments and descriptions of those environments. Specifically, Stein examines how a "modern composition" (“Composition" 514) can alter institutionalized forms of literary styles and genres. She begins the essay by stating, "there is singularly nothing that makes a difference a difference in beginning and in the middle and in ending except that each generation has something different at which they are all looking" (513). She rejects the notion of epistemological paradigms prefaced on a privileged objective observer who can successfully extract information from the environment and systematically organize it within stabilized knowledge structures. She further notes that "the only thing that is different from one time to another is what is seen and what is seen depends upon how everybody is doing everything" (513). Much like her essay "What is English Literature" in which she demonstrates how the collective action of "the daily island life" solidifies strict literary regimes, here she focuses on the collective action of "everybody." However, she proposes that this collective activity registers a difference. She further notes, "this makes the thing we are looking at very different and this makes what those

\footnotetext{
${ }^{53}$ In her study of trans-corporeality, Alaimo examines cultural studies and the nature/culture binarism preserved through dominant modes of representation. She proposes that cultural studies "recast our most basic understandings of self and world as separate entities" (Alaimo, Bodily Natures 4). She is critical of how cultural studies neglect the material interchanges of modes of representation as they discuss bodies and nature "solely in terms of how it is represented" (39).
} 
who describe it make of it, it makes a composition" (514). ${ }^{54}$ Through her notion of composition, she examines how bodies and material environments intra-act to alter established literary conventions.

She contends that knowledge emerges from the material make-up of the human body participating in the material composition of the nonhuman world. She differentiates between the human tendency to create unchanging systems of "prepared" (514) knowledge and "natural phenomena" that ultimately change these established models. To illustrate, she compares the military to the academy, suggesting that both institutions attempt to preserve "prepared" knowledge. This "prepared" knowledge relates to the "descriptive" modes of writing and recording that Stein encountered in the university. She writes, the military "is prepared and to that degree it is like all academies it is not a thing made by being made it is a thing prepared" (514). Stein reveals a dissonance between "prepared" knowledge and experience, indicating that established knowledge structures rely on imitation rather than experience. For example, "prepared" knowledge positions the first world war "as a nineteenth century war although to be fought with twentieth century weapons" (513). Similarly, "prepared" artistic structures that encompass "writing and painting and all that" (514) preserve "classical" art and so "the creator of the new composition in the arts is an outlaw until he is a classic" (514). She states, "for a very long time everybody refuses and then almost without a pause almost everybody accepts" (515). She refers to the change as "a natural phenomena a rather extraordinary natural phenomena" (515). Natural phenomena generate variations in

\footnotetext{
${ }^{54}$ The emphasis on "looking" calls attention to traditional scientific methods of documentation that privilege the eye as the means by which to accumulate information. However, Stein suggests vision is bound up with action.
} 
composition and refigure the social body, further altering systems of classification that standardize artistic conventions.

Like many of Stein's works, the term "natural" appears numerous times in the essay and its meaning varies. The repetition of the term mocks the mimetic and descriptive functions of scientific discourses that presumably record unchanging truths. The variable definitions of the term "natural" display the inevitable changes that occur both in the material composition of the nonhuman world and within the composition of the text. Initially, Stein uses the term to describe the logical progression of an argument. She explains how she "will tell you" about a composition since "naturally one does not know how it happened" (514). The word "naturally" implies a causal relationship between two ideas. This use of "naturally" later shifts to a wider understanding of "natural phenomena" that exceed notions of causality.

As she examines the "natural" transition from traditional artistic conventions to the acceptance of new art forms, she exposes a more precarious "natural" movement. Stein examines the distinction between new art forms and classical forms of art. To be accepted as classical art, new art must conform to "the characteristic quality of a classic" and "the characteristic quality of a classic is that it is beautiful" (515). According to Stein, however, beauty is not a fixed abstract concept. She reimagines beauty, suggesting instead that one must "realise that beauty is beauty even when it is irritating and stimulating not only when it is accepted and classic" (515). New art forms are eventually accepted, but this move from rejection to acceptance is not linear. Stein advances the notion of the "continuous present" which denies causal effects and recognizes the perpetual action of "beginning again and again" (518). The ongoing process of the 
composition subjects "prepared" knowledge structures and established forms of art to a continual recreational process.

She attributes the acceptance of modern art to the war. The war "created the completed recognition of the contemporary composition" (521). The widespread effects of the war disrupted environments and bodies and "the academic thing known as war having been forced to become contemporary made every one not only contemporary in act not only contemporary in thought but contemporary in self-consciousness made every one contemporary with the modern composition" (521). This recognition of the "contemporary" accentuates the "difference" between the "contemporary" moment and "prepared" models. The modern composition reorients the individual within intricate networks. This compositional reorientation suggests that "one finds oneself interesting oneself in an equilibration, that of course means words as well as things and distribution as well as between themselves between the words and themselves and the things and themselves, a distribution as distribution" (521). Like in "What is English Literature," Stein moves away from indirect interactions, which she refers to as description, and emphasizes a direct distribution. Distribution, here, refers to the constant reorganization of bodies, "words," and "things" within a dynamic intra-acting system. ${ }^{55}$

Stein revisits the notion of composition in her essay, "Poetry and Grammar" (1934), in which she examines the interconnection between an individual's capacity to know and to feel. Her focus shifts from "stale" literary words and systematic knowledge structures to grammar, sentence structure, and punctuation. She investigates the function of "diagramming sentences" (Stein, "Poetry" 124), and suggests that established

\footnotetext{
${ }^{55}$ Her use of the term "distribution" calls attention to Whitehead's notion of interrelated material processes in which the human agent is immersed.
} 
grammatical and syntactical rules attempt to regulate bodily processes in order to preserve "prepared" patterns that coordinate reading and writing practices. This strict pattern imposes a rigid linguistic framework, indicating that the production of meaning is separate from the emotional capacities of the individual. Consequently, one becomes habituated to systematized reading and writing practices. However, feeling, according to Stein, is inextricably bound up with meaning, and established grammatical conventions should not reduce the individual's emotional intensity by regulating bodily functions. Stein then proposes that "a long complicated sentence should force itself upon you, make you know yourself knowing it" (131). She limits her use of the comma, suggesting that "a comma is a poor period that it lets you stop and take a breath," adding that "if you want to take a breath you ought to know yourself that you want to take a breath" (130). Stein demonstrates how the body resists the standardized use of punctuation and reconfigures sentence structure. Consequently, instead of using a comma to signal when one should "take a breath," Stein argues, "you are always taking a breath and why emphasize one breath rather than another breath" (130). Her conception of language exhibits "an interest in process over product and a notion of identity as event rather than categorical declaration" (Bean 170). Stein's experimental writing style then aims to integrate bodily processes into sentence structure without implementing standardized codes that restrict these processes.

Language then is always changing since "natural phenomena" enable the continuous reorientation of the self in the world. Immediate bodily experiences do not create a new language, but stimulate mental processes and consequently reorganize established language systems. Stein argues that one cannot "invent new names and new 
language" (Stein, "Poetry" 140), maintaining that one works within established language systems that one adopts. Yet, language is not a rigid system; it is perpetually changing. Stein claims that "language as a real thing is not imitation either of sounds or colors or emotions it is an intellectual recreation and there is no possible doubt about it and it is going to go on being that as long as humanity is anything" (140). Language does not simply imitate or faithfully record material surroundings and bodily experiences. Natural phenomena or natural processes subject language systems to indeterminate alterations as the body interacts with nonhuman matter. Similarly, recent work by ecolinguists such as George Hart and Sune Vork Steffensen investigate the interdependent relation between the environment and cognitive abilities, examining both the production of language as a natural process, and linguistic and cultural codes that modify one's conception of the environment. Hart indicates that "language, like consciousness, separates us from nature, but it is also the means by which we, the 'symbolic species,' in Terrence Deacon's phrase, realize our connection to and participation in nature" (G. Hart 58). Although Stein examines the relation between cultural and natural codes, her study of language does not revert to this simple binarism. She does not advocate a return to a natural environment untouched by cultural codes, but purports that the nonhuman world exceeds the individual's limited cognitive capacities.

By maintaining that language "has in it all the history of its intellectual recreation" (Stein, "Poetry" 140), Stein demonstrates how established language models impose a referential system. This organizational function of language anticipates what cognitive theorist S.J. Cowley refers to as a "language stance" (Cowley qtd. in Steffensen 195) through which individuals become acquainted with linguistic structures and patterns 
that organize a social unit. However, as Stein demonstrates in "Composition as Explanation," these structures are not monolithic, but tenuous, and she provides a dynamic composition in which the relational order of words varies according to one's embodied experience. ${ }^{56}$ Similarly, by examining "how language (strictly, stabilized patterns of languaging in social contexts) influences the human ecological niche" (Steffensen 194), Steffensen contests the notion of human cognition as "organismcentered," and is critical of cognitive theories that "[tear] the brain from its setting, and makes it the overlord of ecology" (200). The rich interaction between different social collectives and their environments thus demonstrates that "language unfolds in human Organism-Environment-Systems [...], and as such it is part of the human ecology" (204). Steffensen then promotes "a cultural meshwork that is constantly renewed by the interaction and co-action of human beings" and so "in this respect the human use of language is similar to the biological phenomena of superorganisms and parasites" (202). Natural and cultural spaces intermesh, producing an ecosystem in which "language vastly enhances the individual human phenotype's capacities for perception and action" (201). Social collectives organize language systems, and the interaction between various social groups “[gives] us an ecology in which we become parts of each other's environment and thus, each other's extended brain-body-world systems" (198). Steffensen's expositions here can be condensed into Stein's rich concept of "composition."

\footnotetext{
${ }^{56}$ By advocating the constant reorganization of words, Stein anticipates the notion of "connectionism" which indicates that "when a 'problem' is posed to the connectionist neural network, various nodes in the mind-brain simultaneously send and receive signals until these nodes settle into a new configuration" (McConachie 56). Stein's investigation of the nervous system and embodied sense perception suggests that the individual's experience in relation to the environment produces multiple constellations of neural patterns that never concretize into stable configurations, but generate variable compositions.
} 
For indeed, Stein promotes the "conception of living composition" (Hazleton 101) which discredits the exclusive separation between mind and body. Cultural linguistic codes and irregular nonhuman processes reciprocally alter each other, exposing the porous interaction between internal mental functions and external forces with which Stein grapples to produce individual portraits. Stein's use of variable language structures reveals that "the composition could as well be understood as a kind of ecosystem" since it is "defined in part by the complex of internal relationships that make it cohere, but also by the extensions of those relationships to influential elements (like other compositions) that influence from outside the immediate purview" (114). Stein claims that words do not exist independently, but are interconnected within the composition. Moreover, she disturbs conventional narrative forms that consolidate a sequential pattern in which a clear beginning, middle, and end align in a consecutive order. As such, Stein reveals an "ecology" of language (John Taylor 58), a term coined by John R. Taylor who claims that "a linguistic unit occupies a 'niche' which is made available by the rest of the language" and further maintains that "this serves to introduce a high degree of entropy into a language system" (58). Ecolinguist Marta Boguslawska-Tafelska expands this concept of a language "niche" through her notion of a "language ecosystem" (Boguslawska-Tafelska 8). She argues that language "is embedded within the global ecosphere of the Earth" (8). By turning to the "ecosphere of the Earth," she indicates that language does not develop at "the level of cognitive structures in the human mind," but proposes that "there is a continual pulsation in the relation of the organism to the external environment, be it societal, cultural, political, ecological, biological, or other" (18). Meaning, therefore, does 
not manifest in a single word, but varies according to phonological, semantic, and symbolic constructions.

These cognitive theorists, however, suggest that ecology refers to the intricate connection of disparate "niches," shedding light on the interaction of different language "stances" which ultimately initiate change in language systems. Stein, I argue, moves beyond units of language to discursive material processes. In this way, ecology does not simply refer to interrelated definitions of a word (niches) or to the human agent's connection to the "Earth." Instead, ecology refers to "thinking the copresence through porous boundaries" (Iovino and Oppermann, "After Green" 329), which becomes evident through Stein's interest in theatre. Stein's use of a dynamic material language is fundamental to the composition of individual verbal portraits. In her works that focus predominantly on the formation of identity, Stein contends that she "wants to condense [the work] as much as possible and change it around, until you could get the movement of a human being" (Stein, "How Writing" 159). Thus, she seeks a textual form that is malleable. She explicitly draws a correlation between the body and writing, reflecting once again her aim to put back "the excitingness of pure being" in writing (Stein qtd. in Meyerowitz 7). Limited by the sequential linguistic patterns of prose, she employs "the lively words" (Stein, "Plays" 69) of plays, which "[do] not privilege one particular line of relationships, as any conventional narrative would do, but rather [suggest] a multitude of possible relations at once" (Ford 28). Stein challenges typical conceptions of theatre that rely on a separation between the spectator and the performance space. ${ }^{57}$ She highlights the spectator's immersive experience, which ultimately transforms the meaning of the play. The body of the spectator along with the bodies of other spectators and the varied

\footnotetext{
${ }^{57}$ See Jane Palatini Bowers.
} 
dimensions of the performance (actors, lighting, etc.) are all agents that recreate the meaning of the play.

According to Stein, the interconnection between the audience and the performance space stimulates states of nervousness in the bodies of the spectators. This nervousness reflects "the excitement in everybody's life" (Stein, "Plays" 62) which, according to Stein, varies in relation to the body's interaction with the environment. "The thing that is fundamental about plays," argues Stein, "is that the scene as depicted on the stage is more often than not one might say it is almost always in syncopated time in relation to the emotion of anybody in the audience" (59). The disjunction between the action that unfolds on the stage, and the spectator's emotional capacities generates this sense of nervousness. The action of the play cannot be assimilated into the bodily sensations of the audience members, and the various elements of the performance space, such as the stage curtain, secure that these competing "tempos" (59) remain unassimilated. These unsynchronized rhythms produce a sense of nervousness and "nervousness is the certain proof that the emotion of the one seeing and the emotion of the thing seen do not progress together" (59). Moreover, elements of the theatrical space stimulate both aural and visual modalities, and the incongruent multi-modal perceptions modify the individual's interpretation of the scene. The spectator, argues Stein, does not exhibit any "real control" (61) over the performance; unable to revisit past sections of the performance action and further unable to jump ahead, the spectator is perpetually subjected to these discordant rhythms, and consequently, never achieves a sense of familiarity with the characters or action on stage. In fact, Stein contends that "it is not possible in the theatre to produce familiarity" (68). The nervousness of the theatre echoes 
the manipulation of the "nerve centers" in her scientific reports. The immersive experience of the theatre denies any sense of familiarity in the same way external stimulation prevented the subject from performing "real" or familiar writing.

Stein's concept of the "lively words" of plays references a process that Bruce McConachie and F. Elizabeth Hart have more recently termed "performative communication" (McConachie and Hart 1). Hart illustrates how spatial configurations of the theatrical space modify the textual component of the performance. She proposes that "matter $[\ldots]$ flows in an interconnected stream between the embodied mind and its representations of embodied experience in language and discourses" (E. Hart 35), suggesting that embodiment is contingent upon both physical and cultural determinants" (34). Similarly, McConachie examines how the spectator's immediate experience affects memory, attention, and cultural codes. Drawing on Edelman's neural Darwinism, he claims that "there is no culture without cognition and no cognition without nature" (Engaging Audiences 4) and so asserts that "the brain [is] the material site where ecology and culture join to shape history and performance" (McConachie qtd. in E. Hart 39). Like Hart and McConachie, Stein focuses on the human agent's bodily responses to a theatrical performance. Specifically, she reveals how physical dimensions of the performance space stimulate excitement or nervousness. Unlike these theorists, she does not position the human agent as the primary interlocutor in which ecology and history combine, but positions the spectator within the ongoing performance of matter. Elucidating that "knowledge as anybody knows is a thing to get by getting" (Stein, "Plays" 58), Stein considers the correlation between the means of obtaining knowledge 
and the individual's corporeal experience, and further upsets traditional understandings of bodily perception.

By highlighting how multimodal responses transform one's understanding of the play, she suggests that the spectator is not separated from the stage, but completely immersed in the theatrical space. According to Stein, the gaze is not the primary means through which one obtains knowledge of the fictional world of the play. She marks a shift in emphasis from the gaze to the sensuous body that is imperative to Whitehead's critique of scientific experimentation that situates the individual as the primary observer who frames the natural environment according to established codes. Stein thus criticizes "the ocular metaphor, the idea of the eye as the privileged organ of knowledge" that severs one's relation with the environment since "it is an image that supports the position of the observer as an unencumbered, transcendental subject" (Legler 245). She examines two distinct features of the theatre that make it exemplary of this reorganization of the senses. First, she examines the dimensions of the theatrical space that encompass the stage and the spectator's relation to the performance space and other audience members. Second, she exposes how the radical shift in perspective is integral to the art form itself.

Stein compares different experiences at the theatre that correspond to different stages in her life, documenting the various degrees to which her physical body responds to the theatrical elements. As a child, she notices that a heightened sensitivity altered her perception of the play and so she proposes that a child is attentive to "the general movement and light and air which any theatre has, and a great deal of glitter in the light and a great deal of height in the air, and then there are moments, a very very few moments but still moments" (Stein, "Plays" 69). Before adolescence, "the theatre consists 
of bright filled space and usually not more than one moment in a play" (69). In her adolescence, Stein recognizes the relation between sight and sound, drawing attention to the disjunction between multi-modal perceptions. Components such as "clothes, voices, what they the actors said, how they were dressed and how that related itself to their moving around" (71) produce an increasing sense of unease. The theatrical space then amplifies the intensity of one's immediate experience which cannot be replicated since when the performance "is all over you cannot remember that is you cannot really reconstruct the thing, the thing that has happened" (66). By "[using] experience to point to the instability of experience as a way of knowing" (248), Stein acknowledges the constant reconstruction of established linguistic paradigms. The multifaceted dimensions of the theatrical space accentuate the variable quality of the textual and spatial compositions of the performance.

The heightened sense of nervousness is not isolated to the performance of a play, however, but manifests in the reading process as well. Stein notes that "the necessity of going forward and backward to the list of characters to find out which was which and then insensibly to know" (68) coupled with the "many little bits in it that were lively words" (69) fragments the reading process and stimulated emotional responses. As she begins to write plays, she proposes that the contradiction between the action of the play and the emotions of the spectator should not be viewed as "a contradiction but a combination" (58). In order to explain what she means by combination, Stein compares plays to landscapes, suggesting that landscapes are not composed of contradictory forces, but constitute a complex network in which intra-acting components create numerous and shifting relations. A landscape cannot be reduced to a single unchanging entity since it 
oscillates between instances where it appears to be static and instances where it is in motion. The individual operates within this complex constellation in which discordant material forces combine. This combination of bodies and material landscapes makes it impossible for the human agent to become "acquainted" (67) or familiar with the landscape. Stein's experiential writing style then attempts "to express this without telling what happened, in short to make a play the essence of what happened" (74).

The comparison between the theatre and landscapes is not exclusive to modernism. In her examination of the etymology of the term 'theatre,' Jane Palatini Bowers exposes how "Stein alluded to a centuries-old practice" (123). Bowers demonstrates how "theatre "was a word much used in the titles of books of travel and [geographic] description,' according to John Brinckerhoff Jackson” (122). Moreover, in the sixteenth and seventeenth centuries, "the Italians developed the proscenium stage that borrowed its vanishing point perspective and disposition of loci in space from landscape painting" (Bowers 122-123). The proscenium arch reveals how the eye is not the “sovereign power" (Mark Roskill qtd. in Bowers 127) generating “one-point perspective to structure landscape" (Bowers 127). Stein's comparison between the theatre and landscapes highlights "a change in the way of seeing" (127). The term theatre then invokes geographical landscapes, as well as performance "landscapes." Stein adds to this material notion of theatrical landscapes by emphasizing the spectator's emotional responses to the performance. Theatre discloses the intra-action between "outside" performance elements, and the "inside" emotional and psychological states of the spectator's body. Theatre thus adds another layer of meaning to her dynamic, networked concept of composition. 
Stein demonstrates how the emotional responses generated by the performance space reveal the "business of Art" which, as she contends, "is to live in the actual present, that is the complete actual present, and to completely express that complete actual present" (Stein, "Plays" 65). The various and intricate responses of the spectators and readers inform her notion of composition, demonstrating how trans-corporeal materiality alters the written text. "Composition" then encompasses the written text, the relation of the reader or spectator to the written text, and the cultural norms that influence and modify one's reaction to the written word. Stein thus examines the complex interplay between established cultural and linguistic codes that engineer the individual's body response, and the bodily processes that are resistant to those established cultural and linguistic paradigms. The spectators are not passive recipients, but actively engage with the performance since their bodily responses alter their understanding of the work and consequently recreate the artistic work. Stein therefore argues that the composition of the work is constantly changing, and her experimental writing reflects how linguistic codes are perpetually in the process of evolving. Maintaining that the spectator "existed in relation to any number of other people and in any number of capacities" (Meyer 255), Stein proposes that "this makes the thing we are looking at very different and this makes what those who describe it make of it, it makes a composition, it confuses, it shows, it is, it looks, it likes it as it is, and this makes what is seen as it is seen" (Stein, "Composition" $513)$.

Stein argues that a writer "can live only in the present of his daily life" and so "[expresses] the thing that is being expressed by everybody in their daily lives" (Stein, "How Writing" 151). This “contemporariness" (151) consists of the complex 
intermingling of the individual's immediate experience and established cultural codes, subjecting the work to constant revisions as new generations of readers modify the composition. Through her use of "lively words," Stein exposes the intricate entanglement of immediate experience, and established language models. Theatre, for Stein, accentuates how the trans-corporeal body modifies language as she combines cultural representations of the body and the physical composition of the body. As she transitions from writing portraits in order to capture an individual's identity to the "lively words" of plays, she implies that aesthetic "captures" are imbricated in the ongoing material performance of the world. Her plays then are not closet dramas, as Martin Puchner suggests, but "are an invitation for the reader to perform the reading with his or her body" (Steidele 156), and so "[demand] an active, bodily recreation of the text" (144). The body, however, intra-acts with a material composition, thereby subjecting the text to an ongoing material-performance that consists of both human and nonhuman actors.

\section{Beginning again and again: Re-creating Ida}

The intricate relation between dynamic textual meaning and Stein's notion of performance comes to fruition in her work Ida: A Novel (1941). This text underwent numerous alterations, appearing in the form of a script titled "Film Deux Soeurs qui ne sont pas Soeurs" (1929) and later expanding into a novel. In this work, Stein accentuates Ida's inability to solidify a static identity as the character moves across various landscapes that cannot be reduced to a clearly coordinated geographical grid. Both the material environment and the established notions of the environment that are discursively produced figure predominantly as active agents that modify Ida's sense of identity. As 
such, in ecocritical terms, the "landscape is no mere scenery, no flimsy stage set, but rather the energizing medium from which human lives emerge and by which those lives are bounded and measured" (Sanders 183). The human agent is an integral component of the environment, susceptible to transformative nonhuman forces that affect one's developmental process. This intimate connection between the human and nonhuman agents alters the way the individual thinks and speaks. Nancy Easterlin, a cognitive ecocritic, stresses that "the [physical surrounding] itself is complex and dynamic and is frequently in a state of change as the individual or group moves through it" and so proposes that "no [physical surrounding] comes to us whole" (Easterlin 261). The intraaction between the human agent and the environment results in the constant reorientation of the self in the world. Stein does not simply "[reverse] 'places' of foreground and background" (Voris 126) to accentuate the environment and minimize the human agent. Rather, the human agent's sense of selfhood becomes malleable as variable nonhuman forces modify individual and collective memories and both organize and dismantle established language structures.

Before diving into an analysis of how Stein presents the evolution of Ida's identity through the construction of material compositions, it is important to note the significance of the title. Stein titles the work Ida: A Novel and not Ida: A Biography. By emphasizing the art form in the title of the work, Stein calls attention to the "meaning" of her literary projects by demonstrating how the composition of the text revitalizes "wornout literary words" (Stein qtd. in Meyerowitz 7). Rather than simply describe a character, the form of the novel attempts to produce "the excitingness of pure being" (7) by intermingling the various compositions outlined in "Composition as Explanation." 
The prose does not result in the culmination of Ida's identity, but her identity is in flux as textual compositions, bodily compositions, and compositions of material environments intra-act. The structure of the novel further upsets the linear teleological development of the character. Stein divides the novel into two halves and the numerical headings of each chapter are arranged chronologically. The first half chronicles parts one through six and the second half ranges from part one to part eight consecutively. This structure does not accurately display the measured development of the character, but performs Stein's notion of "beginning again." Coupled with this notion of "beginning again" is "the time of the composition" (Stein, "Composition" 522). The interaction of the past, present, and future create "a continuous present" from which emerges "a beginning again and again" (522). For example, the novel begins with Ida's birth; however, Stein does not provide the immediate account of the birth, but frames it within the past tense. The novel begins with a concise claim: "there was a baby born named Ida" (Stein, Ida 3). The time frame of the reader is not synchronous with the immediacy of the character's birth. As such, the organic production of the character is framed within a narrative structure, revealing the interrelation between natural and cultural spaces that contribute to Ida's sense of self.

The initial descriptions of Ida underline her entrance into an established language system as she transitions from being identified as "a baby" to adopting the nondescriptive pronoun "its" to her name "Ida" and finally to "Ida-Ida" (3). Although critics such as Harriett Scott Chessman and Sean Murphy view the repetition of Ida as the binary opposition between an established patriarchal language and a prelinguistic language associated with bodily drives or the maternal figure, I propose that Ida-Ida exemplifies Stein's notion of "a double-time" (Stein, "How Writing” 154). The hyphen does not 
demarcate the border between two separate conscious states, but calls attention to the interrelation between psychological states that reflect the "double personality" or "second personality" of Stein's earlier scientific experiments detailed above. According to Stein, the human agent negotiates between "the memory of what you were brought up with" (154) and the information one obtains from immediate sense perceptions. In her essay "How Writing is Written," she explicates how this negotiation is at play in her artistic portraits. Without imposing limitations, Stein attempts to produce "a feeling of movement" (157). The creative process then consists of "a double resistance" (154) as the artist acknowledges established conventions and struggles to move away from an imposed framework. Ida discloses this tension through her process of identity formation as she mediates between the memory of a family history perpetuated through narrative and her bodily experiences. Stein highlights this discrepancy by establishing accounts of Ida's parents who remain absent in the text, indicating that "a little while after [Ida's birth] her parents went off on a trip and never came back" (Stein, Ida 4). Moreover, Ida's great aunt exists only in the retelling of "an old [woman's]" (3) memory of her. Ida then familiarizes herself with linguistic patterns that outline a historical context and produce a narrative that prescribes familial relationships. This descriptive account of a family history fixes Ida within a larger temporal and spatial schema, stabilizing individual identities by overlooking the human agents' immediate experiences with the environment.

The fictional account of Ida's family history illustrates the individual's inability to fully register the material natural world since preconceived notions of the landscape distort the environment. For instance, by re-telling a story of Ida's great-aunt, "an old 
woman who was no relation and who had known the great-aunt when she was young" notes that the great-aunt gave birth to still-born twins and "buried them under a pear tree" (3). For this reason, "all the family always looked at every pear tree and had a funny feeling" (4). The nonhuman world is then imbued with human emotion through the retelling of this fictional recording that alters a collective memory. After establishing this familial historical narrative in which the natural world is defined within a specific framework, Stein then describes Ida's experience with the landscape. She begins to know her surroundings through observation, but "the first time she saw anything it frightened her" (4). For example, "she saw a little boy" and although he waved to her, "she would not look his way" (4). The static depiction of a landscape infused with human emotion then shifts to a volatile environment that excites the human agent. From the narratives of her birth to her emotional reactions to the nonhuman world, Stein insinuates, like ecocritic Glen Love, that "nature is always 'there' in some form or other, and certainly in the evolutionary genetic heritage of our bodies and brains" (40). Although these early fictional accounts perpetuate the memory of the family history, the human agent's bodily experiences with material environments modify these accounts and subject them to multiple variations. As Ida begins to experience the nonhuman world, she will begin to create and recreate a sense of self, revealing how memory is a process "in reconstructing rather than passively recording experience" (Boyd 16).

Fictional representations of the natural world that relate to an individual's personal history ultimately solidify an identity that organizes a collective body. Reductive accounts of the environment strengthen interpersonal bonds by "[affecting] group members' attitudes toward the environment with which that group is associated" 
(Easterlin 262). Stein marks a shift in focus from Ida's relation to her family history, to her participation in the recreation of a cultural identity. Socially constructed accounts of an imagined static environment revealed through superstitious retellings of the spider, the cuckoos, goldfish, and dwarfs (Stein, Ida 99-104) depict the natural world as compassionate to the preservation of the human species. These representations of a strictly ordered nonhuman world expose causal relations that culminate in the successes or misfortunes of the human agent, ensuring the welfare of the human species or casting hardship if the individual deviates from regular natural patterns. These cultural narratives reveal how the individual imposes a systematic universe in which the human participates within natural cycles; however, the natural world is simply an extension of the human will, regulated by sign systems that organize natural processes around human interests. Ida allocates these superstitious modes of thinking to farmers, sailors, and actors, suggesting that they arise from specific contexts in which individuals interact with the environment. As a result, these narratives "[bind] the individual to the social group and to the physical environment through a causal sequence of events" and so "narrative thinking and its organized, communal manifestations in the language of sequential action plans and stories impose order on the group's past existence" (Easterlin 263). Stein, however, undermines these static representations of an ordered natural world constitutive of causal relationships by gesturing to material intra-acting processes that exceed human perception and human understanding.

Ida begins to move away from these preconceived notions of nature that imply repetition and stability. She resists settling in one location. Not only does she transition from one place to another, but realizes that she "[likes] to change places" (4). As Ida 
begins to "change places," Stein structures the novel so that it presents Ida's changing responses to her material surroundings. However, she supposes, like cognitive ecocritic Nancy Easterlin, that the environment "can never be known in an other-than human sense" (Easterlin 259). The novel focuses on Ida's experience. Shortly after she is born, Stein writes, "she saw the moon and she saw the sun and she saw the grass and she saw the streets" (Stein, Ida 4). The nonhuman world is always to some capacity mediated through Ida's observations, immediate experiences, or memories. This does not elevate the human agent as the primary source of knowledge who exercises mastery over nonhuman processes. Ida cannot fully register the immensity and unpredictability of the natural world. The natural world cannot be reduced to a knowable entity. Ida asserts that "nature is not natural and that is natural enough" (116), illustrating the dichotomy between the material natural environment, and a socially accepted form of what is "natural." By this, she refers to habituated behavioural patterns cultivated by social codes and which are upset as the human agent wanders to different locales. Language then does not provide a mimetic representation of the natural world, but its intra-acting relation to nonhuman matter results in the relentless reorganization of linguistic codes.

Stein exposes a tension between standardized modes of speaking and being, and the mutability of speech and behaviour. As Ida travels to different parts of the world, she adopts daily routines (43). As she "settled down in Washington," she regulated her daily actions. That is, "Ida woke up. After a while she got up. Then she stood up. Then she ate something" (43). Although Stein illustrates the logical progression of Ida's activities through the syntactical structure of the lines, she also suggests that these daily activities are trivial. Moreover, despite settling down, Ida never settles. She continues to move and 
"settle" (44) in other places, like Ohio, before moving again. Stein depicts Ida's identity as a process. She upsets a linear trajectory of development and simultaneously frustrates literary conventions that promote the sequential development of a unified self. The highly repetitive phrase "once upon a time" suggests a sequential narrative order that frames Ida's development. Stein writes, "once upon a time Ida stood all alone in the twilight" (49). She later notes, "once upon a time Ida took a train, she did not like trains, and she never took them but once upon a time she took a train" (95). The phrase "once upon a time" imitates a narrative form that contains a chronological procession of events that culminate in a unified expression of selfhood. The phrase indicates that an action or event can be isolated within narrative form. However, these isolated narrative moments are disjointed. They are similar only through the repetition of "once upon a time." Stein denies any sort of logical progression between these moments through which the reader can track Ida's development. She also writes, "Ida never said once upon a time" (108). Therefore, she distinguishes between a type of narrative pattern and Ida's own way of speaking that does not rely on traditional narrative structures. For Ida, "these words [once upon a time] did not mean anything" (108). Instead, she "said yes and then Ida said oh yes, and then Ida said, I said yes, and then Ida said, yes" (108).

Stein stresses the character's mobility as Ida travels to various locales, never residing in one place. While composing the novel, Stein requested "a map of the United States," indicating that she "kind of [needs] it to make Ida go on" (Stein qtd. in Esdale 157). Whereas a map reduces the environment to the ordered arrangement of a grid, Stein blurs the boundaries between delimited geographical coordinates. Ida's ability to easily navigate various parts of the globe without any restrictions suggests that these 
geographical spaces are not isolated from each other, but are part of a larger network as "Brazil, Africa, and France also become part of Ida's consciousness, and her social geography expands" (157). Stein thus provides representations of an ever-expanding world in which she obscures national boundaries, opposing "the growing nationalism of the late 1930s and the thickening borders between countries" (157). As Ida maneuvers between states and countries, she is introduced to different linguistic systems and patterns of speech ranging from the "motto of Minnesota" to formulaic patterns that generate specific responses (Stein, $I d a$ 48). For example, after "she went all around the world," she notes a logical pattern in how people speak to her:

First they asked her, how long before you have to go back to Washington. Second they said, how soon after you get back to Washington will you go back to Ohio. Thirdly they asked her. How do you go back to Washington from Ohio. (40). Ida often refers to a pattern in speech that extends to habitual behaviours that characterize a population. As she moves from Montana to Virginia to Ohio and to Washington, she reflects on daily rituals and standardized modes of speech that are characteristic of each place. Ida "said she was going [to Washington] just to see why they cry. That is what they do there" (41). She also remarks on how it "is very usual" of people in Boston "to be selfish, very usual, indeed" (49).

Ida's mobility calls attention to Whitehead's notion of wandering through which he dismisses the notion of a mechanistic nature. By situating the human within a larger schema of shifting geographies, Whitehead acknowledges the constant reconfiguration of national identities. Constantly shifting landscapes reorient the individual's sense of self and, by extension, sense of community. According to Whitehead, "modern science has 
imposed on humanity the necessity for wandering" since "its progressive thought and its progressive technology make the transition through time, from generation to generation, a true migration into uncharted seas of adventure" (Whitehead 298). Similarly, Stein depicts an immense landscape that cannot be reduced to precise navigational coordinates as Ida travels the globe. Ida's wandering is erratic as different modes of transportation accommodate her ability to travel with ease and without a definite plan. That is, "Ida did not go directly anywhere. She went all around the world" (Stein, Ida 40) and "she went away on a train in an automobile by airplane and walking" (35). As Stein indicates, this technology does not separate exclusively urban centers and natural landscapes, but underscores the interplay between the two. Natural organisms inhabit urban centers and natural forces penetrate the cityscape. In Texas, Ida notices a lizard, "almost black all over and curled, with yellow under and over, hard to tell, it was curled" (44-45), and "in Boston they hear the ocean" (49). This blending of typical cityscapes with natural elements reveals how the nonhuman world exceeds human understanding and systems of classification. Stein thus rejects the notion of an ordered natural setting in lieu of emphasizing fluid nonhuman forces that reorient the individual.

Despite the reinforcement of national borders during both World Wars which established a strict sense of division, Stein suggests that the wars reconceptualized typical conceptions of "nature." As mentioned in "What is English Literature," Stein claims that wars accelerated processes of transformations and consequently make change visible. Similarly, in "Composition as Explanation," she argues that the First World War exploded the shift in focus from a static natural world, to a notion of an unpredictable environment. Stein then notes that "war came and everything being alike and everything 
being simply different brings everything being simply different brings it to romanticism" (Stein, "Composition" 27-28). By "romanticism" she refers to Whitehead's notion of "the romantic reaction" which marks "the abandonment of the traditional materialism, and the substitution of an alternative doctrine of organism" (Whitehead 116). In Ida, the war discloses the complex compositional network of nonhuman matter. The war disproves the notion of an ordered universe, and results in the constant reshaping of the environment through the displacement of different animal breeds and the transposition of flowers. Several characters discuss how returning soldiers contribute to minute changes in the environment resulting from the continuation of interspecies relations. For instance, one soldier returns with a shepherd dog "and now all the shepherd dogs came from the dog [he] had brought home with him from the war" (Stein, Ida 94). Another soldier returns with a "slip of a tree" and "planted it and now every year they had apples off this apple tree" (94). Stein thus discredits the notion of an evolutionary progression that imposes an ordered framework by showcasing the accidental and unguided material transformations. These material transformations are the result of human and nonhuman agents. The results are not determined or measured, but erratic and constantly changing.

The image of the flower, in particular, signifies the interpenetration between cultural and natural spaces. Stein oscillates between clearly defined locales in which plants are uprooted from the ground or understood in concert with the observer's emotional states, to an immense landscape that the individual is unable to fully register. The flower reveals how the human agent cultivates nature, containing elements of the landscape to serve human interests, and also gestures to a larger material matrix that underlines the interconnection between the flower and the vast nonhuman world. Ida 
reflects on two articles of clothing, "a turban of pansies" and "a turban made of poppies," and then states, "flowers should stay where they grow" (112). Stein does not simply reduce the natural world to its instrumentality, but reveals how individuals, as active participants within a larger nonhuman network, alter the environment and are simultaneously affected by it. Subsequently, the nonhuman world influences the individual's creative processes, serving both as the object which human agents shape into creative articles, such as clothing, and as the source that prohibits the individual from settling within habituated routines. The individual's conception of the natural world varies as one interacts with shifting spatial configurations that stimulate perceptual modes and prevent a totalized account of nature that settles within the cultural imaginary. Ida's friends, for instance, are unable to provide a single description of the clouds, relaying instead multiple accounts in which the clouds resemble "a hunting dog," "a dragon," "a dream," and "a queen" (121). The different interpretations of the clouds display the ongoing artistic recreations that Stein champions in her lectures. The variable composition of the landscape informs Stein's notion of textual composition, displaying art as "an agent of change in life, a force that harnesses potentially all the other forces of the earth, not to make sense of them, not to be useful, but to generate affects and to be affected, to affect subjects, but also objects and matter itself' (Grosz 189).

By presenting the environment as a complex network of material intra-actions, Stein highlights the constant reorganization of linguistic structures. For instance, the trajectory of the novel resists a sequential developmental process that culminates in a single, unified expression of identity, and so relates "that feeling that life that necessity that time can express itself in an infinite variety" (Stein, "Poetry" 128). In the final 
section of the novel, Stein undercuts the single-focus of a character by depicting two characters so intricately entangled that their agitated states prevent them from settling within a static representation of selfhood. Both Ida and Andrew occupy various emotional states simultaneously as moments of rest combine with a sense of nervousness. Stein then does not provide a finite description of the characters, but tracks their developmental process, suggesting "it happened slowly and then it was happening and then it happened a little quicker and then it was happening and then it happened it really happened and then it had happened and then it was happening" (Stein, Ida 122). By transitioning from different verb tenses, Stein reveals the "movement" of the characters. This movement is not restricted to a linear progression, but suggests that both Ida and Andrew are perpetually in a state of flux.

This entanglement is further amplified in the final lines of the novel. Stein emphasizes Ida's constant transformation by rejecting a static portrait of Ida. Stein displays a character in motion. That is, Ida is not restricted to a clearly defined space since Stein writes, "if she goes out she comes in" (127). Moreover, earlier in the text, Ida declares, "I change all the time" (25) and Stein exaggerates that change by showing how her attire changes: "she dresses, well perhaps in black why not, and a hat, why not, and another hat, why not, and another dress, why not" (127). This process continues into the final lines of the novel: "she dresses in another hat and she dresses in another dress and Andrew is in, and they go in and that is where they are" (127). By denying an individual portrait of the titular character, and focusing instead on the relation between the characters and the landscape, Stein contemplates the reader's ability to make Ida "go on" (Esdale 126). The variable composition suggests that "reading, like performance, is an 
embodied act that exists only in the moment of its enactment" (Bean 169). Questioning whether "Ida goes on, does she go on even when she does not go on any more" (Stein, Ida 126), Stein reflects on how different generations of readers will modify the text. As such, her "verbal portraiture [...promotes] multiple, nonreproducible reading events" (Bean 170) that subject Ida to constant revisions. The novel thus becomes an experiment in knowing. Stein exposes how Ida's knowledge of her family, her environment, and herself changes throughout the novel, and further discloses how other characters "know." Whereas "everybody thought everybody knew what happened" (Stein, Ida 123), Stein consistently undercuts the reader's ability to make a conclusive statement about Ida. Instead, through "disconnection" and "beginning again," the reader's understanding of Ida changes throughout the text and will continue to change long after the last lines of the novel.

Stein thus explores how bodily experiences reconfigure an individual's conceptualization of the self and of the nonhuman world. Her notion of language as a material process reveals the ecological implications of her work as she underlines the intra-action between mental processes, the body, and the environment. This dynamic relation between the environment and the trans-corporeal body informs Stein's notion of a variable composition. That is, the constant reorganization of the self in the world disrupts established language models that attempt to organize a collective unit and foster stable representations of identity. As such, Stein dismisses the notion of a teleological developmental process and further debunks the notion of a return to an authentic state of being. Language, according to Stein, does not produce a mimetic representation of the environment, nor does it cement a totalized expression of selfhood. By reconceptualizing 
language as an "intellectual recreation," and by extension, a material process, she maintains that systematic linguistic models attempt to preserve reductive representations of the environment and neglect the complex composition of the human being. Examining the discrepancy between the natural world and discursively produced notions of nature, Stein exposes how intra-acting material processes reorganize established linguistic and conceptual systems. The novel then does not contain a stable portrait of Ida by imposing rigid contours that frame the character. Instead, Stein contemplates the persistent "beginning again" as future readers recreate Ida. Stein's literary projects continuously question the transparency of epistemic models by which we come to "know" the world, a notion echoed in her alleged final words: “what is the answer?' she asked, and when no answer came, she laughed and said: 'Then, what is the question?'” (Stein qtd. in Sprigge 17). Stein's works then demonstrate how nature is a "concept for repeated interrogation" (Cohen xxii) and this allows her to "recreate" environments. 


\title{
Chapter Two
}

\section{"Things were in people, people were in things": Material-Discursive} Ecologies in H.D.

\section{Introduction}

\author{
"Where does the body come in? \\ What is the body?"
}

In her manifesto, Notes on Thought and Vision, H.D. boldly claims that "our concern is with the body," suggesting that the body is integral to her artistic projects and animates her literary modernist aesthetic (H.D., Notes 50). Commentaries on her essay, however, have tended to overlook this focus. H.D. began composing the manifesto in 1919 after she experienced a new mode of vision while visiting the Scilly Islands. She visited the islands with Bryher in order to recover from a series of traumatic experiences ranging from the disintegration of her relationships with Ezra Pound and Richard Aldington, the birth of a stillborn child, and the death of her brother during the First World War. While sitting in her hotel room, "H.D. had the first of several visionary experiences" (Friedman, Penelope's Web 64) and saw several images projected on the wall of her hotel room. ${ }^{58}$ During her exchange with Sigmund Freud, H.D. commonly refers to these images as the "writing-on-the-wall." Her close affiliation with Freud and his theories of the unconscious incites some critics to read the experience through a psychoanalytic lens. ${ }^{59}$ The manifesto, however, is not a faithful recording of the experience, but exposes H.D.'s investigation into psychical phenomena, the sensorial apparatus of bodies, and mythical and material environments. She examines the complex intermingling of seemingly

\footnotetext{
${ }^{58}$ For more on H.D.'s visionary experience, see Susan Friedman's Penelope's Web and Adalaide Morris" "The Concept of Projection."

${ }^{59}$ For more on psychoanalysis and H.D., see Susan Stanford Friedman, Rachel Blau DuPlessis, and Elizabeth A. Hirsh.
} 
incommensurable subjects such as physical matter and spirituality, and human and nonhuman natures.

The "writing-on-the-wall" suggests that a spiritual substance manifests in the material construction of the image, dissolving the barrier between spirituality and materiality. In his introduction to Notes on Thought and Vision, Albert Gelpi proposes that H.D. examined "those mysterious moments in which the polarities seemed to fall away, or - more accurately — to find their contradictions lifted and subsumed into a gestalt that illuminated the cross-patch of the past and released her to the chances of the future" (Gelpi 12). The manifesto thus sheds light on a recurring tension in H.D. scholarship. On the one hand, Scott Freer and Rachel Connor investigate the limitations of a "material turn" and seek instead to examine the spiritual dimensions of the author's oeuvre. By focusing on Hermeticism and mythopeism, they consider H.D.'s attempt to transcend the physical world and obtain a spiritual enlightenment that is demarcated from material realities. On the other hand, Christina Walter, Annette Debo, and Adalaide Morris explore H.D.'s engagement with scientific discourses that attended to the physiological composition of the body and the complex material configurations of the universe. This relatively new trend in H.D. scholarship does not directly oppose traditional readings of the author's works, but advances a more nuanced reading through a reconsideration of materiality and spirituality.

Traditional readings of H.D. situate the author's works within a psychoanalytic framework, either demonstrating how the author turns to Freudian psychoanalysis to understand traumatic instances in her life such as the writing-on-the-wall, or how she revises his theories to appropriate a female voice within a predominantly patriarchal 
tradition. As one of Freud's students, H.D. sought "scientific explanations in Freudian analysis" (Gelpi 11) and also tested the limitations of his theories. In Tribute to Freud, H.D. admits that she "was a student, working under the direction of the greatest mind of this and of perhaps many succeeding generations" (24-25). Despite acknowledging Freud's authority, she asserts that "the Professor was not always right" (H.D., Tribute 25). She recognizes how his analyses circumvent the complexities of her psychological states and foster gender hierarchies. Freud acknowledges the dominant role of the psychoanalyst who actively imposes an interpretative framework on his subjects as he discovers and records the contents of their psyches. H.D. describes an instance in which he used images of conquest to confirm his assertive role as the psychoanalyst. She explains how during one of their analysis sessions, he declared: "I struck oil. It was I who struck oil. But the contents of the oil wells have only just been sampled" (25). He further notes, "there is oil enough, material enough for research and exploitation, to last 50 years, to last 100 years—or longer" (25). ${ }^{60}$ In this analogy, H.D.'s mind resembles passive material uncovered and exploited as it is subjected to Freud's interpretations. Moreover, this analogy signals a traditional natural trope in which man asserts his dominance over the nonhuman world through conquest and the subsequent extraction of natural resources. However, whereas Freud reduces H.D.'s trauma to his theories of the unconscious,

\footnotetext{
${ }^{60}$ This image of the body as a reserve from which to exploit resources calls attention to the Wordsworthian trope, emphasizing the close association of women and nature. The close affiliation of women and nature, and the aversion to the body and matter, is at play in Freud's theories of the unconscious and culminates in his well-known work, Civilization and Its Discontents. He argues that civilization initiates a "demand for cleanliness to the body" and nature (Freud, Civilization 38). However, he notes that "while we cannot expect cleanliness in nature, order is in fact copied from her" (38). Women, then, become associated with nature, order, and cultivation and men with agency, control, and civilization. Freud suggests that "the work of civilization has become more and more the business of the menfolk, setting them increasingly difficult tasks and obliging them to sublimate their drives - a task for which women have little aptitude" (51).
} 
indicating that H.D. should restore her relationship with her mother, H.D. claims that "all this seemed almost too simple" (44). Rather than focalize the origin of her trauma within Freud's Oedipal structure, she suggests that "things had happened before [her mother's] death, ordinary as well as extraordinary things" (44) that contributed to her trauma.

Her differences with Freud invite readings of her work that invert the gendered relationship between the psychoanalyst and his analysand. For instance, Susan Stanford Friedman and Rachel Blau DuPlessis argue that "her work is fundamentally dialogic, reflecting her negotiations as a woman to place herself within and through language in a position of authority" ("Preface" xii). Friedman also notes how "H.D.'s perspectives as a woman mediated the influence of patriarchal traditions and led to a poetry centered on woman as both authentic symbol and questor" (Psyche Reborn xi). Adalaide Morris, however, suggests that these psychoanalytic readings are "predominantly biographical or psychological" (How to Live 1) and instead examines the author's works as "an aesthetic artifact abstracted from its historical, political, and ideological contexts" (5). Morris moves "away from psychological and psychoanalytic debates about the formation of H.D's subjectivity, moral debates about the integrity of her character, and aesthetic debates about the 'greatness' and/ or 'originality' of her writing" and instead explores "a wider discussion of the relationship between poetic forms and cultural meanings" (13). To do so, she relies "on the assumption that it is language that carries and contours thought, perception, and meaning" (4) and thereby assesses "the ways in which the materiality of the page interacts with the materiality of social forms on a multitude of levels" (7). This emphasis on materialism sheds light on the "generativity and openness" of H.D's "writing-in-process" (13). Although Morris drastically shifts the focus away 
from H.D.'s psychology, her emphasis on textual and cultural materiality overlooks the author. My project is situated at the intersection of these two trends in H.D. scholarship. Whereas Morris examines how the text as a cultural "artifact" advances the notion of materialism that discloses specific cultural characteristics unfolding within a linear temporal framework, I examine how materiality affects conceptualizations of culture.

My approach here is similar to my analysis of Stein. I move away from a concentrated focus on language as a cultural or abstracted construct, and explore how discursive practices "are co-extensive with material processes" (Iovino and Oppermann, “Theorizing Material” 454). Beginning with H.D.'s “concern" for the body, as articulated in Notes on Thought and Vision, I show how H.D. radically reconceptualizes the human and, by extension, language. Like Stein's early scientific experiments, H.D. reconsiders normative ideas of bodies and consciousness. She proposes two states of consciousness that widen a human agent's conception of a precarious nonhuman world. Whereas Stein refers to this intra-action between bodies, materiality, and language as a "composition," H.D. turns to the notion of the palimpsest. In fact, H.D.'s works tend to be compared to palimpsests since they "involve reading through layers of significance, living with multiple meanings, and being alert to the play of meaning between a given text and its intertexts" (Collecott 2). I propose that this notion of a palimpsest as an "over-written text, consisting of erasures as well as fresh inscriptions, of previous as well as subsequent writings" is not simply "a metaphor for the collective process of reading and rereading her work" (2). I read this idea of a palimpsest in light of material ecocritical understandings of "narratives of matter" (Iovino and Oppermann, "Theorizing Material" 467-468). The palimpsest is not a metaphor for H.D.'s experimental writing style, but it 
exposes "matter as a text, as a site of narrativity, a storied matter, a corporeal palimpsest" (468). Whereas Stein imagines the trans-corporal reconceptualization of language as an exercise in microscopic stylistic innovation rooted in syntactical disruption, H.D. reconceptualizes language as a global performance through which she reveals the intraaction between trans-corporeal bodies and "the world's dynamic self-articulation" (468).

H.D.'s theorizations on a material language stems from the dynamism of the material-discursive processes of the "writing-on-the wall." Her description of the writing as articulated in Tribute to Freud suggests that the writing resembles "a curve like a reversed, unfinished $\mathrm{S}$ and a dot beneath it, a question-mark, the shadow of a questionis this it?" (43). From this, she proposes that "the question-mark threatened to shadow the apparently most satisfactory answers. No answer was final" (H.D., Tribute 43). She claims that "the Professor's explanations were too illuminating" (43) and that her "batlike thought-wings would beat finally in that sudden search-light" (43). She admits that the finality of his interpretations entrapped her thoughts, but Freud "did not set the traps, he did not really fling nets" (43). Instead, H.D explains that "by [her] own subconscious volition or unconscious will" she "walked or flew into them" (43). She "purposely and painfully dwelt on certain events in the past about which [she] was none too happy" (43). Freud interprets these events as manifestations of H.D.'s desire "to tell [her] mother" (44), but as mentioned above, H.D. considers this interpretation "too simple" (44). She does not simply substantiate Freud's theories but reveals her active engagement with theories of the subconscious. In particular, her thoughts do not systematically conform to Freud's notion of the Oedipal complex since they cannot be reduced to her relationship with her mother. In Tribute to Freud, H.D. responds to Freud's "simple" theoretical 
framework by examining the fourth dimension and suggesting that "there were things under things, as well as things inside things" (29). ${ }^{61}$ According to H.D., the "past, present, [and] future" do not unfold in a linear chronological order since "there is another time-element, popularly called the fourth-dimensional" (32). The writing-on-the-wall is characteristic of the fourth dimension since it exceeds forms of finality and reveals a form of entanglement that includes the material, discursive, and temporal dimensions of "things." Freud's theories do not reject the " $4^{\text {th }}$ dimension," but this dimension only "appears variously disguised and under different sub-titles, described and elaborately tabulated in the Professor's volumes" (33). It is "more elaborately detailed in the compilations of his followers, disciples and pseudo-disciples and imitators" (33) ${ }^{62}$

The material-discursive processes of the writing-on-the-wall that disclose the fourth dimension contrast the systematic forms of writing practiced by Freud and H.D.'s father, Charles Doolittle. Freud writes in "rows and rows of numbers" (H.D., Tribute 26) and her father "writes columns and columns of numbers" (35-36). This opposition between dynamic and systematic writing processes is traditionally read as H.D.'s

\footnotetext{
${ }^{61}$ The complex layering of “things” influences H.D.'s understanding of language. In particular, this is at play in HERmione, a novel in which she examines how "to put the thing in writing" (71). She is not concerned primarily with the constant rearrangement of words alone, like Stein. Rather, she explores more fully the ongoing discursive processes of "storied matter."

${ }^{62}$ Christina Walter notes how H.D.'s lengthy engagement with Freudian psychoanalysis" reveals her "affiliation with science," but her interest in science extends beyond psychoanalysis.

This is evidenced by her library collection at her death. The collection "includes numerous popular works on physics and materiality, such as the British Physicist Sir James Jeans' The Mysterious Universe (1930) and the Stars in Their Courses (1931), issues of Proteus: A Journal of the Science, Philosophy, and Therapy of Nature, and reviews of the Russian physiologist Ivan Pavlov's work on conditioned reflexes" (Optical Impersonality 86). Walter points to "a new effort to trace H.D.'s dialogue with contemporary sciences of the body, primarily sexology and eugenics" (284). Adalaide Morris also explores H.D.'s affiliation with theories of relativity and quantum physics. Mark Morrisson's study, although not focused on H.D., provides key insights to the new sciences in the twentieth century, noting how "the non-Euclidean geometries of a spatial fourth dimension became an important feature of early modernist art and literature, of popular culture, and even of religious and occult speculation" (50).
} 
retaliation of patriarchal systems, as evidenced in the famous retelling of the formation of her name. Traditionally, H.D. is often read in relation to Ezra Pound. Specifically, critics focus on the instance in which Pound notoriously edited one of her poems in the tearoom of the British Museum and designated her "H.D. Imagiste." This founding moment marks H.D.'s inclusion into the imagist movement and subsequently signals her entry into a masculine poetic tradition. Susan Stanford Friedman, for instance, contends that the violent "slashing" of the editorial process and the crafting of her nom de plume exemplifies "a condensation that ritualizes the act by evoking prior male inscriptions or figurations of women" (Friedman, Penelope's Web 37). Similarly, Diana Collecott suggests that H.D.'s experimental writing displays a "female imaginary" that is directly opposed to "the performative masculine model that dominated English-speaking modernism" (Collecott 41). These critics demonstrate how H.D. persistently strives to separate herself from masculine literary traditions by developing an experimental writing style that exposes a feminine subjectivity. These feminist readings tend to "focus predominantly on how various bodies have been discursively produced" and "[cast] the body as passive, plastic matter" (Alaimo, Bodily Natures 3). H.D.'s own theoretical overviews on language are subsumed by the editorial "slashing" that frames the poet's identity.

Collecott, however, argues that “H.D.'s resistance to psychoanalysis involved a resistance to systems of interpretation that depend on patterns of inclusion and exclusion" (Collecott 111). Collecott thus moves toward "a post-Freudian context" (2) to explore the intertextuality of H.D.'s works. She proposes that “the most sustained intertext for this study is the poet Sappho - understood as an imaginative construct as well as a body of 
writing” (2). By tracing Sapphic tropes and motifs throughout H.D.'s works, Collecott reveals how Sappho is discursively recreated and "recovers the female body from the erotic writing of H.D." (6). This focus on Sappho extends to H.D.'s preoccupation with Greece, which Collecott further notes figures in H.D.'s texts “as a literal place, and also as a body of knowledge that both invites and resists interpretation" (110). Building off of Collecott's study, I examine how the "body of knowledge" surrounding both Sappho and Greece is imbricated in material nonhuman processes. I read Notes on Thought and Vision in relation with "The Wise Sappho" which is appended to the manifesto. In Notes on Thought and Vision, H.D. outlines her theories of artistic practices. She advances a notion of the artist that surpasses Freud's theoretical framework. This text, however, cannot be read on its own. Although H.D. proposes her theories of the body and language, she develops them further in "The Wise Sappho." My contention is that H.D. looks at how the poet Sappho (a corporeal and discursive subject) is completely imbricated in the discursive processes of the material world.

I propose that H.D.'s theories of the body as articulated in Notes on Thought and Vision illustrate how H.D. is attentive to changes in the environment as she investigates how these changes alter biological processes and, by extension, perception and language. Her understanding of the body reconceptualises traditional binarisms that exclusively separate subject and object, and male and female. Psychoanalytic readings, by contrast, tend to perpetuate the distinction between nature and culture and thereby support the reductive association of women and nature. ${ }^{63}$ Instead, H.D. advances the trans-corporeal body. My research thus joins with new ecocritical theorizations of materiality that move

\footnotetext{
${ }^{63}$ This distinction situates H.D. within a mythopoetic or pastoral tradition that advances notions of "the earth-as-feminine body" (852), as seen in Cynthia Hogue's ecocritical readings of H.D.
} 
away from an "economy of desire" (Friedman, Penelope's Web 2) and a form of materially-mediated cultural poetics. ${ }^{64}$ H.D. pays particular attention to language as a process that is affected by the environment. Although she first grappled with these issues in her manifesto, it is important to note that her interest in visual mediums, such as film, expands on these theories. H.D.'s contributions to the film journal Close-Up explicate how film's capacity to generate new forms of expression has implications for understanding language. She maps a complex interconnection between the material mechanization of film, bodies and environments represented on screen, and the stimulated response of the spectator's body. This material interchange challenges commonplace understandings of language by moving beyond its merely representational function to explore its material dimensions. Film does not provide an alternative visual language that substitutes established language models; rather it illuminates an interdependent relationship that results in the perpetual reconstruction of these models.

By placing her manifesto in dialogue with her theoretical overviews of film, I demonstrate how H.D. undermines depictions of a monolithic environment in favour of unpredictable, permeable environments that are central to her artistic projects. These theories come to fruition in her work, HERmione, a novel that radically alters systematic linguistic models that perpetuate reductive representations of the human agent's relation to environments. H.D. examines the tension between competing linguistic reconstructions of external reality as the protagonist transitions from dominant scientific methods of classification to artistic experimentations that produce alternative conceptions of the individual in relation to fluctuating environments. She reimagines dominant scientific

\footnotetext{
${ }^{64}$ For more on cultural poetics, see Adalaide Morris who examines the mediation between "the materiality of the page" and "the materiality of social forms" (7).
} 
categorizations of nature in favour of environmental processes. These processes do not simply conform to linguistic models but are active in reorganizing these established scientific models. Hermione deviates from standardized scientific methodologies that exert mastery over the elemental organization of environments and, by extension, perpetuate social codes that organize social collectives. Alternatively, she enacts a new mode of vision instigated by cinematic technologies in order to investigate the various and convoluted material networks to which environments and physical bodies belong. As such, she displays how corporeal, discursive, and material reconstructions of the self, the artist, and environments are subject to processes that exceed human-centric interpretative models. The experimental form of the fictional autobiography reinforces this perpetual process since H.D. proposes that artists and their creative reconstructions are entangled with continual nonhuman processes.

\section{Redefining "the murky, dead, old, thousand-times explored old world": Notes on Thought and Vision and The Wise Sappho}

H.D.'s manifesto, Notes on Thought and Vision, was published posthumously in 1982 with "The Wise Sappho" as an appendage. In Notes on Thought and Vision, she explicates her theory of the over-mind, arguing that the human body is not separate from the nonhuman world, but receptive to material processes in the environment. The interplay between external environments and embodied psychical processes reveal how the body is unable to fully register the immensity of the nonhuman world. H.D. reconceptualizes the body and sexual desire to focus on the body's relation to "Nature" (H.D., Notes 37) and the chemical transmutation of desire. The manifesto investigates how the physical composition of the body intra-acts with nonhuman matter. Unlike 
Freud, ${ }^{65}$ H.D. moves beyond object/subject and male/female binarisms, as she advances a notion of desire that reanimates and "[destroys] the world of dead, murky thought" (27). Her concept of desire, however, is not solely attributed to the human, but to "things as well as people" (28). In "The Wise Sappho," H.D. displays how these theories of the body, psychology, and environment are actualized in literature.

H.D. refrains from advancing a single world-view as well as a concept of a singular world. Instead, she accentuates the plurality of the world by examining the human agent's relation to "three worlds": the "world of abstraction: Helios, Athene"; the "intermediate or Nature world: Pan, the Naids"; and the "world of the uninitiated men and women" (37). By listing these three worlds, she imitates the form of columns and rows practiced by Freud and her father without imposing a hierarchical framework. Her notion of the over-mind reveals how the human agent accesses these worlds and showcases how human, nonhuman, and discursive material intra-act. Her manifesto also posits "three states of being" (42) which reimagine the human agent's porous intra-action with material environments through which the boundaries of the external world blend with the boundaries of the internal subjective mind. These three states of being range from "a mind that may be conscious in the ordinary, scholarly, literal sense of the world"; a "subconscious - those sub-conscious states varying in different states of dream or physical feeling, or illness, delirium or madness"; and "a mind, overconscious as well, able to enter into a whole life" (42). The intra-action between material-discursive worlds and the human agent's "states of being" demonstrate how "material agencies reconfigure the very boundaries of the human as such" (Alaimo, Bodily Natures 154). By applying

\footnotetext{
${ }^{65}$ In his work Civilization and Its Discontents, Freud supports the separation between nature and culture, and further explains the association between nature, women, and matter while men are associated with culture, agency, and rational thought.
} 
Alaimo's notion of trans-corporeality to her work, I argue that H.D.'s manifesto suggests "matter is agency [...], an agency that transforms the very stuff of the human" (155).

H.D. suggests that the human being is a composite of physical tissue and nerve fibres, intellect, and over-mind, a mental state that supersedes consciousness but does not transcend the physical world. The body is not a closed, self-sustaining entity that works toward producing an autonomous formation of selfhood. Instead, she re-imagines the individual's body place in relation to a larger geographical plane and postulates a new state of vision that holistically registers the world. She reconceptualizes normative notions of bodies, and reinforces the interrelation between nerve fibres and consciousness. Rather than track a linear developmental process that begins with the body and culminates in the over-mind, she proposes that the individual should strive to achieve a balance between body, mind, and over-mind. She suggests that "brain without physical strength is a manifestation of weakness, a disease comparable to cancerous growth or tumor" (H.D., Notes 17). Similarly, by exclusively demarcating consciousness from the body, the individual becomes "an empty fibrous bundle of glands as ugly and little to be desired as body of a victim of some form of elephantiasis or fatty-degeneracy" (17). Moreover, the development of the over-mind to the neglect of the body results in "madness and a person so developed should have as much respect as a reasonable maniac and no more" (17). H.D. thus dismisses the notion of disembodied consciousness, suggesting instead that psychical processes are bound up in the corporeal functions of the body and receptive to changes in the environment. The composition of the body displays the network of heterogeneous processes that revise traditional understandings of the mechanistic material organization of the physical body. 
Through her understanding of the body, H.D. directly opposes scientific modes of observation that aim to catalogue the nonhuman world and reduce it to a knowable entity. H.D. proposes that the body functions as a type of device that records information of the external world. She claims that there are two centres of consciousness in the body that act as two lenses, and much like a microscopic apparatus, the body can manoeuvre these lenses in various ways. The perceiving body is thus actively engaged and physically exerting itself in order to understand the environment. This manoeuvring of the lenses, however, is not solely the result of a conscious individual exerting force, but is also a response stimulated by the active forces of a material reality. Christina Walter maintains that H.D. engages with the "new physiology of vision" by suggesting that "the perceiving subject was itself part of that physical world, and its embodied processes, structures, and defects shaped perception, including the ocular apparatus, visual cognition, and visual memory" (Walter, Optical Impersonality 3). This "then new model of vision contested notions of an objective, rational observer that took in faithful representations of external objects in the world" (5). H.D. reconsiders scientific technologies such as microscopic and telescopic lenses whose claim to accurate representation of the world rests on a separation of the observer from the environment. ${ }^{66}$ These lenses suggest that images of

\footnotetext{
${ }^{66}$ H.D. undermines traditional scientific modes of observation that "[rely] on the Newtonian assumption that there is a real world separate from the observer, a world it is possible to assess without in any way altering" (Morris, How to Live 160) and extensively revises models of codification and classification that attempt to consolidate representations of a mechanistic universe. Her father and grandfather practiced these hegemonic modes of scientific analysis that relied on the collection of data and mathematical equations as she intervened in new scientific debates regarding perception, psychology, and nature. Adalaide Morris illustrates how her stylistic writing style reveals a "more ambitious and dynamic approach toward science" (Morris 159) than that practiced by her grandfather, Francis Wolle, and her father, Charles Doolittle. They perpetuated the notion of a stable natural world that can be reduced to a closed, definitive entity. Francis Wolle extracted and itemized various plant types without recording how larger ecosystemic forces modified and interacted with the various plant species. Similarly, Charles Doolittle's study of astronomy reduced planetary motion to rigid mathematical formulas. Morris
} 
the environment are easily translatable since the eye retains a factual reproduction of the environment and the observer can meticulously study the image. ${ }^{67}$ As Walter suggests, this method of recording and analyzing the environment aims to divide the external physical world from the inner subjective space of the observer's mind.

H.D, however, demonstrates how consciousness does not reside in the brain, but the whole body is capable of generating thought. She reimagines the traditional hierarchical structure of the body that privileges the intellectual capacity of the mind that is only enhanced by suppressing the senses. Instead, she defends the notion that there are two centres of consciousness, one located in the head and the other in the womb or "loveregion" of the body. These centres of consciousness are not isolated from one another, but interact. As such, both the over-mind or "jelly-fish, placed over and above the brain" and "the womb-brain" or "love-brain" (H.D., Notes 22) are intricately intertwined in the elemental structure of the body. The capacity for thought is no longer secluded in the brain, nor is thought composed of extraneous material different from the tissue and corporeal make-up of the body. By suggesting that consciousness is dispersed throughout the body, H.D. dismisses the traditionally privileged position of the brain as the organ capable of calculable, rational analysis divorced from emotion. She dissolves the dichotomy between rational thought typically associated with a healthy male mind, and female hysteria, a weaker psychological state triggered by intense emotional responses

notes that Charles Doolittle was "acclaimed for his exactitude" (158). Both Francis Wolle and Charles Doolittle practice analytical modes that affirm the notion of predictable environments and produce formulaic patterns that can be accurately documented by a privileged observer.

${ }^{67}$ Morris also reveals how Charles Doolittle and Francie Wolle practiced "the collection and classification of data characteristic of late Victorian science" (How to Live 155). She suggests that their methodologies were limited since "the lenses they looked through took them toward the edges of Newton's three-dimensional, linear, deterministic model of the universe" (155). These lenses failed to recognize quantum mechanics and theories of relativity as articulated by Einstein (155). In other words, these lenses do not access "the fourth dimension" that interests H.D. 
and originating in the body. Instead, H.D. modifies dominant conceptions of normative and gendered bodies by demonstrating how alterations in the physiological structure of the body transform established discursive models. The body becomes a site in which discursively produced commonplace understandings of masculine and feminine psychological patterns interact. The individual should not seek to develop one centre of consciousness and neglect the other, but aim to strengthen the communion between the two.

Although her manifesto attends to biology and materiality in order to explicate psychological processes, H.D. does not advance a solipsistic understanding of the body. In order to obtain the state of the over-mind, she declares that the "concern is with the body" (50) as it interacts with the environment. She examines a form of communication between human and nonhuman agents by suggesting that the brain is a "receiving station" (47). She also proposes that the human body and the physical world "are both receiving stations, capable of storing up energy, over-world energy" (47). H.D. refers to the statue of the Delphic Charioteer to explain the interrelationship between animated matter and the sensorial apparatus of the body. Both the individual body and the material structure of the statue resemble "telegraphic centre(s)," communicating through "dots and lines" that are "received and translated into definite thought" (26). She further exemplifies the exchange between physical realities and human bodies by indicating how Leonardo da Vinci's ${ }^{68}$ hyper attention to precise details in the environment such as "the lines of the

\footnotetext{
${ }^{68}$ Freud composes an essay on Leonardo da Vinci in which he examines why da Vinci was more interested in research rather than love. He argues that research became a substitute for love, suggesting that Leonardo pursued "research with the same passionate devotion that another would give to his love, and he would be able to investigate instead of loving" (77). He focuses on Leonardo's development from childhood to adulthood to reveal how "the research becomes to some extent compulsive and a substitute for sexual activity" (80). To understand why this is,
} 
bird's back" (27) inspired the over-mind consciousness that animated his artistic projects.

The body thus acts as a transit and the ongoing interchange generates a new type of vision and new form of expression that manifest in her artistic projects. She uses the Delphic statue to consolidate her theory of animated matter that dismisses established conceptions of the body as a contained entity. The body maintains a porous interaction through which discursive practices intermesh with dynamic physical realities.

The different states of consciousness proposed by H.D. are not separate progressive developmental stages that culminate in the final stage of the over-mind. Instead, these states are interconnected. Moreover, consciousness is interwoven with the corporeal fabric of the body, which is further interwoven with the material fabric of the environment. This is evidenced by H.D.'s definition of the over-mind, which resembles "a closed sea-plant, jelly-fish or anemone" (19) that reaches out and intercepts the external environment through sense perception. The over-mind is both "fluid yet with definite shape" (18) and is "contained in a definite space" (19). Like the jelly-fish, it extends "super-feelings" (19) in order to register the material world. Body, mind, and the environment become sites of movement as H.D. sheds light on the complex networks of agentive matter that stimulate a new mode of vision. The reciprocal relationship between these material networks begins by concentrating on a single object, which initiates the

Freud reduces Leonardo's life to the Oedipal complex to document a causal relationship between the artist's childhood, and his later research compensates for deviant sexual instincts. Freud focuses extensively on Leonardo's sexual drives and contends that "the core of his nature, and the secret of it, would appear to be that after his curiosity had been activated in infancy in the service of sexual interests he succeeded in sublimating the greater part of his libido into an urge for research" (80-81). Whereas Freud focuses on locating the origin of da Vinci's deviation and substantiates his theory by reducing it to the framework of sexual repression, H.D. examines the on-going creative process of the artist. She investigates how da Vinci experienced the nonhuman world. Unlike Freud, H.D. focuses on how the nonhuman material "acted on" (Notes 27) da Vinci, and this intra-acting process of the artist and the nonhuman world generate the artistic process. 
over-mind, stimulating the over-mind to register a holistic view of the world. The overmind, thus, is "a mind, overconscious as well, able to enter a whole life" (H.D., Notes 42). Famous artists such as Leonardo da Vinci and Euripides are exemplary figures who have achieved this state of vision that in turn animated their aesthetic projects. Artists should strive to achieve this state of the overconscious through concentration, and imitate "the painter who concentrated on one tuft of pine branch with its brown cone until every needle was a separate entity to him and every pine needle bore to every other one, a clear relationship like a drawing of a layer mechanical twentieth century bridge builder" (43).

The body is not a static entity, but an organism that is in a perpetual state of transformation as it interacts with external material realities. H.D. contends that "the body of a man is a means of approach, or can be used as a means of approach to ecstasy" (46). She compares the body to the chemical transmutation of burning coal, suggesting that "coal may be used to make gas, an essence, a concentrated, ethereal form of coal" (48). The coextensive relationship between the body and the environment generates a chemical reaction. HD is theorizing just what Alaimo has more recently theorized as trans-corporeality. This "chemical sensitivity" is "the quintessential example of what [Alaimo] is calling trans-corporeality" (Alaimo 116). According to Alaimo, however, this chemical sensitivity refers to the body's sensitivity to pollutants and toxins in the environment. For H.D., it refers to spirituality. In both cases, Alaimo and H.D. examine the porous intra-action through this sensitivity and suggest that it widens the human agent's awareness of the world and their place in it. Chemical sensitivity, for H.D. focuses on "energy" that is "transmitted" to "another body or another mind that is in sympathy with it” (H.D., Notes 47). Specifically, the ecstatic body becomes a means to 
"approach" the spiritual and so "she links the notions of body and spirit to the practice of sex in the modern age" (Mackay 54). The body then is "a natural phenomenon which stores and mediates energy" through sexual desire and so "not only do sexual instincts not become an obstacle to the achievement of this new state of being, they initiate it" (54).

What she refers to as "spirit" is not extracted from the body, but mutually dependent and existing within the material composition of the body. H.D. also notes that although "the body consumed with love gives off heat" (H.D., Notes 48), this love does not "burn out simply as heat or physical love" (48). She compares the transformation of the body to natural entities such as coal and the physical make-up of the oyster, suggesting that the fabric of the body is not isolated from the nonhuman world; it undergoes similar processes as nonhuman objects and organisms. Like coal, "the heat of the body is transmuted to this other, this different form, concentrated, ethereal, which we refer to in the common as spirit" (48). She describes how the body's relation to the material world, which is necessary to nurture the relationship between the "head" and "body," makes "a spiritual birth" (50). In this "spiritual birth," the head and body are like "two flecks of protoplasm" producing not a child, but "the very first germs that grow into a child" (50). Moreover, the interrelationship between the spirit and the body relates to "the oyster [that] makes the pearl" (51). She concludes that the body "casts off the spirit, a concentrated essence, not itself, but made, in a sense, created by itself' (51). H.D. argues that "we cannot have spirit without the body, the body of nature, or the body of individual men and women" (48). Thus, just as the nonhuman world is in a perpetual 
emergent state, so too is the body. The individual must not neglect the body, but focus on strengthening its relationship to material environments.

This intricate network of body, spirit, and "nature" invites "green" readings of H.D.'s work wherein nature connotes traditional "green” environments. Critics who examine the spiritual dimension of H.D.'s works tend to situate her texts within a pastoral tradition and thereby cast nature as a pure otherness exclusively separated from modernity. ${ }^{69}$ This conflation of the material and the sacred emerges from H.D.'s interest in "Hermeticism's view of the universe as a web of connections" and the "view of the divine as ceaselessly unfolding within the world" (Anderson 158). This comingling of the material and the spiritual, however, is characteristic of twentieth-century sciences that advance theories of the "material and universal" as they "[overturn] the nineteenthcentury mechanistic, deterministic 'old' physics and [invite] religious interpretations of science" (Vetter 1). The early twentieth century was an era of "enormous transition, in which competing and conflicting scientific paradigms coexisted" (4). Lara Vetter examines how religious and scientific institutions utilized similar rhetoric in their exploration and documentation of the universe. Indeed, modern sciences adopt "a language that merges science and religion" (2) and "facilitates a notion of the universe that dissolves the borders between soul and body, humanity and deity" (7). H.D. grappled with an assortment of epistemological paradigms, ranging from dominant scientific discourses on biology, astrology, and botany, Freudian psychoanalysis, and Greek and Hellenic conceptions of the environment.

However, readings that focus on the spiritual or pastoral dimensions of H.D.'s work tend to focus extensively on an environment that is both feminine and pure. For

${ }^{69}$ For more on pastoral tropes in H.D.'s works, see Cynthia Hogue and Harriet Tarlo. 
instance, Cynthia Hogue contends that H.D. promotes "a gynocentric vision of a replenished natural world" (Hogue 841). This limited notion of the environment overlooks H.D.'s depictions of complex material spaces in favour of a feminine space that nurtures and restores the body. This notion of a feminized natural space extends to a discussion about a feminine language that originates from the body's restored relationship with a pure environment. Scott Freer suggests that H.D.'s experimental writing imitates the fluid motions of the natural world. ${ }^{70}$ This pastoral reading of H.D. exposes an idealized and essentialist view of a gendered body. Yet, in Notes on Thought and Vision, H.D. indicates that "the body was not a very rare or lovely thing" (H.D., Notes 51). The body, she argues, "seemed an elementary, unbeautiful, and transitory form of life" (51). She does not promote an escape from the body nor does her manifesto expose an aversion to the body. Instead, "the body, with all its emotions and fears and pain in time casts off the spirit” (51). The spiritual dimension of H.D.'s work thus does not necessitate a need to restore the body by eliminating "emotions," "fears," and "pain," but uses these elements to develop the spirit.

She refers to the spirit as "a seed" (52) that is planted in the body. The body becomes a type of ecosystem and the human agent's "concern" for the body aids the "growth" of the spirit. H.D. proposes that "no man by thought can add an inch to his stature, no initiate by the strength and power of his intellect can force his spirit to grow" (52). That is, intellect alone cannot control the development of the spirit. The human agent "can retard its growth by neglect of his body because the body of a man as the body of nature is the ground into which the seed or spirit is cast" (52). The human agent must

\footnotetext{
70 This "fluid" or natural form of writing contrasts the violent "slashing" motion Pound uses to "carve" out H.D.'s name in the tearoom at the British museum.
} 
take care of the complex structure of the body, which consists of intellect and emotion. The growth of the spirit cannot be controlled by thought, but through constant awareness of the well-being of the body. This image relates to the growth of nonhuman environments. Just as "no man by intellectual striving can make his spirit expand," so too can "no man by thought $[\ldots]$ make the grain sprout or the acorn break its shell" (52). H.D. denies the human agent complete control over the body and over the nonhuman world. She further states, "every man can till the field, can clear weeds from about the stems of flowers" (52). The human cannot exert mastery over the nonhuman world, but act as another agent within a complex network of material processes. Thus, by imagining the body as "a means of approach" (46), H.D. reveals the porous dimensions of bodily matter. The "concern" for the body that also stimulates a "concern" for the environment focuses on the human agent's well-being. However, this well-being does not compare to the type of restorative health that critics address in pastoral readings of H.D. This transcorporeal body accentuates the "boundary-crossing between humans and nonhumans, where lines are deliberately questioned, dismantled, and redrawn" (Iovino and Oppermann, "After Green" 332). H.D. supports the notion of a complex material matrix in which "the environment can no longer figure as background, resource, or passive matter, discrete substances that remain below or behind the human" (Alaimo, Bodily Natures 154).

Whereas green ecologies "[emphasize] balance, the innate, the primal, landscapes with few people, macrosystems, the refined" (Iovinno and Oppermann, "After Green" 330), H.D.'s understanding of the body suggests that "the human is essentially co-opted, hybridized, and entangled with alien beings, always in negotiations with other agencies, 
other bodies, and other natures" (333). Her descriptions of material surroundings range from common conceptions of a green nature such as trees and birds, to nonhuman matter such as statues, and chemical compounds. Her examination of "thought" and "vision" advances the notion of "a materially mediated observer" (Walter, Optical Impersonality 7) ${ }^{71}$ as she reconsiders modes of vision whereby the body's intra-action with nonhuman matter generates images that are "unreliable at any particular moment and that [are] not an instantaneous record but instead unfolded over time" (7). Her manifesto neither champions the erasure of the poet as a means to accurately "capture" an image of the nonhuman world, ${ }^{72}$ nor does it circumscribe a space for female subjectivity. Her notion of experimental language questions the authenticity of artistic reproductions of the body and environments and so "offers possibilities for the representation of ecological relationships that go beyond the range of local place and individual perception" (Heist qtd. in Kerridge 368-369).

\footnotetext{
${ }^{71}$ Walter demonstrates how the "incoherence, materiality, and performativity" (Optical Impersonality 25) of the body dismissed "the bounded and singularizing nineteenth-century definition of personality" (22), promoting instead that "embodied identities are not individual possessions but the unstable product of a nexus of social and organic imperatives, a politically consequential notion that rejects both biological essentialist and social constructivist views of race and gender" (29). She revises a traditional notion of a modernist impersonal aesthetic that is typically understood as segregating "a masculinist refusal of the body, a pursuit of concreteness' and 'objective truth about reality" from a "'personal', 'feminine,' aesthetic" (Walter, "From Image to Screen" 292). Walter's revised notion of an impersonal aesthetic "[gestures] toward a new locus and meaning for embodied identity" (293). Rather than align H.D.'s imagism with "an impersonal aesthetic [that] incorporates a transparent image in the name of scientific objectivity in order to evade bodily contingency and cloak masculine power," Walter argues that "modernism's appeal to the image is not simply a solipsistic escape from the body, the passion, or even identity categories like gender, sexuality, and race, but rather a detailed engagement with the oscillating concerns of cultural and scientific modernity" (309). Whereas Walter focuses on H.D.'s interest in optics, I propose that ecology is integral to the new mode of vision that she articulates in Notes on Thought in Vision.

${ }^{72}$ Kaufman argues that H.D.'s poetry relies on the impersonality of the poet. She suggests that H.D.'s attention to "natural elements" reveals the impersonality of the speaker as she "focuses on the natural phenomenon itself rather than the cleverness of the speaker's reaction" (Kaufmann 63). Although Kaufman moves away from common trends in H.D. scholarship, she relies on the separation between a "green" nature and the human agent.
} 
Her manifesto therefore champions the trans-corporeal body that ultimately advances what Iovino and Oppermann suggest is a "nonanthropocentric humanism [that] debunks ontological hierarchies and rejects totalizing moral systems" (Iovino and Oppermann, “After Green” 335). Whereas Notes on Thought and Vision proposes new theories on the body, psychology, and language inflected by conflicting scientific studies and H.D.'s own mental collapse, “The Wise Sappho” reveals a textual performance through which she tests the limits of established linguistic models and revises typical conceptualizations of the poet. The interrelationship between the spiritual, the material, and the natural informs her concept of the artist who affects and is affected by what material ecocritics term "narratives of hybridity, participation, and coevolution" (335). Sappho exemplifies Iovino and Oppermann's conception of the human as "co-opted" and "hybridized" (333). Little is known of Sappho. ${ }^{73}$ The knowledge we have of this poetic figure derives from interpretation. ${ }^{74}$ Sappho, then, is part of a narrative that is always "in negotiations with other agencies, other bodies, and other natures" (333). In "The Wise Sappho," H.D. contemplates the significance of Sappho as a literary and cultural figure, and as a physical body existing within a specific social-historical environment. The essay showcases H.D.'s notion of a fluid image of the artist as she investigates the interconnection between Sappho, the poet, and artistic reproductions of the poet.

\footnotetext{
${ }^{73}$ As Margaret Williamson notes, little biographical information exists and most of Sappho's poetic works exist in fragments. A Greek poet, Sappho "lived on the island of Lesbos around the turn of the seventh and sixth centuries BCE" and "she was the most highly regarded women poet in Greek and Roman antiquity" (1). Williamson further notes that "only a fraction of her output has survived, and almost all of what now exists is in fragments" (1).

${ }^{74}$ Since we cannot rely on the existing fragments of Sappho's works to convey accurate autobiographical information from which to construct her identity, Sappho remains an elusive figure imagined and reimagined by "antiquity's accumulated wisdom" (Williamson 1) and the various scholars and artists who contribute to the discussion.
} 
The essay does not conjure up a static image of Sappho as a definite, immortal entity, but displays how Meleager's tribute, "Little, but all roses” (H.D., “The Wise Sappho" 57), is part of and, by extension, affects a larger assemblage of different interpretations of Sappho. ${ }^{75}$ H.D. does not conclude the essay with a definite portrait of the poet, but demonstrates how this esoteric figure is integral to the evolution of literary modern aesthetics. "The Wise Sappho" illuminates H.D.'s interest in the palimpsest. The notion of the palimpsest exposes the intricacies of literal and discursive ecologies that are integral to the formation and transformation of individual and national narratives.

Temporal, physical, and discursive environments intermesh and are at play in her notion of the palimpsest. ${ }^{76}$ H.D.'s criticism of Meleager's tribute to Sappho animates her essay as she considers how his tribute is not an authoritative description of the poet. Critics such as Diana Collecott examine how H.D.'s critical response to Meleager is an attempt to uncover a feminine space distinct from masculine literary traditions. Sappho acts as a quintessential female body who possesses a female voice. Some critics such as Ellen Greene perform a biographical reading of the essay, suggesting that Sappho becomes a surrogate for H.D., and the classical figure's beloveds are either Aldington or Bryher. Eileen Gregory, however, recognizes a process in the essay, arguing that H.D. “[articulates] the network of association defining for her the nature of Sappho's immortality" (Gregory 137). Building on this notion of a textual process that exposes a “network of association,” I propose that H.D.'s understanding of Sappho exemplifies her idea of the body as articulated in her manifesto. Sappho reveals how the body is a site of

\footnotetext{
${ }^{75}$ H.D. begins the work by stating how she is "inclined to disagree" with the tribute "little, but all roses" by "the Alexandrine poet" ("The Wise Sappho" 57).

${ }^{76}$ The palimpsest exemplifies Karen Barad's notion of agential realism which insists that the "human always exists within, not outside of, material intra-actions" (157).
} 
transit and a "means of approach" (H.D., Notes 46), further demonstrating how the artist, the art, and the nonhuman world are imbricated in "narratives of hybridity."

H.D.'s critique of Meleager's tribute extends to a critique of the imagist movement as described by Pound. ${ }^{77}$ The brevity of the lines in Meleager's tribute and the precision of the image resemble the form of poetic imagism, a style that lacks ornamental and superfluous language and relies on the concise articulation of a concrete object. H.D., however, demonstrates how language and representation are entangled within a complex network of energized matter. By taking apart Meleager's line, H.D. indicates how inadequate it is to convey Sappho's work. Sappho and her work are not isolated, clearly demarcated objects, but objects in relation to a larger schema of interrelated matter. H.D. marks the evolution from language as an abstraction to the tactile, material characteristic of language, and further outlines how language is immersed in a larger network ranging from individual roses to roses in relation to national and planetary configurations. First, she examines the materiality of language by associating Sappho's language with "rich colour...violets, purple woof of cloth, scarlet garments... stains on cloth and flesh and parchment" (H.D., "The Wise Sappho" 57) in order to convey the richness and suggestiveness of Sappho that Meleager seems to gloss over. Instead, she proposes that language does not correlate to isolated chemical compounds or material objects such as "warmth," "sunlight," or "heat" (57), but "another element containing all these, magnetic, vibrant; not the lightning as it falls from the thunder cloud, yet lightning in a sense: white, unhuman element, containing fire and light and warmth, yet in its essence differing from all these" (57). In doing so, she is poetically seeking a language for talking about

\footnotetext{
${ }^{77}$ In his essay “A few Don'ts by an Imagiste," Pound describes imagism as a focused experiment on language and impersonality, distilling language and senses into the most precise meaning.
} 
Sappho's poetics without relying on methods of codification that categorize distinct material elements.

In order to understand this complex figure who is both an "abstraction" and material, both spiritual and "embodied," one must practice the form of vision articulated in Notes on Thought and Vision. H.D. equates the "white, unhuman element” of Sappho's poems to the warmth of a "jewel, sent by the beloved" (58), calling attention to the state of ecstasy necessary to initiate a new mode of vision. H.D. then tracks a movement from Sappho's poetry to a wider global scale. She states, "we are inclined to visualize these broken sentences and unfinished rhythms as rocks - perfect rock shelves and layers of rock between which flowers by some chance may grow but which endure when staunch blossoms have perished" (58). This telescopic vision mimics the form of a film lens moving from a close-up to a bird's eye view. Through this mode of vision, H.D. visualizes the intricate conglomeration of the sentences with rock beds, extending to "an island with innumerable, tiny, irregular bays and fjords" (58). Finally, the movement extends from an island, to "a country, a continent, a planet, a world of emotion, differing entirely from any present day imaginable world of emotion" (58). Beginning with the fragments of Sappho's lines, H.D. proposes that one can begin to imagine aesthetic renderings of Sappho. However, much like the artistic figures in Notes, H.D. suggests that only a few will achieve these new insights of the poet by visualizing the fluid interconnecting processes of language, environments, and bodies. This movement from concise poetic lines to larger global and imaginary worlds does not mark a linear teleological progression that culminates in a definite, accurate image of Sappho, but gestures to numerous ways in which one can visualize and, by extension, aestheticize the 
poet. These artistic representations are fragments that combine and contribute to an ongoing palimpsestic image of the poet.

H.D. visualizes a trans-corporeal body if we understand "trans" as Alaimo defines it: "movement across different sites" (Alaimo, "Feminist Science" 190). Sappho concretizes H.D.'s understanding of spirituality, a state that does not transcend the material world, but originates from the combination of material forces. H.D. proposes that although the poet is a spiritual figure, she is also "embodied-terribly a human being, a woman, a personality as the most impersonal become when they confront human beings" (H.D., "The Wise Sappho" 59). This description supports Walter's understanding of a modernist aesthetic that undermines "nineteenth century, Western accounts of human vision [which] tended to separate the eye that registered external forms from a rational mind that reflected upon and even perfected those forms" (Walter, Optical Impersonality 2). H.D. suggests that abstractions are not only contingent on the body, but intertwined with material realities. She imagines the nonconformist and crude mannerisms of Sappho and her subjects. When describing the country girl in Sappho's fragments, H.D. reveals that her garments are "ill-fitting or ill-cut" and "her mannerisms, her gestures are crude" (60) as she uses "her flawless talent to destroy custom and mob-thought" (59). The physical features defy normative bodily conventions and typical representations of beauty and femininity. Moreover, the physical body is constantly in motion, as exemplified through Sappho’s facial features: "she protrudes a little her under-lip, twists her eyes, screws her face out of proportion as she searches for the most telling phrase" (60). Not only is this a body in constant flux, but a body creating and producing language. 
Even though H.D. gives these very specific physical descriptions, she also points out that we, in fact, only have Sappho's poetic fragments which inspire our visual imagination of her appearance and those she writes about. For instance, H.D. claims that "we have no definite portraits from her hands of these young women of Mitylene" (62), women addressed by the speaker of the poems. However, only "the most intense spirit and the most wary and subtle intellect can hope even in moments of ardent imagination, to fill in these broken couplets" (62). Thus, through the combination of the literary fragments and the reader's active participation to imagine the subjects of the poems, H.D. reveals how ecstatic visual modes are intertwined with literary production. Sappho's erotic and sensuous relationships generate these poetic lines. Furthermore, the type of intellect necessary to conjure up images of the poet and her subjects originates from a type of ecstasy. "All her ecstasies, her burnings, her Asiatic riot of colour, her cry to that Phoenician deity, 'Adonis, Adonis"” (63) animate her poetry. Sappho's creative "genius" then is not isolated to the untouched depths of a pure disembodied consciousness, nor is it filtered by a transcendental power mediated by her body. Her creative projects, by contrast, emerge from the multiple relations with other bodies as well as environments. Her body and the subjects of her poems are not isolated entities but interconnected with the landscape. As Williamson indicates, both Sappho and her subjects exist in poetic fragments obtained through excavation. ${ }^{78}$ Embedded in dirt before uncovered and preserved, these fragments typify what Barad calls discursive processes since the poetic texts are completely imbricated in landscapes that change over large periods of time. Although H.D. imagines "the cheeks of the girl" as "black and burnt" (60), these

\footnotetext{
${ }^{78}$ See Sappho's Immortal Daughters.
} 
characteristics might also refer to the condition of the fragments that bare traces of the material environment.

In her attempt to visualize the subjects of Sappho's poems, H.D. calls attention to one subject in particular: a girl whose only attribute is "wisdom" (63). This unnamed woman reveals the process through which the combination of corporeal bodies and physical environments produce the spiritual. Turning to the "brief fragments" of Sappho's works, H.D. reads, "I think no girl can never stand beneath the sun or ever will again and be as wise as you are" (63). From this, she supposes that this woman "stood in the heavy Graeco-Asiatic sunlight" (63). This specific temporal-historical landscape expands as "the wind from Asia, heavy with ardent myrrh and Persian spices, was yet tempered with a Western gale, bearing in its strength and its salt sting, the image of another" (63). The mixture of Asian and Western gales demonstrates how a specific locale is interconnected with larger geographical forces. H.D. suggests that "the image of another" is Athena, since her "eyes shadowed by the helmet rim, the goddess indomitable" (63) typify the common attributes of the classical figure. Thus, the merging of geographical elements blends the woman's wisdom with the classical figure who is emblematic of wisdom. Similarly, she suggests that Sappho achieved this rich intermingling of the material and the spiritual in her poems as "she constructed perfect and flawless $[\ldots]$ the whole, the perfection, the undying spirit of goddess, muse or sacred being from the simple grace of some tall, half-developed girl" (65). Specific, minute features of physical bodies or material realities compel the artist to obtain a new state of consciousness. For instance, "the simple gesture of a half-grown awkward girl, a being, a companion, and equal" or "the momentary circlet of strange rust-coloured hair" produced 
by the sun, permits the poet to visualize "an almost disembodied spirit" (65). Through this textual process, the poet does not ultimately transition to a disembodied spiritual realm. Sappho instead achieves a state of consciousness that exposes the intricate interactions between the material and the spiritual. She thus visualizes the arrangement and perpetual rearrangements of large geographical expanses.

In attempting to conjure up an image of Sappho and her poetic subjects, H.D. does not supplant Meleager's tribute with another authorial claim. Rather, she illustrates how this tribute is one of various interpretations of the poet that derive from different states of consciousness. She does not fully reject "the testimony of [an] Alexandrian or late Roman scholastic to assure us the artistic wisdom, the scientific precision of metre and musical notation, the finely tempered intellect of the woman" (64), but examines how these various types of wisdom combine to form a fluid image of the poet. H.D. also notes how "emotional wisdom" (65) significantly transforms scholarly and institutionalized representations of Sappho. This "emotional wisdom" refers to the poet's physical relation to the subjects of her poems and the imaginary translations of the readers. This type of wisdom further displays how the poet and the subjects of her poems adhere to H.D.'s definition of the spiritual as a hybrid between material bodies and social-cultural discourses that abstract these figures. That is, Sappho is a "woman whom love paralysed till she seemed to herself a dead body yet burnt, as the desert grass is burnt, white by the desert heat" (65). She undergoes physical repercussions from her relationships as she "trembled and was sick and sweated at the mere presence of another" (64). Plato, by contrast, abstracts this severely material existence by defining her as "the morning star among the living" (68). H.D. thus resolves that "the name of muse and goddess and of 
human woman merge, interspersed among these verses" (64). Sappho is "a name, an abstraction as well as a pseudonym for poignant human feeling" and also "rocks set in a blue sea, she is the sea itself, breaking and tortured and torturing, but never broken" (67). The different verb tenses highlight a process and the sea stresses the fluid reconstructions of the poet that stem from Sappho's trans-corporeality.

\section{The Image and the Cyclops: H.D.'s Film Reviews}

H.D.'s contributions to the film-journal Close-Up expand this complex nexus of mind, body, and environment explained in her manifesto by exposing how the material dimensions of film reveal a material language. As Laura Marcus notes, H.D.’s publications in the film journal provide ample insight to her literary projects as she reflects on her active participation in the production of film (Marcus 96). H.D. did not simply review films and reflect on the varying forms and genres from the perspective of a spectator. Her work as an actor, projectionist, and editor equipped her with knowledge pertaining to the mechanical production of film. Through these various roles, she cultivated theoretical overviews of film that dismiss linear historical, individual, linguistic, and even evolutionary processes. H.D.'s film reviews compare to Stein's theories on theatre as she focuses on the spectator's response to film. Her film reviews, however, also extend her focus to the medium itself and demonstrate how "natural" and artificial environments intra-act with spectator's bodies so to expose what contemporary film critic Adrien J. Ivakhiv terms "relational ecologies" (Ivakhiv 5). As H.D. investigates the interaction between bodies and dynamic physical realities, she explicates how film's capacity to generate new forms of expression has implications for 
understanding modernist linguistic practices. In doing so, she challenges commonplace understandings of language by moving beyond its merely representational function and pays particular attention to "the many ways material realities are enmeshed with meanings and narratives" (Iovino and Oppermann, "Theorizing Material" 448) in order to revise standardized linguistic models and reconsider the body as part of a complex ecological network.

H.D.'s tripartite essay in Close-up, "The Cinema and the Classics," deflates the notion of a monolithic environment and investigates film's capacity to authoritatively document psychical, bodily, and natural spaces. ${ }^{79}$ In the first section of the essay, she distinguishes between film's capacity to display reality in all its complexity, and specific formulaic patterns imposed by censorship laws to craft an artificial representation of the external world. She refers to the relation between cinematic technology and artists and audiences as "the leaven, turning in the lump" (H.D., "Cinema and Classics I" 105), underlining the chemical reaction of film mechanization and its effects on the bodies of the spectators. This new artistic medium, according to H.D., is "a Juggernaught crushing

\footnotetext{
${ }^{79}$ Film as a new artistic medium in the late nineteenth and early twentieth century evolved simultaneously with new theories of psychology and vision. Anthony Enns and Shelly Trower discuss the similarities between film technologies and the physiological apparatus of the brain, revealing how film mechanizations influence studies on embodied cognitive processes and optics. Similarly, Frank Kessler and Harro Segeberg examine new modes of vision and "distinctive new modes of thinking about and experiencing time and space" (Segeberg 69), which contest traditional "approaches that take the filmic image to be a simple reproduction of reality" (Kessler 23). Emerging cinematic techniques demanded new modes of perception and questioned standardized methods of classification, thereby interrogating both the camera's and the individual's ability to faithfully replicate environments and the individual's place within an existing environment. It is important to note that the cinema does not simply provide an analogy for the visual arts and literature. As Jonathan Foltz contends, H.D.'s interest in film should not be "limited to the ways that H.D.'s fiction emulates cinematic techniques; rather in H.D.'s film criticism she develops a kind of literary spectatorship, a way of writing about the act of seeing" (Foltz 2). H.D. does not reject standardized linguistic models by turning to stylistic experiments that imitate cinematic conventions. She is interested in the reciprocal effects of the mechanization of the medium and the spectator, and how this relationship produces new languages.
} 
out mind and perception in one vast orgy of the senses" (105). This "orgy of the senses" makes it difficult to rationally explain the capacities of this new medium. She describes the audience as "the fair-to-middling intellectual" and the "little army of the advance guard or the franc-tireur of the arts, in whose hands mercifully since the days of the stone-writers, the arts really interested" (105). This artisanal production of the arts relies on the tactile, material exchange of the artist and the art form. The audience is not separate from the medium and therefore cannot authoritatively define the components of the medium. Instead, the spectators are "wedged securely in the lump (we won't class ourselves as sniffingly above it)" and they want "to prod [their] little microbe way into its understanding" (105). The camera is not simply an extension of the body used to enhance the individual's "natural vision," but it becomes a type of organism, a "microscopic leaven" with a "microscopic mind" (105). ${ }^{80}$ By referring to the microscopic composition of film technologies ${ }^{81}$ that exert agency as they interact with physical realities and bodies, H.D. recognizes the interplay between animated matter and artistic production, a mutual dependency fundamental to her reconsideration of language.

She compares the composition of the shot to writing, suggesting that the placid, aestheticized representations of an external world organized by a lens mirrors the sterility of established linguistic models. Cinematic conventions aim to catalogue various

\footnotetext{
${ }^{80}$ H.D. contests traditional understandings of the cinema that indicate how film mechanizations imitate bodily processes. The relationship between the audience and the cinema does not simply disclose "the artist as moving-picture machine" (Morris, "The Concept" 95), but exposes the intricate material entanglement at the level of microscopic chemical reactions.

${ }^{81}$ The leaven turning in the lump is also a biblical metaphor for Jesus' spirituality. By applying this metaphor to cinematic technologies and physical bodies, H.D. calls attention to her notion of the spiritual that she advances in Notes on Thought and Vision. The cinema does not initiate a transcendental move away from materiality, but is completely imbricated in materiality. The chemical reaction of the leaven and the lump compares to "the process whereby the heat of the physical body is transmuted to this other, this different form, concentrated, ethereal, which we refer to in common speech as spirit" (H.D., Notes 48).
} 
components of physical realities in the same way established linguistic models aim to solidify strict definitions. To illustrate, she begins the essay by contemplating the standardized "word-reaction" (105) associated with the cinema. The structure of the essay imitates the form of a mathematical equation as she attempts to formulate a finite definition of the word "cinema":

(cinema $=$ movies), boredom, tedium, suffocation, pink lemonade, saw-dust even: old reactions connected with cheap circuses, crowds and crowds, and crowds and illiteracy and more crowds and breathless suffocation and $[\ldots]$ peanut shells and grit and perhaps a sudden collapse of jerry-built scaffoldings. (105)

This methodical definition of the cinema, however, carefully details a specific environment inflected by distinct cultural codes. That is, the term cinema equates to popular cinema houses in America that attract crowds for the sole purpose of entertainment. These codes of American culture are then replicated and preserved within a linguistic formula. This rigid definition displays the limitations of the new art form that becomes heavily censored in America. H.D. suggests "the American censor," also known as the "Cyclops" (106), imposes strict patterns that codify the American landscape and human bodies and aims to preserve these representations. H.D. is critical of this Cyclops that typifies a detached observer who fragments, isolates, and retains select reproductions of physical realities, and thereby emulates a form of single vision that imposes severe restrictions. Her critique of the Cyclops echoes her desire to move away from objective modes of observation articulated in her manifesto. She compares the violent selective patterns of the Cyclops/censor to acts of harvesting, thereby calling attention to her father's and grandfather's cataloguing regimes. The censorship in America performs "a 
vast deflowering" (106) in order to manage representations of environments and bodies. ${ }^{82}$ For instance, "films that blossom here in Europe (perhaps a frail, little, appreciated flower) are swiftly cut and grafted in America into a more sturdy, respectable rootstock" (105). Strict cinematic patterns produce artificial renderings of reality and severely distort reality. The film apparatus simply "[determines] structures for a social nature” (Barad, Meeting 142).

The association between the cinema and images of flowers continues throughout the essay to emphasize film's potential to undermine the artificiality of the censor and expose a "natural" mode of observation, despite the limitations of the censor. By examining the chemical reaction of the cinema and the microscopic agentive matter associated with the medium, H.D. reconsiders the sterile standardized cinematic conventions reflected in the "word-reaction." Greta Garbo inspires this realization, permitting H.D. to examine how the mechanization of the medium discloses the vibrancy of the human body as it interacts with and is affected by vast spatial and temporal environments. Censorship laws "deflowered, deracinated, [and] devitalized" the actor as she has been "actively and acutely distorted by an unbelievable parody of life, of beauty" (106). Regularized cinematic patterns craft an artificial representation of the actor. However, while viewing Garbo’s performance in the film Joyless Street, H.D. notices “a clue, a new angle, and a new sense of elation" (107) that reveal how conventional forms of beauty attempt to quell the body's vitality and coerce the actor to conform to a static representation of beauty. That is, the "frail and tortuous veils of light and shadow, wandering in photogenetic guise that Leonardo would have marveled at" (107) expose

\footnotetext{
${ }^{82}$ This image of "deflowering" contrasts the image of "[tilling] the field" (H.D., Notes 52) in Notes on Thought and Vision.
} 
the ongoing material interchange that resists formulaic patterns. Garbo "momentarily $[\ldots]$ touched the screen with her purity and glamour" and so the screen "must finally respond" (109). This symbiotic relationship reveals how the spectator interacts with physical realities in which nature, bodies, and matter are bound up in a complex network that undergoes endless transformations. The reference to Leonardo epitomizes H.D.'s theories of the over-mind in Notes on Thought and Vision and reinforces the notion of the overmind achieved through the cinema.

H.D. opposes the static aestheticized versions of reality with the energized form of light, emphasizing the physical interaction between the spectator and the screen. She is critical of popular cinematic conventions that present bodies as contained entities moving within clearly delimited environments. These conventions distinguish between artificial environments (sceneries fabricated within studios) and natural settings. H.D., however, maintains that "the naturalistic and the sheer artificial must merge and melt together" (H.D., "The Cinema and the Classics II" 111) and so she proposes a more complex understanding of what constitutes the "natural" and nature. Cinematic conventions that favour "elaborate and false studio interior[s]" (H.D., "Russian Films" 138) and that esteem the star system create a systematic symbolic language through images in order to create and preserve an illusion of reality. Studios imitate "general natural effect[s]" which adhere to a constricted notion of "naturalness" (138). Similarly, the star system attempts to consolidate precise representations of exemplary bodies. These conventions thus attempt to solidify stringent systems of representation, but as H.D. notes, "we cannot worship sheer mechanical perfection" (H.D., "The Cinema and the Classics III" 119). The cinema must move away from ornamental, grandiose, preconceived ideas of reality. 
Although the medium has the potential to sanction strict systems of representation, H.D. argues that cinema's resistance to this is inherent in the material mechanization of the medium. She compares two modes of vision to support her claim: the first relies on objective modes of scientific analysis that oppose the subject and object, and the second explores alternative modes of vision. She maintains that the Movietone is "an instrument of international understanding," but it risks constructing and sustaining artificial representations of reality as it "places people and things, catalogues them" (119).

Although this "magnascope" enhances the spectator's vision, it is an instrument through which "art is cut open, dissected" and meticulously "analysed" (119) ${ }^{83}$ In its attempt to accurately replicate reality, the movietone creates precise and consistent renditions of reality as it "welded" (115) environments and bodies to stable images.

\footnotetext{
${ }^{83}$ H.D. contests traditional notions of the cinema that rely on a detached observer who consumes the images on a screen. Walter Benjamin advances popular conceptions of modern cinema in his essay, "The Work of Art in the Age of Mechanical Reproduction," as he reflects on both the medium's limitations and film's "revolutionary" potential. He argues that film has "enriched our field of perception" (Benjamin) since the technological equipment "isolates" and magnifies behavioral patterns that disclose contents of the subconscious as they surface and manifest in the actors' bodily impulses. In this way, he fosters the notion of the detached observer by distinguishing between the contents on the screen and the spectator. Film technologies distort everyday realities through the representation of time and space. Through his description of the camera's ability to magnify and enlarge spatial dimensions and to alter the progression of time, he distinguishes between two natures. Firstly, the film camera reproduces an external environment, enlarging minute details and isolating individual components within the environment. Secondly, it exposes "a different nature," an internalized subjective space of the unconscious mind that he refers to as "unconscious optics" (Benjamin). The use of the close-up, in particular, enhances the detached observer's ability to register and understand his or her environment through the expansion of space. Similarly, "with slow motion, movement is extended" (Benjamin). Thus, film's ability to reproduce material realities at a "tenth of second" enhances an individual's "natural vision" (Benjamin) in order to perceive an authentic external environment. Furthermore, "the enlargement of a snapshot does not simply render more precise what in any case was visible, though unclear: it reveals entirely new structural formations of the subject" (Benjamin). He suggests that film displays the interiority of the mind, noting a separation between unconscious space and the corporeality of the body. He is interested in how the lens circumscribes physical worlds and amplifies minute changes in both forms of "nature" that often go unnoticed. His understanding of film is influenced by Freudian psychoanalysis as he suggests that the spectator can objectively analyze the contents on the screen by assuming the role of the psychoanalyst.
} 
The cinema's ability to mimetically reproduce material environments suggests that the camera lens can effectively organize authentic images of the external world. H.D., however, differentiates between cinematic technologies that weld material objects to images and those that wed objects with images. The former relies on an authoritative agent that assimilates objects with established images and so compares to dominant scientific methods of categorization. This method suggests that objects exist as singular definitive forms that can be extracted from larger material forces. "Wed," in contrast, anticipates theories of intra-action in which agency is not attributed to one creator but implies that all matter reorganizes itself. In this way, systems of representation are bound up in intra-active processes and are constantly recombining and rearranging. The act of welding attempts to assimilate individual objects in order to form a "perfect" whole; the act of wedding, by contrast, dismisses this model of assemblage. The movietone that welds also fragments bodies as "voice follows face, face follows voice" (115). However, instances in which "face and voice with all their subtle blending are accurately and mechanically welded" manufacture a type of aesthetic process "robbed of the thing behind the thing that has grown to matter so much to the picture adept" (115). This type of movietone provides complete images that a passive spectator simply absorbs. H.D., however, claims that she wants "to help to add imagination to a mask, a half finished image, not have everything done for [her]" (116). She argues that "cinema art [is] a matter [...] of inter-action" (116). The spectator does not absorb images but actively engages with the screen in order to create images. The cinema is a medium that exposes how "tone and vision, sight and sound, eyes and ears the gate ways to the mind are all appealed to" (118). H.D. proposes that "we are visionaries, we may become prophets" 
(118). That is, the spectator should engage with a new mode of vision that does not simply select and retain absolute images of an external world. ${ }^{84}$

It is important to note that H.D. does not completely reject established systems of classification, but examines how systems are fluid and constantly in motion. Cinema should not embellish human bodies, environments, or psychological states, but turn to Hellenic ideals of restraint and simplicity in order to aestheticize environments and bodies. In this way, she advances a new notion of reality, one that cannot be codified or classified within static systems of representation. She proposes an alternative "Sophoclean formula" which recognizes matter's potential energies (H.D., "The Cinema and the Classics II" 114). Cinematic art should strive to showcase "Hellenic restraint and Hellenic naturalization" through its emphasis on "Greek attributes" such as "simplicity, restraint, [and] formalization" (113). This generates a new mode of vision, "a new point of view" which does not extract and isolate objects, but examines "the fitness of things in their interrelation" (113). "True modernity," she notes, "approaches more and more to classic standards" (113) since new technologies like those used in the cinema illuminate the interdependency between individual bodies and shifting geographies. By evoking "classic standards," H.D. does not insist on a return to a distant past, but imagines a

\footnotetext{
${ }^{84}$ Recently, scholars have begun to explore how H.D.'s interest in film coupled with her study of optics influences epistemological concerns as she reimagines the body and subjectivity. Rachel Connor explains how H.D.'s understanding of a visionary cinematic experience initiates a spiritual transformation that permits the spectator to acknowledge "a dimension that lies beyond the surface" (1). Christina Walter revises "the visionary" experience by turning to the new physiology of vision that collapses the divide between internal subjective space and external objective reality. Walter demonstrates how H.D. "[insists] on the unbounded nature of the seeing subject" (Walter, Optical Impersonality 83) by destabilizing traditional conceptions of the image as stable and mimetic. In an earlier study, Susan McCabe displays how the cinema provides new modes of vision that are "acts of projection that establish a meeting-ground between internal and external experience" (139). Although McCabe provides astute insights into montage as a form of cutting that "disrupts cultural fantasies as it attempts to refashion them" (167), she focuses primarily on how "H.D. refashions female embodiment through montage" (133).
} 
holistic worldview in which environments, matter, bodies, and aesthetic processes are entangled.

Although cinematic conventions might categorize concise aestheticizations of an artificial reality, H.D. notices how cinema not only displays how the screen intersects and intermeshes with physical bodies, but also provides a new language and new modes of expression. Language is not simply an abstracted system that objects enter into, but, H.D. notes how "languages filter into her consciousness" (H.D., "Conrad Veidt" 124) and, by extension, her body. Cinema exposes the spectator to different languages commonly accompanied with music, and the vibrations that produce images, language, and music generate "extravagant electricity" (130). The screen speaks to the spectator and the spectator, in turn, speaks to the screen, and so "languages...dead languages, living languages" intermingle with "a wee voice" that "[whispers] there within me," producing "a universal language, a universal art open alike to the pleb and the initiate" (124). ${ }^{85}$ The visual language of film does not substitute established linguistic models, but through a reconsideration of what constitutes the visual, H.D. reveals a dynamic material language. The "universal language," however, is not oppressive or singular. It does not organize human agents within a uniform linguistic model. This universal language is a discursive process.

H.D.'s understanding of a material interchange between the screen and the spectator moves away from an emphasis on an individual's viewing experience to a

\footnotetext{
${ }^{85}$ H.D.'s notion of "living languages" differs from Stein's "lively words." H.D. is not only focused on rearranging syntactical and grammatical structures, but explores how images alter the way we speak. The human agent's capacity to speak is not limited to words alone. The cinema composes narratives through images; however, cinematic narratives are not limited to the sequential arrangement of images, but are affected by the technology of the medium and the intraaction with the spectator.
} 
"universal" experience. She exposes the "substance" of cinematic language and subsequently reveals "relational ecologies" (Ivakhiv 5), a term coined by contemporary film theorist Adrien J. Ivakhiv. He states:

These ecologies entail the material production and consumption of those produced images; the social or intersubjective relations of people whose efforts shape and inform those images; the people and things portrayed or represented by them; those delivering, receiving, interpreting, and being moved by them; and the cognitive, affective, and perceptual relations connecting bodies, sensations, desires, sensory organs, and media formations. (5)

These ecologies accentuate the interrelationship between the body's ability to perceive and interpret the world and a world that is "perceptive and communicative in its nature" (35). Cinematic technologies expose "relational ecologies" in which the perceiving subject is intricately bound up with physical, social, and discursive environments. Relational ecologies illuminate the "ethical action" of film, indicating how the individual spectator is bound up with a conglomeration of human and nonhuman environments. This ethical action supports Alaimo's understanding of ethics "that is not circumscribed by the human but is instead accountable to a material world that is never merely an external place but always the very substance of our selves and others" (158). This artistic medium allows H.D. to explore methods of observation and systems of representation in order to pursue new ways of understanding the self in relation to a larger world.

This interrelation of human and nonhuman agents shifts from an anthropocentric understanding of the world through which environments and bodies are transparent and thereby translatable, to a holistic understanding of the world. H.D. advances a new notion 
of reality, one that does not adhere to dominant systems of classification. Art, thus, does not consist of preserving the essential qualities of an isolated object, but becomes a means through which to explore material objects in relation to other objects. Reality cannot be reduced to a clearly delimited bounded entity directly translated by established codes but differs from 'the wax candy-box 'realism' of the so much so-called film art" (H.D., "Expiation" 127). The material interaction that she explores through the cinema is characteristic of all matter. She thus proposes that "life and the film must not be separated, people and things must pass across the screen naturally like shadows of trees on grass or passing reflections in a crowded city window" (H.D., "Russian Films" 138). Bodies interact with material realities and entangled in this nexus of energized matter is the combination and recombination of aesthetic images. H.D. thus asserts that "the world of the film to-day (there is not getting away from it) is no longer the world of the film, it is the world" (135).

The cinema becomes a medium through which to "understand" (H.D., "The Cinema and the Classics III" 117) the world and, by extension, nationalities. She promotes a global perspective through which she reconceptualizes the organization of different nations. Nations are not individual units with unique characteristics that can be reduced to a "'bottled' Germany, and 'bottled' America” (118). Cinema allows us to understand "that a new world is open, a new world of political understanding, of educational reform, or art (in its pure sense) even" (118). H.D. claims that "we are no longer nations" (H.D., "Russian Films" 136), dismissing the notion that individual national boundaries constitute rigid geographical parameters which make-up the world. Instead, she champions the notion that "we are or should be $a$ nation" (137), calling 
attention to the interrelationship between nations. The First World War discloses this interconnection "for if one suffers, eventually the other must, and if one nation to-day befouls its own integrity and strikes blindly at a lesser nation, the whole world, willy (as they say) nilly must be sooner or later dragged into the fray" (136). At first, she constructs this interconnection between nations by categorizing them: "we all know everything about the so called Great War, that A was base, that B was good, that C was heroic, that $\mathrm{D}$ lost diplomatic papers, that $\mathrm{E}$ was really to blame, that it was all called from F shooting G" (137). The structure of the sentence imitates a mathematical formula that promotes a method of "knowing" rooted in systems of classification. She then restructures the sentence in order to remove strict categories and focuses on the relational process between nations: "if $\mathrm{C}$ has smallpox, no doubt $\mathrm{D}$ will catch it and hand it on to $\mathrm{E}$, and maybe F even" (136). In order to see this interdependent relationship, "nations must understand each other" and therefore she reinforces the need to pursue new epistemological inquiries in order to "know, know, KNOW" (136). The porous interaction between film technologies and the spectator extends to a "relational ecology" in which human and nonhuman agents participate in and affect knowledge structures.

Whereas H.D. compares the physical and psychological composition of the body to lenses in Notes on Thought and Vision, her discussion of film suggests that the body does not simply imitate the mechanical processes of the cinema lens. Instead, she reveals how human bodies and literal and artistic representations of material surroundings are imbricated within a matrix of material processes that revise established epistemological models. Her theorizations on film compare to contemporary theorizations on "relational ecologies" that exceed typical conceptions of green ecologies. "Relational ecologies" 
extend to prismatic ecologies as H.D. investigates "the way our human gaze participates in a world of alterity and likeness" (Iovino and Oppermann, "After Green" 335). Her understanding of film decentres the human as it exposes the porous boundaries of the physical body and the material composition of the medium.

\section{HERmione: "put the thing in writing"}

Having mapped the development of H.D.'s theories on the body, materiality, and language, I would like now to turn to HERmione, a novel H.D. began composing in 1927, the same year that Close- $U p$ was first published. The novel is a fictional autobiography that chronicles Hermione's development as an artist in relation to a shifting landscape. The novel begins with Hermione's failed attempt as a scientist as she contemplates her recent "failure" to pursue a university degree in modern science. She criticizes dominant scientific methodologies practiced by her father and brother, noting the severe limitations of these modes of research. This institutionalized science attempts to categorize environments and bodies through the use of precise formulas and "exact definition" (H.D., HERmione 3). As she reflects on the reductive modes of "the more modern science," she deflates the notion of "[posting] signs over emotional bog and intellectual lagoon ('failure complex,' 'compensation reflex') to show us where we may or where we may not stand" (4). Her critique conflates the emotional and intellection capacities of the body with natural phenomena. This blending is persistent throughout the novel, dismissing traditional notions of the environment as pure, non-human, and "other." Hermione revises authoritative scientific modes of observation, noting how this nexus of human and non-human spaces resists rigid scientific methods of classification. For 
instance, as Hermione "[gazes] into branches of liriodendron, into network of oak and deflowered dogwood," she recognizes that "she was nebulous" (3). Her "failure" marks her deviation from the family tradition since she does not conform to "the Gart theorum of mathematical biological intention" (4). She is unable to assimilate the complex physical and psychical composition of her body with a single definitive nominal categorization. Her focus then extends to the environment as she reveals how landscapes are not contained entities that can be clearly circumscribed by categorical confines. She thus transitions from scientific methods which isolate and contain single entities to the arts in order to examine images, "no matter how fluid, how inchoate" (5).

Although questions concerning representations of the environment and geographical configurations of nations are central to the text, few studies focus on how the novel contributes to environmental issues or how ecological inquiries animate the novel. These studies vary from traditional readings of nature as distinctly associated with classical myths and spiritual forces to conceptions of erratic natural forces that are constantly reorganizing themselves. Recently, Cynthia Hogue examines the "ecological sensibility" (41) of H.D.'s works. She argues that H.D.'s nature is "maternally connoted" (855) as she casts "the earth-as-feminine body" (852), and thereby depicts "a gynocentric vision of a replenished natural world" (841). Whereas Hogue foregrounds an ecocritical reading of H.D.'s works, her study builds upon the rich body of scholarship that examines representations of nature in H.D.'s texts. Harriet Tarlo, for instance, explores H.D.'s interest in classical and pastoral traditions, framing the natural world as a spiritual "escape" (237). She purports "the idea (or fantasy) of wilderness, the longing to return to a pre-lapserian state when relationships between natural elements (benignly or 
aggressive) acted always within their own nature" (247). In accordance with this theory of nature, Scott Freer traces H.D.'s investment in mythological recreations of the natural world as she fashions "patterns of death and rebirth" as "themes of hope and resurrection in the natural order" (109). These "symbolic constants" (109) imitate the cyclical patterns of natural elements, generating "narrative patterns" (109) and tropes that connote spiritual resurrection. In these readings, nature connotes a return to a primordial locale uncontaminated by human agents.

Moving away from a focus on mythical landscapes, James H. Christianson and Adalaide Morris demonstrate H.D.'s engagement with new scientific discoveries in physics, quantum theories, and relativity. These discoveries radically altered nineteenthcentury conceptions of a deterministic universe by "re-imagining temporal, spatial, and material places" (Christianson 33). Christianson, in particular, claims that H.D.'s experimental writing "subverts the old illusion of precise, controllable measurements" and "[elicits] instead a universe in continual warp and weave, with matter coefficient with energy-field, sheer vibration and wave, irrepressible drift, and a stubborn uncertainty always eluding homogenous Law" (39). Morris also demonstrates how H.D. grapples with the tension between structured and chaotic models of the universe; she depicts "a universe that is determinate but also uncertain, law-abiding but also unpredictable" (How to Live 168). These critics refashion the natural world not as a return to a primordial place of restoration and recovery, but as an ongoing process. Furthermore, both Annette Debo and Celena E. Kusch mark a shift in focus from figurative esoteric landscapes to literal configurations of environments that are integral to H.D.'s modernist aesthetic. However, whereas Debo proposes that the unique characteristics of a clearly demarcated American 
landscape are central to H.D.'s experimental writing style, Kusch argues that national borders are tenuous and subject to change. According to Kusch, H.D. "[nullifies] American exceptionalism by destabilizing the geographical fixity of the concept of nation itself' (Kusch 50) and thereby deflates the notion of a fundamental American landscape. These contesting theories on universal and national dispositions emphasize how nature figures predominantly in H.D.'s writing.

By examining what constitutes nature or the "natural," I will show how H.D. reveals complex interactions between material agencies that dismantle idyllic representations of nature and blur the boundaries between natural spaces of refuge and culturally constructed destructive locales. I argue that H.D.'s palimpsestic imagery marks a shift in focus from an individual's corporeal experiences within a particular place to a more global perspective that results from one's reimaging of discursively produced configurations of place. H.D.'s landscapes are violent spaces as exemplified through the threatening environmental processes in HERmione. As Hermione turns to artistic reconstructions of the self, nations and the environment do not substitute rigid systems of classification. Instead, she exposes how artistic recreations affect and are affected by violent and volatile material phenomena. The fictional autobiographical form further deflates authoritative scientific claims about finite reconstructions of bodies and environments. H.D. demonstrates how the individual in relation to material realities cannot be assimilated into a static representation in the same way scientists reduce all matter to codes. The author is not an autonomous figure organizing truthful representations of external reality, but the artist and aesthetic processes are imbricated in the flow of agentive matter. 
In this novel, H.D. depicts the interconnection between human and non-human spaces by presenting the human and nature as chemical compounds that resist formulaic patterns and causal results typically achieved within the controlled setting of the laboratory. Hermione rejects her father's scientific formulas that reduce the body in all its complexity to a single mathematical equation, and dismisses the mode of scientific observation that manufactures detailed accounts of the environment. Hermione grapples with the tension between analytical accounts of the world and alternative lines of inquiry. At first, she attempts to conform to scientific modes of observation and even ventriloquizes her father's and brother's scientific rhetoric, but as the novel progresses, she transitions to new ways of seeing and documenting the world. The novel begins with Hermione resisting a formulaic linguistic pattern as she attempts to correspond her physical existence with a definitive categorical term. She attempts to synchronize her physical body with her name, Her Gart, but this attempt at cohesion fails since there are different variations of her name. She cannot claim that she is "Hermione Gart precisely" (H.D., HERmione 3) since her names changes from Hermione Gart to "Her Gart" to "Her, Her, Her," to different pronunciations such as "Aum." Unlike her father and brother, "she could not predict later common usage of uncommon syllogism; 'failure complex,' 'compensation reflex,' and that conniving phrase 'arrested development'” (3). Her inability to harmonize her physical body with linguistic patterns and diagnostics suggests that she is a failed scientist, but even the term "failure" (3) is an attempt to categorize her deviation from strict scientific regimes. She does not then completely reject this scientific practice, but notices the limitations of a science that fabricates systematic patterns. She then turns to the arts as an alternative mode of investigating immeasurable mutations and 
transformations in the environment. She conducts scientific experiments through her writing. Whereas "her development [is] forced along slippery lines of exact definition, marked supernorm, marked subnorm, on some sort of chart or soul barometer" (3), Hermione aims to explore new forms of expression that can effectively represent the environment and which are, in turn, affected by environmental processes. ${ }^{86}$

Her deviation from strict scientific discourses reveals the inconsistency of the "Gart theorum" (4). Her digression from the traditional family practice of engaging with the sciences is not simply the result of her resistance to participate in a rigid regime, but the physiological structure of her body also exposes a departure from the theorem. Under the tutelage of her father and brother, she is trained to "[see] in a head that had been pushed too far toward a biological-mathematical definition of the universe, a world known to her as Pennsylvania" (6). However, she recognizes that such regulated "science, as she saw it, had eluded her perception. Science as Carl Gart, as Bertrand Gart defined it, had eluded her perception" (6). Her perception permits her to view the world differently in a way that calls attention to Walter's "physiology of vision." Hermione does not track linear movements in the environment, but notices an intricate layering that occurs in non-human spaces with dense forestry and also in human locales in which

\footnotetext{
${ }^{86}$ Material ecocritics reconsider Lawrence Buell's ideas of artistic representations since they suggest that representations are intricately bound up with the material processes of the environment. Buell examines the limitations of both "the human sensory apparatus" (Buell, The Environmental 84) and literature to faithfully reproduce the environment. He contends that human agents are "highly selective: we perceive discrete objects better than objects in relation, and large objects much better than the average life-form (about the size of a small insect)" (84). Consequently, "our reconstructions of environment cannot be other than skewed and partial" (84). He notes how literature cannot accurately reconstruct the environment since "art removes itself from nature" (84). New material ecocriticism revises Buell's initial claims on human reconstructions of non-human spaces and champions the interdependent relationship between literary and visual aestheticizations of the environment and the material formation and reformation of environments.
} 
"conversation went on in layers" (71). To illustrate, as she attempts to focus her "psychic lens" (5) to follow the flying pattern of a single bird, her vision widens in order to view the bird in relation to the forest. Moreover, her body registers colours as "blobs" as she "perceived matter colour as pure tone" (23). In this way, she recognizes a symbiotic relationship between the body and the environment as the interchange between material elements and different modes of perception result in a radical reimaging of the environment. She notices a shift from anthropocentric scientific methodologies which severely demarcate the human from non-human spaces and holistic scientific practices which recognize the human as intricately bound up in non-human spaces, affected and affecting planetary forces. The dominant scientific modes practiced by her father and brother assume that the human agent can adequately document the organizational processes of the environment. Through formulaic patterns, they assert control over inactive matter in order to regulate natural forces, and by extension, regiment social bodies.

Their scientific formulas support nationalistic organizational practices typified by the national authoritative figure, Uncle Sam, who reiterates the notion of the body and the environment as calculable bounded entities; like her father, he "[presses] things down in test tubes" (112). The Gart theorem and Uncle Sam manufacture a precise form of measurement that authoritatively allocates the environment and bodies to particular units. As such, Hermione compares this monolithic approach to the autonomy granted to a supreme creator "with hegemony over everything that moves" (Morris, How to Live 162). She thus conflates Uncle Sam, her father, and brother within a unifying godhead figure, suggesting, "God, some sort of Uncle Sam, Carl-Bertrand-Gart God shut us up in a box, 
with temperatures too high and temperatures too low to breed new specimens like Bertrand Gart, like Carl Gart in their aquariums" (H.D., HERmione 96). By distancing the creator from its creation, she criticizes objective modes of study that orient all life forms to a single form of measurement which preserves "one solution" (96). Her failure from school, however, originates from her inability to assimilate to the Gart theorem and so opens new lines of inquiry which exceed established mathematical principles. As she contemplates her exception from a rigid biological formula, she begins to examine her family lineage and understand how her genealogy is not limited to a succession of bodies that share similar biological features. In lieu of this deterministic biological approach, she notices that her ancestry cannot be exclusively separated from the environment.

Annette Debo argues that "attachment to place is embedded in a literal, biological way" (146), revealing how "the land is pivotal in shaping Hermione's sense of what it means to be a writer" (146). According to Debo, Hermione is an "American writer" (147) since "being an artist is tied to the ability to write in a way that is evocative of place" (146). Since "part of her is moss-grown already, embedded into the American subsoil that she carries with her forever" (146), the unique elemental composition of a distinctly American landscape informs her writing style. However, Lawrence Buell's distinction between place and space frustrates the notion of a nation with distinct geographical parameters that correspond to cultural codes. Place, he argues, "entails spatial location, entails a spatial container of some sort" that can be measured and to which "meaning has been ascribed" (Buell, The Future 63). Space, by contrast, "connotes geometrical or topographical abstraction" (63). Hermione's understanding of space reconsiders astute measurements that distinguish cultural and natural locales. At first, she practices an 
established analytical mode that divides the world into distinct nation states. Both her mother and father are expatriates, transitioning from Europe to live in Pennsylvania. Hermione describes her parents as organisms that have been transplanted and stabilized within New England. For example, her mother, Eugenia Gart, has "fibres [that] were rooted and mossed over and not to be disrupted" (H.D., HERmione 9). Eugenia "had grown into the subsoil" and if she "pulled her mossgrown fibres, Pennsylvania itself would ache like a jaw from which has been extracted a somewhat cumbrous molar" (9). Similarly, her father, Carl Gart, "was comforted being at peace in the green shadows after the inland prairies and the stark glare of inimical Atlantic waters" (9). By examining this heritage, Hermione recognizes that she "was both mossgrown, inbedded and at the same time staring with her inner vision on forever tumbled breakers" (9). She utilizes the same methodical formulas as her father to examine the individual's relation to place. However, this rigid formula gestures to unstable and shifting boundaries.

Hermione recognizes that her criticism of mathematical and biological equations stems from a privileged observer's treatment of the object of study, or "thing” (9). Dominant scientific methodologies aim to extract objects or "things" from their surrounding and integrate them into formulas. For instance, "an owl her grandfather had kept in an old loft, a toad her brother had found unearthed near a wellhead in the process of being mortared, a litter of tiny moles about to be crushed flat beneath a garden shovel" compose "the sort of [things] that would mean to her- Pennsylvania" (9). This method of isolating components from their surrounding fosters the notion that all matter is subordinate to the agency of the human. This method of categorization that attributes power to the human agent is what constitutes her understanding of Pennsylvania. 
However, "she did not know that Pennsylvania bears traces of a superimposed countyEngland and of a luscious beauty-loving Saxony" (9). A new mode of observation accentuates the entanglement of all nations, permitting her to "know that the birdfoot violets she so especially cherished had far Alpine kinsfolk, that the hepaticas she called 'American' grew in still more luminous cluster at the base of the Grammont, along the ridges of the Jura, in rock shelves above Leman and the Bodensee" (9). According to the classification techniques of the Gart theorem, Hermione "only felt that she was a disappointment to her father, an odd duckling to her mother, an importunate overgrown, unincarnated entity that had no place here" (10). By understanding that "no race is in itself integral but that each has its fibres elsewhere" (10), she seeks new forms of observation that register the intra-action of things. Rather than endorse formulaic linguistic patterns and mathematical equations that discredit implausible outcomes, she demonstrates how linguistic models are imbricated in material realities.

To contest rigid mathematical formulas, Hermione decides to "reveal [herself] in words" (76). She contends that "words may now supercede a scheme of mathematicalbiological definition" (76) and seeks to engage with new sciences by treating dominant scientific rhetoric as an object of study. Through words, she will "prove conic sections a falsity" and further "disprove science and biological-mathematical definition" (76). She debunks the notion that language is a type of template consisting of formulaic codes through which external objects are assimilated. She criticizes the unidirectional flow of objects into language through which a human agent authoritatively maps things with systematic definitions. She notices instead that "her perception was ahead of her definition" (13) and investigates the symbiotic relation between perception and language 
production. This realization results from ways in which she observes the world. Her modes of observation vary from tracking linear dimensions and patterns in the environment to divulging an intricate nexus of material entities that are constantly recombining. This alternative way of looking at the world combats subject/object binarisms preserved through established scientific practices. For instances, whereas her father observes the world through a kaleidoscope, positioning the instrument as an extension of the body in order to enhance a human subject's vision, Hermione assumes that her body acts as a lens. She imagines herself as an octopus reaching out with "a thousand eyes" (71) in order to comprehend the world. This visual mode relies on the body's sensation and movement through space and therefore exemplifies H.D.'s new mode of vision inspired by cinematic technologies. She argues that "in Philadelphia people did not realize that life went on in varying dimension, here a starfish and there a point of fibrous peony stalk with a snail clinging underneath it" (13). The environment thus takes on characteristics of a palimpsest, revealing how the very structure of nature and bodies resists the stagnant systems of classification.

Hermione suggests that the restricted means of looking at the world and being cognizant of linear dimensions is characteristic of a "precinematographic conscience" (60). She is aware of this transition, proposing that "she would later have seen form superimposed on thought and thought making its spirals in a manner not wholly related to matter but pertaining to it and the peony petals magnified out of proportion" (60). This mode of vision does not rely on the eye's ability to retain accurate representations of an external world, but originates from a vibrant material world acting upon and being affected by her physical body. This dynamic energy is not characteristic of biological 
bodies, but all matter. To illustrate, when Hermione first encounters Fayne Rabb, she distinguishes between two modes of vision. The first mode reveals how the physiological structure of the body "sees" as she places her hand on a piano, feeling the vibrations. The "live quiver of naked nerves" makes her hand "conscious, acquisitive, making her say my hand can dip down into this very black pool (the piano-polished top of the piano) and lift up odd star-notes, and things drawn out like the nerves in the dissected frog [she] did for the biological treatise that went on kicking after he was carefully dead" (108). The interaction between "naked nerves" and matter stimulates the character in ways that cannot be obtained by a "precinematographic conscience" (60). These vibrations emanate from the piano as Fayne performs without relying on sheet music. This mode of observation is then contrasted with a more limited type of vision once Fayne puts "on her glasses again, [and] is running over a sheaf of pages she has unrolled from a rather shabby music-role" (110). The sheet music introduces codes that adhere to "a geometric pattern" (110), moving away from the vibrations and returning to a more metrical rhythm. By contrasting these two modes of vision, Hermione resolves that she is "tired of things that make molecule pattern and pattern like planets rotating round the sun and planets making just so much of a slight variation in their so set circle" (110). This mode of vision "[cuts] things up" (110), isolating individual entities without recognizing vibratory intra-actions.

This alternate mode of vision recognizes the intricate network of dynamic environments, the sensorial apparatus of the body, and energized matter and therefore underlines the mutable texture of language. Throughout the novel, Hermione grapples with systematic linguistic models that foster definitive individual and national identities. 
She contemplates how anyone "could tell anyone about things" (20), assuming a dichotomous relation between abstract linguistic formulas and physical objects. She then reflects on the limitations of art forms that "[discriminate] and [select] and [bring] odd distorted images into right perspective" (139). She dismisses art forms that imitate scientific formulaic patterns which "put the thing in writing" (71). Rather than assimilate objects into strict definitions, she highlights the intra-action between material objects and language. As such, she argues that "things were in people, people were in things" (204) and further notes that "names are in people, people are in names" (5). The syntactical structure of these lines does not simply substitute the first clause with a contrary statement, but puts it in dialogue with its inverted claim. The structure of the sentence thus illustrates the interrelationship between things and people, and people and names. These lines reinforce how linguistic practices are enmeshed in a mutually dependent system that consists of bodies, nature, and matter.

Hermione further stresses the materiality of language through the articulation of her name, noting how the vibrations of her vocal chords produce multiple variations. She experiments with different pronunciations of her name: "I am Hermione out of Shakespeare. I am the word AUM. She said Em, Hem, Um, clearing her throat” (193). These variations mark the complex layering of identity, ranging from a classical fictional character, to physical mutations of her name as "her breath made a runnel in her throat like an icicle on a hot stove" (193). H.D. compares the materiality of language to natural processes, indicating that language is not an abstract system outside of the environment through which human agents can organize material objects into systematic definitions. Instead, language is bound up with the material processes of the natural world since the 
"runnels in the throat" produce "different shapes like frost on nursery windows" (193). AUM draws attention to an earlier scene in the novel in which she conducts a similar experiment with language, suggesting that "God is in a word. God is in Her...I am the word AUM" (32). However, through this new experimental process which produces multiple linguistic variations, Hermione revises established modes of scientific rhetoric. Furthermore, she dismisses the privileged position of the scientist to use language as a means to authoritatively document and replicate external realities. The transformation of the word God deflates the "Carl-Bertrand-Gart God" figure who creates and preserves systematic categorical models.

This interdependent relation comes to fruition in the final scene of the novel in which Hermione is immersed in a natural setting, her body attuned to the shifting environment. The versatile landscape becomes a parchment and her feet pencils as she produces new forms of expression. Prior to her venture outdoors, she suffers from an illness; her sense perceptions are heightened and she is committed to bed rest. She is unable to differentiate one sense perception from another in order to observe the precise dimensions of the bodies and objects which surround her. Instead, all senses are stimulated simultaneously, resulting in an amplified emotional state that distorts an otherwise familiar place. As such, she shifts from an analytical mode of observation which methodically arranges different components of the environment to a state of vision in which "Her saw everything" (210). While George is speaking to her, she sees a mosquito "[breaking] through the ceiling" and notices how "his red antennae gnawed her" (210). At the same time, she observes "a train [rushing] past the window" (210). She registers multiple points of view as she recognizes how objects and bodies are relative to 
each other. Not only are bodies entangled with each other in that "Her was Fayne, Fayne was Her," but she "knew George saw Her, saw George, saw Fayne" (210). Her vision then extends from her immediate surroundings to a larger geographical plane. The confinement of the room does not severely separate her from the external environment since she has brief interactions with natural elements whenever someone opens the window. This permits her to see "triangles stars and the beat, beat that was the in-growl, that was the out-growl of Atlantic breakers" (210). This heightened stimulation arouses an enhanced type of vision which George simply reduces to a form of hysteria. By dismissing her intensified psychological and emotional state as "hysterical" (210), he definitively encapsulates her state of being within a strict categorical term.

Hermione, however, dismisses this practice of categorizing states of being, drawing attention to the limitations of scientific discourses which attempt to standardize strict definitions. She argues that there are different forms of communication, suggesting that "images form, we can't talk in mere words" (218). To undermine finite systems of classification, she highlights the relational interactions of different nations. Bodies are intricately bound up in the geographical configurations of nations since "the climate makes us" (218). However, she does not propose that nations produce distinct climates that generate unique physiological compositions which can be classified as distinctly American, Russian, etc. Instead, she reveals how bodies interact with each other and are affected by different geographical elements. Hermione suggests that she and Fayne Rabb are "deracinated Europeans holding valiant intellectual standards...caught here on the narrow strip of the Atlantic seaboard" (218). Although the term "deracinated" connotes a violent reorientation of their bodies, H.D. does not propose that their bodies are passive 
entities which can be relocated and cultivated by a new geographical locale. The term calls attention to the reorganization of the environment as it transforms, often violently, into new elemental configurations. By using the term "deracinated," H.D. compares their bodies to forms of vegetation, intimating that bodies are organisms that are intricately bound up in ecosystems. The transplantation of different bodies exposes the symbiotic relationship between bodies and environments, and reveals the connectivity between nations.

Moreover, the "narrow strip of the Atlantic seaboard" further accentuates the fluid boundaries between commonly conceived stable divisions between nations. Kusch suggests that the sea represents this mobility, noting that it "dislocates national identity from its geographical foundation and sets it in motion and in contact with other nations" (Kusch 50). These nations are not simply interacting in that separate entities are coming into contact with each other. This interrelation demonstrates a form of intra-action, "a term that situates the action as always already inside a larger flow" (Kerridge 366). Individual bodies are not simply transposed, but constitute a larger organism, "a creature even now seething with life cells; phosphorescent cells" (220). Individual bodies and nations are part of a larger ecosystem in which each component resembles a "little blood corpuscle" moving within "the whole inchoate mass" (220). H.D., thus, opposes Uncle Sam's conventional representation of nations as isolated units and displays a global network which resists regimented organizational patterns. Hermione, however, not only registers this complex network of intra-acting agencies, but demands a new mode of expression which effectively relays the mobility of the environment. She defends a new type of language which does not classify and predict possible outcomes of this intra- 
action, but "acknowledges the often unpredictable and unwanted actions of human bodies, nonhuman creatures, ecological systems, chemical agents, and other actors" (Alaimo, "Feminist Science" 190).

Hermione eventually ventures into the woods. She is not escaping the confines of a domestic interior in order to find refuge in a natural environment. To preserve this division between violent patriarchal spaces and "replenished" gynocentric environments, Hermione would have to perform according to the Gart theorem that "exposes the gendered substructure of a science that rests on the hypothesis that objectivity is male, subjectivity female" (Morris, How to Live 163). H.D. dissolves this division, suggesting that the natural landscape "does not remain a benign backdrop for the action" (Debo 145), but the complex composition and transformations of environments is bound up with the action. Nature does not exist outside of cultural spaces and domestic interiors, but intersects with these places. Insects and plants appear in the Gart home and national and familial ancestries are intertwined with shifting environments. Moreover, human agents cannot obtain control over the natural world by organizing it according to mathematical codes and linguistic formulas. The environment acts as both a slate on which a human agent inscribes numerical and linguistic codes, and actively reorganizes and generates new forms of expression. For instance, Hermione compares her backyard to a blackboard on which a single creator transcribes codes. At first, the blackboard is a clearly cultivated "symmetrical square" with "too clear, too perfect" dimensions "across which in a moment lightning, white chalk, will brandish its symbols (give the answers perhaps) from some cruel and dynamic unseen hand" (H.D., HERmione 83). Afterward, Hermione notices how a storm "had smudged out numbers and the blackboard and the grey slate of 
lawn were washed clear, clear for another number, for another set of numbers" (90). As such, she casts the environment as passive matter arranged by a human agent who authoritatively documents and controls the dimensions of the landscape. At the same time, she undermines this scientific method of organization by showing how vulnerable human agents are to environmental changes.

Nature does not connote "pure, untouched otherness" (Alaimo, "Feminist Science" 194) through which the individual achieves transcendence. H.D. does not depict a "healed and restored earth" (Hogue 841) wherein Hermione heals from her illness, but a chaotic space which threatens to annihilate the human agent. She emphasizes the violent material interchange between Hermione's body and the harsh environmental conditions: "snow caught against eyelashes, made a delicate runnel against out-thrust chin and hollowed cheekbone" (222). Moreover, the "snow scratched softly, made the most distant of delicate sound falling" and acts as "an anesthetic" (222). Hermione undergoes a type of remedial procedure as the snow "cleansed" (222) her, but the intra-action which occurs is not restorative. Although the snow-covered fields imply a type of erasure in which all that had existed has been obliterated, H.D. uses "virginal" white fields to magnify the vibrations and reverberations that are produced by the perpetual intra-action of agentive matter. The snow does not completely erase what existed before, but draws attention to H.D.'s notion of the palimpsest. The landscape becomes an endless "scroll" and the movement of Hermione's feet creates a new language. Hermione does not propose that this new form of expression ultimately replaces older forms, but, like material ecocritics, indicates that matter is "a corporeal palimpsest in which stories are inscribed" (Iovino and Oppermann, “Theorizing Material” 451). Hermione once again compares the 
environment to a blackboard, and calls attention to an authorial figure who transcribes. In doing so, she meditates on an instance in summer in which "the Creator had been white lightning brandished against blackness," suggesting that "now the creator was Her's feet, narrow black crayon across the winter whiteness" (H.D., HERmione 223). By distinguishing between the "Creator" and the "creator," she dismisses the notion of a single authorial figure such as the Gart-God figure, and proposes multiple authors which consist of both human and non-human agents.

Whereas the novel begins with Hermione's deviation from normative codes and traditions, she does not return to a normative healthy body. Conversely, Hermione explodes the complex layering of human and non-human spaces, substantiating her theories of the body and the environment. She disproves an anthropocentric understanding of the world preserved in mathematical equations and established scientific rhetoric. She champions instead the relationality between people and things and this interconnection reinforces her understanding of language. Whereas the authoritative figure of the scientist represented through her father and brother perpetuate the notion that things can be assimilated into established linguistic models, Hermione recognizes that her perception and the configuration of the environment exceed established formulaic patterns. She comes to the realization that she "is part of things" (228) and her intra-action with material "things" in the environment inspire an "ineffable remembrance" (226) which invites new forms of expression. This type of remembering calls attention to the Delphic statue in Notes on Thought and Vision in which H.D. explores a material interchange between human bodies and non-human matter which discloses a complex layering of cultural, temporal, and physical environments. The 
process of remembering extends beyond the individualistic act of remembering and suggests that the interrelation of embodied psychical processes, bodies, and physical matter situates the human within a larger environment. The individual is not an isolated entity but in a perpetual state of transformation as one intra-acts with other bodies and agentive matter.

Hermione describes this physical interaction with a material environment as she finds a "foothold" (224) on the ice. The ice does not form a stable platform on which she can stand, but allows her to register a "faint reverberation" beneath the surface; her body recognizes "the frail thing breaking" (225). Hermione experiences a new mode of vision that permits her to perceive the constant motion of the environment rather than simply rely on the eye's ability to obtain accurate representations of an external world. As such, she realizes that "it never does freeze properly. There's always water running" (224). She perceives this perpetual movement as she senses "a moment and an infinitesimal fraction of a moment" that exposes "a quivering, a slightest infinitesimal shivering" (212). The motion invites her to look for variations in patterns, and so she seeks to uncover "violets in December" (225). Volatile environmental forces dismiss established notions of what is "proper" and so invite her to develop a new language which undermines static "wordreactions" that adhere to rigid patterns. She compares the reverberations to "a violin string" (225) which, in turn, compels her to think of Fayne. Her imagined representation of Fayne, however, resonates with her theories on the cinema as the reverberations inspire her to imagine "a white hand" which "took her" (225). H.D. suggests that "Her was held like a star visible in daylight that suddenly by some shift adjustment of phosphorescent values comes quite clear" (225). In her study of film, H.D. pays 
particular attention to electrical energies exhibited by the use of light, and draws attention to the "capacity of electricity to restore exhausted energies" (Marcus 98 ) ${ }^{87}$ In this moment, the physical interchange of material energies revitalizes her and she begins to "see things" (228) as interrelated and in flux.

This holistic view of the world is the "true perspective" that opposes "the just perspective" (233) or "right perspective" (138) preserved by dominant scientific models. Hermione notices that "the great tree in itself was a world" and further proposes that she "saw Jimmie Farrand as part of the whole scheme of things" (227). As such, she declares that "if Jimmie was part of things and Her having accepted things was part of things, then Her was part of Jimmie" (228). She criticizes established customs in America that neglect this intricate intermingling by preserving "stabilization and exact formalization (Uncle Sam pressing things down in test tubes)" (233). She opposes this predominant mode of establishing patterns with Europe. In America, "there was nothing but standardization" and "no nuances" (233). Europe, by contrast, "was a room painted over with bright figures and within it people dancing" (232). H.D. makes this same distinction in her film reviews, demanding that American cinematic conventions employ European cinematic techniques. Whereas the novel begins with Hermione attempting to conform to strict "formalization and exact fitting to one type" (233), the ending reveals the limitations of

\footnotetext{
${ }^{87}$ This notion of energized light displays H.D.'s engagement with film studies that examined vibratory phenomena. The exchange of physical substances and energized matter displays how "to a large extent the workshop of the material universe, and...the phenomena of nature as we see them are fabrics woven in the looms of this unseen universe" (Joseph John Thompson qtd. in Enns and Trower 3). As such, "matter and energy were indistinguishable [...] because they were both vibratory phenomena, and this idea effectively blurred the boundaries between materiality and immateriality by suggesting that the material universe consisted of nothing but vibration of varying frequencies" (4). Moreover, energized matter "informed [...] an understanding of the body as borderless," and reimagined language since "it explained how energy or expression or communication could be transmitted between and beyond bodies across space and time" (5).
} 
such methodologies and turns to alternative modes of seeing, experiencing, and speaking. She no longer perceives herself as an isolated entity that corresponds to a strict categorical definition. The fictional autobiography establishes intricate networks of bodies in relation to material agents. Hermione, who is "part of things," recognizes her relation to a larger geographical plane and to other bodies, Fayne in particular. The vibrations which inspired a new mode of vision also cultivate "a feeling of elation" (233), which is similar to H.D.'s theories of the ecstatic body in Notes on Thought and Vision. By understanding her body as "a part of things," particularly in relation to the body who enhanced this new mode of vision, the fictional autobiography does not conclude with a "return" to a fixed representation of selfhood, but a self that is intricately bound up with a constantly fluctuating material environment. 


\section{Chapter Three}

\section{"Dispersed Are We": Re-imagining Environmental Holism in Woolf's Between the Acts and other essays}

"Behind the cotton wool is hidden a pattern; that we-I mean all human beings-are connected with this; that the whole world is a work of art; that we are parts of the work of art. Hamlet or a

Beethoven quartet is the truth about this vast mass that we call the world. But there is no

Shakespeare, there is no Beethoven; certainly and emphatically there is no God; we are the words; we are the music; we are the thing itself. And I see this when I have a shock." - Woolf, "A

Sketch of the Past"

\section{Introduction}

Unlike Stein and H.D., Woolf's works have been the subject of extensive and varied ecocritical readings within modernist scholarship. Many critics who apply an ecocritical lens to Woolf's texts turn to the famous flower imagery from "A Sketch of the Past," contending that this image of organic unity typifies the author's awareness of an environmental ethics. ${ }^{88}$ Woolf's observation "that the flower itself was part of the earth" (Woolf, “A Sketch" 71) suggests that “the flower wasn't an entirely separate entity but a growing organism whose essence was somehow indistinguishable from the quickening earth in which it was embedded [and] hints at her innate consciousness of interconnected ecological systems" (Sultzbach 75). The image displays an environmental holism in which organisms interconnect with their material surroundings, disclosing an organic unity that also encompasses the human agent's interrelationship with the nonhuman world. Typically, these readings depend upon traditional representations of green ecologies. ${ }^{89}$ The often-quoted epiphanic moment in which Woolf notices the flower's

\footnotetext{
${ }^{88}$ See Kelly Sultzbach's "The Fertile Potential of Virginia Woolf's Environmental Ethic," Justyna Kostkowska's Ecocriticism and Women Writers, and Bonnie Kime Scott's In the Hollow of the Wave: Virginia Woolf and Modernist Uses of Nature.

${ }^{89}$ Green ecologies focus on conventional representations of nature and neglect the "unwanted" and "unpredictable" agents which Alaimo explores through her notion of trans-corporeality. Jeffrey Jerome Cohen investigates ways to "trace the impress and interspaces created by ecologies that cannot be easily accommodated within the bucolic expanses of green readings"
} 
attachment to the earth invites many critics to explore representations of environments as "renewable" (Scott 12) co-operative systems as well as to investigate the author's "global vision" that invokes a peaceful unity among all nations on this "grain of sand we call Earth" (Henry 158). As a result, unstable and shocking environments are overlooked in favour of conventional representations of calm and idyllic landscapes.

These readings, however, examine how Woolf aesthetically reproduces the nonhuman world without considering how these aesthetic reproductions are imbricated in the material environment. Moreover, this notion of unity inspires the idea of a return in which seemingly disjointed entities (human and nonhuman agents) transition from a chaotic to a harmonious relationship. This cordial relationship is what Bunny Guinness proposes is "vital" to Woolf"s creative process. I want to turn to another image from "A Sketch of the Past," one that reinforces the notion of environmental holism but also considers the material emergence of artistic creations. Woolf proposes that "the whole world is a work of art" (Woolf, "A Sketch" 72), reiterating the idea of an intricate interconnected network in which "we are the words; we are the music; we are the thing itself." I argue that this matrix of human agents, art, and the world is integral to Woolf's modernist aesthetic. By turning to Alaimo's notion of trans-corporeality and Barad's notion of intra-action, I provide a different reading of the flower imagery. The recognition that the "flower was itself part of the earth" should not simply endorse ecocritical readings that "celebrate connectivity" (Högberg 148). Although these readings provide key insights to Woolf's texts, rather than focus on the image of the flower (a

(xxii). He claims that "balanced" landscapes conceal "the catastrophic, the disruptive, urban ecologies, the eruptive, heterogeneous microclimates, inhumanely vast or tiny scales of being and time, the mixed spaces where the separation of nature and culture are impossible to maintain" (xxii). 
traditional representation of "green ecologies"), we should instead investigate what Woolf means by the "earth."

The nonhuman world, as I have shown in the previous chapters, is never a given in these authors' texts, but an intra-acting network of creative agents that modify language. Similarly, Woolf proposes that the earth is not "fixed [...] immovably in the center of the imagination" ("Flying" 167). This suggests that the earth is not a static, unchanging entity, and it is not a product of human imagination. Woolf's understanding of the nonhuman world exceeds that of Stein and H.D. who examine historical and geographical nonhuman processes. Woolf's conception of the nonhuman world extends to the atmospheric barriers of the earth. Although her awareness of the planet reinforces a universal perspective of the earth, she emphasizes the chaotic and extensive nonhuman processes that surpass human understanding. She examines the tension between this expansive and unruly earth, and literary and historical trends that attempt to "fix" the earth through what she terms the "campaign" (Woolf, "On Being Ill” 199) of language. Furthermore, she differentiates between the utility of words and the "nature" of words. Linguistic campaigns regulate social actions and this regulatory use of language solidifies conventional literary forms. These campaigns perpetuate a form of realism that ignores a fluctuating world. Woolf instead champions the "nature" of words and advances a dynamic material language that is not subjected to the formulaic patterns of linguistic “campaigns" but open to “infinite possibilities" (Woolf, "Modern Fiction” 110).

Although critics like Bonnie Kime Scott, Justyna Kostkowska, and Holly Henry emphasize the author's conscious attempt to establish an ecological ethics by restoring a harmonious order on a global scale, the notion of environmental processes that promote 
"ideas of balanced and sustainable order" (Scott 12) diminishes what Madelyn Detloff claims is the "experience of openness and transformation" (Detloff 209) fundamental to Woolf's works. Building off of this claim, I propose that Woolf's examination of precarious global environments exposes this "openness and transformation" and further dismantles the "hard shell of habitus (what we might call norms or ideologies) that deadens our perceptions and makes us susceptible to lockstep thinking" (208). In some of Woolf's works, it might seem as though she suggests that the human agent is susceptible to "lockstep thinking." For instance, in her posthumously published essay, "Flying over London," she states, "so inveterately anthropocentric is the mind" (167). This statement suggests that human imagination might be habitually crippled by anthropocentricism. In this case, an ecocritical reading of her work should begin with what Lawrence Buell proposes is "a crisis of the imagination" through which we can "[find] better ways of imaging nature and humanity's relation to it" (Buell, The Environmental 2). For Woolf, this does not mean restoring humanity's relation to a remedial nature, but examining more fully what it means to be "human." By drawing awareness to the human through her reconceptualization of the body, Woolf breaks the "illusion" ("On Being Ill" 196) of an ordered world restricted by "lockstep thinking." She emphatically exposes the "crisis" of the present moment. She advances the notion of the trans-corporeal body through her examination of illness and her famous reconsideration of an "ordinary" day in which the body experiences a tumultuous "shower of innumerable atoms" ("Modern Fiction" 106). The body's relation to nonhuman processes can never be reduced to or concretized within artistic "campaigns." ${ }^{90}$ In fact, it is always imbricated in the creation and recreation of languages.

\footnotetext{
${ }^{90}$ Similarly, Jesse Oak Taylor examines how Woolf presents "numerous instances in which
} 
Woolf, I argue, does not champion traditional green spaces, but precarious processes that exhibit an "ever unfinished world" (Cohen xxii). Language stems from and is perpetually transformed by the trans-corporeal body as it intra-acts with a chaotic nonhuman world. Like Stein and H.D., Woolf turns to the visual arts to examine this trans-corporeal intra-action. Whereas Stein turns to the theatre to demonstrate how the unfamiliarity of the performance space triggers nervousness, Woolf widens this sense of nervousness by suggesting that the environment inspires a sense of "shock." Moreover, just as H.D. turns to the cinema to explore a language that exceeds formulas, Woolf turns to the cinema to expose the absolute "chaos" ("The Cinema" 268) of the evolution of art. Woolf expands on Stein's and H.D.'s turn to the performing arts by revealing how the whole world is a performance, and therefore "a work of art." In this chapter, I trace Woolf's interest in "the drama of the body," which she claims has been absent from literary trends, both thematically and representationally. The "drama of the body" opens up to a historical performance in Woolf's final novel, Between the Acts. Here, Miss La Trobe's historical play showcases "an ongoing performance of the world" (Barad, "Posthumanist" 139) that upsets "useful" historical narratives. She thus extends the

\footnotetext{
nature appears unsettled, its laws suspended or overturned without surrendering [her] claims to an overtly constructed fictional reality" (12). However, he turns to the Anthropocene in order to discuss how "atmosphere is central to the way fiction works (in the sense that a machine works) to produce imagined worlds that are nonetheless inhabited and shared by diverse publics distributed across space and time. In so doing, the novel opens a space for genuinely new ways of thinking, knowing, and being to enter the world, including such unthinkable occurrences as spontaneous human combustion or a planet deleteriously modified by the acts of a single species" (12). He argues that crystallized effects in the geological layering of the earth cannot be accumulated and recorded in narratives of causation, but demand new ways of imagining material intra-actions on wider spatial and temporal dimensions. He also notes that "it is through the stories we tell that habitat - the material circumstances of our lives-becomes a world in the full sense of the term" (12). Although my project does not focus on atmosphere or the Anthropocene, I trace the intimate connection between "the stories we tell" and the material performance of the world.
} 
"concern" for the body that H.D. articulates in Notes on Thought and Vision to a concern for the future as she contemplates the human agent's creative ability to persevere.

By reading Woolf's notion of a modernist aesthetic in dialogue with Alaimo's trans-corporeal materiality that extends to the chaotic material processes of the nonhuman world, I will show how Woolf devises new aesthetizations of history. In a series of essays, she exposes the limitations of historical ontological narratives that preserve strict regimes of conventionality. These historical narratives rely on the elevated position of a human agent who can visibly locate a point of origin that orients the historical development of individuals, nations, and nonhuman environments. As Alaimo notes, "origins often presume or shore up ontological boundaries, delimiting material agencies and possibilities of becoming" (Alaimo, "States of Suspension" 478-479). Woolf, by contrast, reveals how the ambitious task of the author is to resist enclosed forms that preserve complacent and reductive understandings of environments. In her final novel Between the Acts, she reconfigures the historical drama and demonstrates how an experimental historical play opposes dominant origin stories such as the Outline of History and the Encyclopaedia. Woolf displays imaginative efforts that upset standardized spatial and temporal dimensions. These imaginative endeavours ultimately end with a return to the body. This return does not position the body as a stable entity, but exposes a trans-corporeal body and therefore opens up a "mobile space" from which to reconsider the "infinite possibilities" (Woolf, "Modern Fiction" 110) of aesthetically reproducing the nonhuman world. 


\section{From the "co-operative imagination" to a "common" experience}

In "On Being Ill," Woolf examines the dissonance between literary convention and the physical body, demonstrating how illness and the ill body are overlooked in literary traditions. She begins the essay by exposing "the prime themes of literature," which range from "love, battle, and jealousy" and yet neglect "illness" (193). Her critique of traditional literary themes emphasizes a chasm between representation and material realities. The inclusion of illness in literature sheds light on the entanglement of bodies, nonhuman reality, and language, which she claims is needed to surpass the limitations of predominant literary traditions. To do so, Woolf proposes illness engenders a greater awareness of "how the world has changed its shape" ("On Being Ill” 195). Woolf does not simply expose the natural world through her "uses of nature" (Scott 220) but frustrates commonplace conceptions of a green nature. This essay, as I will demonstrate, reveals a shift in emphasis from a focus on nature as a thematic concern to a focus on the material dimension of language that is entangled with bodily and nonhuman material processes. Specifically, Woolf's preoccupation with illness demonstrates how the body and nonhuman matter are intimately entangled. This interrelationship between the body and environments is not one of mastery or healing, but one of a new material language. This new language works to disable historical master narratives and generate holistic new ways of thinking.

It is not surprising that an author known for mental health issues composes an essay "on being ill." What is remarkable about the essay is its emphasis on illness and its liberating effect on the body and consciousness. Woolf in no way romanticizes illness by privileging it as a more enticing alternative to traditional representations of bodies in 
literature. She recognizes the disorienting effects of illness and how it incapacitates the body. My intention is not to read this essay as Woolf's glorification of illness since she does not invoke illness as a superior state of being. The author's well-documented traumatic experiences recognize the debilitating effects of illness. Moreover, her famous hand-written suicide note admits to the insufferable effects of "this terrible disease" (Woolf qtd. in Girard 41). In "On Being Ill," however, Woolf stresses that "there is no record" (194) of illness in literature. More specifically, "there is no record" of the body. By "considering how common illness is" (Woolf, "On Being Ill” 193), Woolf extensively revises literary tradition by bringing the body into literature. She does not only pen an appeal for more literary representations of bodies and illnesses in order to pioneer a "record" of bodies, but examines how material processes occasion new ways of recording. According to Woolf, the individual "must go through the whole unending process of changes, heat and cold, comfort and discomfort, hunger and satisfaction, health and illness" (193). Despite the prevalence of illnesses and the radical alterations effected by "a slight attack of influenza" or "a little rise of temperature" (193), representations of the ill body are excluded from literature. Woolf then reconsiders how the body is integral to literary production, proposing a new literary aesthetic grounded in "a new hierarchy of the passions" (195). Not only does she advance a new form of literature that stems from the body's physicality, she also further stresses the human agent must tap into "a reason rooted in the bowels of the earth" (194).

The overall playful tone of the essay exposes the absurdity of romantic ideals of the body. By demonstrating how illness is a "common" (193) occurrence, Woolf revises commonplace conceptions of the human as divided between disembodied consciousness 
and the corporeality of the body. She dismantles traditional celebrations of human conquest and grandiose expressions of love, advocating that illness should take "its place" with "the prime themes of literature" (193). This dualism between the mind and the body elevates the human being and perpetuates romantic notions of the human seeking communion with god in nature. Woolf suggests "the very opposite is true. All day, all night the body intervenes" (193). The human body is not separate from nature, but receptive to the irregular processes of the environment. She deflates the romantic notion of the natural world, indicating that the discrepancy between the human and nonhuman spaces suggests that the human can manipulate the natural landscape. This romantic notion of the environment severs the relationship between the mind and body, extoling the mind and dismissing the physical body. Literary tradition, argues Woolf, perpetuates this dualism and "[maintains] that its concern is with the mind" (193). Moreover, she notes that "people write always about the doings of the mind; the thoughts that come to it; its noble plans; how it has civilised the universe" (194). The body is depicted simply as a mass that the mind "[kicks]... like a leather football, across leagues of snow and desert in the pursuit of conquest or discovery" (194). Woolf uses images of invasion to illustrate the militant endeavours that delimit the environment and forcibly acquire territorial claims. She, however, rejects these pursuits of human conquest that reduce the nonhuman world to systems of classification and moves beyond fanciful romantic tropes.

By examining fictional reconstructions of "Nature" (198), Woolf argues that the individual does not exercise mastery over natural forces, but is subordinated to and threatened by the material processes of the environment. The mind cannot order the 
natural world by harnessing the chaotic forces of the environment. In addition, the natural world is not a projection of the mind, and consequently the mind cannot translate the chaotic natural realm into a knowable entity. Instead, Woolf proposes that consciousness is "an embodied condition" and so "to account for illness, literature would need to take such forms of embodiment seriously" (Jesse Taylor 191). Her study of the interplay between human and nonhuman domains displays an environmental consciousness as her depictions of nature "provide a promising move into an order that takes up things of the earth, disperses the self into them, and enters a collective of creatures, in the process of deconstructing patriarchal ideals of dominion" (Scott 198). The material composition of the body is intermeshed with nonhuman matter as it affects and is affected by seasonal conditions: the body "turns to wax in the warmth of June, hardens to tallow in the murk of February" (Woolf, “On Being Ill” 193). This image suggests that there is regularity to bodies and environments, but as Woolf continues to describe the ill body, she exposes a trans-corporeal materiality that deviates from normative and predictable physical conditions in order to stress material emergences that are "unwelcome and unexpected" (Alaimo, Bodily Natures 146).

Woolf's theorization of the ill body compares to Alaimo's notion of "environmental illness" which "extends the body outward into a trans-corporeal space" (115). Alaimo proposes that "such a body (or mind) cannot be distinguished from that which surrounds it, since various substances may provoke pain, illness, disability, confusion, and fatigue" (115). Although Alaimo considers the detrimental effects of various toxic pollutants on the body and frames illness as "chemical sensitivity," she suggests that "those who are chemically reactive experience their selves as coextensive 
with the material world" (116). That is, environmental illness reveals "an ever-emergent world of risky knowledges, mangled practices, and disturbing, potentially deviant material agencies" (116). Alaimo argues that this deviation is "both ideological and material, as both a form of critique and an ideal" and "[considers] deviation as a form of material/ discursive agency of thoroughly embodied beings who are always inseparable from the environment" (116). Similarly, Woolf explores how ill bodies are "coextensive with the material world," and so human agents experience "their bodies as scientific instruments" (116) recording nonhuman environments that conflict with established models of knowledge. She suggests that illness brings awareness to the body's interaction with larger environments since illness discloses "undiscovered countries," revealing "wastes and deserts of the soul" and "precipices and lawns sprinkled with bright flowers" (Woolf, "On Being Ill” 193). Woolf, however, does not simply call for more representations of ill bodies and illnesses to fill a noticeable absence in literary trends, but considers how established linguistic models cannot adequately represent material intraactions between bodies and environments.

Woolf explains how the intra-acting processes of bodies and environments undermine typical literary representations of heroic bodies. Heroic bodies are typically synonymous with male bodies. Conventional "English" literature "can express the thoughts of Hamlet and the tragedy of Lear" but "has no words for the shiver and the headache" (194). English literature thus provides a template of emotions that aggrandize emotional experiences, and consequently neglects "common" experiences: "the merest schoolgirl, when she falls in love, has Shakespeare or Keats to speak her mind for her" (194). The schoolgirl simply has available to her a predominantly masculine language 
that ignores the emotions and experiences of any body that deviates from the norm of male perfection and rationale. The permeable and unpredictable ill body, by contrast, contests the stability and restraint of literary reproductions of normative bodies. Whereas literary traditions attempt to distill matter and being into strict classifications, Woolf demonstrates how the body is intricately entangled in "unruly materiality" and examines how ill bodies or deviant bodies "depart from norms, standards, and models of prediction" (Alaimo, Bodily Natures 116). As traditional literary representations of bodies preserve insufficient models of being that privilege normative and heroic bodies, Woolf shows how bodies intra-act with the "endless activity" (Woolf, "On Being Ill" 197) of material nonhuman processes. The ill body thus signals "movement across different sites" (Alaimo, "Feminist Science" 190) and this intra-action generates a new language to combat "the poverty of the language" (Woolf, "On Being Ill" 194) that enables literature to secure static repetitive representations of everyday life which act as universal models of being.

By dismissing an anthropocentric notion of an ordered world in which the chaotic nonhuman forces have been cultivated by human exploits, and the vastness of the nonhuman realm is reduced to clearly demarcated boundaries, Woolf uncovers the human. The human is not simply a product of cultural norms, participating in "the army of the upright" (197). She criticises established ideological frameworks that impose stability, and by extension critiques the notion of an established linguistic order that perpetuates social norms that homogenize a collective unit. Instead, Woolf recognizes that illness compels the individual to acknowledge their vulnerability in relation to the ongoing material processes that stimulate the sensorial body, but remain indifferent to the 
preservation of the human species. "The army of the upright" privileges the civilizing force of the mind and regiments the body, conditioning "the co-operative imagination of mankind [which draws] some firm outline" (198). Furthermore, this "co-operative imagination" is preserved in "the long campaigns that prose exacts" (199). Manufacturing the notion that "the law is on the side of the normal" (201), the army maintains "the genial pretense $[\ldots]$ to communicate, to civilize, to share, to cultivate the desert [and] educate the native" (196). The "army of the upright" thus opposes the "recumbent" (198) body of "the invalid" (195). These contrasting bodies parody the progressive developmental processes of the human species. That is, as human agents become more rational beings, they adopt an upright position. Woolf, however, rejects the notion of a linear trajectory of progression which will inevitably culminate in an evolutionary goal. Instead, she indicates that the developmental processes are random. The erratic laws of the universe constantly alter the interrelationship between the human agent and the environment. Woolf therefore resists the notion of a return to a primordial natural environment.

Illness initiates a deviation from normative representations of bodies by upsetting repetitive quotidian regimes. Whereas the regimented routine of the army of the upright veils the "extraordinary spectacle" (197) of the nonhuman world, illness enables the body to perceive the "incessant" processes of the nonhuman world. Unlike the army of the upright that marches in unison, signifying the endurance and superiority of the human species, nonhuman material processes are erratic. The body of "the invalid" experiences a "rashness" (200) that distinguishes it from the habituated motion of the army of the upright and enhances their experience of these irregular processes. In illness, "the sky is 
discovered to be something so different from [city buildings] that really it is a little shocking" (197). Woolf thus proposes that nature or the nonhuman world "shocks" the body rather than restores the body to its normative state. She stresses nature's "indifference," suggesting that it is not a clearly delimited space in which the human agent can find "religion" or "learn virtue from plants" (198). Regardless, "human beings have made companions" of flowers since they "symbolize their passions, decorate their festivals, and lie $[\ldots]$ upon the pillows of the dead" (198), but they are not limited to these symbolic uses. Only in illness can the human agent recognize how the "immeasurable resources" of the nonhuman world "are used for some purpose which has nothing to do with human pleasure or human profit" (197). The body's physical condition exposes how the army of the upright is simply "make-believe" (196) and so discredits the illusion of the "tyrannical I" that imposes strict models of selfhood. Bodies are unstable and unpredictable and so too are identities. Those who have "played our parts here as William or Alice" will not "remain William or Alice for ever" (199).

Woolf also undermines the heroism characteristic of healthy normative bodies by exposing a mysticism in illness. This mysticism refers to new ways of perceiving the external world and triggers new ways of thinking. This mystical experience, however, is not a unique transcendental escape from the world, but a "common" experience since illness is a casual occurrence. Although Woolf suggests that illness generates changes that are "tremendous" and "spiritual" (193), "tremendous" and "spiritual" do not imply a transcendental move away from the material world. Like H.D., Woolf uses the term "spiritual" to refer to material processes. Woolf, however, differs from H.D. by suggesting that spiritual experiences are "common" everyday occurrences; the human 
agent does not need to actively care for the growth of the spirit. She begins the essay by describing the effects on the body as a dentist extracts a tooth from a patient. This commonplace occurrence initiates an imaginative flight that "discloses" (193) vast expanses of land, and illness amplifies one's sensorial apparatus to the extent that one imagines the possibility of self-annihilation. Woolf writes, "how we go down into the pit of death and feel the waters of annihilation close above our heads" (193). Rather than be completely obliterated, the patient is drawn back to her body and notices how the external world takes on different dimensions. We "come to the surface in the dentist's arm chair and confuse his 'Rinse the mouth—rinse the mouth' with the greeting of the Deity stooping from the floor of Heaven to welcome us" (193). By merging a familiar encounter with the dentist and a grandiose spiritual transformation, Woolf mimics the heroic exploits of the mind in romantic tropes. However, she also highlights a transcorporeal rather than a transcendental experience. This mystical quotidian occurrence is a common trope in Woolf's texts, one that reoccurs in the essay as she contemplates the possibility of the extinction of the human species.

Woolf imagines a futurity in which nature "in the end will conquer; the heat will leave the world; stiff with frost we shall cease to drag our feet about the fields; ice will lie thick upon factory and engine; the sun will go out" (198). She conjectures that "when the whole earth is sheeted and slippery some undulation, some irregularity of surface will mark the boundary of an ancient garden, and there thrusting its head up undaunted in the starlight, the rose will flower, the crocus will burn" (198). In her depiction of an imagined garden, Woolf does not present a harmonious natural landscape in which the rose and the crocus achieve an ideal permanent state. Instead, she stresses the continuous motion of 
the nonhuman world as she meditates on the transformation of the rose and the crocus. The rose blossoms and the burning of the crocus intimates the dynamic energies of the nonhuman world that are destructive. Although Woolf isolates the rose and the crocus within this ancient garden, she does not suggest that the rose and the crocus exist in a stable, clearly delimited environment. Woolf then calls attention to a possible future in which the nonhuman environment extinguishes the human species, but does not extinguish the vibrancy of nonhuman processes that establish a sense of continuity. Furthermore, she calls attention to this imagined future in order to dismiss it. This imagined future enhances an awareness of the human as Woolf shifts her focus from the dynamism of the rose and crocus to the vibrancy of the human species. She suggests that "with the hook of life still in us still, we must wriggle" (198).

By recognizing the perpetual motion of the body, she examines the human agent's relation to complex ecosystems wherein urban spaces blend with natural landscapes. She advances a notion of the environment that compares to Alaimo's conceptualization of "the world as an emergent place of entangled material agencies" (Alaimo, Bodily Natures 115). Like Alaimo, Woolf's understanding of the environment "is fleshy, emergent, and ultimately inseparable from the stuff of the human" (140). Woolf proposes that nonhuman processes continue "without our knowing it" (Woolf, "On Being Ill" 197). Illness makes us aware of this motion and the nonhuman world will always, in some capacity, exceed the human agent's knowledge of it. This reconsideration of ecosystems occasions different formations of selfhood. The interplay between the actions of the human body that are regulated by social obligations, and the "endless activity" (197) of the nonhuman environment creates new forms of expression. The "incessant making up 
of shapes and casting them down, this buffeting of clouds together, and drawing vast trains of ships and waggons from North to South" and the "incessant ringing up and down of curtains of light and shade, this interminable experiment with gold shafts and blue shadows with veiling the sun and unveiling it" (197) demonstrate how the continuous routinized actions of the quotidian experience are interwoven with the ongoing processes of the landscape. The human body resists conforming to rigid cultural frameworks that attempt to regiment the body in order to foster "the illusion of a world so shaped that it echoes every groan, of human beings so tied together by common needs and fears that a twitch at one wrist jerks another" (196). Woolf thus undercuts a harmonious union to display a more precarious interrelationship. The "incessant" movement underlines how "Woolf's writing consistently values humans not as a superior species, but instead as a single component jostling in a matrix of larger natural forces" (Sultzbach 73).

According to Woolf, words are fundamental to the complex composition of ecosystems. She revises a traditional cultivated language which "has all grown one way" (Woolf, “On Being Ill” 194), and which "at once runs dry” since it widens the gap between conventional literary language and bodily experiences. To remedy this, Woolf champions "a new language" that is "more primitive, more sensual, more obscene" (194195 ) and one that is not restricted to "those dried symbols of sorrow" (195). Language is not simply a cultural construct that shapes matter, but originates from and is affected by the processes of the sensorial body intra-acting with the environment. Kelly Sultzbach relates Woolf's notion of language to a "living, organic process that is not entirely owned or controlled by the conscious will of her own mind" (Sultzbach 75). I expand on this 
view of language as an organic alternative to cultural linguistic constructs by proposing that Woolf's notion of language is a discursive process. Her understanding of illness "rejects representationalism" and reveals Barad's notion of "a material/discursive form of performativity" (Alaimo, Bodily Natures 146). Woolf, like Barad, "insists that discourse and materiality are not external to each other, but instead 'the material and the discursive are mutually implicated in the dynamics of intra-activity"' (146).

This dynamic material language intra-acts with nonhuman material agents. As such, "matter is not a passive resource for human manipulation and consumption, nor a deterministic force of biological reductionism, nor a library of codes, objects, and things to be collected and codified" (Alaimo, Bodily Natures 142). Words do not exist outside of the body, and the human body does not enter into an abstracted linguistic order that regulates the body in order to comply with social norms. For Woolf, language is unpredictable and exceeds the limitations of social decorum and courtesy. She suggests that the "rashness" of the ill body amplifies the precariousness of words as they "give out their scent, and ripple like leaves, and chequer us with light and shadow" (Woolf, "On Being Ill" 200). This new language is possible through illness since "illness is the great confessional" (196). That is, there is "a childish outspokenness in illness; things are said, truths blurted out, which the cautious respectability of health conceals" (196). Woolf stresses the materiality of language altered by the processes of the trans-corporeal body as she proposes that in illness, the individual is better able to "coin words" (195). The body is no longer attuned to social obligations, but one can then "[take] his pain in one hand, and a lump of pure sound in the other $[\ldots]$ so to crush together that a brand new word in the end drops out" (195). Illness does not simply "innervate" language as Stein 
suggests, or exceed the finality of established discourses as H.D. proposes. Woolf expands on their conceptions of language by explicitly stating how material intra-acting processes produce new words.

Woolf later expands her study of a material language in a 1937 essay, "Craftsmanship." This essay, composed for a BBC series titled, Words Fail Me, elaborates on some of the claims made in "On Being Ill." For example, whereas Woolf proposes that literary custom is synonymous with the preservation of social convention in "On Being Ill," she suggests that social habits substantiate systematic systems that associate one meaning with each word in "Craftsmanship." This system of language discloses the "utility" of words. She begins by explaining how the title of the essay is insufficient. According to Woolf, to discuss "the craftsmanship of the writer" and their "craft of words" (Woolf, "Craftsmanship" 127) is to suppose that words are singular in their meaning. She would rather title the essay "A Ramble round Words" (127) in order to expose the "nature" of words. She refers to the double meaning of the word "craft," highlighting the "failure" of words rather than the author's craftsmanship, which privileges precision and exactness of meaning. The term means "making useful objects out of solid matter" (126). It also means "cajolery, cunning, deceit" (126). This double meaning highlights a tension between usefulness and deception. Woolf then moves away from a focus on the "utility" of words to emphasize their changeability. According to Woolf, the "nature" of words is "not to express one simple statement but a thousand possibilities" (127). Woolf thus proposes that "it is the nature of words to mean many things" (128). Words are dynamic, material, and "many-sided" "things" (130). 
Like Stein, Woolf claims that "the language is old" (130) and yet "it is easy to invent new words - they spring to the lips whenever we see a new sight or feel a new sensation" (130). Whereas Stein suggests that language is an "intellectual recreation" that instigates the rearrangement of words as the body experiences sensations, Woolf examines how to "combine the old words in the new orders" (130). To do so, the human agent cannot "pin them down to one meaning, their useful meaning" (132). That is, the writer should not strive to convey "the meaning which makes us catch the train" or "the meaning which makes us pass the examination" (132). The writer cannot rely on the utility of words to organize regimented actions, but they must recognize the open-ended movement of language. Woolf then suggests that the writer move away from the systematic uses of language outlined in dictionaries, and turn to "a language of signs" (127). The language of signs recognizes the changeability and movement of words. Woolf argues that "one of the mysterious properties of words" is the "power of suggestion" (129). Words must not be restricted within a given social recognition of what is "useful," but understood in relation to other words and in relation to larger historical and environmental changes. Words that "come fresh from a human brain" (129) upset socially constructed schematic patterns.

Words are neither individually "tapped out by a typewriter" (129) nor are they systematically confined to the "alphabetical order" (130) of dictionaries. Woolf argues that "words do not live in dictionaries; they live in the mind" (130). In "On Being Ill," she compares the unconscious space of the mind to "a virgin forest, tangled pathless" (Woolf, "On Being Ill" 196). The mind then opens up to the vast expanses of the nonhuman world that exceed the cultivation efforts of the "army of the upright," 
resembling "a snow field where even the print of birds' feet is unknown" (196). She continues with this image in "Craftsmanship." Woolf contends that "words are the wildest, freest, most irresponsible, most unteachable of all things" (Woolf, "Craftsmanship" 130) and so language, like the nonhuman world and the human body, is subject to continuous alterations. The mind is not an abstracted entity separate from the body, but varies according to how "human beings live" which is both "variously and strangely" (131). Specifically, Woolf highlights the limitations of the English language that consists of a repository of words that "are full of echoes, of memories, of associations" (129). Words are not a limited resource that can be contained and catalogued since they emerge from "that deep, dark and only fitfully illuminated cavern in which they live - the mind" (131). Like "On Being Ill," Woolf suggests that the mind is not exclusively separated from the body since "she frequently draws upon evolutionary concepts for their imaginative power" (Alt 107). The biological processes of the human body extend to the performance of words as they "[mate] together" (Woolf, “Craftsmanship" 131): "royal words mate with commoners" and "English words marry French words" (131). To attempt to confine words to a singular meaning within a systematic linguistic order fosters the "illusion" (Woolf, "On Being” 196) of an ordered environment. Instead, the materiality of words diminishes systematic frameworks by collapsing the boundaries between various linguistic orders.

Woolf thus displays how material intra-acting processes undermine habit and produce a new language that ultimately resists the "tyrannical" (Woolf, "On Being Ill" 196) impulse to systematically record accurate representations of being. This is integral to her notion of art and modern fiction. Whereas she begins "Craftsmanship" by 
dismissing the utility of words, suggesting that they cannot be made "out of solid matter," she supports the notion of a vibrant matter in "Modern Fiction." Moreover, her essay "The Cinema" expands on her notion of a "language of signs" and the "suggestive power" of words. Furthermore, in "Flying Over London," Woolf explains more fully the material composition of environments as she depicts an imaginative flight over London. She describes the many and diverse perspectives initiated by the body's intra-action with nonhuman material processes. In doing so, she reveals how this trans-corporeal body resists "habit" and ultimately resists the notion of a stable earth.

\section{"This little hard granular knob": Aimless Wandering and the "Proper Stuff of Fiction"}

As mentioned above, Woolf's environmental awareness is not grounded in a nature conservationist movement to preserve green ecologies, but in a "crisis of the imagination" (Buell, The Environmental 2). In a series of essays detailing her modernist aesthetic, Woolf examines how the human agent's conception of the world always eludes artistic reconstructions. In "Modern Fiction" and "The Cinema," she champions a new language and new modes of recording that do not systematically archive new discoveries. Like ecocritics, Woolf seeks a new language that discloses how "the image of the whole earth opens upon 'abyssal dimensions to which we can never suitably bear witness"” (Clark, Ecocriticism 16). She opposes literary conventions that sanction a "solid" representation of the world. Instead, she supports an experimental literary form that advances a "globular" perspective without sanctioning a dominant worldview. To illustrate, in "A Sketch of the Past," Woolf contemplates "the number of different ways in which memoirs can be written" (64) and argues "that one's life is not confined to one's 
body and what one says and does" (73). She does not support a transcendental move away from the body, but accentuates how "one is living all the time in relation to certain background rods and conceptions" (Woolf, "A Sketch" 73). Since the body extends "outward into a trans-corporeal space" (Alaimo, Bodily Natures 115), the "rods and conceptions" are also undergoing change. She admits that literary artistic reproductions extend to the physical surroundings and compares the act of writing to making "a picture" that is "globular" (Woolf, "A Sketch" 66). Her intention is to compose a "semitransparent" representation without delineating "a clear outline" (66). The artist then cannot reproduce nature's eternal design since the artist's body and aesthetic reproductions are imbricated in an ever-emergent world.

Woolf's preoccupation with aesthetic reproductions of the nonhuman world stems from a discrepancy in "Modern Fiction." In arguably her most famous essay, she addresses an inadequate analogy between literature and "the process [...] of making motor cars" (Woolf, "Modern Fiction" 103). This analogy implies the opposition between literature's reliance on traditional methods of recording life, and the century's advancements with innovative technologies that produce new discoveries. For instance, Woolf reimagines a new materialism that differs from the Edwardian's preoccupation with the "great clod of clay" that is rigidly reproduced within "well-constructed" and "solid" novels (104). Woolf's conceptualization of language derives from the shift in new modern sciences, which make it possible to create "globular," "semi-transparent" artistic reproductions that appeal to both "sound and sight" (Woolf, "A Sketch" 66). Twentiethcentury advancements in technology uncovered new conceptions of materiality that enhanced our understanding of human bodies and the nonhuman world. As Christina Alt 
notes, early twentieth-century sciences transitioned from dominant taxonomic methodologies that resulted in the instrumentalisation of the planet, to new modes of observation and documentation that recognized the fluctuating processes of the earth. Woolf's comparison between literature and a picture that is "globular," "semitransparent," and without "a clear outline" exposes the author's awareness of how "nature itself is accorded less importance than the human tabulation of it" (Alt 76). ${ }^{91}$ Woolf makes the reader aware of the body or instrument recording nonhuman materiality. Like Alaimo, she reminds the reader that "aesthetic captures" are always part of the "unruly materiality" of the environment and therefore subject to change.

In "Modern Fiction," Woolf explains the main tenets of her artistic projects without arriving at a precise definition of modern fiction. Instead, she reconceptualizes the definitive notions of materialism and realism constructed and preserved by the Edwardians, and acknowledges the symbiotic relationship between a fluctuating world and an individual's physical and psychological interpretations of their environment. The structure of the essay thus demystifies absolute definitions of materialism and realism and ends with an appeal to modernist authors and readers to participate in an unending creational process. Language then becomes a process which Alison Lacivita proposes is integral to ecocritical approaches to modernism in order to expose "some sense of the environment as a process rather than as a constant or a given" (Buell qtd. in Lacivita 68). Woolf begins by deflating the notion of a linear teleological order in which a chronological historical narrative is innately bound up with progress and "improvement upon the old" (Woolf, "Modern Fiction" 103). She differentiates between "the historian

\footnotetext{
${ }^{91}$ Alt also suggests that "she is wary of lapsing into such a reductive view of nature herself and conscious of the self-importance and competitiveness underlying the pretense of objective scientific reportage" (76).
} 
of literature" (103) who organizes and catalogues historical movements from a vantage point, and the artist. From "a sufficiently lofty pinnacle" (103), the historian observes and delineates "the whole course of the track" (103). Woolf suggests that there is a tendency to view modern fiction as an advancement on the "simple tools and primitive materials" (103) of past writers. In order to move away from common notions of innovation and progress, she shifts from a focus on an evolutionary order unfolding in linear time through "the course of the centuries" to spatial dimensions in which the modern author is immersed "on the flat, in the crowd, half blind with dust" (103). The development of history does not adhere to unidirectional and predetermined movements of "tracks." The modern artist, according to Woolf, digresses from this measured design and instead wanders aimlessly. That is, "all that we can be said to do is to keep moving, now a little in this direction, now in that, but with a circular tendency" (103).

This aimless wandering denies the modern artist the ability to make any authoritative claims about existence derived from an objective mode of observation. The artist does not rely on the eye to accurately document historical movements, but acknowledges the tumultuous assault on all the senses that is at play throughout a human agent's everyday experiences. Woolf dismisses notions of authenticity typically associated with ocular functions, suggesting that from the modern artist's perspective "down in the plain little is visible" (103). The artist then is not an objective observer separated from the environment on which they gaze, but completely immersed "in the plain." Woolf denies the hierarchical order of the senses on which dominant scientific methodologies rely, and instead purports her notion of psychology which relies on the sensual apparatus of the body. "The historian of literature" consciously "decide[s]... if we 
are now beginning or ending or standing in the middle of a great period of prose fiction" (103). The historian thus imposes a coherent and linear structure on an environment, arranging temporal and physical realities. Woolf positions the historian as a human agent who consciously customizes constructed notions of reality. The essay, by contrast, moves away from the limitations of realism as a traditional literary genre to complicate anthropocentric conceptions of historical processes.

Considering the complexities of psychological and sensual capacities, Woolf champions a new process of writing that relies on the body's porous intra-action with material environments. Fiction emerges from the intricate cognitive activities of "an ordinary mind on an ordinary day" as "the mind receives a myriad impressions - trivial, fantastic, evanescent, or engraved with the sharpness of steel" (106). Artists who adhere to the conditions of the "customary way" (106) conform to a formulaic pattern since they are severely conditioned by "some powerful and unscrupulous tyrant" (106). They impose a strict framework and join repetitive customary ways with notions of eternity. The Edwardians or the "materialists" who compose fiction according to regimented patterns "spend immense skill and immense industry making the trivial and the transitory appear the true and enduring" (105). Woolf critiques earlier materialists for their conscious efforts to create a "likeness to life" (106), a semblance that simply showcases how fiction imitates and accurately reproduces the reality of a particular social-cultural climate. Characters "are dressed down to the last button of their coats in the fashion of the hour" (106) and the material "fabric" of books reflect this "solidity of [...] fabric" (104). An Edwardian "can make a book so well constructed and solid in its craftsmanship that it is difficult of the most exacting of critics to see through what chink or crevice 
decay can creep in" (104). The solid fabric of texts attempts to perpetuate enduring notions of existence, but simply records transient fashions of "the hour."

Woolf attempts to shed light on "the proper stuff of fiction," but the aim of the artist is not to accurately reproduce "the proper stuff of fiction" by categorizing it within a rigid structure. Instead, Woolf opposes generic conventional forms that depend on formulaic patterns such as "plot," “comedy," and "tragedy" (106). The proper stuff of fiction cannot be allocated to and contained within customary stylistic structures, but is actively engaged in the creative artistic process. The interrelationship between "an incessant shower of innumerable atoms" (106) and the elemental composition of the body and mind compose the "fabric" of fiction. Life, thus, consists of the intra-action between bodily materiality and the "disconnected and incoherent" (107) atomic patterns as they fall. Woolf refers to this intra-action as "this unknown and uncircumscribed spirit, whatever aberration or complexity it may display" (106). The "uncircumscribed spirit" expands on her notion of spirit in "On Being Ill." Woolf refers to the nonlinear atomic interactions that make up "a luminous halo, a semi-transparent envelope surrounding us from the beginning of consciousness to the end" (106). For Woolf, the spirit opposes attempts to organize life in a pattern that resembles "a series of gig lamps symmetrically arranged" (106), and so she initiates a movement away from linear deterministic patterns visible to the human eye. Like H.D., Woolf suggests that spirit refers to a new mode of vision produced by the interdependent relation between the sensorial body and the material world and occasions cognitive "flickerings" that "[flash]...messages through the brain" (107). She does not simply call for a turn inward in order to escape the external 
material world, but illuminates the porous interaction between "the dark places of psychology" (108) and material nonhuman realities.

Psychical activity animated by the external material world demonstrates how the complexities of human bodies differ significantly from the bounded human models outlined in earlier materialists' works. Woolf focuses on the inconclusiveness and profound depths of the human agent, characteristics that she recognizes in Russian literature. She admires the Russian writer who demonstrates "sympathy for the sufferings of others, [and] love towards them" (109). Woolf thus appeals to the modern artist to acknowledge the intricacies of psychological, emotional, and bodily compositions of others rather than show compassion to those bodies that are similar and familiar. Moreover, she commends "the inconclusive-ness of the Russian mind" (109). The "honestly examined life" (109) cannot be accurately documented and definitively categorized, but "presents question after question which must be left to sound on and on after the story is over in hopeless interrogation that fills us with a deep, and [...] resentful, despair" (109). The essay ends with an inconclusive definition of "modern fiction." Woolf appeals to the modern artist to actively engage in a process. She incites the artist to "imagine the art of fiction come alive and standing in our midst" who "would undoubtedly bid us break her and bully her, as well as honour and love her" (110). This call to action that involves both violence and reverence provides a "view of the infinite possibilities of the art and remind us that there is no limit to the horizon" (110). Thus, “'the proper stuff of fiction' does not exist; everything is the proper stuff of fiction, every feeling, every thought; every quality of brain and spirit is drawn upon; no perception comes amiss" (110). 
Woolf's critique of literary conventions is not exclusive to literature, but extends to artistic reproductions that appeal to the human agent's visionary field. Her investigation of literature and technology later extends to the rapid movement of cinematic images that influence her artistic attempts to compose a "globular" picture. Emerging "visualization technologies" such as cinematic cameras and telescopes questioned notions of objectivity and "engaged in a major modernist rethinking of how visualization technologies could have a shaping effect on the development of fiction" (Henry 104). Holly Henry explores how telescopic lenses exposed the immeasurable boundaries of the universe, introducing new visionary experience that Woolf seeks to reproduce in her literary projects. Telescopes, in particular, permit "a looking back in cosmological time" (54) as well as "stimulated co-existence of the past and present" (55). Henry sheds light on Woolf's “awareness of, and response to, a public concern regarding a modern human re-scaling due in part to a new generation of large astronomical telescopes that had demonstrated the vast distances of intergalactic space" (54). This "rescaling" influences Woolf's displacement of the literary historian from the "lofty pinnacle" in "Modern Fiction." This "re-scaling" is also reiterated in "On Being Ill" as Woolf describes how illness widens the viewer's field of vision. The visionary expansion compares to cinematic movements as she details how illness exposes "undiscovered countries," "wastes and deserts of the soul," and "ancient and obdurate oaks" (193). However, this expanding visionary field is not the result of ocular functions, but of the body's physical imbrication in material realities. The body's multi-modal capacities stimulate a new form of vision that Woolf explores more fully in "The Cinema." This essay, composed around the same time as "On Being Ill," demonstrates how this 
relatively new medium introduces new ways of seeing, experiencing, and aesthetically reproducing material environments.

In "The Cinema," Woolf proposes that film produces a "secret language" distinct from established linguistic systems. ${ }^{92}$ Like the "new language" (Woolf, "On Being Ill" 194) of the "invalid" in "On Being Ill," the "secret language" of film (Woolf, "The Cinema" 271) derives from the vibrancy of the material surroundings. Moreover, Woolf compares the "endless activity" of the nonhuman world to a "gigantic cinema" (Woolf, "On Being Ill" 197). Integral to her study of this new art form is a critique of linear evolutionary processes. Her study generates ontological and epistemological inquiries that subvert a sequential evolutionary process that progresses towards the pinnacle of civilization. She begins the essay by tracing the linear progression of linguistic and artistic pursuits that have been sophisticated and subsequently exhausted by artists and audiences of the twentieth century. She writes: "people say that the savage no longer exists in us, that we are at the fag end of civilization, that everything has been said" (Woolf, "The Cinema" 268). This assumption implies that "everything" has been firmly tabulated and recorded within established linguistic models; however, as Woolf notes, "these philosophers have presumably forgotten the movies" (268). Typically, the cinema is associated with the transforming landscapes of modernity, which are commonly conceived as a fundamental cause for the contamination, and subsequent deterioration of

\footnotetext{
${ }^{92}$ Like H.D., Woolf explores the material language of the cinema. Rather than focus on the technology of the medium such as the light and cinema houses, Woolf relates the art form to "accretions of alien matter" ("The Cinema" 268). Common conceptions of this relatively new medium compared cinematic images to the unveiled contents of the unconscious. For Woolf, the cinema exposes more than the projections of the individual mind. The term "alien" does not refer to the unfamiliar contents of the self, but to the erratic nonhuman world. I read the term "alien" in relation to Holly Henry's study of telescopic lenses that disclose the universe.
} 
"natural" environments. ${ }^{93}$ However, Woolf's exploration of the mechanization of cinematic technologies subverts standardized notions of linear spatial and temporal dimensions. For Woolf, the cinema is not a modern technology that contaminates the body and subsequently interrupts humanity's progress. Film is a new medium that explodes conceptions of linear time and progress by radically altering perceptions of the world.

Woolf discredits evolutionary processes that trace the gradual progression of the human species by revealing how there is "no great distance" between a twentieth-century audience and "those bright-eyed naked men who knocked two bars of iron together and heard in that clangour a foretaste of the music of Mozart" (268). The advancements of the human species are not reflected in the advancements in new artistic mediums. Although cinematic technologies are a late nineteenth/ early-twentieth century invention, film is not considered a more sophisticated artistic medium better suited for the reproduction of reality than older artistic mediums. Woolf relates the act of watching cinema to "peering over the edge of a cauldron in which fragments of all shapes and savours seem to simmer; now and again some form heaves itself up and seems to haul itself out of chaos" (268). As a result, cinematic technologies and the "secret language of film" do not conform to established formulaic conventions. Instead, "it is as if the savage tribe, instead of finding two bars of iron to play with, had found scattering the seashore fiddles, flutes, saxophones, trumpets, grand pianos $[\ldots]$ and began with incredible energy, but without knowing a note of music, to hammer and thump upon them all at the same time" (272).

\footnotetext{
${ }^{93}$ Characters in Between the Acts vocalize this sentiment, noting how material alterations to the land result from an increase in population and new infrastructure, such as "the building of a car factory and of an aerodrome" (Woolf, Between the Acts 47). These buildings eliminate "the green mounds," an extermination that is propelled by the increasing presence of "the motorbike, the motor bus, and the movies" (47).
} 
Woolf demonstrates how cinematic technologies do not authentically reproduce the external world by reducing external reality to clearly delineated frames. She proposes that "the cinema has within its grasp innumerable symbols for emotions that have so far failed to find expression" (270). The medium produces shadows and effects that are "accidental" and "unintentional" (270) and yet add to the narrative mode of film. This ongoing and accidental creational process affects the human agent's conception of the world. Moreover, the secret language of film both exposes and is affected by chaotic matter that "will flourish whether we behold it or not" (269) and therefore differs from the "vocabulary" of the English which "is miserably insufficient" (269).

The "accidental" and "unintentional" cinematic language reveals the intra-action between human and nonhuman materiality. As Alaimo suggests, this type of intra-action "necessitates rich, complex modes of analysis that travel through the entangled territories of material and discursive, natural and cultural, biological and textual" (Alaimo, "Feminist Science" 190). Woolf demonstrates how the brain and the eye work in conjunction to decipher the content on the screen and considers how "so much of our thinking and feeling is connected with seeing" (Woolf, "The Cinema" 271). Thought is an extension of the physiological structure of the body affected by visual and emotional receptors. Film exposes embodied psychical processes, depicting the "speed and slowness" of thought, its "dartlike directness and vaporous circumlocution" (271), allowing "thought to be conveyed by shape more effectively than by words" (270). Woolf arrives at this realization after watching the film, The Cabinet of Dr. Caligari, during which "a shadow shaped like a tadpole" appeared, "swelled," "quivered," bulged," and "sank back into nonentity" (270). For Woolf, "the monstrous quivering tadpole seemed to 
be fear itself, and not the statement 'I am afraid"' (270). The material emergence of this "shadow" reveals new forms of expression that do not conform to established English "words" (270). She states, "anger is not merely rant and rhetoric, red faces and clenched fists. It is perhaps a black line wriggling upon a white sheet" (270). This image then does not convey the usefulness of an emotion, but the spontaneous emergence of an emotion. The material dimension of the "secret language" of cinema exposes "wild and lovely grotesque thoughts" that combine and affect each other as they "pour" from the characters' physical bodies. The narrative capacity of film is not the result of imitation, but "collision" (272) as it generates a language that "we feel and see" (271). ${ }^{94}$ Film neither reproduces everyday reality nor does it imitate the fictional worlds from "all the famous novels of the world, with their well-known characters and their famous scenes" (269).

The visual field available through cinematic technologies contests "the ordinary eye" of the spectator, or more specifically, "the English unaesthetic eye" (268). ${ }^{95}$ Whereas "the ordinary eye" is "a simple mechanism" (268), the cinema exposes chaotic, energetic material processes that exceed traditional models of knowledge. Images produced by film technologies differ from "the simple photograph of real life" (268) since moving images prevent the eye from absorbing a static image. Instead "the eye is in difficulties. The eye wants help. The eye says to the brain, 'something is happening

\footnotetext{
94 "Collision" implies a more violent "combination" than what Stein suggests occurs in the theatre. Woolf does not simply track the shift in focus from the ordinary to the unfamiliar, but proposes that the ordinary is chaotic.

${ }_{95}$ Woolf"s critique of the "unaesthetic eye" emphasizes the limitations of consuming accurate representations of the world. This relates to Holly Henry's study of telescopic lenses. Henry suggests that these new lenses rivaled "taxonomical photographs [that] capture a moment" (196), reducing human and nonhuman agents to the contours of a strict framing device. These mediums "illustrated the fallacy of any single correct perspective" (Henry 103).
} 
which I do not in the least understand" (268) ${ }^{96}$ Film then does not systematically reproduce reality but discloses how "the chaos of the streets" and human emotion "[mingle] together and [affect] each other" (272). Physical realities on the screen do not transcend one's everyday lived reality, but combine with the chaos in the streets. The cinema's "immense dexterity and enormous technical proficiency" discloses "some momentary assembly of colour, sound, [and] movement" (272). Woolf thus suggests that art should not simply relay this experience but proposes that the combination of physical environments and bodily experiences is implemented in the production of narratives. In this way, we can read "The Cinema" in dialogue with Woolf"s earlier essay, "Modern Fiction," in which she advocates that fiction should convey "every feeling, every thought" (164) as we record the "myriad impressions" and incoherent patterns of atoms that fall upon the mind on an ordinary day.

The porosity of the body sketched in the above essays demands a reconceptualization of time and space. By drawing attention to the immediate and intricate entanglement of human and nonhuman materiality, Woolf does not simply propose that a human agent intra-acts with the predominant ideological and social structures emblematic of a specific historical moment preserved within exacting national borders. Instead, she calls for "extending our imaginative vision beyond the human [which] means not only extending it backward into the depths of prehistory but also forward, past the end of the world as we know it" (Jesse Taylor 203). Woolf's aesthetic projects deflate strict historical records that focus primarily on what the human agent conceives as plausible. Adam Barrows examines Woolf's interest in the psychological,

\footnotetext{
${ }^{96}$ Whereas Stein explores the disconnection between the action on stage and the spectator's response to the action, Woolf looks more closely at how that disconnection is at play within the body.
} 
biological, and physical conceptions of time that upset standardized temporal measurements, arguing that modernist "stylistic innovations map out cartographic projections of time and temporal experience that are endlessly productive in their elaboration of the rhythmic linkages between micro and macro systems, or between the biorhythms of a small organism and the rhythms of the global or planetary" (Barrows 6061). His study of intermixing human and nonhuman rhythms reimagines time "as a mediator between micro- and macro- spaces, between local and global senses of spatiality" (59-60); however, his explanation of space skirts the intricate network of material agencies that constitute dynamic spatial relationships.

Alaimo's notion of trans-corporeality expands on these claims. Rather than focus on the interplay between micro and macro "rhythms," she looks at material intra-acting agencies. She also explores "ways of conceptualizing how the more-than-human world acts, how scientific practices and technologies 'capture' those actions" and reveals how complex networks of entanglement expose an "ever-emergent material world" (Alaimo, "Feminist Science" 190). Woolf, I argue, suggests that this material intra-action recreates the world. She often depicts the human agent's intra-action with the material performance of the world, which is temporally and spatially expansive and complex. For instance, in her essay "Flying Over London,” Woolf demonstrates how new modern inventions both expose environmental and atmospheric phenomena and are intricately bound up in those material forces. She details the visionary experience of observing the world from an aircraft only to conclude the essay by revealing that she imagined the flight. Influenced by film, she demonstrates how the human agent has the capacity to achieve the same expansive visionary experience that she describes in her essay, "The Cinema." The 
aircraft provides an elevated vantage point that contests the pinnacle on which "the historian of literature" stands in "Modern Fiction." Rather than objectively trace the outlines of history, Woolf imagines a "globular" and "semi-transparent" world without any clearly delimited signposts that archive incremental historical changes. The imaginary flight generates a resentment for "symmetrical" (171) spatial arrangements of the world through which an objective observer can "[assemble] things that lie on the surface" (172).

Woolf imagines a telescopic view of the world as human agents are reduced to microscopic phenomena. She does not describe the flight as an escape from human civilization, but demonstrates how microscopic and macroscopic material processes are interconnected. Woolf begins the essay by comparing the machinery of the aircraft to insects, conflating two seemingly antithetical realms: technology and nature. By suggesting that "aeroplanes were collected in the shed like a flock of grasshoppers" and further relating aspects of the aircraft to the grasshopper's "same enormous thighs, the same little boat-shaped body resting between its thighs, and if touched with a blade of grass, he too springs high into the air" (Woolf, "Flying" 167), she dissolves the barrier between human and nonhuman materiality. That is, she implies that the seemingly artificial aircraft is in fact a material agent within a larger ecosystemic network. Her imaginative flight into the limitless atmosphere is not unique since "a thousand pens have described the sensation of leaving earth" (167). The focus of the essay, however, is not to convey the bodily sensations associated with the flight, but to conjure up multiple perspectives of the world that destabilize habituated methods of constructing worldviews. Habit, she argues, "has fixed the earth immovably in the centre of the imagination like a 
hard ball" (167). The aim of the essay is to generate imaginative space that destabilizes routine. ${ }^{97}$ Woolf thus extends the human agent's limited perceptions, but also remains cognizant of human limits. That is, she is constantly aware of her body as she imagines a flight away from human civilization and the subsequent return.

By drawing attention to the limits of human perception and imagination, Woolf combats the human's capacity to provide and secure authoritative claims. The human agent is not an omniscient being who can achieve mastery over an environment. As Woolf ascends to new heights, her imaginative wandering corroborates her affiliation with the material composition of her body and mind. This is not unique to her own being, but characteristic of the human species. She notes that "as one rises up into the sky, as the sky pours down over one, this little hard granular knob, with its carvings and frettings, dissolved, crumbles, loses its domes, its pinnacles, its firesides, its habits, one becomes conscious of being a little mammal" (167). Advanced modern technologies such as an aircraft typically signify progress and transcendence. Darwinian evolutionary theories trace linear trajectories as changes in species' developments anticipate advancements. Woolf, however, notes that the human agent is a mammal within an expansive ecosystem. Despite this recognition, she remarks, "so inveterately anthropocentric is the mind" (167). Although she imagines what it is like to be suspended above the earth and observes immeasurable expanses, there is a tendency to assume one's own security as one's mind assures the preservation of the human body. Woolf suggests, "instinctively the aeroplane becomes a boat and we are sailing towards a harbour and there we shall be received by hands that lift themselves from swaying garments; welcoming, accepting" (167). We

\footnotetext{
${ }^{97}$ Similarly, in Between the Acts, Miss La Trobe attempts to produce a new historical performance that resists conventional aesthetic formulas by presenting the simultaneous depiction of past, present, and future, while interweaving multiple perspectives.
} 
imagine a "home," a harbour with a spiritual human figure "welcoming" and "accepting." This anthropocentric worldview dominates as one cannot fully conceptualize the possible extinction of the self. As she contemplates how a cloud might "extinguish" her, "the incurable vanity of the human mind" (169) compels her to think of the self as she is reminded "of a contact with one's own mind" (169).

This alternating movement of withdrawing from human civilization and returning to it does not generate a linear trajectory consisting of an upward and subsequent downward movement. Woolf notices a change, indicating how the initial habituated earth fixed "immovably in the centre of the imagination" transforms as she transitions from physical environments to vapours in the atmosphere. Her conception of the body changes drastically. She reveals the heterogeneous makeup of the body, realizing how various materials such as "vertebra, ribs, and entrails," and "vapour and air" (168) constitute physical and psychological compositions. As she maneuvers from the regimented routine of industrial society to the vast expanses of the sky wherein there "are winds tapering, vanishing, and the untimed manoeuvre of clouds, and nothing permanent, but vanishing and melting" (167), she recognizes the tenuousness of regimented structures fabricated to orient the human species. As she gazes below from new heights, she reflects on how "the fields that with us are meted into yards and grow punctually wheat and barley are here made and remade perpetually with flourishes of rain and flights of hail and spaces tranquil as the deep sea" (167). Her imagined flight undermines commonplace conceptions of the world in which the standardized routines of England characterize universal regimes. 
Furthermore, the past and present exist simultaneously. Woolf imagines a "temporal platform" on which the components of "civilization" such as "a spire, a factory chimney, [and] a gasometer" (168) emerge and "the wild rhinoceros was chased out of sight for ever" (168). This flight of the imagination, however, does not allow her to extract distinct objects from their specific historical moments as she accesses the past. As she imagines the airplane moving to higher altitudes, the human becomes insignificant, unrecognizable, and animalistic. The human agent becomes a "spot $[\ldots]$ something squat and minute" and similar to "a horse" (168). This perspective deflates the notion of a hierarchical order that grants the human species superiority over the nonhuman world. By contrast, Woolf draws attention to how the human species is interwoven into the physical and vaporous fabric of the environment. By observing the human as an insignificant, unfamiliar speck, she imagines a possible future wherein the human species is extinct.

Like "On Being Ill," the thought of a possible extinction reveals the limits of her imaginative capacities and, by extension, the constraints of her ability to aesthetically contain the borders of this imaginative world. She suggests that "as colour runs to the end of a paint brush, so the blue sky had run into one blob beneath it" (170). The vapourous state which she achieves returns to "the ribs and entrails of the sprout-eating mammal" (170) as "the spectral universe" (170) dissolves. "The fairy earth" (170) reappears and she descends to the earth which resembles "a mere slice or knife blade of colour floating" (170). The descent imitates the movement of a cinematic lens as the earth transforms from a "dark blot which soon began to be pricked with spires and blown into bubbles and domes" (170). The movement marks the transition from the boundless outskirts of the atmosphere, to familiar geographical coordinates of the earth, to "the whole civilization," 
to the fields of London and eventually focuses on human agents. The movement from vast expanses to human populated environments is disorienting. Human bodies and horses emerge as "dot[s]" and "all speed and size were so reduced that the speed of the horse seemed very, very slow, and its size minute" (170). Masses of human agents resemble "millions of insects moving" (170), transforming into "men, men of business, in the heart of the white city buildings" (170-171). The obscure, illimitable fabric of the earth now takes on fixed coordinates, as she becomes "resentful of all the flags and surfaces and of the innumerable windows symmetrical as avenues, symmetrical as forest groves, and wished for some opening" (171). However, she does not resume her place within a symmetrically assembled environment as she returns to civilization. Instead, she notes that "everything had changed its values seen from the air" (171-172). As such, this imaginative flight produces multiple perspectives, and so transforms the fixity of the earth as she imagines the human species within larger temporal and expansive spatial dimensions.

Thus, the transition from a "fixed" earth to "globular" and "semi-transparent" perspectives is integral to Woolf's understanding of a modernist aesthetic. She continues to grapple with questions of material environments, physical bodies, and human imagination in her final novel, Between the Acts. In this work, Miss La Trobe aesthetically reproduces accounts of human and nonhuman realities as the characteristics of her "vanishing play" (Woolf, Between the Acts 127) attempt to capture "the fairy earth." This novel is heavily influenced by scenes from her final diary entries as she investigates how war technologies record and imagine a global "Crisis" (Woolf, Diaries 230). Specifically, Woolf examines how the war magnifies the elusive quality of the 
world as it continuously changes shape. She compares the war to a "desperate illness" (285), and like her essay, "On Being Ill," she exposes how this "desperate illness" sheds light on the porosity of all matter which ultimately modifies language.

\section{"The vanishing play": Unpredictable Environments in Woolf's Diaries and Between the Acts}

By tracing the development of Woolf's notion of a material language that is bound up with questions of the body and environments, I have demonstrated the material dimension of her understanding of modern fiction. These concerns are at play in her final work, Between the Acts. In this novel, Woolf examines the ambitious task of an artist to aesthetically reproduce the history of England, and by extension the history of the world, in the form of a drama. By demonstrating the vast temporal and spatial dimensions on which this historical retelling unfolds, Woolf depicts an imaginative flight that ends with a return to bodies. That is, she begins the novel by introducing the reader to an anonymous "they" who are "talking" within the domestic interior of Pointz Hall. By the end of the novel, Woolf returns to the same setting as the initial characters reunite to reflect on Miss La Trobe's historical drama without successfully imposing a strict interpretative framework. Woolf ends the novel with a simple statement: "Then the curtain rose. They spoke" (Woolf, Between the Acts 130). This return to the same spatial setting begs the question: do the characters speak differently and how does language change throughout the novel? To answer this question, it is important to first put the work in dialogue with the author's final diary entries ranging from 1936 to 1941 . The novel elaborates on many of the quotidian scenes from these diary entries that record Woolf's growing awareness of the terrific and irreversible effects of human activity on the 
environment. Like her essays, her diary exposes the noticeable shift from taxonomic representations of nonhuman phenomena to complex and immeasurable intra-actions of agentive matter that are integral to aesthetic reproductions.

Her diaries intimate how the Second World War reconfigured global geographies and occasioned new aesthetic recreations of world histories. War technologies contributed exponentially to the detrimental effects of human activity on the environment. Woolf expresses her concern for the scarcity of resources, censorship regulations, and possible extinction that are at play during her daily experience with the war. On September 23, 1939, she writes, "Poland has been gobbled up. Russia and Germany divide it" (Woolf, Diary 237). She further notes that "[c]ivilisation has shrunk. The Amenities are wilting. Theres no petrol today" (237). Her diaries highlight her relation to global warfare as she sheds light on political tensions and depleting resources. In 1940, the severity of her condition is augmented as she reflects on the battle of Dunkirk. ${ }^{98}$ She admits that "questions of suicide [are] severely debated" as "the great battle which decides [her and Leonard's] life or death goes on" (292). Furthermore, in 1941, despite "a lull in the war," she contemplates how "the greatest struggle is about to come" (355). As she notices "a few snowdrops in the garden," she writes, "I was thinking: we live without a future. Thats whats queer, with our noses pressed to a closed door" (355). This image contrasts the typical representation of the Monk's house garden.

\footnotetext{
${ }^{98}$ As the war continues, Woolf examines the dissonance between horrific war images and an unresponsive environment. Although she details the atrocities of the battle of Dunkirk and how "many men shot themselves as the planes swooped" (Diary 297), she also remarks on "the fine weather" (294). Moreover, she refers to the "blossoms on the grass" (294) after noting the death of a soldier. Blossoms typically refer to rebirth, but the stark contrast between the blossom and the corpse suggests the inadequacy of traditional seasonal imagery which connote harmony and restoration. The juxtaposition between these images exemplifies how "those dried symbols of sorrow" (Woolf, "On Being Ill" 195) that Woolf dismisses in "On Being Ill" inadequately record daily experiences.
} 
This bleak image reveals how the garden does not enclose a space unaffected by the war as she anticipates the possible extinction of the human species. ${ }^{99}$ The "closed door" marks the fragile separation between the individual and the state of the world. Throughout her diaries, this barrier dissolves as Woolf explores the porous interaction between the body and larger environments that are unstable and erratic.

Woolf dismantles the borders of the house as the war penetrates everyday routines. Air raids are consistent and random, and her close proximity to various battles permit her to sense the vibrations. The vibratory matter thus disrupts common conceptions of space, compelling her to imagine wider spatial interconnections. The house becomes a "shell" as the war infiltrates the home, joining everyone in a common crisis. "The endless interruptions" (234) of BBC broadcasts consistently punctuate everyday actions by bringing awareness to the war crisis. These broadcasts relay "Hitler's speech—Churchill's—a ship sunk—no survivors—a raft capsized—men rowing for 10 or 12 or 30 hours" (263). This relatively new medium combines isolated home interiors with larger spatial dimensions, informing many listeners of a universal plight and generating a global consciousness. Listeners are imaginatively transported to places outside of the home. Moreover, common everyday items typically associated with calm domestic interiors are modified to compose war technologies that obliterate the home along with its notions of security and preservation. For example, as Woolf stands in her kitchen, she contemplates how saucepans will be recycled to "make aeroplanes" (302).

\footnotetext{
${ }^{99}$ Similarly, Woolf contemplates the future of the human species in "On Being Ill." However, whereas here the view of the garden invites her to reflect on a desolate future, the essay positions an ancient garden as a possible future. In both instances, the garden is not associated with peacefulness and tranquility but with uncertainty and instability.
} 
The war thus alters common conceptions of the home, as everyday items function as resources for the war effort, and air raids pose a constant threat.

Ultimately, Woolf suggests that the war makes it impossible to "be at home, central" (299). She demonstrates how she is affected by other people and by the war. In June 1941, she writes about how difficult it is "to make oneself a centre after all the rings a visitor stirs in one" (299). ${ }^{100}$ Her interactions with people and with objects generate "rough rapid twinkling ripples" (299) that increase her awareness of her surroundings. This "after-visit feeling" (299) then extends to her reflections on the war, which she claims "has taken away the outer wall of security" (299). The war thus makes Woolf conscious of the dissolution of barriers and she remarks how people have a similar decentering effect. Consultations with others produce "ripples" as she states, "I'm loosely anchored" (299). From her own quotidian experiences, she maintains that there are no organizational principles that foreground or "centre" the individual. According to Woolf, "we pour to the edge of a precipice" (299) rather than move to a teleological end in an ordered fashion.

The dissolution of the home is integral to ecological readings of Woolf. Typically, the meaning of ecology is understood in relation to the Greek term oikos, ${ }^{101}$ which is often translated as "'house' or 'dwelling"” (Jesse Taylor 5). By dismantling the home, Woolf suggests that "we share our oikos —our home-with nonhuman beings at microscopic as well as molecular levels" (Iovino and Oppermann, “After Green” 329). In this way, she moves away from anthropocentric accounts of ecology wherein the oikos is not so much a bounded home as an ever-unfinished world" (Cohen xxii). As she begins to

\footnotetext{
${ }^{100}$ Specifically, she refers to Elizabeth Bowen.

${ }^{101}$ Also see, Jeffrey Jerome Cohen's Prismatic Ecology: "oikos: a fundamental unit, a household, a collectivizing space, a gathering of people and things" (xvii).
} 
destabilize the individual, she proposes that a "new conception of the writer [is] needed" (Woolf, Diary 267). The writer, according to Woolf, should explore the complexity of the individual without "[cutting] the outline sharper" (267). The author, then, should not aim to accurately reconstruct a firm "outline" of the individual. Her diaries expose a disjointed, complex, and changing sense of selfhood. She tends to convey her restlessness and anxiety for the war, as demonstrated in September 1939. She focuses on "a loose jointed mind - misty clouded, suffusive" and further suggests that "nothing has outline" (238). The body is never able to recover a unified sense of self, but is always fluid as it interacts with people and its surroundings. ${ }^{102}$

The war thus generates new conceptions of space and time as mediums such as the radio and the newspaper reveal how world geographies are created and recreated daily. This perpetual global reorientation compels Woolf to reconceptualize the role of the artist in order to reimagine the human agent's relation to indeterminate ecosystemic networks. As the war progresses, however, she stresses the need for new aestheticizations of reality to contest the stagnant repetitive accounts of the world disseminated by BBC broadcasts. Whereas Woolf considers how human and nonhuman activity unfold within "the platform of time" (281) ${ }^{103}$ as opposed to the progressive advancements of ordered

\footnotetext{
102 The interplay between expansive and individual atmospheres in her diary punctuate the novel she is composing at the time. The characters in Between the Acts have "orbits" (Woolf, Between the Acts 72) that relate to complex formations of selfhood. Furthermore, Woolf compares physical compositions of bodies to the dispersion and convergence of "mist" (18). The connection she establishes between nonhuman material environments and the human body is consistent throughout her essays and her novels.

${ }^{103}$ Woolf refers to her own "memoirs" as unfolding within "the platform of time" (Diary 281). Specifically, she writes about her changing perception of her father both as "a child" and as "a woman of 58 understanding" (281). Time does not develop in progressive increments. Instead, she suggests that both perceptions occur simultaneously, intermingling the past and the present. This notion of time is characteristic of Woolf's texts and appears in Between the Acts as she attempts to move away from chronological accounts of history which are bound up with ideas of progress and civilization.
} 
units of time, the radio and the newspaper use repetitive stories to expand the present moment. Like H.D., she is concerned about strict regulations that secure a form of realism that diverges from the war experiences. These broadcasts ensure the use of repetitive terms and phrases to craft stories centred on "hero-making" (292). She refers to the BBC reports as "the myth making stage of the war" (292). The BBC functions as "the eyes of the whole world" (252), constructing a narrative of the war. Woolf criticizes the types of speeches about "valour, \& history" that employ the same phrases "where one knows the end of a sentence" (288). Despite efforts to limit a greater awareness of the war, these mediums utilize language to produce a static image of the world in order to impose a sense of stability that will quell the world's violent reorganization. These broadcasts then demonstrate the tension between the utility of words and the "nature" of words from "Craftsmanship." Woolf acknowledges how the radio and the newspaper in particular create a greater awareness of a global crisis in which all nations are integrated, suggesting that no nation is exempt from the "Crisis" (230). However, she dismisses the notion of transparency with these mediums, suggesting that the newspaper and the radio are implicit in the creation of historical narratives.

Woolf's diaries expose the limitations of the BBC's formulaic accounts of the war that inform a fixed record of history. Jesse Oak Taylor, however, reveals how Woolf champions a "nonlinear history," which is not to say history out of order but a philosophy of history informed by nonlinear dynamics" (Jesse Taylor 195). He achieves this through his understanding of the Anthropocene. This dynamic "scale effect" revises linear historical narratives, and, as Taylor argues, permits us to imagine possible futures. He claims that the Anthropocene marks a moment in geological history in which human 
beings become "climatological agents" (11). ${ }^{104}$ This "means radically expanding our conception of the human, and acknowledging that the collectives into which individuals are incorporated are ecosystems rather than purely social entities such as nations, classes, or cultures" (11). For Taylor, the Anthropocene is an "epistemological concern" since it demands a radical reconsideration of standard representations of bodies and ecosystems and the methods by which we record these entities. He suggests that "not only do we have to expand our thinking across far larger realms of time and space than human history generally requires but that expansion entails attending to different dimensions of scale created in part by the dynamics of the atmosphere itself" (195).

The concerns outlined in her diaries are at play in Between the Acts as Woolf depicts an artist who exposes variable historical accounts occasioned by new imaginative scales of time and space. In the novel, members of a community come together to watch a performance of a historical drama directed by Miss La Trobe. By experimenting with the form of the historical drama, Woolf depicts a nonhuman landscape in which the human drama unfolds, detailing extensive foliage, diverse animal life, and vast expanses of fields

${ }^{104}$ Although her daily meteorological reports seem commonplace and insignificant, Woolf makes poignant statements on the frequency of unusual weather patterns. Violent weather phenomena become unbearable and hostile, ranging from the "bitter cold" (Woolf, Diaries 267) to a "record heat wave" (315) to "wild tempest(s)" wherein "rain [lashes] \& [streaks] the windows" (275). Woolf is aware of the changes in weather as she attributes the more violent weather patterns to "the effect of the war on the weather" (275). She is unable to distinguish "a great thunderstorm" from "the guns on the channel ports" (288). This fusion calls attention to the Time Passes section in To the Lighthouse. This section is typically understood as Woolf's conscious efforts to invert a hierarchical order of human and natural environments by relocating humans to a parenthetical aside. For example, Christina Alt suggests that this is among "two frequently cited examples" from Woolf"s oeuvre that show "her alertness to the more-than-human world" (8). In this section, "Woolf decentres the human through her description of the slow action of nature upon the Ramsey house" (8-9). This scene compares to "the village pageant at the centre of Between the Acts" which "highlights the constant interaction and exchange between human beings and the natural world" (9). However, this stylistic effect does not simply show how human action is miniscule in relation to larger temporal and spatial scales, but also demonstrates how human action is interwoven within larger environmental phenomena to the extent that human activity is indiscernible from nonhuman phenomena. 
that provide a "natural stage" (Woolf, Between the Acts 97) on which to perform. Several critics, including Renée Dickinson and Bonnie Kime Scott, describe this novel as an ecocritical text, investigating how Woolf's depiction of a palimpsestic landscape results in the continual reframing of historical narratives. Although both critics provide key insights to environmental concerns animating Woolf's works, they advance the notion of harmonious union between human agents and nonhuman spaces. Dickinson examines a mutual relationship between the land and human history. The land acts as a physical "wax tablet" on which human agents inscribe their histories to produce a complex "layering" (16) of natural and cultural histories. Similarly, Scott examines Woolf's representations of "various ecological ideas of holistic order" (12) that "[foster] richly varied, contextual, and relational thinking, holding in high regard all living beings" (2). She contends that Woolf advances "ideas of balanced and sustainable order" (12), perpetuating an environmental ethics that preserves "natural" surroundings and the human species.

Taylor's understanding of the Anthropocene, by contrast, upsets environmental studies that focus on a physical "natural" landscape since it introduces "a new epoch of geological time" (Jesse Taylor 188). He reveals how "modernity refigures our relationship to deep time, making any moment at once immediate and radically dispersed on scales that exceed human memory" (189). He considers how "the challenge of locating the Anthropocene's emergence" is "a problem for history not only because it forces us to extend the bounds of historical inquiry beyond the human but also because of the way in which it refigures the very definition of an event or agent" (193). The atmospheric emergence is a material environmental phenomenon that "[envelopes] both 
'human' and 'natural' history, rendering them indistinct" (196). Similarly, Woolf reveals how technological advancements alter one's understanding of the world, highlighting the individual's inability to fully comprehend a vibrant environment that exceeds clearly demarcated boundaries. "The motor bike, the motor bus, and the movies" (Woolf, Between the Acts 47) expose the rapidity at which world geographies are transforming. Moreover, the warplanes that fly overhead and the persistent hum of farming equipment gesture to great expanses that exceed the individual's limited perception. These technologies arouse characters to reflect on the vastness and fluidity of the landscape. Characters look up at the sky and contemplate how "this little coloured ball of earth" (16) exists within a greater schema of the universe.

Woolf immediately upsets conventional notions of linear time and draws attention to variable interpretations of history. The first lines of the novel establish clearly divisible spatial and temporal coordinates, situating the human agents within a domestic interior on "a summer's night" (5) as they converse in "the big room with the windows open to the garden" (5). Woolf then shifts the focus from this intimate singular scene to a telescopic view of time and space. The characters discuss a "cesspool" (5), which dismisses the notion of a pristine natural space uncontaminated by human agents, and the discussion of the cesspool initiates a discussion about the environment. That is Mr. Oliver suggests that if one were positioned in "an aeroplane" then one "could still see, plainly marked, the scars made by the Britons; by the Romans; by the Elizabethan manor house; and by the plough, when they ploughed the hill to grow wheat in the Napoleonic wars" (5). Traces of human interaction with the environment are visible, and temporal and spatial dimensions converge without delineating any quantifiable units that can be symmetrically 
aligned within a sequential historical order. Although modern technologies make this new visionary experience possible, Mr. Oliver does not inform the other characters on the workings of aerodynamics that generate this type of visionary experience, but invites his listeners to imagine new dimensions of space and time. Mr. Oliver is an "old man," "retired," and fixed "in the arm-chair" (5). He conjures up a momentary flight of the mind that imagines a spatial platform on which the residue of human activity is interwoven with the environment. Thus, Mr. Oliver's meditation on the landscape entices his listeners to imagine an extensive record of history that expands beyond dominant historical narratives.

Mr. Oliver's imaginative flight exemplifies Woolf's ability to create "rich fictive worlds" that are "vantage points from which to defamiliarize the present" (Jesse Taylor 15). She begins the novel by introducing human agents participating in quotidian discourses that extend to reflections on history. These individual ponderings on environments and history are inherent in Miss La Trobe's play. Specifically, Mr. Oliver's reimagining of history is similar to the visionary experience Miss La Trobe aims to achieve through her play. As such, these aesthetic renditions of expansive historical representations of space and time display how narrative "[mediates] between the vast and the microscopic, the slow and the fast, the planetary and the local, the continuing, repetitive rhythms of the planetary and the fugitive temporal rhythms of random experiences" and thereby "[intervenes] powerfully in the ways in which we formulate conceptual strategies of relating temporally to space and place" (Barrows 11). Individual imaginative historical records coupled with Miss La Trobe's aestheticization of history complicates linear historical narratives that rely on the progressive evolution of isolated 
sequential events. To achieve this, Woolf examines human embodied experiences that open up to expansive temporal and spatial dimensions in which individual, national, and planetary forces intra-act.

Woolf does not describe the environment as an intricate assemblage of individual components that can be dismantled and properly organized. Rather, she proposes that the dissolution of barriers between houses and nonhuman surroundings does not simply reveal how "human history is implicated in natural history" (Buell, The Environmental 7), but demonstrates how human artifacts can never be fully extracted from nonhuman environments and itemized within distinct narrative structures. For example, chimney smoke "curl[s] up to the nests of the rocks" (Woolf, Between the Acts 7) and dissolves in the air, demonstrating the entanglement of material agents. The image of the smoke compares to Woolf's description of human bodies as "mist" (18) which disperses through the air. The dissolution of physical substances does not adhere to formulaic patterns accessible to human perception. Taylor argues that Woolf's focus on the changeability of atmospheric conditions calls attention to the Anthropocene "in which the human species becomes legible in the geological record" (Jesse Taylor 4). However, as mentioned above, Taylor argues that this geological record does not clearly delineate "singular acts at singular moments," uncovering events "whose consequences can be traced in terms of linear cause and effect" (194). Similarly, Woolf's interest in dissolving substances relates to "the quintessentially distributed, adjacent quality of the atmosphere, an encompassing substance at once everywhere and nowhere" and so "is shared by the very notion of the archive, the body of adjacent traces through which events become legible as history" (194). 
This revision of temporal and spatial scales in the recreation of history is at play as Woolf attempts to contextualize the history of Pointz Hall in relation to vast expanses of historical time. Noting that the house "did not rank among the houses that are mentioned in guide books" (Woolf, Between the Acts 7), Woolf suggests that the hall is not easily assimilated into systematic ranks. The hall is "over a century" old, and "the Olivers, who had bought the place [...] had no connection with the Warings, the Elveys, the Mannerings or the Burnets; the old families who had all inter-married" (7). The Olivers interrupt the traditional line of inheritance sustained for over a century, illustrating how unpredictable forces disrupt seemingly permanent historical patterns. The inter-marriages exemplify a conscious effort to manage a strict order, securing a progressive heritage rooted in the preservation of class. This effort extends to the physical layout of the house, which adheres to hierarchical social structures such as class and implements precarious divisive barriers meant to manage human bodies. There are two staircases, "the principle staircase" and "another, a mere ladder at the back for the servants" (7). Pointz Hall, however, signifies the dissolution of social constructs that organize and manage collective bodies. Although inter-marriages attempted to purify a unified order, the interaction between different families dismisses notions of singularity and exclusivity. "The old families" composed of disparate familial units intermix "and lay in their deaths intertwisted, like the ivy roots, beneath the churchyard wall" (7).

The hall also accumulates artifacts. For example, "under a glass case, there was a watch that had stopped a bullet on the field of Waterloo" (7). The watch presumably belongs to "the butler [who] had been a soldier [and] had married a lady's maid" (7). This object calls attention to Woolf's earlier essay, "Mr. Bennett and Mrs. Brown," in which 
she notices a historic change. She writes, "all human relations have shifted-those between masters and servants, husbands and wives, parents and children" (Woolf, "Mr. Bennett and Mrs. Brown" 321). She attempts to document this change by assigning it an exact date, suggesting that "in or about December, 1910, human character changed" (320). However, she also notes that despite these visual cues which signal transformations, "the change was not sudden and definite like that" (320). The watch enclosed in the glass case is a visual artifact characteristic of a specific moment from a chronological account of history. The encasing preserves an object that has been extracted from the past and exists within the present. As such, the watch both refers to linear time, reminiscent of the past, and also dismisses the notion of a linear temporal scale. The bullet has literally stopped mechanized time that records the incremental progression of temporal units, and yet the watch reveals the simultaneous existence of past and present. Read in relation to "Mr. Bennett and Mrs. Brown," the watch is a visual cue marking a moment of transformation, but the moment of transformation is "not sudden and definite." The watch, then, can be read in relation to Taylor's understanding of the Anthropocene which demands "our historical imagination around the dimensions of scale" (Jesse Taylor 194).

This superimposition of past and present is consistent throughout the novel. Lucy Swithin reveals various sources from which she constructs a historical narrative. These sources range from encyclopedias, history books, and imaginative reconstructions composed of personal accounts of the past and imagined futures. She experiences time in different ways, reflecting on the cyclicality of the seasons and the birds whose chirpings 
punctuate the dawn. The Outline of History, "her favourite reading" (Woolf, Between the Acts 8), permits her to extend "the hours between three and five" to think: of rhododendron forests in Piccadilly; when the entire continent, not then, she understood, divided by a channel, was all one; populated, she understood, by elephant-bodied, seal-necked, heaving, surging, slowly writhing, and, she supposed, barking monsters; the inguanodon, the mammoth, and the mastodon; from whom presumably, she thought, jerking the window open, we descend. (Woolf, Between the Acts 8)

This historical account establishes progressive evolutionary processes that originated with animals and culminated in the human species. This archival narrative whose title indicates a systematic progression of history outlines a skeletal blueprint of evolution. The footnote specifies that "H.G. Wells, The Outline of History: Being a Plain History of Life and Mankind (Cassell, 1920) is merged with G.M. Trevelyan, History of England (Longmans, Green, 1926) in the work Lucy Swithin reads" (Beer 131, Note 4). Woolf, however, undermines the teleological process documented in the book by interjecting Lucy Swithin's interpretations and imaginative restructuring of history. She reveals what she "understood" rather than passively consumes and accurately reproduces what is written. Gillian Beer indicates Woolf is critical of Trevelyan's book since it relies on "the absence of women from its social history" (Beer xxx). Through Lucy, Woolf provides a woman's reflections on an authoritative historical document and transforms it. Swithin, thus, both transforms historical accounts and draws attention to imaginative flights that extend beyond the present moment. 
Swithin's imaginative reconstruction of history disrupts standardized notions of space and time. Time is not symmetrically divisible and therefore history cannot be subjected to temporal formulas. Instead, "five seconds in actual time" become "in mind time ever so much longer" (Woolf, Between the Acts 8). She "continue[s] her imaginative reconstruction of the past" and is "given to increasing the bounds of the moment by flights into past or future" (8). This imaginative recreation of history thus dissolves notions of predictable environments. She further deconstructs the barrier between the house and the external nonhuman world as she imagines the "whole continent" while remaining within the perimeters of her room. The domestic interior and landscapes of antiquity exist simultaneously and defamiliarize her environment. When the maid enters her room, Swithin imagines a hybrid entity, suspecting both "a beast in a swamp" and "a maid in a print frock and white apron" (8). This dissolution of barriers permits Swithin to reimagine the notion of a dwelling, expanding the contours of the domestic interior to encompass vast expanses of the environment. Swithin imagines herself within an expansive unpredictable ecosystem. As she reflects on the position of the house in nature, she notes how "nature had provided a site for a house; man had built his house in a hollow" (9). The hollow exposes them to potential weather risks. Her brother recites "the famous story of the great eighteenth-century winter" wherein "for a whole month the house had been blocked by snow. And the trees had fallen" (8). This unpredictable seasonal event could not be prevented by human agents and, instead, posed a threat to the survival of those agents. Nature does not adhere to specific formulas and, as such, it cannot be controlled or predicted by human agents. 
Variable weather phenomena persistently punctuate the text. "The pageant and the weather" (16) are repetitive topics of concern which align with seasonal cycles. Isa Oliver "[hears] the same words" animating conversation "every summer, for seven summers" (16). Characters often remark on "the forecast" as "they all looked at the sky to see whether the sky obeyed the meteorologist" (16). The meteorologist, however, cannot effectively predict weather patterns since "certainly the weather was variable" (16). The movement of the clouds demonstrates the erratic characteristics of weather, depicting "a fecklessness, a lack of symmetry, and order" (16). Isa wonders if the clouds obey "their own law, or no law" (16), dismissing the notion of an omniscient force that regulates nonhuman processes. The sporadic movements of the clouds gesture to the boundless atmosphere that exceeds human registers. Isa notes that "beyond that was blue, pure blue, black blue; blue that had never filtered down; that had escaped registration" (16). Woolf draws attention to the expanses of the universe that "never fell as sun, shadow, or rain upon the world, but disregarded the little coloured ball of earth entirely" (16). These distant expanses exist beyond the level of human control and they are indifferent to the preservation of the human species. The sky thus opens up to an abyss. This abyss stresses both the vulnerability of the human species and the frailty of the planet. By drawing attention to "the pure blue, black blue" levels of the atmosphere that exceed human registration and, by extension, human control, Woolf emphasizes the unpredictability of existence.

Miss La Trobe draws attention to this limitless environment in her historical play, illustrating how history is composed of "scraps" and "fragments" (111) that resist formulaic patterns. Her historical drama reimagines the evolution of a world history that 
differs from standardized anthropocentric accounts that condense the complexity of human nature and world history to a linear developmental process. In order to accomplish this, she frustrates established linguistic models that fail to articulate how human history is interwoven with nonhuman history. Miss La Trobe's reflection on the play is revealing as she uses the same language and images as Woolf's "The Cinema" to advocate a new artistic aesthetic. She promotes a material language that differs from the sterile language found in encyclopedias, which several characters, including Lucy Swithin and Lemprière, reference in order to locate "the origin" (17) of colloquial expressions. The tangible, motile words of the play are susceptible to nonhuman forces, blown apart by the wind and "[sink] down in the mud" (125). This tactile language emerges from the nonhuman world as the trees and animal life produce "a rhapsody, a quivering cacophony, a whizz and vibrant rapture" (124) that combine with "words of one syllable" (125). From this new "fertile" (125) language, Miss La Trobe dismisses a reductive and systematic account of history. The language of the play is part of the many "scraps" and "fragments" that compose the historical drama. Fragmentary language is not unique to the play, but as Woolf suggests, is characteristic of modern discourses. "For [Isa's] generation the newspaper was a book" (15) that interweaves disparate local and global stories. Moreover, the newspaper presents a type of realism that Woolf advocates in "Modern Fiction," detailing events that conventional literary styles exclude. For example, Isa reads about " the guard of Whitehall" (15), an article which combines romantic and fantastic genres to report a violent and factual account of rape.

Miss La Trobe's play exemplifies this form of realism, blending different genres in order to upset traditional theatrical and literary formulas. Moreover, the play combines 
different_temporal scales as it presents a chronological arrangement of English history that is continually interrupted by the present moment. Similarly, the performance space intertwines local and global areas, displaying how conventional routines and traditions are threatened by the violence of the world war. The distant channel in relation to the "natural stage" acts a reminder of the close proximity of the war, which is further emphasized by the intrusion of airplanes. There is no clearly delimited barrier that separates the battleground and the home front, but as the characters reflect on the landscapes, they are reminded of their vulnerability. For instance, Giles is irritated as he waits for the play to begin. He reflects on how "the whole of Europe over there-was bristling $[\ldots]$ with guns, poised with planes" (34). Specifically, the ending of the play is marked by "twelve aeroplanes in perfect formation like a flight of wild duck" (114), a telling sign that "the planes are in battle formation" (Beer 143, Note 119). Although the play attempts to catalogue various "scenes from English History" (51), providing an ordered history of a particular nation, the spectators combine the fictional world of the play with their imaginative wanderings. The structure of the play, thus, resists any strict formulas as it compares to "a mellay" (Woolf, Between the Acts 57) or "mixture" (138), a compilation of various characters' interpretations. Woolf thus rejects the notion of clearly delimited national boundaries, shedding light on the interrelationship between local, global, and planetary formations and reformations.

Miss La Trobe utilizes the historical drama to dismiss notions of strict evolutionary processes from which a prehistoric barbarism transforms into progressive civilizations. Early on, the spectators are introduced to a "village idiot" (53), which entices Mr. Oliver to assert that "we're more civilized" (68). The "village idiot" is 
focalized within the Elizabethan era of the drama, relocating him to a distinct historical moment. Mrs. Parker advances "a notion of history that acts as an antidote to the spreading barbarism of the day" (Angeliki 145), intimating a sequential historical scale on which modernity signals a "more civilized" (Woolf, Between the Acts 68) stage. This hierarchical order suggests that "inferior" mental capacities inhibit a human agent's developmental growth. Woolf, however, suggests that the "village idiot" cannot be contained within definitive temporal and spatial coordinates since "there was no need to dress him up. There he came, acting his part to perfection" (53). This type of historical narrative that documents progressive states of being reflects the evolutionary processes delineated in the Outline of History. While waiting for the play to begin, Lucy also imposes this historical framework on the landscape, maintaining that:

before there was a channel, when the earth, upon which the Windsor chair was planted was a riot of rhododendrons, and humming birds quivered at the mouths of scarlet trumpets, as she read that morning in her Outline of History, they had come ... Here Bart rose from his chair. (66) This scene mocks Darwinian evolutionary theories from which prehistoric animals culminate in a more superior creation typified by the erected human figure. As the play unfolds, the actors shift from the early times of Chaucer to a future moment in which the wall of civilization collapses into "orts and scraps," demonstrating what Lucy reads in the Outline of History: "Prehistoric man [...] half-human, half-ape, roused himself from his semi-crouching position and raised great stones" (129). Again, Woolf deflates linear historical narratives, intimating that the fragmented wall of civilization does not corroborate a teleological evolutionary process in which the human species has reached a 
precipice and now must descend into prehistoric barbarism. History, as she suggests, consists of multiple and discrete scraps and fragments that combine and recombine.

The structure of the play thus contests notions of unchanging truths such as those recorded in the Guide Book and the Outline of History. The historical drama calls attention to the radical shift from taxonomic scientific studies to a focus on life processes, as noted by Christina Alt. The characters are aware of this transition in the sciences, indicating how "science $[\ldots]$ is making things (so to speak) more spiritual" by recognizing that "nothing's solid" (118). While Giles is setting up chairs for the spectators, he notices how “the ground sloped up, so that to quote Figgis's Guide Book (1833), 'it commanded a fine view of the surrounding country" (34). By relying solely on objective modes of observation, Giles suggests that "the Guide Book still told the truth. 1833 was true in 1939” (24). Familiar landscapes imply enduring truths that can be archived, permitting observers to "[look] at the view" and simultaneously "[look] at what they knew, to see if what they knew might perhaps be different today" (34). The play, however, disorients the spectators as Woolf complicates standard scientific methodologies that link objective observation with factual reproductions. Woolf provides an exact date for the production: "at this very moment, half-past three on a June day in 1939 they greeted each other" (47). The play, by contrast, resists this type of exact measurement of temporal units since a fixed beginning and end cannot determinately circumscribe it. Mrs. Carter's conversation is interrupted by what might be the beginning of the play. While attempting to locate a concrete point of origin, the characters are confused by the "chuff, chuff, chuff [that] sounded from the bushes" (48). Woolf continues to deny the spectators a fixed beginning. She suggests, "the play had begun" 
(49) and yet late arrivals prolong the start of the play. Similarly, there is no fixed ending as the spectators question, "was that the end?" (116). The duration of the play cannot be precisely measured, and consequently cannot provide an exact reproduction of historical time recorded in textbooks.

The position of the "natural stage" also attempts to orient the observers by providing a fixed focal point that unifies a collective gaze. The nonhuman world arranges the perimeters for the stage, providing "the very space for a pageant" (47). That is, "the lawn was as flat as the floor of a theatre. The terrace, rising, made a natural stage. The trees barred the stage like pillars. And the human figure was seen to great advantage against a background of sky" (47). By observing the contours of the landscape, Miss La Trobe delimits a performance space that effectively enhances the human agent. Initially, the structure of the stage suggests that the nonhuman world functions as an inert background. By objectively observing the performance space, one recognizes that the stage perfectly circumscribes the human agent. Specifically, the portrayal of Queen Elizabeth invites audience members to compare the "natural stage" to "the Globe theatre" (54). This fabricated performance space with a clearly delimited circumference encapsulates human activity. As such, this microscopic Globe elevates the significance of human agents to the extent that it eclipses the focus on the nonhuman world. Woolf, however, suggests that the performance space opens up to vast environments, disclosing "cow language" (19), the rustle of leaves, and the war. That is, Woolf draws attention to the spectators' embodied viewing experiences which register the surrounding environment, consequently diminishing the focus of the human agent. The dimensions of 
the "natural stage" and the globe dissolve to expose the "globular" and "semitransparent" artistic reproductions Woolf champions in "A Sketch of the Past."

The dimensions of the stage expose how the characters are not distant observers separate from the environment under examination, but are immersed in and receptive to the environment. Miss La Trobe recognizes how "every cell in her body was absorbent, [and] looked at the view" (91). This embodied mode of observation does not systematically register accurate representations of external reality, but complex heterogeneous networks. Mrs. Swithin debunks the notion of the human body as a perfectly bounded entity, suggesting "“we live in others [...] we live in things"” (44). Similarly, Mrs. Manresa imagines threads that conjoin different individuals, "visible, invisible, like those threads, now seen, now not, that unite trembling grass blades in autumn before the sun rises" (36). She notices "the air around her became threaded with sensation" (36). The threads reveal irregular material processes occurring in the atmosphere and between bodies. The threads call attention to the new materialism described in "Modern Fiction," exposing the myriad impressions that fall on the brain. This is the type of visionary experience that Miss La Trobe attempts to achieve with her play by decentering the spectators so that "they felt-how could one put it - a little not quite here or there" (90). Despite the play’s attempt to depict a linear historical evolution, the spectators are never fully contained within the past or the present, but always bound up in the simultaneous existence of past, present, and future. The intermission does not isolate a moment in time in which they can return to a sanitized version of the present moment uncontaminated by the past. During the intermission, Giles kicks a stone and imagines that it is "a flinty yellow stone, a sharp stone edged as if cut by a savage for an 
arrow. A barbaric stone; a pre-historic [stone]" (61). He also reflects on the history of the barn, "the barn that had been built over seven hundred years ago and reminded some people of a Greek temple, others of the middle ages, most people of an age before their own, scarcely anybody of the present moment" (61).

This interval destabilizes the superiority of human agents. As Giles makes his way to the barn, he sees a snake consuming a toad. As Christina Alt notes, he does not recognize the organic feeding patterns of the reptile but misinterprets it as a deviation from "natural processes" (Alt 165). According to him, "the snake was unable to swallow; the toad was unable to die [...]. It was birth the wrong way round — a monstrous inversion" (Woolf, Between the Acts 61) and so he eliminates it by crushing it with his boot. Although he attempts to assert his mastery over the nonhuman world, Woolf draws attention to a larger ecosystem in which the human agent is a miniscule component. Lucy notices various animals in the barn, but does not anthropomorphize them. Unlike Giles, she does not attempt to organize the multiple components of the nonhuman world. She notices how the "mice slid in and out of holes or stood upright, nibbling. Swallows were busy with straw in pockets of earth in the rafters, countless beetles and insects of various sorts burrowed in draw wood" (61). Rather than attempt to explain the animals' activities, she focuses on the heterogeneous visionary experiences of the animals as "all these eyes, expanding, narrowing, some adapted to light, others to darkness, looked from different angles and edges" (62). The human spectators of the play participate in a similar disorienting visionary experience through an embodied mode of observation that is not exclusive to the human body. 
Miss La Trobe relies on this mode of vision to create a new re-telling of history. The intermission, the "ten mins. Of present time" (107), and the section on the modern period demand the active participation of the spectators. In the section of the play devoted to "Present time, Ourselves" (105), the spectators acknowledge that "they were all caught and caged; prisoners; watching a spectacle" (105). Woolf thus traces the movement from the characters' recognition of themselves as objectified objects to their perceptive awareness that registers changes in the environment. Miss La Trobe notices how "always some cold eye crawled over the surface like a winter blue-bottle!" and "she flicked [it] off" (105). Similarly, the spectators realize how "all their nerves were on edge. They sat exposed. The machine ticked" (106). Rather than passively consume the spectacle located directly in front of their gaze, they become aware of larger expanses of the environment, noticing "the horns of cars on the high road" and "the swish of the trees" (106). Later, as the actors display mirrors and other reflective surfaces, the spectators sit exposed once again. The effect of the mirrors "break; shiver into splinters the old vision; [and] smash to atoms what was whole" (109). The mirrors are "distorting and upsetting and utterly unfair" (109), revealing how "the reticence of nature was undone, and the barriers which should divide Man the Master from the Brute were dissolved" (109).

This new mode of observation sheds light on a "re-created world" (92) through which the spectators, the environment, and Miss La Trobe's experimental theatrical production are inextricably bound up in the retelling of history. Woolf describes this "recreated world" as emerging from a "cauldron," the same image that she uses to describe the cinema screen in her essay, "The Cinema." The screen is a "cauldron" through which 
emotion and embodied thoughts pour out of bodies. Moreover, as the actors produce mirrors that "darted, flashed, [and] exposed" (109) much like the cinema screen, and turn them on the audience, the spectators see only "orts, scraps and fragments" (111). The mirrors are then followed by "a megaphonic, anonymous, loud-speaking affirmation" (111). Rather than provide an affirmative conclusive interpretation of the play, the voice reveals the mutability of language. The tone of the voice transitions from authoritative to an "adopted colloquial, conversational tone" (111) and is further reduced to an "anonymous bray" (112). In this way, Woolf mocks the BBC broadcasts and their inability to accurately and authoritatively preserve history. Fragmented sentences and inaudible words continue to prevent a clear, accessible interpretation of the play. Whereas in earlier scenes, "the wind blew away the connecting words" (50), a technological "hitch" (112) causes gaps in the speech. The play then stimulates "the whole population of the mind's immeasurable profundity [which] came flocking; from the unprotected, the unskinned; and dawn rose; and azure; from chaos and cacophony measure" (112). The play thus appeals to the vast expanses of the mind and its fluctuating language as illustrated in "Craftsmanship." It creates the same effect as the cinema, demonstrating how language pours out of these "orts, scraps and fragments" that rearrange and recombine in order to stress the fluidity and immensity of this "re-created world."

Nevertheless, the spectators attempt to impose a meaningful framework on the play. Etty Springett attempts to find meaning, suggesting that the sequential unravelling of the drama will ultimately move toward a definitive statement. She, like many others, "liked to leave a theatre knowing exactly what was meant" (98). Moreover, the Rev. G.W. Streatfield, "the reporter" (112), stands to make a definitive statement at the end of 
the play. As he attempts to summarize the drama, he becomes a focalized point of a collective gaze. Standing, he becomes "their representative spokesman; their symbol" (113). Woolf, however, suggests that he is not the authoritative commentator since she calls attention to the spectators' diverse interpretations of him. More than just a unifying symbol, organizing the collective body of spectators, he is also "a butt, a clod, laughed at by looking-glasses; ignored by the cows, condemned by the clouds which continued their majestic rearrangement of the celestial landscape; an irrelevant forked stake and majesty of the summer silent world" (113). His interpretation of the play suggests "that we are members one of another. Each is part of the whole" (114) and "we act different parts; but are the same" (114). He calls attention to a unifying whole which assimilates heterogeneous parts, further insinuating that "nature takes part" (117). This wholesome environment in which all individual components strive to achieve equilibrium is synonymous with Mrs. Swithin's “one-making” (104). Through a "circular tour of the imagination," she implies a unified whole in which "sheep, cows, grass, ourselves-all are one" (104). This harmonious organization, however, implies a mechanized understanding of the environment, demonstrating how "inveterately anthropocentric is the mind" (Woolf, "Flying over London" 167). Although these characters impulsively attempt to impose formulaic meanings, Woolf stresses the precariousness of these formulas in relation to boundless environments. For instance, Lucy Swithin notices how "above, the air rushed; beneath was water. She stood between two fluidities, caressing her cross" (Woolf, Between the Acts 121).

Woolf refuses to impose any singular meaningful framework on the play and dismisses the notion that the play is a single-authored production. When asked if she 
agrees with Streatfield's summary, Isa Oliver answers "yes" and "no" (127). She indicates that "it was Yes, No. Yes, yes, yes (the tide rushed out embracing. No, no, no, it contracted" (127), further asking herself, "what did [Miss La Trobe] mean?" (126). Woolf thus stresses the limitations of the human agents' attempts to impose meaningful structures on aesthetic reproductions of history. Rather than reach any conclusive statements, she proposes that the aesthetic representation of human evolution and historical environments are very much a part of the nonhuman world, immersed in and affected by the "messy materiality" (Alaimo, "Feminist Science" 195). Rather than have Miss La Trobe make an authoritative claim by producing her interpretation, Woolf draws attention to the various human and nonhuman actors that composed the play. In the end, we are left with questions, which, according to Woolf, is a fundamental characteristic of "modern fiction" since it displays "the infinite possibilities of the art and [reminds] us that there is no limit to the horizon" (Woolf, "Modern Fiction" 110). Miss La Trobe acknowledges the vibrancy of life which continues after the play, noting "a whizz and vibrant rapture, branches, leaves, birds syllabling discordantly life, life, life, without measure, without stop devouring the tree" (Woolf, Between the Acts 124). The elusive ending exposes ongoing life processes. As such, Woolf calls attention to an image earlier on in the novel in which the library is conceived as "the heart of the house" (12), preserved from atmospheric conditions. She, however, imagines a future, suggesting, "if no human being ever came $[\ldots]$, the books would be mouldy" (13) and thereby subject to material disintegration. By the end of the novel, the house becomes "a shell" (128), dissolving the barriers between human and external nonhuman spaces as the variable 
components of the play disperse and combine with immeasurable on-going life processes within a vast unpredictable ecosystem.

To return to my original questions: do the characters speak differently at the end of the novel and how does language change throughout the novel? The comparison between the first and last lines of the novel shed light on the "unwanted" and "unpredictable" characteristics of Woolf's material language. The opening scene reveals anonymous speakers who focus on the utility of language. They discuss "country council" and their attempts to organize the nonhuman world through their "[promise] to bring water to the village" (1). The topics of conversation and the way bodies "speak" change drastically throughout the novel, as I have shown. The novel's return to the original speakers does not corroborate an anthropocentric worldview. Rather than concern themselves with the actions of "county council" who might also be synonymous with the "army of the upright," "they" are concerned with the sky: "the window was all sky without colour" (129). The sky calls attention to the revelatory moment of the "invalid" in "On Being Ill" who recognizes "the extraordinary spectacle" of nonhuman material processes. The "endless activity" which is then disclosed to the ill body is "shocking." Similarly, in Between the Acts, "they" are exposed to the "endless activity" of the sky and the "house [loses] its shape" (129). Thus, Woolf's focus on a nonhuman material world that "shocks" human agents demonstrates how their perceptions of the world change and, by extension, the way they speak about and imagine the world. This final image of the intricate entanglement of human and nonhuman matter suggests that Miss La Trobe's historical drama achieved a "globular" and "semi-transparent" representation of the world in which "we are the words; we are the music; we are the 
thing itself” (Woolf, “A Sketch” 71). The novel resists environments that adhere to traditional representations of "the oikos" as "a bounded home" and instead exposes "an ever-unfinished world" (Cohen xxii). Woolf enacts an ongoing material performance that surpasses the human agent's need to preserve green ecologies. 


\section{Conclusion}

Beyond the Point of No Return

The sombre tone of a diary entry dated January $26^{\text {th }}, 1941$ conveys, to some degree, Woolf's "battle against depression" (Woolf, Diary 354). She contemplates her "rejection" from Harper's Bazaar's London office and resolves that "this trough of despair shall not [...] engulf me" (354). ${ }^{105}$ Writing from Monk's House, she comments on "the solitude" of life in Rodmell and further notes, "the house is damp. The house is untidy. But there is no alternative" (354-355). The description of Monk's House and her activities there conform to the traditional narrative of the house as a place of repose and restoration. She engages in "sleep \& slackness; musing; reading; cooking; cycling; oh \& a good hard rather rocky book" (355). This is her "prescription" (255). This personal despair that stems from rejection expands to a global despair. Despite "a lull in the war," she anticipates that "the greatest struggle is about to come" (255). Her description of the garden, however, is calm in relation to the threat of war. She notes, "it's the cold hour, this, before the lights go up" and there are "a few snowdrops in the garden" (355). The garden seems to harbour a place of solitude and introspection as Woolf proposes, "we live without a future. That's whats queer, with our noses pressed to a closed door" (355). The enclosed area of the garden symbolizes peace and tranquility as opposed to a sinister future which is associated with violence and extinction.

This brief diary entry gestures to one of the main concerns with which I began this dissertation: this sample of Woolf's "battle against depression" unfolds in Monk's House, indicating the author's return to a remedial green space. This typical conception

\footnotetext{
${ }^{105}$ Specifically, she refers to the rejection of her short story "The Legacy" which would only be published posthumously.
} 
of the interaction between nature and bodies (specifically women's bodies) applies to the ways in which nature has been commonly read in relation to Stein and H.D. Traditional green spaces tend to function as prescriptive places for transgressive or "unnatural" bodies. Catriona Sandilands argues that this notion of return is a "fantasy" and it derives from "a capitalist reproductive futurity in which some lives (human and nonhuman) are biopolitically encouraged, and others, decidedly, are not" (449). ${ }^{106}$ This return is often "organized around the fantasy that we may somehow return to our own innocence or childhood, to a time that never-quite-was, through constant attempts to protect our future world and our future children"” (449). This fantasy infuses green spaces with a sense of nostalgia and innocence that are nurtured within wild natural spaces. However, in her meditation on the future, Woolf does not consider childhood innocence or preservation. The future, like the material environment in which she lives, is unstable and unpredictable. In order to exceed limited understandings of nature informed by the notion of a "return," I propose that environmental studies must move beyond traditional green natures in order to rethink bodies in environments as well as to rethink the way we speak, imagine, and frame the nonhuman world.

My dissertation builds off of this critique of common conceptions of the return to "wild" or "pure" spaces. It is important to note that attempts to revise the traditional notion of a "return" do not simply rely on expanding our field of vision in order to

\footnotetext{
106 This notion of futurity fosters a "heteronormative telos" through which "queerness comes to be figured as the 'unfuture' or limit of the system, as death itself' (148) and [...] the reproductivities of others can come to be posed as a threat to the future rather than as part of its flourishing" (Sandilands 449).
} 
broaden our limited understandings of the world. ${ }^{107}$ It also relies on the recognition of the precarious intra-action between human and nonhuman agents. Ecological readings of Stein's, H.D.'s, and Woolf's works must then consider how bodies, language, and nonhuman matter are discursively produced. By situating these authors in relation to the nonhuman world and exploring their theorizations of the body that extend to the nonhuman world, my intention is not to situate ecology as an alternative to social constructions of identity. Instead, ecology discloses how social, economic, and linguistic constructions affect and are affected by nonhuman material processes. Discursive material processes necessitate a reconsideration of the human. That is, these material processes reconsider the human and "the sense of belonging to a common idea of the human" which supposes a model of "natural" bodies and social organizations prefaced on constructed notions of "naturalization" (Braidotti 21). ${ }^{108}$ Rosi Braidotti contends that "women, natives, and earthly Others" are "the secularized, racialized, and naturalized 'Others' whose social and symbolic existence is disposable and unprotected" (24). She proposes "the practice of defamiliarization" (30) to combat limited conceptions of naturalization.

Although nature figures predominantly in Stein's, H.D.'s, and Woolf's works, it does not conform to constructed models of "naturalization." As I have shown, nature as an erratic material performance is central to these authors' epistemological concerns,

\footnotetext{
${ }^{107}$ I refer here to studies like Susan Stanford Friedman's Planetary Modernisms. Although heavily influential, it focuses on expanding a larger panoramic view of the planet without necessarily exploring material processes.

${ }^{108}$ Rosi Braidotti examines how social structures preserve "the idea of the human that is implicit in the humanist ideal of 'Man' as the alleged "measure of all things" (22). This ideal "combines high standards of physical perfection with intellectual and moral values, turning into a civilizational standard" (22). Feminism undermines this ideal of "Man" or the universal model of "human" by suggesting that "nobody is actually in charge of the course of historical progress" (23).
} 
which are enacted in their experimental writing. Integral to their aesthetic projects are questions of representation in dialogue with a radical reconceptualization of the human. They propose that we move beyond traditional conceptions of bodies to the "unpredictable and unwanted actions" (Alaimo, "Feminist Science" 191) of the transcorporeal body. Stein's exploration of the intimate connection between "natural phenomena" and a modern "composition" undermines the semblance of "everything being alike" by exposing how "things" are "naturally simply different" ("Composition" 519). ${ }^{109}$ Her understanding of composition revises common conceptions of bodies, suggesting that what is typically understood as extraneous to the human body is intricately bound up in the material make-up of the human. ${ }^{110}$ The "concern" for the body outlined in H.D.'s Notes on Thought and Vision extends to a concern for the environment, a concern that relates directly to our contemporary world in which the tension between precarious environments and the impulse to regulate and classify human and nonhuman matter threatens our survival. Woolf's consideration of a modern aesthetic

${ }^{109}$ Stein also redefines the concept of artistic representations of "beauty" ("Composition" 515). She contends that beauty in art is not simply defined as something that is serene and passively accepted, but "irritating," "annoying," and "stimulating" (515). Alaimo echoes this reconsideration of "beauty" through her critique of aesthetic reproductions of ocean life. She states, "the more taxonomical and aesthetic representations of ocean life puts each distinct species in the spotlight, framing them as distinctive and worthy of attention" ("Feminist Science Studies" 196). However, she notes "that every single thing in the ocean is not breathtakingly beautiful" and "[highlights] the fact that the striking aesthetically rendered photographs of ocean creatures has become a dominant style, a particular mode of representation and not merely a transparent window onto the world" (197). This reconsideration of aesthetically beautiful reproductions of the nonhuman world expands traditional representations of beautiful "green ecologies" in art, such as the sublime in romantic humanism.

${ }^{110}$ Material ecocriticism contests and challenges familiar representations and conceptions of the human body. Alaimo suggests that the defamiliarization of the body fosters an environmental ethics since it forces us to recognize that human bodies are always bound up with nonhuman matter. Specifically, in her study of marine life, she claims that "dubbing ocean creatures 'aliens' is a common trope with a rather long history" ("Feminist Science" 194). These unfamiliar creatures are often cast "as strange or alien or monstrous" (200) and yet they are very much affected by human activities. As a result, these creatures are not "alien" or outside of the human, but very much a part of them. 
adds to this as her exploration of illness sheds light on the "illusion" (Woolf, "On Being

Ill" 196) of both social customs and literary patterns that promote homogeneity and

repetition. Contemporary environmental conditions such as growing food shortages and

rising levels of contamination substantiate her theory of "how common illness is" (193).

By advancing their own theorizations on the body and the nonhuman world, these authors

actively revise typical conceptions of the human defined by "powers of reason and

progress" (Braidotti 23).

Pertinent to Stein's, H.D.'s, and Woolf's works is an attempt to revise the notion of a linear history. They heavily critique historical narratives in which the past is associated with essentialist notions of the body and nature; the future marks a deviation from authentic states of being. Stein, H.D., and Woolf explore "non-linear" historical narratives that resist the notion of a "return" to a primordial or calm state. ${ }^{111}$ The complete imbrication of human and nonhuman agents makes it impossible to conceive of a "return." Stein articulates this best through her definition of composition: "the composition is different and always going to be different everything is not the same"

${ }^{111}$ This tenuous opposition between past and future is part of a larger conversation of literary modernism. Stein differentiates the classics from the modern composition, suggesting that the classics are a type of "prepared" knowledge that has been accepted (Stein, "Composition" 514). The classics typically refer to the past, a contained spatial-temporal historical moment that can be classified. This understanding, of course, parodies the type of scientific methods of documentation that Stein opposed in the university. She also highlights the "rapidity" with which artistic movements are "refused" (515) and then accepted as a classical and definable movement. The immediacy with which the canon rejects or accepts a work of art questions the legitimacy of strict systems of classification. H.D. does not necessarily distinguish the classics from the modern in the same way Stein does, but suggests, "modernity in dress, in thought, true modernity approaches more and more to classic standards" (H.D., "The Cinema and the Classics II" 112). As I argue in chapter two, H.D. does not refer to a chronological history in which modernism reverts to an ancient past. She proposes that the classic is "a point of view" that considers "a sense of the rightness and the fitness of things in their interrelation" (113). Moving away from the limitations of strict mechanizations and "stark reality" (113), H.D. champions a dynamic and uncertain "nature." Similarly, Woolf distinguishes between the historian of literature and the modern artist, indicating that they must "keep moving" (Woolf, "Modern Fiction" 103) and continue to ask questions so to avoid settling within conventional artistic models. 
(Stein, "Composition" 516). This reconsideration of a return to a primordial or natural state begs the question of futurities: do we live without a future as Woolf so bleakly implies? Does the human species move toward the same future? How do current environmental crises alter the way we think or imagine futures? These questions encompass many possibilities and consider the future of literary modernism, the future of the humanities, and the future of the planet.

I have framed this dissertation as a case study for three canonical women authors. I have shown how Stein, H.D., and Woolf were attentive to their environments and the dominant narratives that fostered specific conceptualizations of these environments. As Alaimo proposes, however, any framework (cultural, scientific, academic, etc.) is openended and subject to further questioning. My dissertation opens out to three different strains of academic thought. That is, I see my dissertation as being more than just concerned with three modernist writers and their experimental writing; it is also a part of a larger conversation about current environmental crises, new feminisms, and mental health issues. First, the contemporary environmental crisis provides insights to new material dimensions of the future that are not restricted by notions of progress and innovation. The current condition of the planet reveals how the human agent can never return to a "pure" bodily state or seek refuge in a "pure" environment. ${ }^{112}$ This is evidenced by the unprecedented amount of plastic which has accumulated in remote and

\footnotetext{
${ }^{112}$ As erratic weather phenomena increase in frequency and growing levels of pollutants continue to contaminate ecosystems, humans attempt to move away from depleted environments. This movement does not unfold on a stable nonhuman backdrop. Human agents cannot move toward "pure" and healthy spaces nor can they restore places of devastation that they had left. See Brett Milligan's "Landscape Migration: Environmental design in the Anthropocene."
} 
uninhabited places on the earth. ${ }^{113}$ More and more studies are available to the public which explore how plastic has infiltrated our drinking water ${ }^{114}$ and investigate how the effects of particles digested by nonhuman life forms drastically alter those life forms. ${ }^{115}$ Despite these visible signposts of human intervention that results in drastic alterations in ecosystems, the "war" on climate continues as climate change deniers antagonize scientific discourses. The climate war is also intimately bound up with growing tensions between and within nations. Mass migration, unprecedented flooding and hurricanes lead to widespread devastation and are often pitted against political strength and economic growth.

Second, contemporary environmental crises lead to new discussions of feminism. Current environmental, political, and economic tensions impose divisive barriers between nations rather than recognize the implications of mass production and consumption outside of economic and social growth. ${ }^{116}$ These tensions arise from "established patterns of thought" or traditional forms of "naturalization" (Braidotti 31). Political and social conflicts on climate change are informed by "the masculine authority of an institutional scientific discourse" (viii) which is focused on the impulse to categorize, name, and

\footnotetext{
${ }^{113}$ Unpopulated sections of the earth still bare traces of human activity. See Sandra Laville's and Matthew Taylor's "A million bottles a minute: world's plastic binge 'as dangerous as climate change"" and Heather Brady's "Deepest Place on Earth Contains 'Extraordinary' Pollution Levels."

${ }^{114}$ See Damian Carrington's "Plastic fibres found in tap water around the world, study reveals" and Jessica Glenza's "Sea salt around the world is contaminated by plastic, studies show." The recent mass flooding in Houston has also resulted in large levels of contaminated water. See Brady Dennis' and Darryl Fears' "Houston's polluted Superfund sites threaten to contaminate floodwaters."

${ }^{115}$ See Susan Noakes' "Human antidepressants building up in brains of fish in Niagara River." ${ }^{116}$ Naomi Klein examines how the necessary steps to divert the catastrophic events of climate change oppose "deregulated capitalism" and opportunities to accumulate wealth. She writes, "it is our great collective misfortune that the scientific community made its decisive diagnosis of the climate threat at the precise moment when those elites were enjoying more unfettered political, cultural, and intellectual power than at any point since the 1920s" (18). For more on this, see Klein's This Changes Everything: Capitalism Vs. the Climate.
} 
control both the nonhuman world and bodies. Subsequently, these impulses manufacture an artificial division between nature and culture. This "artificial but time-honored distinction between natural and human histories" (27), according to Braidotti, dominates the humanities. Barad's notion of agential realism and Alaimo's notion of transcorporeality reconceptualize traditional understandings of the body and nonhuman matter that can be productively central to emerging discussions on modernist women authors. New feminist studies continue to engage with this complex entanglement of bodies and nonhuman matter as seen through theorizations on the newly termed Anthropocene feminism. Anthropocene feminism moves away from institutionalized notions of "nature" and "naturalization" which ultimately produce narratives that police humanity. Anthropocene feminism champions a posthumanist feminism which does not simply offer "counteridentity formations" (Braidotti 37) to subvert dominant gender binarisms, but advances "a generative ontological force that cannot be adequately contained within the dichotomous view of gender defined as the social constructions of differences between the sexes" (38). ${ }^{117}$

Third, questions of the environment alter the way in which we think about illness and this can inspire new discussions around mental health issues. Although I have deviated somewhat from my focus on women modernist authors, I would like to revisit the traditional readings of these authors with which I began this dissertation. Specifically, I would like to return briefly to the association between the garden and Woolf's mental health. Monk's House becomes a sanctuary through which Woolf achieves creative inspiration that is impeded by illness. This relation between green spaces and mental

\footnotetext{
${ }^{117}$ Braidotti further proposes a relational and precarious materialism that subverts "the fantasy of unity, totality, and oneness" as well as "the oedipalized narratives of primordial loss, incommensurable lack, and irreparable separation" (39).
} 
health also applies to biographical narratives of Stein and H.D. According to such accounts, these authors are similar in that they "return" to green spaces in order to restore the body that has been contaminated by the industrial landscapes of modernity. As a result, these narratives suggest that illness is "unnatural." They further insist that green ecologies are healing spaces that inspire creative surges which permit these authors to produce artistic work. This work produced in the absence of chaos and catastrophe characterizes these canonical women modernist writers. However, the intimate interlacing of human bodies and nonhuman matter demands reconsiderations of illness.

Recent environmental conditions shed light on this traditional notion of how a stable nature that attends to the physical and psychological well-being of a human agent is not plausible. Current traces of human intervention in the nonhuman world are not reserved for the contemporary historical moment, but are the effects of long-lasting events. The porous boundaries of human bodies and nonhuman matter render the human species vulnerable to illness. Illnesses are complex and, in some cases, unknown, and therefore demand new treatments that surpass standardized methods and institutionalized knowledge. More complex notions of nature thus revise traditional frameworks which focus extensively on the authors' illness. Illness is not "unnatural." It does not signal a deviation from the norm, but, as Woolf suggests, it is a "common" occurrence (Woolf, "On Being Ill" 193). The intersection of literary modernism and material ecocriticism opens up new avenues to investigate representations of illness in modernist writers' works that are not restricted to prevalent binarisms in modernism, such as city and nature, and male and female. 


\section{Works Cited}

Alaimo, Stacy. Bodily Natures: Science, Environment, and the Material Self. Indiana UP, 2010.

---. "Feminist Science Studies and Ecocriticism: Aesthetic and Entanglement in the Deep Sea." The Oxford Handbook of Ecocriticism, edited by Greg Garrard, Oxford UP, 2014, pp. 188-204.

---. "States of Suspension: Trans-Corporeality at Sea." Isle: Interdisciplinary Studies in Literature and Environment, vol. 19, no. 3, 2012, pp. 476-493. MLA International Bibliography, doi: 10.1093/isle/iss068. Accessed 24 April 2017.

---. "Violet-Black." Prismatic Ecology: Ecotheory Beyond Green, edited by Jeffrey Jerome Cohen, U of Minnesota P, 2013, pp. 233-51.

Alt, Christina. Virginia Woolf and the Study of Nature. Cambridge UP, 2010.

Anderson, Elizabeth. H.D. and Modernist Religious Imagination: Mysticism and Writing. Bloomsbury Publishing, 2013.

Angeliki, Spiropoulou. Virginia Woolf, Modernity and History: Constellations with Walter Benjamin. Palgrave MacMillan, 2010.

Banfield, Ann. The Phantom Table: Woolf, Fry, Russell and the Epistemology of Modernism. Cambridge UP, 2000.

Barad, Karen. Meeting the Universe Halfway: Quantum Physics and the Entanglement of Matter. Duke UP, 2007.

---. “'Posthumanist Performativity': Toward an Understanding of how Matter Comes to Matter." Material Feminisms, edited by Stacy Alaimo and Susan Hekman, Indiana UP, 2008, pp. 120-54. 
Barrows, Adam. Time, Literature, and Cartography After the Spatial Turn: The Chronometric Imaginary. Palgrave Macmillan, 2016.

Bate, Jonathan. Romantic Ecology: Wordsworth and the Environmental Tradition. Routledge, 1991.

Bean, Heidi R. "Repeating Gertrude Stein: Language, Performativity, and Hypermediated Theatre." Text and Performance Quarterly, vol. 27, no. 3, 2007, pp. 168-193. MLA International Bibliography, doi: http://dx.doi.org.proxy.library.carleton.ca/ 10.1080/10462930701412312. Accessed 25 July 2017.

Beer, Gillian. Introduction. Between the Acts, edited by Stella McNichol, Penguin, 1992, pp. ix- xxxv.

---. Notes. Between the Acts, edited by Stella McNichol, Penguin, 1992, pp. 131-45.

Bell, Quentin. "1917.” The Diary of Virginia Woolf, edited by Anne Olivier Bell, Hogarth Press, 1977, p. 39.

Benjamin, Walter. "The Work of Art in the Age of Mechanical Reproduction." Edited by Hannah Arrendt, Random House, 2005, www.marxists.org/reference/ subject/philosophy/works/ge/benjamin.htm. Accessed 23 April 2017.

Boguslawska-Tafelska, Marta. Towards an Ecology of Language, Communication and the Mind. Peter Lang, 2013.

Bowers, Jane Palatini. "They watch me as they watch this": Gertrude Stein's Metadrama. U of Pennsylvania P, 1991.

Boyd, Brian. On the Origin of Stories: Evolution, Cognition, and Fiction. Belknap Press of Harvard UP, 2009. 
Brady, Heather. "Deepest Place on Earth Contains 'Extraordinary' Pollution Levels." National Geographic, 14 Feb. 2017, news.nationalgeographic.com/2017/02/mariana-trench-pollution-pacific-oceanchemicals/. Accessed 3 Nov. 2017.

Braidotti, Rosi. "Four Thesis on Posthuman Feminism." Anthropocene Feminism, edited by Richard Grusin, U of Minnesota P, 2017, pp. 21-48.

Bryant, Levi R. "Black.” Prismatic Ecology: Ecotheory Beyond Green, edited by Jeffrey Jerome Cohen, U of Minnesota P, 2013, pp. 290-310.

Buell, Lawrence. The Environmental Imagination: Thoreau, Nature Writing, and the Formation of American Culture. Belknap Press of Harvard UP, 1995.

---. The Future of Environmental Criticism: Environmental Crisis and Literary Imagination. Blackwell, 2005.

Campbell, Andrea. Introduction. New Directions in Ecofeminist Literary Criticism, edited by Andrea Campbell, Cambridge Scholars Publishing, 2008, pp. vii-xii.

Caramagno, Thomas C. The Flight of the Mind: Virginia Woolf's Art and Manic Depressive Illness. U of California P, 1992.

Carrington, Damian. "Plastic fibres found in tap water around the world, study reveals." The Guardian, 6 Sept. 2017, www.theguardian.com/environment/2017/sep/06/plastic-fibres-found-tap-wateraround-world-study-reveals. Accessed 3 Nov. 2017.

Chessman, Harriett Scott. The Public is Invited to Dance: Representation, the Body, and Dialogue in Gertrude Stein. Stanford UP, 1989. 
Chodat, Robert. "Sense, Science, and the Interpretations of Gertrude Stein.” Modernism/ Modernity, vol. 12, no. 4, 2005, pp. 581-605. MLA International Bibliography, doi: http://dx.doi.org.proxy.library.carleton.ca/ 10.1353/mod.2005.0108. Accessed 23 Apr. 2017.

Christianson, James H. “Things Fall Apart, and Fold Back: Tense Communions of Wholeness \& Ruin in Modern Narrative." Revue du Centre de Research sur LImaginaire dans les Littératures de Langue Anglaise, vol. 12, 2008, pp. 33-46. MLA International Bibliography, doi: proxy.library.carleton.ca/login?url=http://go.galegroup.com/ps/i.do?p=MLA\&sw $=\mathrm{w} \& \mathrm{u}=\mathrm{ocul}$ carleton $\& \mathrm{v}=2.1 \& \mathrm{id}=\mathrm{GALE} \% 7 \mathrm{CN} 2812476075 \& \mathrm{it}=\mathrm{r} \&$ asid $=3 \mathrm{ed} 7 \mathrm{cfe}$ 55cbe6b07b108d13792232326. Accessed 3 Nov. 2017.

Clark, Timothy. Ecocriticism on the Edge: The Anthropocene as a Threshold Concept. Bloomsbury, 2015.

---. "Nature, Post Nature." The Cambridge Companion to Literature and the Environment, edited by Louise Wrestling, Cambridge UP, 2014, pp. 75-89.

Cohen, Jeffrey Jerome. “Ecology's Rainbow.” Prismatic Ecology: Ecotheory Beyond Green, edited by Jeffrey Jerome Cohen, U of Minnesota P, 2013, pp. xv-xxxv. Collecott, Diana. H.D. and Sapphic Modernism 1910-1950. Cambridge UP, 1999.

Connor, Rachel. H.D. and the Image. Manchester UP, 2004.

Conrad, Joseph. Heart of Darkness. Knopf, 1993.

Daniel, Lucy. Gertrude Stein. Reaktion Books, 2009.

Deacon, Terrence W. The Symbolic Species: The Co-Evolution of Language and the Brain. W.W. Norton, 1997. 
Debo, Annette. The American H.D. U of Iowa P, 2012.

DeKoven, Marianne. A Different Language: Gertrude Stein's Experimental Writing. U of Wisconsin P, 1983.

---. "Modernism and Gender." The Cambridge Companion to Modernism, edited by Michael Levenson, Cambirdge UP, 1999, pp. 174-93.

Dennis, Brady and Darryl Fears. "Houston's polluted Superfund sites threaten to contaminate floodwaters." The Washington Post, 29 Aug. 2017, www.washingtonpost.com/news/energy-environment/wp/2017/08/29/houstonsflood threatens-to-turn-polluted-superfund-sites-into-a-toxicgumbo/?utm_term=.4b27b0d57e6f. Accessed 3 Nov. 2017.

Detloff, Madelyn. "The Precarity of 'Civilization' in Woolf's Creative Worldmaking." Virginia Woolf Writing the World: Selected Papers from the Twenty-Fourth Annual International Conference on Virginia Woolf, edited by Pamela L. Caughie and Diana L. Swanson, Clemson UP, 2015, pp. 204-10.

Dickinson, Renée. "Writing the Land: Between the Acts as Ecocritical Text." Virginia Woolf Miscellany, vol. 81, 2012, pp. 16-18.

Doolittle, Hilda. "Conrad Veidt: The Student of Prague." Close-Up 1927-1933: Cinema and Modernism, edited by James Donald, Anne Friedberg, and Laura Marcus, Princeton UP, 1998, pp. 120-24.

---. "Expiation." Close-Up 1927-1933: Cinema and Modernism, edited by James Donald, Anne Friedberg, and Laura Marcus, Princeton UP, 1998, pp. 125-30.

---. HERmione. New Directions, 1981.

---. Notes on Thought and Vision and The Wise Sappho. City Lights Books, 1982. 
---. "Russian Films." Close-Up 1927-1933: Cinema and Modernism, edited by James Donald, Anne Friedberg, and Laura Marcus, Princeton UP, 1998, pp. 134-39.

---. "The Cinema and the Classics I: Beauty." Close-Up 1927-1933: Cinema and Modernism, edited by James Donald, Anne Friedberg, and Laura Marcus, Princeton UP, 1998, pp. 105-09.

---. "The Cinema and the Classics II: Restraint." Close-Up 1927-1933: Cinema and Modernism, edited by James Donald, Anne Friedberg, and Laura Marcus, Princeton UP, 1998, pp. 110-14.

---. "The Cinema and the Classics III: The Mask and the Movietone." Close-Up 19271933: Cinema and Modernism, edited by James Donald, Anne Friedberg, and Laura Marcus, Princeton UP, 1998, pp. 114-20.

---. “The Wise Sappho.” City Lights Books, 1982, pp. 57-69.

---. Tribute to Freud. Pantheon, 1956.

DuPlessis, Rachel Blau. H.D.: The Career of that Struggle. Harvester Press, 1986.

---. Preface. Signets: Reading H.D., edited by Susan Stanford Friedman and Rachel Blau DuPlessis, U of Wisconsin P, 1990, pp. xi-xvi.

---. "Woolfsteinian, the Sequel." Primary Stein: Returning to the Writing of Gertrude Stein, edited by Janet Boyd, Sharon J. Kirsch, Lexington Books, 2014, pp. 37-56. Easterlin, Nancy. "Cognitive Ecocriticism: Human Wayfinding, Sociality, and Literary Interpretation.” Introduction to Cognitive Cultural Studies, edited by Lisa Zunshine, Johns Hopkins UP, 2010, pp. 257-74.

Enns, Anthony and Shelley Trower. Introduction. Vibratory Modernism, edited by Anthony Enns and Shelley Trower, Palgrave Macmillan, 2013, pp. 1-29. 
Esdale, Logan. “Genealogy of Ida A Novel.” Ida: A Novel, edited by Logan Esdale, Yale UP, 2012, pp. 144-79.

Eysteinsson, Astradur. The Concept of Modernism. Cornell UP, 1990.

Fernald, Anne. "Women's Fiction, New Modernist Studies, and Feminism.” MFS

Modern Fiction Studies, vol. 59, no. 2, 2013, pp. 229-40. Project Muse, doi: 10.1353/mfs.2013.0024. Accessed 28 Oct. 2017.

Fitzpatrick, Bethany. "My Body, My People, My Land: Healing the Bonds that are Broken in Linda Hogan's Solar Storms," New Directions In Ecofeminist Literary Criticism, edited by Andrea Campbell, Cambridge Scholars Publishing, 2008, pp. 1-14.

Foltz, Jonathan. "The Laws of Comparison: H.D. and Cinematic Formalism." Modernism/Modernity, vol. 18, no. 1, 2011, pp. 1-25. MLA International Bibliography, doi: http://dx. doi.org.proxy. library.carleton.ca /10.1353/ mod.2011. 0006. Accessed 2 June 2017.

Ford, Sara J. Gertrude Stein and Wallace Stevens: The Performance of Modern Consciousness, edited by William E. Cain, Routledge, 2002.

Freer, Scott. Modernist Mythopoeia: The Twilight of the Gods. Palgrave Macmillan, 2015.

Freud, Sigmund. Civilization and Its Discontents. Penguin, 2004.

---. "Leonardo da Vinci and A Memory of his Childhood." The Standard Edition of the Complete Psychological Works of Sigmund Freud. Hogarth Press, 1957, pp. 63137. 
Friedman, Susan Stanford. Penelope's Web: Gender, Modernity, H.D. 's Fiction. Cambridge UP, 1990.

---. Planetary Modernism: Provocations on Modernity Across Time. Columbia UP, 2015. ---. Psyche Reborn: The Emergence of H.D. Indiana UP, 1981.

Galvin, Mary E. Queer Poetics: Five Modernist Women Writers, Greenwood, 1999. Gärdenfors, Peter. "Cognitive Semantics and Image Schemas with Embodied Forces." Embodiment in Cognition and Culture, edited by John Michael Krois, et al, John Benjamins Publishing, 2007, pp. 57-76.

Gelpi, Albert. "The Thistle and the Serpent." Notes on Thought and Vision and The Wise Sappho. City Lights Books, 1982, pp. 7-14.

Girard, Monica. "Virginia Woolf Suicide Notes." Last Letters, edited by Sylvie Crinquand, Cambridge Scholars, 2008, pp. 37-57.

Glenza, Jessica. "Sea salt around the world is contaminated by plastic, studies show." The Guardian, 8 Sept. 2017, www.theguardian.com/environment/2017/sep/08/seasalt-around-world-contaminated-by-plastic-studies. Accessed 3 Nov. 2017. Gregory, Eileen. "Rose Cut in Rock: Sappho and H.D.'s Sea Garden.” Signets: Reading H.D., edited by Susan Stanford Friedman and Rachel Blau DuPlessis, $\mathrm{U}$ of Wisconsin P, 1990, pp. 129-54.

Grosz, Elizabeth. Becoming Undone: Darwinian Reflections on Life, Politics, and Art. Duke UP, 2011.

Guinness, Bunny. "Monk's House, the garden that inspired Virginia Woolf." The Telegraph, 15 Oct. 2013, 
http://www.telegraph.co.uk/gardening/gardenstovisit/10377203/Monks-Housethe-garden-that-inspired-Virginia-Woolf.html. Accessed 3 Nov. 2017.

Hancock, Nuala. "Virginia Woolf and Gardens." The Edinburgh Companion to Virginia Woolf and the Arts, edited by Maggie Humm, Edinburgh UP, 2010, pp. 245-60. Harrison, Elizabeth Jane, and Shirley Peterson. Introduction. Unmanning Modernism: Gendered Re-Readings, edited by Harrison and Peterson, U of Tennessee P, 1997, pp. vii-xv.

Hart. F. Elizabeth. "Performance, Phenomenology, and the Cognitive Turn." Performance and Cognition: Theatre Studies and the Cognitive Turn, edited by Bruce McConachie and F. Elizabeth Hart, Routledge, 2006, pp. 29-51.

Hart, George. "The Strain in the Skull: Biopoetics and the Biology of Consciousness." Inventing the Language to Tell It: Robinson Jeffers and the Biology of Consciousness. Fordham UP, 2013, pp. 39-60.

Hazleton, Gregory J. "Composition as Ecology: Environments of Writing in American Poetry in the Emersonian Tradition." Dissertation Abstracts International, Section A: The Humanities and Social Sciences, vol. 69, no. 5, 2008, p. 1781. MLA International Bibliography, proxy.library.carleton.ca/login?url=http://go.galegroup.com/ps/i.do?p=MLA\&sw $=\mathrm{w} \& \mathrm{u}=\mathrm{ocul}$ carleton $\& \mathrm{v}=2.1 \& \mathrm{id}=\mathrm{GALE} \% 7 \mathrm{CN} 2812425312 \& \mathrm{it}=\mathrm{r} \& \mathrm{asid}=06 \mathrm{baf} 71 \mathrm{f}$ 2a5ae3e91ae67475b9b39735. Accessed 24 July 2017.

Heine, Bernd. Cognitive Foundations of Grammar. Oxford UP, 1997. Henry, Holly. Virginia Woolf and the Discourse of Science: The Aesthetics of Astronomy. Cambridge UP, 2003. 
Hess, Scott. William Wordsworth and the Ecology of Authorship: The Roots of Environmentalism in Nineteenth-Century Culture. U of Virginia P, 2012.

Hirsh, Elizabeth A. “Imaginary Images: 'H.D.,' Modernism, and the Psychoanalysis of Seeing." Signets: Reading H.D., edited by Susan Stanford Friedman and Rachel Blau DuPlessis, U of Wisconsin P, 1990, pp. 430-54.

Högberg, Elsa. "Virginia Woolf's Object-Oriented Ecology." Virginia Woolf Writing the World: Selected Papers from the Twenty-Fourth Annual International Conference on Virginia Woolf, edited by Pamela L. Caughie and Diana L. Swanson, Clemson UP, 2015, pp. 148-53.

Hogue, Cynthia. “(Re)Storing Happiness: Toward an Ecopoetic Reading of H.D.'s The Sword Went out to Sea (Synthesis of a Dream), by Delia Alton." Isle Interdisciplinary Studies in Literature and Environment, vol. 18, no. 4, 2011, pp. 840-60. MLA International Bibliography, doi: http://dx.doi.org.proxy.library.carleton.ca/10.1093/isle/isr110. Accessed 2 June 2017.

Iovino, Serenella and Serpil Oppermann. "After Green Ecologies: Prismatic Visions.” Prismatic Ecology: Ecotheory Beyond Green, edited by Jeffrey Jerome Cohen, U of Minnesota P, 2013, pp. 328-36.

---. Material Ecocriticism. Edited by Serenella Iovino and Serpil Oppermann, Indiana UP, 2014.

---. "Theorizing Material Ecocriticism: A Diptych.” Isle: Interdisciplinary Studies in Literature and Environment, vol. 19, no. 3, 2012, pp. 448-75. MLA International 
Bibliography, doi: http://dx.doi.org.proxy.library.carleton.ca/ 10.1093/isle/iss087. Accessed 2 June 2017.

Ivakhiv, Adrien J. Ecologies of the Moving Image: Cinema, Affect, Nature. Wilfred Laurier UP, 2013.

James, Williams. Principles of Psychology.1890, http://psychclassics.yorku.ca/ James/ Principles/. Accessed 25 Apr. 2017.

Kaufmann, Michael. “Gendering Modernism: H.D., Imagism, and Masculinist Aesthetics." Unmanning Modernism: Gendered Re-Readings, edited by Elizabeth Jane Harrison and Shirley Peterson, U of Tennesse P, 1997, pp. 59-72.

Kerridge, Richard. "Ecocritical Approaches to Literary Form and Genre: Urgency, Depth, Provisionality, Temporality." The Oxford Handbook of Ecocriticism, edited by Greg Garrard, Oxford UP, 2014, pp. 361-76.

Kessler, Frank. "Viewing Change, Changing Views: The 'History of Vision'—Debate." Film 1900: Technology, Perception, Culture, edited by Annemone Ligensa and Klaus Kreimeier, John Libbey Publishing, 2009, pp. 23-36.

Klein, Naomi. This Changes Everything: Capitalism Vs. the Climate. Simon \& Schuster, 2014.

Kostkowska, Justyna. Ecocriticism and Women Writers: Environmentalist Poetics of Virginia Woolf, Jeanette Winterson, and Ali Smith. Palgrave Macmillan, 2013.

Kusch, Celena E. “H. D.’s American Sea Garden: Drowning the Idyll Threat to US Modernism.” Twentieth Century Literature, vol. 56, no. 1, 2010, pp. 47-70. MLA International Bibliography, proxy.library.carleton.ca/login?url=http://go.Galegroup.com.proxy.library.carleto 
n.ca/ps/i.do? $\mathrm{p}=\mathrm{MLA} \& \mathrm{sw}=\mathrm{w} \& \mathrm{u}=\mathrm{ocul}$ carleton $\& \mathrm{v}=2.1 \& \mathrm{it}=\mathrm{r} \& \mathrm{id}=\mathrm{GALE} \% 7 \mathrm{CN} 28$ 12590855\&asid=6352a0556afe6bb519ff3dd9d0a90556. Accessed 4 Nov. 2017.

Lacivita, Allison. The Ecology of Finnegans Wake. UP of Florida, 2015.

Laville, Sandra and Matthew Taylor. “A million bottles a minute: world's plastic binge 'as dangerous as climate change.'” The Guardian, 28 June 2017, www.theguardian.com/environment/2017/jun/28/a-million-a-minute-worldsplastic-bottle-binge-as-dangerous-as-climate-change/. Accessed 3 Nov. 2017.

Lawrence, D. H. Women in Love. Oxford UP, 1998.

Legler, Gretchen. “'I Am a Transparent Eyeball': The Politics of Vision in American Nature Writing." Reading under the Sign of Nature: New Essays in Ecocriticism, edited by John Tallmadge and Henry Harrington, The U of Utah P, 2000, pp. $243-250$.

Linett, Maren Tova. “Modernist Women's Literature: An Introduction.” Modernist Women Writers, edited by Maren Tova Linett, Cambridge UP, 2010, pp 1-16. Love, Glen A. Practical Ecocriticism: Literature, Biology, and the Environment. U of Virginia P, 2003.

Mackay, Polina. “H.D.'s modernism.” The Cambridge Companion to H.D., edited by Nephie J. Christodoulides and Polina Mackay, Cambridge UP, 2012, pp. 51-62. Marcus, Laura. Introduction. Close-Up 1927-1933: Cinema and Modernism, edited by James Donald, Anne Friedberg, and Laura Marcus, Princeton UP, 1998, pp. 96114.

Marinetti, F.T. "The Founding and Manifesto of Futurism (1909)." Futurist Manifestos, edited by Umbro Apollonio, Thames and Hudson, 1973, pp. 19-24. 
Marland, Pippa. “Ecocriticism.” Literature Compass, vol. 10, no. 11, 2013, pp. 846-48. MLA International Bibliography. doi: http://dx.doi.org.proxy.library.carleton.ca/10.1111/lic3.12105. Accessed 23 Apr. 2017.

McCabe, Susan. Cinematic Modernism: Modernist Poetry and Film. Cambridge UP, 2005 .

McConachie, Bruce. Engaging Audiences: A Cognitive Approach to Spectating in the Theatre. Palgrave Macmillan, 2008.

McConachie, Bruce and F. Elizabeth Hart. Introduction. Performance and Cognition: Theatre Studies and the Cognitive Turn, edited by Bruce McConachie and F. Elizabeth Hart, Routledge, 2006, pp. 1-25.

Meyer, Steven. Irresistible Dictation: Gertrude Stein and the Correlations of Writing and Science, edited by Timothy Lenoir and Hans Ulrich Gumbrecht, Stanford UP, 2001

Meyerowitz, Patricia. Editor's Forward. Gertrude Stein: Writings and Lectures 19111945, edited by Patricia Meyerowitz, Peter Owen, 1969, pp.7-9.

Milligan, Brett. "Landscape Migration: Environmental Design in the Anthropocene." Places Journal, June 2015, URL: https://doi.org/10.22269/150629. Accessed 3 Nov 2017.

Morris, Adalaide. How to Live/ What to Do: H.D. 's Cultural Poetics. U of Illinois P, 2003 
---. “The Concept of Projection: H.D.'s Visionary Powers." Signets: Reading H.D., edited by Susan Stanford Friedman and Rachel Blau DuPlessis, U of Wisconsin P, 1990, pp. 273-296.

Morrisson, Mark S. Modernism, Science, and Technology. Bloomsbury, 2017.

Murphy, Sean P. “'Ida Did Not Go Directly Anywhere’: Symbolic Peregrinations, Desire, and Linearity in Gertrude Stein's Ida." Literature and Psychology, vol. 47, no. 1-2, 2001, pp. 1-11. MLA International Bibliography, proxy. library.carleton.ca/login? url=http:/go.galegroup.com.proxy.library.carleton.ca/ps/i.do?p=MLA\&sw=w\&u $=$ ocul_carleton\&v=2.1\&it=r\&id=GALE\%7CN2811724184\&asid=1a5fe $8 \mathrm{f} 2 \mathrm{fd} 40 \mathrm{e}$ c853108ef3b8f57aa47. Accessed 16 September 2017.

Noakes, Susan. "Human antidepressants building up in brains of fish in Niagara River." CBC News, 4 Sept. 2017, www.cbc.ca/news/technology/human-antidepressantsbuilding-up-in-brains-of-fish-in-niagara-river-1.4274735. Accessed 3 Nov. 2017.

Pound, Ezra. “A few Don’ts by an Imagiste.” Poetry Magazine, 30 Oct. 2005, www.poetryfoundation.org/poetrymagazine/articles/detail/58900. Accessed 23 Apr. 2017.

Puchner, Martin. "Drama and Performance: Toward a Theory of Adaptation." Common Knowledge, vol. 17, no. 2, 2011, pp. 292-305. MLA International Bibliography, doi: http://dx.doi.org.proxy.library.carleton.ca/10.1215/0961754X-1187986. Accessed 28 Oct. 2017.

Raine, Anne. "Ecocriticism and Modernism." The Oxford Handbook of Ecocriticism, edited by Greg Garrard, Oxford UP, 2014, pp. 98-117. 
---. "Science, Nature Work, and the Kinaesthetic Body in Cather and Stein." American Literature: A Journal of Literary History, Criticism, and Bibliography, vol. 80, no. 4, 2008, pp. 799-830. MLA International Bibliography, doi: http://dx.doi.org.proxy.library.carleton.ca/10.1215/00029831-2008-039. Accessed 20 Apr. 2017.

Reno, Seth T. "Rethinking the Romantics' Love of Nature." Wordsworth and the Green Romantics: Affect and Ecology in the Nineteenth Century, edited by Lisa Ottum and Seth T. Reno, U of New Hampshire P, 2016, pp. 28-58.

Richardson, Alan. "Studies in Literature and Cognition." The Work of Fiction:Cognition, Culture, and Complexity, edited by Alan Richardson and Ellen Spolsky, Ashgate, 2004, pp. 1-30.

Rohrbach, Erika. "H.D. and Sappho: A Precious Inch of Palimpsest." Re-Reading Sappho: Reception and Transmission, edited by Ellen Greene, U of California P, Classics and Contemporary Thought, 1996, pp. 184-98.

Sanders, Scott Russell. "Speaking a Word for Nature." The Ecocritical Reader: Landmarks in Literary Ecology, edited by Cheryll Glotfelty and Harold Fromm. U of Georgia P, 1996, pp. 182-95.

Sandilands, Catriona. "Some 'F' Words for the Environmental Humanities: Feralities, Feminisms, Futurities." The Routledge Companion to the Environmental Humanities, edited by Ursula K. Heise, et al., Routledge, 2017, pp. 443-451. Schuster, Joshua. The Ecology of Modernism: American Environments and Avant-Garde Poetics. U of Alabama P, 2015. 
Scott, Bonnie Kime. In the Hollow of the Wave: Virginia Woolf and Modernist Uses of Nature. U of Virginia P, 2012.

Segeberg, Harro. “'Is Everything Relative?': Cinema and the Revolution of Knowledge Around 1900." Film 1900: Technology, Perception, Culture, edited by Annemone Ligensa and Klaus Kreimeier, John Libbey Publishing, 2009, pp. 6776.

Solomons, Leon M. and Gertrude Stein. "Normal Motor Automatism." The Psychological Review, vol. 3, no. 5, 1896, pp. 492-512. PsycArticles. 26 July 2017.

Sprigge, Elizabeth. Introduction. Gertrude Stein: Writings and Lectures 1911-1945, edited by Patricia Meyerowitz, Peter Owen, 1967, pp. 11-17.

Steffensen, Sune Vork. "Beyond Mind: An Extended Ecology of Languaging." Distributed Language, edited by Stephen J. Cowley. Benjamins, 2011, pp. 185210.

Steidele, Angela. "Reading with the Body: Sound, rhythm, and music in Gertrude Stein." Embodiment in Cognition and Culture, edited by John Michael Krois et al, John Benjamins Publishing, 2007, pp. 143-63.

Stein, Gertrude. "Composition as Explanation." Gertrude Stein: Writings and Lectures 1911-1945, edited by Patricia Meyerowitz, Peter Owen, 1967, pp. 21-30.

---. "Cultivated Motor Automatism; A Study of Character in its Relation to Attention." The Psychological Review, vol. 5, no. 3, 1898, pp. 295-306. PsyArticles. 26 July 2017. 
---. "Gertrude Stein, American writer, speaks and reads from her libretto for Opera H.D. Stock Footage." Youtube, uploaded by CriticalPast, 21 March 2014, https://www.youtube.com/watch?v=TtV6f6ZIFdE.

---. "How Writing is Written." Volume II of the Previously Uncollected Writings of Gertrude Stein: How Writing is Written, edited by Robert Bartlett Haas, Black Sparrow Press, 1974, pp. 151-60.

---. Ida: A Novel. Edited by Logan Esdale. Yale UP, 2012.

---. "Plays." Gertrude Stein: Writing and Lectures 1911-1945, edited by Patricia Meyerowitz, Peter Owen, 1967, pp. 58-81.

---. "Poetry and Grammar." Gertrude Stein: Writings and Lectures 1911-1945, edited by Patricia Meyerowitz, Peter Owen, 1967, pp. 123-45.

---. "What is English Literature" Gertrude Stein: Writings and Lectures 1911-1945, edited by Patricia Meyerowitz, Peter Owen, 1967, pp. 31-57.

Sultzbach, Kelly. "The Fertile Potential of Virginia Woolf’s Environmental Ethic." Woolf and the Art of Exploration: Selected Papers from the Fifteenth International Conference on Virginia Woolf, edited by Helen Southworth and Elisa Kay Sparks, Clemson U Digital P, 2006, pp. 71-77.

Tarlo, Harriet. ““An Insurmountable Chasm?’: Re-Visiting, Re-Imagining and Re-writing Classical Pastoral through the Modernist Poetry of H.D." Classical Receptions Journal, vol. 4, no. 2, 2012, pp. 235-60. MLA International Bibliography, doi: http://dx.doi.org.proxy.library.carleton.ca/10.1093/crj/cls020. Accessed 3 June 2016. 
Taylor, Jesse O. The Sky of our Manufacture: The London fog and British Fiction From Dickens to Woolf. U of Virginia P, 2016.

Taylor, John R. “The Ecology of Constructions.” Studies in Linguistic Motivation, edited by Günter Radden and Klaus-Uwe Panther, Mouton de Gruyter, 2004, pp. 49-73.

Timoche, Anne. “The Body: Figure/ Text: A Reading of Marguerite Duras and Gertrude Stein.” Dissertation Abstracts International, vol. 50, no. 9, 1990, pp. 2890-91. MLA International Bibliography, proxy. library.carleton.ca/login?url=http://go.galegroup.com.proxy.library.carleton.ca/ps/ i.do? $\mathrm{p}=\mathrm{MLA} \& \mathrm{sw}=\mathrm{w} \& \mathrm{u}=\mathrm{ocul}$ carleton $\& \mathrm{v}=2.1 \& \mathrm{it}=\mathrm{r} \& \mathrm{id}=\mathrm{GALE} \% 7 \mathrm{CN} 28109983$ 44\&asid=0ee3efc66bc2dfbe08e053a73415b130. Accessed 16 Sept. 2017.

Vetter, Lara. Modernist Writings and Religio-Scientific Discourse: H.D., Loy, and Toomer. Palgrave Macmillan, 2010.

Voris, Linda. "Framing Devices: Reading Background in the Sequence of Gertrude Stein's Composition." Primary Stein: Returning to the Writing of Gertrude Stein, edited by Janet Boyd et al., Lexington Books, 2014, pp. 125-44.

Walter, Christina. "From Image to Screen: H.D. and the Visual Origins of Modernist Impersonality." Textual Practice, vol. 22, no. 2, 2008, pp. 291-313. MLA International Bibliography, doi: http://muse.jhu.edu.proxy.library.carleton.ca/books/9781421413648. Accessed 1 June 2017.

---. Optical Impersonality: Science, Images, and Literary Modernism. Johns Hopkins UP, 2014. 
Whitehead, Alfred North. Science and the Modern World: Lowell Lectures 1925. Macmillan, 1947.

Will, Barbara. Gertrude Stein, Modernism, and the Problem of "Genius." Edinburgh UP, 2000.

Williamson, Margaret. Sappho's Immortal Daughters. Harvard UP, 1995.

Woolf, Virginia. “A Sketch of the Past.” Virginia Woolf: Moments of Being, edited by Jeanne Schulkind, Hogarth Press, 1985, pp. 64-159.

---. Between the Acts. Penguin, 1991.

---. "Craftsmanship." The Death of the Moth and Other Essays. Hogarth Press, 1942, pp. 126-32.

---. "Flying Over London.” Collected Essays by Virginia Woolf. Vol. 4. Hogarth Press, 1967, pp. 167-72.

---. "Modern Fiction." Collected Essays by Virginia Woolf. Vol. 2. Hogarth Press, 1966, pp. 103-10.

---. "Mr. Bennett and Mrs. Brown." Collected Essays by Virginia Woolf. Vol. 1. Hogarth Press, 1966, pp. 319-37.

---. “On Being Ill.” Collected Essays by Virginia Woolf. Vol. 4. Hogarth Press, 1967, pp. 193-203.

---. "The Cinema." Collected Essays by Virginia Woolf. Vol. 2. Hogarth Press, 1966, pp. $268-72$.

---. The Diary of Virginia Woolf, edited by Anne Olivier Bell, Hogarth Press, 1977-1984.

Zoob, Caroline. Virginia Woolf's Garden: The Story of the Garden at Monk's House. Jacqui Small, 2013. 